\title{
NUEVAS HABILIDADES PARA LA ECONOMÍA DIGITAL
}

MIDIENDO LA OFERTA Y LA DEMANDA DE HABILIDADES PARA EL USO DE LAS TIC EN EL TRABAJO

REUNIÓN DE MINISTROS SOBRE ECONOMÍA DIGITAL 2016

INFORME TÉCNICO

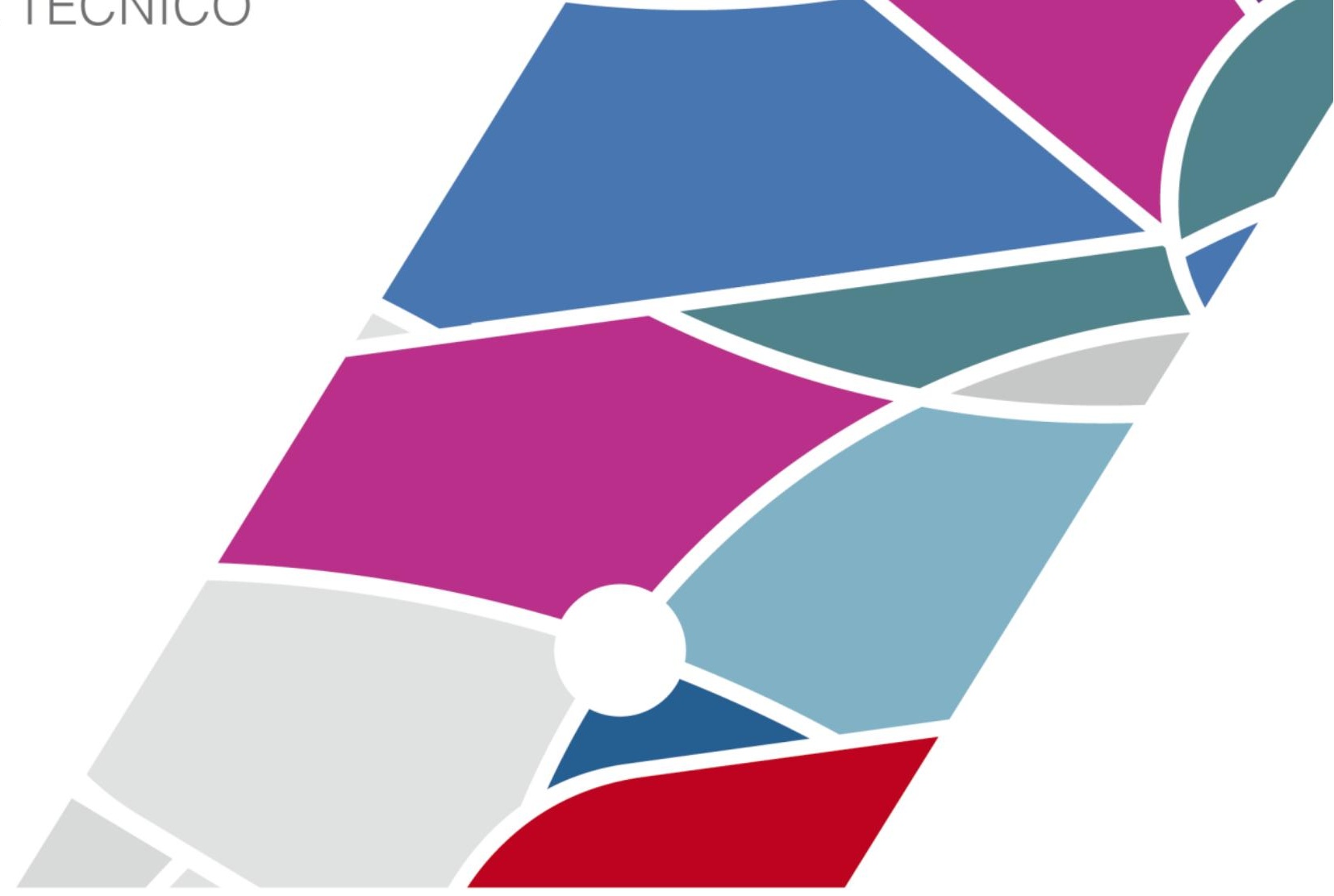

Traducido por: 



\title{
NUEVAS HABILIDADES PARA LA ECONOMÍA DIGITAL
} MIDIENDO LA OFERTA Y LA DEMANDA

\author{
DE HABILIDADES PARA EL USO DE LAS TIC EN EL TRABAJO
}

REUNIÓN DE MINISTROS SOBRE ECONOMÍA DIGITAL 2016

INFORME TÉCNICO

Esta traducción se publica por acuerdo con la OCDE. No es una traducción oficial de la OCDE. La calidad de la traducción y su coherencia con el texto del idioma original de la obra son responsabilidad exclusiva del autor (es) de la traducción. En el caso de cualquier discrepancia entre el trabajo original y la traducción, solo el texto del trabajo original se considerará válido. 


\section{Prefacio}

El presente informe fue preparado como una contribución al antecedente del informe del Panel 4.2 "Habilidades para un Mundo Digital" de la Reunión de Ministros de la OCDE sobre la Economía Digital, del 21 al 23 de junio 2016, en Cancún (México). Presenta nueva evidencia sobre cómo el uso de las TIC en el trabajo está cambiando la demanda de tres conjuntos de habilidades relacionadas con las TIC: habilidades genéricas, habilidades especializadas y habilidades complementarias. También compara la demanda de habilidades genéricas en TIC con la oferta de las mismas.

El informe fue preparado por Vincenzo Spiezia, Elif Koksal-Oudot y Pierre Montagnier, de la OCDE, para el Grupo de trabajo sobre la Medición y el Análisis de la Economía Digital (MADE, por sus siglas en inglés). Se agradece la contribución voluntaria de Telecom Italia.

El informe fue aprobado y desclasificado por el Comité de Políticas sobre Economía Digital (CDEP, por sus siglas en inglés) el 13 de mayo 2016 y fue preparado para su publicación por la Secretaría de la OCDE.

Este documento y los mapas incluidos en él no perjudican el estatus de soberanía de cualquier territorio ni la delimitación internacional de las fronteras ni límites así como el nombre de ningún territorio, ciudad o área.

Los datos estadísticos de Israel fueron recogidos por y bajo la responsabilidad de las autoridades israelíes correspondientes. El uso de esos datos por parte de la OCDE es sin prejuicio del estatus de los Altos del Golan, en la parte Este de Jerusalén y de los asentamientos israelíes en la franja oeste bajo los términos de la ley internacional.

Publicado originalmente por la OCDE en inglés bajo el título: OCDE (2016), "New Skills for the Digital Economy", OECD Digital Economy Papers, No. 258, OECD Publishing, París, https://doi.org/10.1787/5jlwnkm2fc9x-en

@ 2019 Secretaría de Educación de Coahuila para esta edición en español.

Traductora: Maestra Ana Isabel González García

Diseñadora: Lic. Gina Orozco Ordieres 


\section{ÍNDICE}

\section{PRÓLOGO}

NUEVAS HABILIDADES PARA LA ECONOMÍA DIGITAL

MIDIENDO LA OFERTA Y LA DEMANDA DE HABILIDADES PARA EL USO DE LAS TIC EN EL TRABAJO

\section{RESUMEN EJECUTIVO}

\section{Introducción}

2. La demanda de habilidades genéricas para el uso de las TIC

2.1 Intensidad de uso de las TIC por ocupación

2.2 Demanda laboral de ocupaciones con uso intensivo de las TIC

3. Habilidades especializadas para el uso de las TIC

3.1 La demanda de habilidades especializadas para el uso de las TIC

3.2 Vacantes en los servicios de la información y las comunicaciones: tendencias recientes

3.3 Salarios para servicios de las TIC: tendencias recientes

3.4 Tendencias en ocupaciones de las TIC: evidencia proveniente de vacantes en línea

3.5 Evidencia a partir de encuestas a los empleadores

4. La demanda de habilidades complementarias para el uso de las TIC

4.1 Habilidades complementarias para el uso de las TIC: breve reseña de la literatura

4.2 ¿Qué habilidades son complementarias a las TIC? Evidencia proveniente del PIAAC

4.3 ¿Qué habilidades son complementarias a las TIC? Evidencia proveniente de O*NET

5. Medición de la oferta de habilidades genéricas para el uso de las TIC a través del desempeño del PRSTE

6. Conclusiones y orientaciones para futuras investigaciones

ANEXO A1. Las 20 ocupaciones con mayor intensidad de uso de CBI por país, 2012

ANEXO A2. Las 20 ocupaciones con mayor intensidad de uso de SPO por país, 2012

ANEXO B. Las 20 ocupaciones especialistas de las TIC con mayor intensidad de uso por país, 2012

ANEXO C1. Tablas de correlación de pares basadas en el PIAAC en grupos del CIUO de 1 dígito (CBI), 2012

ANEXO C2. Tablas de correlación de pares basadas en el PIAAC en grupos del CIUO de 1 dígito (SPO), 2012

\section{REFERENCIAS}




\section{NUEVAS HABILIDADES PARA LA ECONOMÍA DIGITAL: MIDIENDO LA DEMANDA Y LA OFERTA DE HABILIDADES PARA EL USO DE LAS TIC EN EL TRABAJO}

\section{RESUMEN EJECUTIVO}

El incremento en el uso de las Tecnologías de la Información y de la Comunicación (TIC) en el trabajo ha elevado la demanda de nuevas habilidades en tres áreas: habilidades especializadas para programar, desarrollar aplicaciones y gestionar redes de trabajo; habilidades genéricas para usar esas tecnologías con propósitos profesionales; habilidades complementarias para desempeñar nuevas tareas asociadas con el uso de las TIC en el trabajo, esto es, comunicar por medio de redes sociales de trabajo, posicionar productos en plataformas de comercio electrónico o analizar grandes datos.

Este documento presenta evidencia nueva sobre cómo las TIC están cambiando la demanda de estos tres conjuntos de habilidades fundamentado en el Programa para la Evaluación Internacional de Competencias de Adultos (PIAAC) de la OCDE. Igualmente compara la oferta y la demanda de habilidades genéricas para el uso de TIC.

La demanda de habilidades genéricas se ha incrementado en la mayoría de los países entre 2011 y 2014. La proporción de trabajadores que usan comunicación y búsqueda de información (CBI) o software de productividad para oficina (SPO) diariamente se incrementó en promedio un 0.9 y 0.6 puntos porcentuales respectivamente. Además, la proporción de trabajadores que usan las TIC diariamente en el lugar de trabajo varía significativamente entre los países según los resultados del PIAAC, posicionando a Noruega con $64 \%$ y a la República Eslovaca con $34 \%$ en cuanto a CBI, y al Reino Unido con $43 \%$ y a Polonia con $26 \%$ en cuanto a SPO.

Al parecer un número significativo de trabajadores que usan las TIC diariamente no tiene las habilidades suficientes para usarlas de forma efectiva según los resultados de la evaluación del PIAAC. La proporción de trabajadores con insuficientes habilidades genéricas para el uso de las TIC es, en promedio, de 9.5\% para CBI y más de $40 \%$ para SPO. Estos hallazgos muestran una disparidad significativa entre la demanda y la oferta de habilidades genéricas para el uso de las TIC.

La demanda de especialistas en TIC ha ido creciendo rápidamente en los últimos años, pero la evidencia disponible sobre primas salariales, tasas de vacantes y la duración de las mismas sugiere que la potencial escasez en habilidades para el uso de las TIC es poca y está limitada a un pequeño número de países. Aun así, las estadísticas disponibles no aportan elementos para abordar completamente estas cuestiones y el desarrollo de mejores medidas es importante para futuras investigaciones.

La difusión de las TIC está cambiando también la forma en que se lleva a cabo el trabajo, incrementando la demanda de habilidades complementarias para el uso de las TIC. Este documento muestra un enfoque sencillo y refutable para identificar tareas laborales complementarias a las TIC y medir la demanda de habilidades requeridas para desempeñar esas tareas.

Un descubrimiento importante es que los cambios en las tareas asociadas con el incremento en el uso de las TIC tienden a ser más grandes para la gente de ocupaciones con bajas habilidades que para aquellos de ocupaciones con medianas y altas habilidades. En promedio, el uso intensivo de las TIC en el trabajo está asociado con tareas que requieren más interacción con los compañeros de trabajo y clientes, más solución de problemas así como menos trabajo físico.

Aunque los resultados antes mencionados ofrecen perspectivas nuevas e interesantes, se abren otras para ulteriores análisis, incluyendo la identificación de perfiles de habilidades, como combinaciones particulares de habilidades usadas en conjunto y el recurso a bancos de datos nacionales que dispongan de mayor información a través del tiempo. 


\section{Introducción}

El incremento en el uso de las TIC en el trabajo está elevando la demanda de nuevas habilidades. Lo anterior está ocurriendo en tres áreas. En primer lugar, la elaboración de productos y servicios de TIC (software, páginas web, comercio electrónico, la nube, grandes datos, etcétera) requiere habilidades especializadas para el uso de las TIC para programar, desarrollar aplicaciones y gestionar redes de trabajo. En segundo lugar, trabajadores de una gran variedad de ocupaciones necesitan adquirir habilidades genéricas para el uso de las TIC y ser capaces de usar esas tecnologías en su desempeño diario, como acceso a información en línea, uso de software, etc. En último lugar, el uso de las TIC está cambiando la forma en que se lleva a cabo el trabajo y está aumentando la demanda de habilidades complementarias para el uso de las TIC, como la capacidad de comunicar en las redes sociales de trabajo, posicionar productos en plataformas de comercio electrónico, etcétera.

Los responsables de las políticas públicas y los analistas se han concentrado principalmente en los dos primeros grupos de habilidades, las específicas y genéricas, mientras que las habilidades complementarias para el uso de las TIC han recibido menor atención. Además, la medición tanto de la demanda como de la oferta de esas habilidades parece no cubrir la necesidad de información requerida para las políticas educativas y de formación.

El objetivo de este documento es contribuir a llenar ese vacío. La sección 2 proporciona nueva evidencia sobre el uso en el trabajo de las habilidades genéricas al relacionar los datos del Programa para la Evaluación Internacional de Competencias de Adultos (PIAAC, por sus siglas en inglés) y las encuestas nacionales de población activa. La sección 3 presenta un conjunto de mediciones de la demanda de habilidades especializadas para el uso de las TIC basadas en datos de vacantes y salarios tomados de estadísticas oficiales y fuentes de datos en línea. Las complementariedades entre las TIC y otras habilidades en el trabajo se analizan en la sección 4 basadas en las encuestas del PIAAC y en la Red de Información Ocupacional de los Estados Unidos ( $\mathrm{O}^{*} \mathrm{NET}$, por sus siglas en inglés). La sección 5 compara la demanda de habilidades genéricas para el uso de las TIC con la oferta usando los resultados de la evaluación de competencias del PIAAC. La sección 6 trata sobre las implicaciones de los principales hallazgos y elabora conclusiones.

\section{La demanda de habilidades genéricas para el uso de las TIC}

El objetivo de esta sección es proporcionar nueva evidencia sobre la demanda en el trabajo de habilidades genéricas en los países seleccionados de la OCDE. El análisis se desarrolló en dos pasos. El primero mide la frecuencia en el uso de las TIC en cada actividad con base en la encuesta del PIAAC. El segundo mide la demanda de habilidades genéricas en el trabajo al relacionar la frecuencia de uso de las TIC con la proporción de empleo en cada ocupación basada en las encuestas de población activa.

\subsection{Intensidad de uso de las TIC por ocupación}

El cuestionario de base del PIAAC recoge una variedad de información sobre el uso de las TIC en el trabajo preguntando con qué frecuencia los encuestados:

- envían/reciben correos electrónicos (pregunta g_q05a)

- encuentran información relacionada con el trabajo en Internet (g_q05c)

- llevan a cabo transacciones en Internet (g_q05d)

- usan hojas de cálculo (g_q05e)

- usan procesadores de texto (g_q05f)

- usan lenguajes de programación (g_q05g)

- tienen conversaciones en tiempo real (g_q05h)

Las respuestas podían ser: Nunca; Menos de una vez al mes; Menos de una vez a la semana pero al menos una vez al mes; Al menos una vez a la semana pero no todos los días; y Diariamente.

En la encuesta del PIAAC las preguntas sobre el uso de las TIC en el trabajo se aplicaron solamente a las personas que dijeron "tener experiencia con computadoras en el trabajo". Puesto que la gente sin experiencia con las computadoras no fue incluida, las respuestas a estas preguntas tienden a sobrevalorar la frecuencia del 
uso de las TIC en el trabajo. Adicionalmente, la distribución de los que no tienen experiencia con computadoras entre las distintas ocupaciones es desconocida, el sesgo no es uniforme: la frecuencia en el uso de las TIC puede estar sobrevalorada en algunas ocupaciones e infravalorada en otras.

La Figura 1 muestra que este sesgo puede ser importante. Casi un cuarto (24.5\%) de todos los encuestados (ponderados) en el PIAAC reportaron que no tenían experiencia con computadoras en el trabajo, mientras que un pequeñísimo porcentaje de individuos $(0.07 \%)$ se negaron a contestar o contestaron "No sé". El sesgo es más importante en Polonia, Italia y España y menor en Países Bajos, Suecia y Noruega. Para corregir este sesgo, la frecuencia del uso de las TIC en el trabajo no fue calculado como el porcentaje de los encuestados en preguntas sobre las TIC, sino como el porcentaje de todos los individuos.

Figura 1. Individuos sin experiencia con el uso de la computadora, 2012

Porcentaje ponderado de todos los individuos

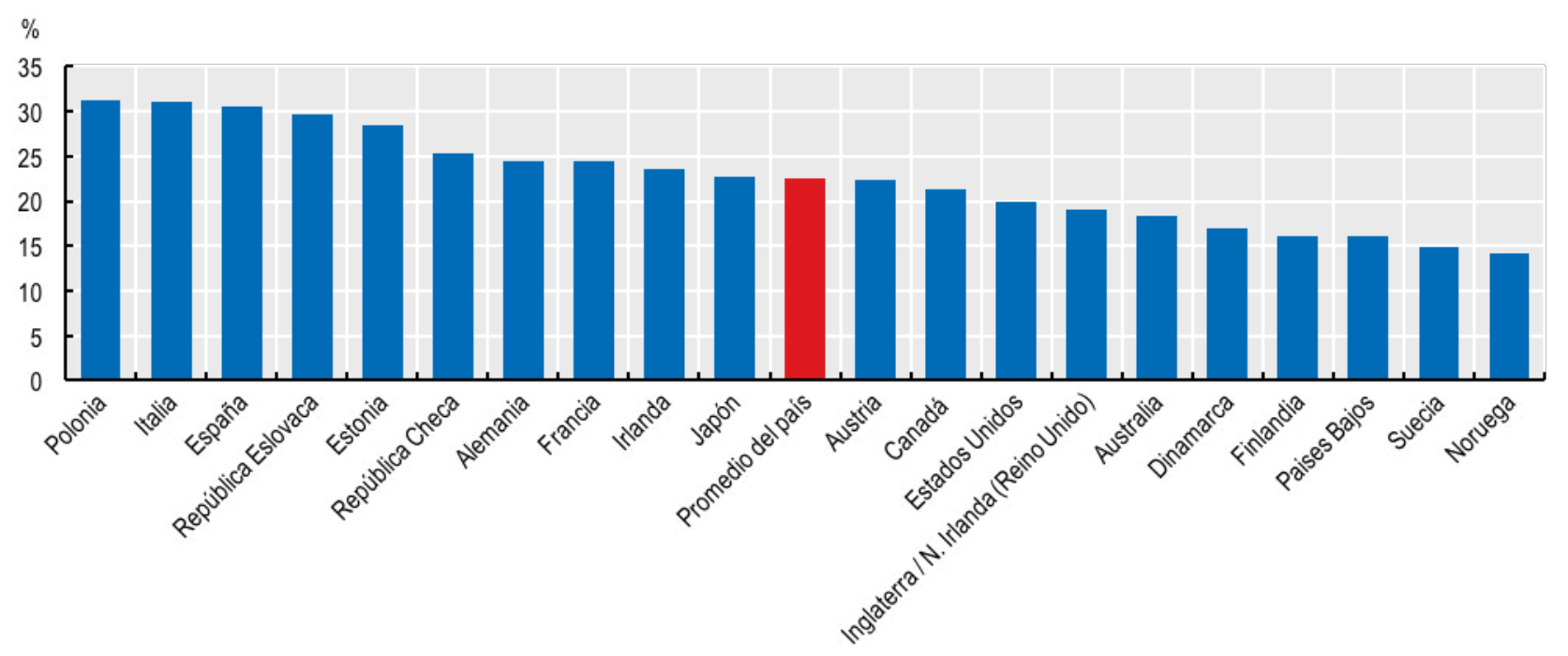

Fuente: OCDE, con base en datos del PIAAC Database, junio 2015.

Algunas de las respuestas a las preguntas antes mencionadas fueron agrupadas en dos series de tareas. La primera serie "Comunicación y búsqueda de información" (CBI) incluye "enviar y recibir correos electrónicos" y "encontrar información relacionada con el trabajo en Internet"; la segunda serie "Uso de software de productividad para oficina" (SPO) incluye "uso de procesadores de texto" y "uso de hojas de cálculo". Ambos, CBI y SPO requieren habilidades genéricas en el uso de las TIC, pero SPO implica un uso más sofisticado y un nivel más alto de habilidades.

Las demás preguntas se refieren ya sea a las habilidades especializadas en el uso de las TIC (uso de lenguajes de programación) y se examinarán en la siguiente sección, o están asociadas a tareas específicas con baja frecuencia en el trabajo ("lleva a cabo transacciones en Internet" y "tiene conversaciones en tiempo real").

La Figura 2 muestra la proporción de individuos que usan CBI y SPO diariamente por país en todas las ocupaciones. El índice de individuos que usan habilidades de CBI diariamente varía entre el $51.5 \%$ en Noruega y el $22.8 \%$ en Italia. En la mayoría de los países menos del $40 \%$ usa diariamente Internet para enviar correos electrónicos o buscar información relacionada con propósitos laborales. El índice de individuos que usa SPO diariamente varía entre el 36.6\% en Países Bajos y el 17\% en Italia y Polonia.

No es sorprendente ya que la frecuencia de usuarios diarios es sistemáticamente menor en CBI que en SPO en todos los países incluidos en la muestra del PIAAC. 


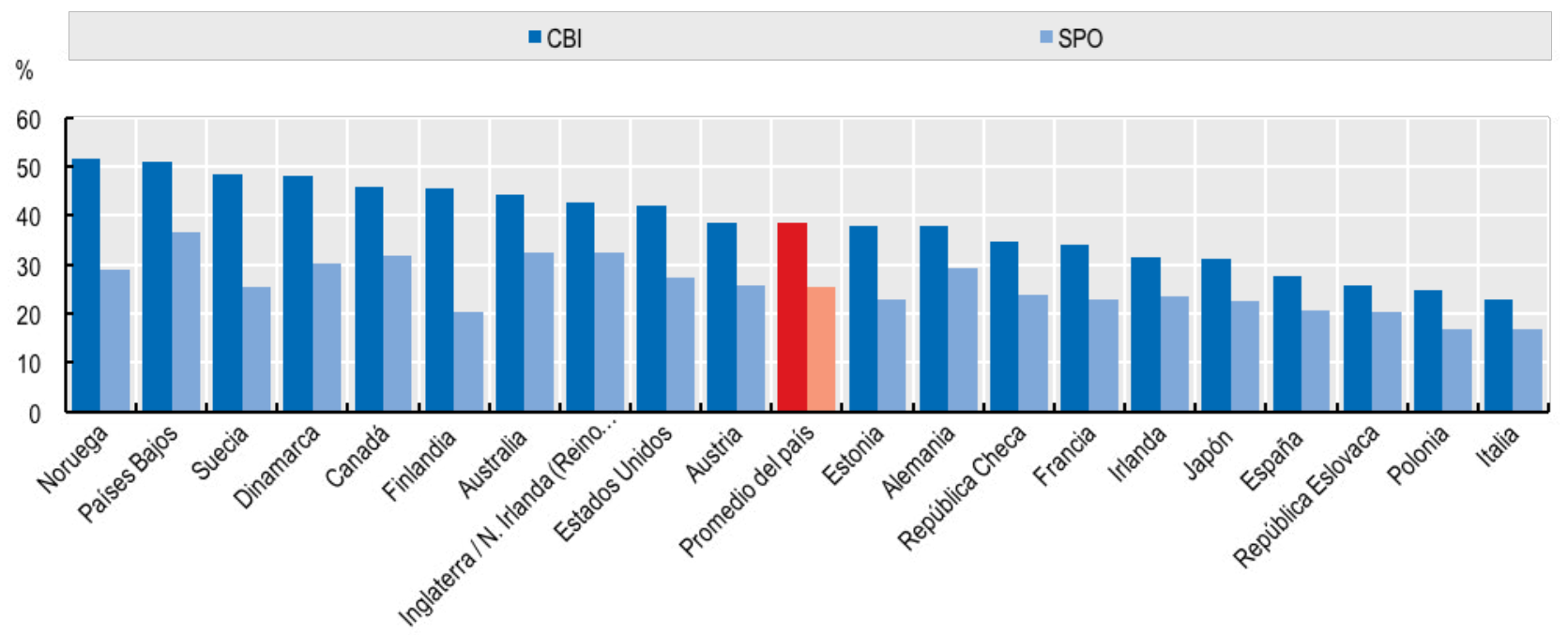

Fuente: OCDE, con base en datos del PIAAC Database, enero 2016.

Para medir la intensidad del uso de las TIC por ocupación se calculó la proporción de individuos por ocupación que usan las TIC diariamente con base en: i) su ocupación actual, si están trabajando; o ii) su última ocupación, si han estado desempleados no más de un año. La última situación laboral permite aprovechar al máximo la información disponible, esto es, la última ocupación de los desempleados, al mismo tiempo que se garantiza que la información sobre el uso de las TIC no es obsoleta, es decir, no mayor a un año. Las ocupaciones están definidas de acuerdo a la Clasificación Internacional Uniforme de Ocupaciones (CIUO) 2008 en el nivel del dígito 3 (127 ocupaciones, sin las Fuerzas Armadas), a excepción de Australia y Finlandia, donde los datos del PIAAC solo están disponibles en 2 dígitos (40 ocupaciones, sin las Fuerzas Armadas).

La Tabla 1 muestra las 20 ocupaciones más altas en el uso intensivo de CBI entre los países. De manera interesante se observa que 15 de ellas (en itálicas) no son ocupaciones especialistas en el uso de las TIC. Incluyen administradores y gerentes (CIUO-08 242, 121, 112 y 134); directores de ventas, comercialización y desarrollo $(122,243)$; matemáticos, actuarios y estadísticos, especialistas en finanzas y profesionales de nivel medio de finanzas $(212,241$ y 331); científicos e ingenieros (211 y 214) así como profesores de universidades y de la enseñanza superior (231); profesionales en derecho (261); archivistas, bibliotecarios, curadores y afines (262); miembros del poder ejecutivo y de los cuerpos legislativos (111). 
Tabla 1. Las 20 ocupaciones más altas en el uso intensivo de CBI entre los países, 2012

Proporción de países donde la ocupación está entre las 20 más altas de CBI

\begin{tabular}{clcc} 
Rango & \multicolumn{1}{c}{ Ocupación } & CIUO-08 & Frecuencia \\
1 & Directores de servicios de tecnología de la información y las comunicaciones & 133 & $94 \%$ \\
2 & Especialistas en finanzas & 241 & $94 \%$ \\
3 & Directores de ventas, comercialización y desarrollo & 122 & $89 \%$ \\
4 & Especialistas en bases de datos y en redes de computadoras & 252 & $89 \%$ \\
5 & Directores de administración y servicios & 121 & $78 \%$ \\
6 & Especialistas en organización de administración & 242 & $78 \%$ \\
7 & Desarrolladores y analistas de software y multimedia & 251 & $72 \%$ \\
8 & Miembros del poder ejecutivo y de los cuerpos legislativos & 111 & $67 \%$ \\
9 & Ingenieros en electrotecnología & 215 & $67 \%$ \\
10 & Profesionales de las ventas, la comercialización y las relaciones públicas & 243 & $67 \%$ \\
11 & Físicos, químicos y afines & 211 & $61 \%$ \\
12 & Matemáticos, actuarios y estadisticos & 212 & $61 \%$ \\
13 & Ingenieros (excluyendo electrotecnólogos) & 214 & $61 \%$ \\
14 & Profesionales en derecho & 261 & $61 \%$ \\
15 & Técnicos en operaciones de tecnología de la información y las comunicaciones y & 351 & $61 \%$ \\
16 & asistencia al usuario & Archivistas, bibliotecarios, curadores y afines & 262 \\
17 & Profesores de universidades y de la enseñanza superior & 231 & $56 \%$ \\
18 & Directores generales y gerentes generales & 112 & $44 \%$ \\
19 & Directores y gerentes de servicios profesionales & 134 & $44 \%$ \\
20 & Profesionales de nivel medio en finanzas y matemáticas & 331 & $44 \%$
\end{tabular}

Fuente: OCDE, con base en datos del PIAAC Database, octubre 2015.

La Tabla 2 muestra las 20 ocupaciones más altas de uso intensivo de SPO entre los países. Del mismo modo que las ocupaciones con uso intensivo de CBI, la mayoría de las ocupaciones con uso intensivo de SPO no son ocupaciones especialistas en el uso de las TIC y generalmente incluyen ocupaciones similares como administradores y gerentes; científicos e ingenieros; matemáticos, actuarios, estadísticos y afines, además de secretarios y auxiliares contables $(334,412,431)$; especialistas en ciencias sociales y teología (263); autores, periodistas y lingüistas (264); agentes de servicios comerciales (333); agentes de la administración pública para la aplicación de la ley y afines (335). 
Tabla 2. Las 20 ocupaciones más altas de uso intensivo de SPO entre los países, 2012

Proporción de países donde la ocupación está entre las 20 más altas de SPO

Rango
1
2
3
4
5
6
7
8
9
10
11
12
13
14
15
16
17
18
19
20

$\quad$ Ocupación
Especialistas en finanzas
Especialistas en organización de administración
Profesionales del derecho
Directores de administración y servicios
Directores de ventas, comercialización y desarrollo
Profesores de universidades y de la enseñanza superior
Secretarios administrativos y especializados
Físicos, químicos y afines
Autores, periodistas y lingüistas
Directores de servicios de tecnología de la información y las comunicaciones
Matemáticos, actuarios y estadísticos
Ingenieros (excluyendo electrotecnólogos)
Especialistas en bases de datos y en redes de computadoras
Agentes de la administración pública para la aplicación de la ley y afines
Secretarios (general)
Auxiliares contables y financieros
Directores y gerentes de servicios profesionales
Especialistas en ciencias sociales y teología
Profesionales de nivel medio en finanzas y matemáticas
Agentes de servicios comerciales

Ocupación

$\begin{array}{cc}\text { CIUO-08 } & \text { Frecuencia } \\ 241 & 100 \% \\ 242 & 94 \% \\ 261 & 94 \% \\ 121 & 89 \% \\ 122 & 83 \% \\ 231 & 78 \% \\ 334 & 78 \% \\ 211 & 72 \% \\ 264 & 72 \% \\ 133 & 67 \% \\ 212 & 67 \% \\ 214 & 61 \% \\ 252 & 61 \% \\ 335 & 56 \% \\ 412 & 56 \% \\ 431 & 56 \% \\ 134 & 50 \% \\ 263 & 50 \% \\ 331 & 50 \% \\ 333 & 50 \%\end{array}$

Fuente: OCDE, con base en datos del PIAAC Database, octubre 2015.

Se presenta un informe con las 20 ocupaciones más altas de uso intensivo de las TIC para CBI y SPO por país en los Anexos A1 y A2 respectivamente. Llama la atención que algunas ocupaciones que no están comúnmente asociadas con el uso intensivo de las TIC están entre las 20 más altas en algunos países. Los practicantes paramédicos están entre las 20 más altas ocupaciones en el uso intensivo de CBI en República Checa, Dinamarca y Estonia; los marineros de cubierta y afines en Irlanda, Países Bajos y los Estados Unidos. De manera semejante, los veterinarios están entre las 20 más altas ocupaciones de uso de SPO en Austria, la República Checa, Italia, Japón, Países Bajos, la República Eslovaca, España y los Estados Unidos; los médicos en Alemania y en Noruega.

\subsection{Demanda laboral de ocupaciones con uso intensivo de TIC}

Una vez que se han clasificado todas las ocupaciones según la intensidad del uso de las TIC -CBI y SPOel siguiente paso del análisis es calcular una medida económica amplia de uso intensivo de las TIC en el trabajo. Esto se hace vinculando la intensidad del uso de las TIC por ocupación con la proporción de empleo en cada ocupación para valorar la demanda de habilidades genéricas para el uso de las TIC en el trabajo por país.

La proporción de empleo en cada ocupación fue calculada con base en las encuestas nacionales de población activa. Los datos de los países de la Unión Europea fueron obtenidos de la encuesta de población activa de la Unión Europea, donde las ocupaciones están clasificadas según la CIUO-08 de 2011. En otros países las clasificaciones nacionales de ocupaciones fueron convertidas a la CIUO-08. En Estados Unidos, las ocupaciones de 3 dígitos de la CIUO-08 fueron estimadas por la OCDE a partir de la Encuesta de Población Actual de la Oficina de Estadísticas Laborales de Estados Unidos (BLS, por sus siglas en inglés) basada en la tabla de concordancias entre el Sistema de Clasificación Internacional de Ocupaciones (SOC, por sus siglas en inglés) 2010 y la CIUO-08 (para mayor información, véase Eckardt y Squicciarini, de próxima publicación). En Australia, el empleo de las ocupaciones de 2 dígitos según la CIUO-08 fue estimado a partir de los datos de la Oficina de Estadísticas de Australia (ABS, por sus siglas en inglés) con base en la concordancia entre el 
Estándar Australiano y Neozelandés de Clasificación de Ocupaciones (ANZSCO, por sus siglas en inglés) 2006 y la CIUO-08 desarrollada por las Estadísticas de Nueva Zelanda.

La Figura 3a muestra la intensidad de uso de CBI en el trabajo por ocupación, la cual varía significativamente en el conjunto de la economía entre los países. En 2014 la intensidad de CBI fue del 64\% en Noruega en todas las ocupaciones y del 33\% en la República Eslovaca. Entre 2011 y 2014 la proporción de empleo de ocupaciones con uso intenso de CBI fue estable o se incrementó en la mayoría de los países excepto en Dinamarca, Irlanda, Italia, Japón y la República Eslovaca, donde hubo un ligero decremento. E1 incremento más notorio fue en Noruega (3.7 puntos porcentuales), seguido por Francia (2.9) y Polonia (1.7).

Figura 3a. Demanda de habilidades genéricas de TIC (CBI) por país, 2011 y 2014

Porcentaje de individuos empleados que usan $\mathrm{CBI}$ diariamente en el trabajo

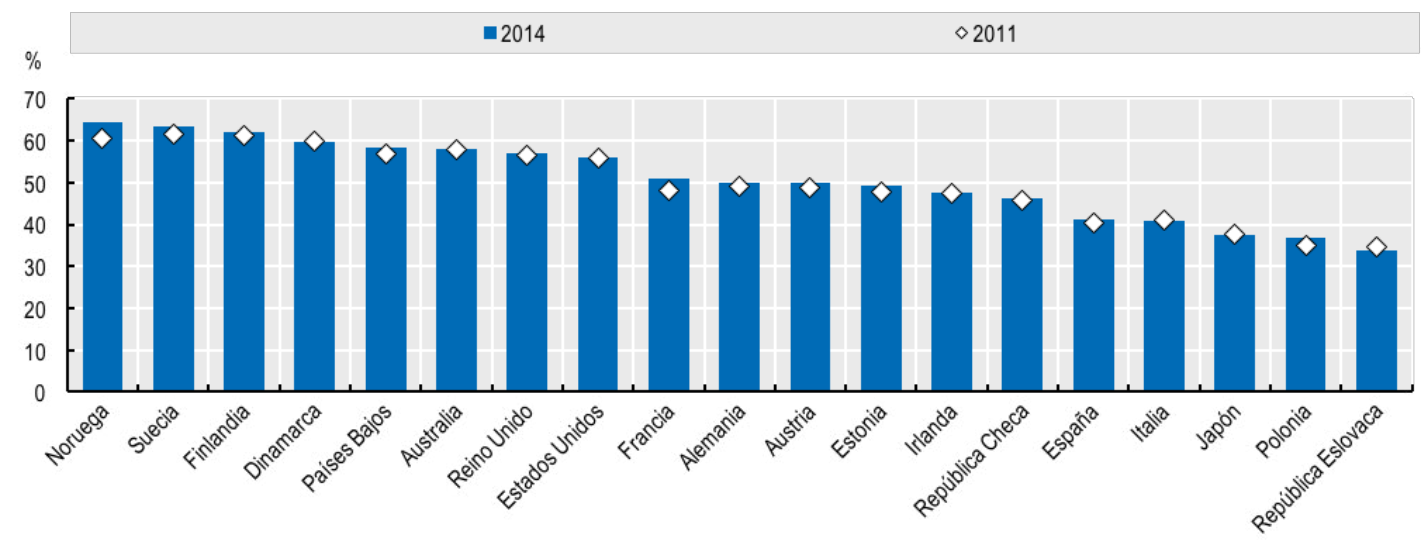

Nota: 2011 se refiere al 2010 para Japón.

Fuente: cálculos de la OCDE, con base en datos del PIAAC Database y de las encuestas nacionales de población activa, enero 2016.

La Figura 3b muestra la intensidad de uso en el trabajo de SPO en el conjunto de la economía en 2011 y 2014. La intensidad de uso de SPO varía en 2014 entre el 42.6\% en todas las ocupaciones en el Reino Unido y el $25.7 \%$ en Polonia. En el periodo entre 2011 y 2014 la proporción de empleo de ocupaciones con uso intensivo de SPO fue estable y a la vez se incrementó en la mayoría de los países excepto en la República Eslovaca y en Japón, donde decreció. El incremento más significativo se observó en Noruega (2.5 puntos porcentuales), Francia (2.0) y Suecia (1.5).

Figura 3b. Demanda de habilidades genéricas de TIC (SPO) por país, 2011 y 2014Porcentaje de individuos empleados que usan SPO diariamente en el trabajo

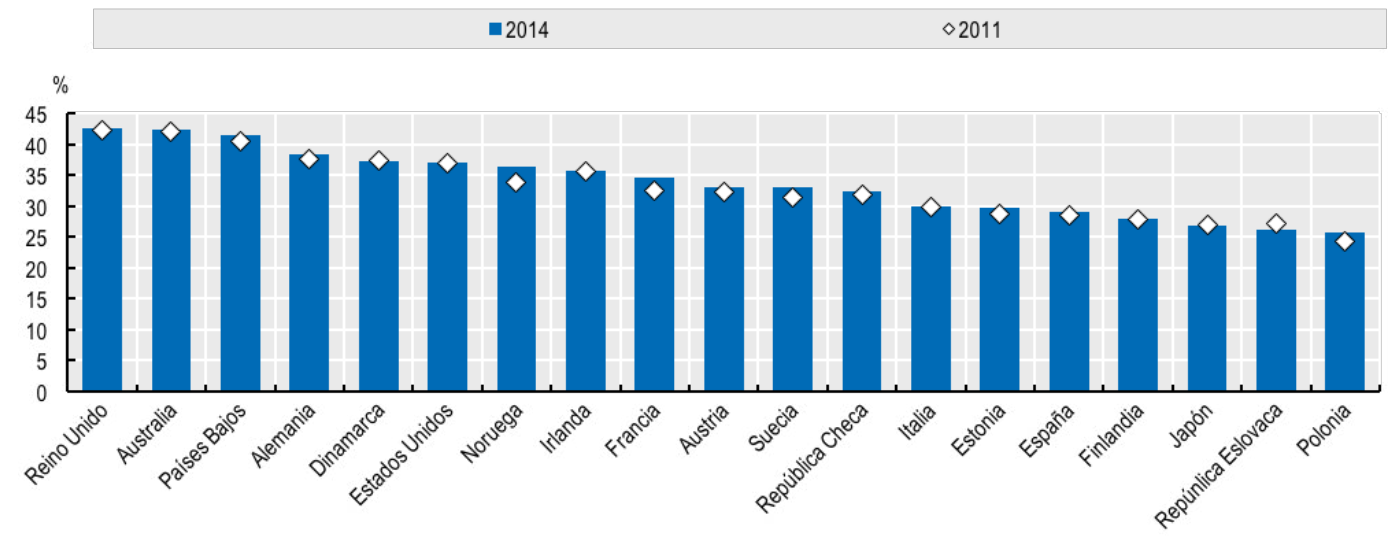

Nota: 2011 se refiere al 2010 para Japón.

Fuente: cálculos de la OCDE, con base en datos del PIAAC Database y de las encuestas nacionales de población activa, enero 2016. 


\section{Habilidades especializadas para el uso de las TIC}

Las especialidades en TIC están entre las ocupaciones más dinámicas de los años recientes. "Desarrolladores y analistas de software y multimedia" y "técnicos en operaciones de tecnología de la información y las comunicaciones y asistencia al usuario" están entre las 10 ocupaciones con más crecimiento en UE-26 desde 2012q2 a 2013q2, que va de 156,300 y 64,500 empleados respectivamente (Comisión Europea, 2014a). En Australia el empleo de gerentes en las TIC se incrementó en 29.7\% de 2009 a 2013, según el Gobierno Australiano (Agencia Australiana de Empleo y Productividad, 2013). En Estados Unidos la industria TI perdió solamente el 1\% de su fuerza laboral durante la recesión y el empleo creció $7.5 \%$ de 2009 a 2011 (BLS, 2013), superando el nivel que tenía antes de la recesión.

Varios pronósticos sugieren que la demanda de profesionales de las TIC crecerá todavía más durante los próximos años. De acuerdo con las proyecciones de la Oficina de Estadísticas Laborales (Lacey y Wright, 2009), "se espera que las ocupaciones de matemáticas e informática en los Estados Unidos crezcan como grupo más del doble y tan rápido como el promedio de todas las ocupaciones". La Agencia Australiana de Empleo y Productividad estima que las vacantes para las ocupaciones de las TIC en Australia alcanzarán 1.18 millones en 2025 y se espera que este incremento esté impulsado por un nuevo crecimiento y no debido a la demanda de reemplazo. Un estudio encargado por el Ministerio Noruego de Modernización y Gobierno Local predice una escasez de personal de las TIC de alrededor 10,500 personas en 2030 en Noruega (OCDE, 2014a). La Comisión Europea (2014b) pronostica que el vacío entre la demanda y la oferta de profesionales de las TIC en UE-27 se incremente en promedio $16.39 \%$ al año de 2013 a 2020.

Estos pronósticos se basan en un enfoque que, por su naturaleza, es muy difícil validar. Aun así, generan preocupación sobre la capacidad del mercado laboral para proveer suficientes trabajadores con las habilidades requeridas. De hecho, una escasez de especialistas en las TIC requerirá que los países adopten políticas que desarrollen estas habilidades en los trabajadores así como entre los recién llegados al mercado laboral.

El objetivo de esta sección es revisar la evidencia estadística disponible sobre la potencial escasez de especialistas de las TIC. Si las empresas enfrentan dificultades para cubrir estas vacantes, la escasez resultará en al menos una de las siguientes situaciones: $i$ ) una tendencia creciente en los niveles de vacantes de empleo para especialistas en las TIC; ii) una duración más larga de estas vacantes y iii) un incremento salarial para esos especialistas.

Desafortunadamente las estadísticas disponibles respecto a las vacantes de empleo y a los salarios no tienen los elementos para solucionar estas cuestiones. Las estadísticas oficiales disponibles respecto a las vacantes de empleo y a los salarios se refieren al sector de la industria y no al de las ocupaciones. Recientemente, la información sobre el número y la duración de las vacantes relacionadas con las TIC fue calculada a partir de vacantes publicadas en Internet (vacantes en línea). Aunque pueden servir para detectar y medir tendencias en el mercado laboral, las vacantes en línea no parecen apropiadas para medir la escasez laboral debido a su cobertura limitada y a su baja comparabilidad internacional.

El enfoque de este análisis, por lo tanto, es tener una idea general de la demanda de especialistas en TIC basada en diferentes fuentes estadísticas disponibles que solamente proveen, cada una por su parte, una medida parcial del problema. Teniendo en mente estas limitantes, la evidencia presentada en esta sección confirma que la demanda de especialistas en TIC está creciendo rápidamente, pero también sugiere que la potencial escasez de estas habilidades se limita a un reducido número de países.

El análisis está organizado de la siguiente forma. La sección 3.1 examina nueva evidencia en la demanda de habilidades especializadas para el uso de las TIC en el trabajo vinculando del PIAAC de la OCDE y de las encuestas nacionales de población activa. Las secciones 3.2 y 3.3 revisan las tendencias recientes de vacantes de empleo y salarios, respectivamente, en las industrias de la información, mientras que la sección 4 examina las tendencias de las vacantes en línea para ocupaciones de TIC y su duración. Los resultados de las encuestas a los empleadores están resumidas en la sección 3.5. 


\subsection{La demanda de habilidades especializadas en TIC}

La frecuencia con la que los encuestados del PIAAC "usan lenguajes de programación" ii es un indicativo de la demanda de habilidades especializadas en TIC. Usando la misma metodología para la valoración de la intensidad de las habilidades genéricas para el uso de las TIC, la intensidad de las habilidades especializadas en el trabajo está manifestada en la proporción de individuos que reportaron usar lenguajes de programación diariamente.

La Tabla 3 muestra las 20 ocupaciones con el índice de intensidad en el uso de las TIC más alto entre los países. Es interesante notar que 13 de las 20 ocupaciones más altas (en itálica) no están clasificadas como ocupaciones de TIC. Incluyen profesores de universidades y de formación profesional (CIUO-08 231 y 232); científicos, ingenieros y arquitectos $(211,214$ y 216$)$; técnicos en ciencias físicas y en ingeniería; directores de administración y servicios $(121,132)$; profesionales de las ventas, la comercialización y las relaciones públicas (243) así como pagadores y cobradores de ventanilla y afines (421); empleados de servicios de información al cliente (422), herreros, herramentistas y afines (722), operadores de instalaciones de procesamiento y recubridoras de metales (812).

Tabla 3. Las 20 ocupaciones más altas de uso especializado en TIC entre los países

Proporción de países donde la ocupación está entre las 20 más altas

\begin{tabular}{|c|c|c|c|}
\hline $\begin{array}{c}\text { Rango } \\
1\end{array}$ & $\begin{array}{l}\text { Ocupación } \\
\text { Técnicos en operaciones de tecnología de la información y las comunicaciones y } \\
\text { asistencia al usuario }\end{array}$ & $\begin{array}{c}\text { CIUO-08 } \\
351\end{array}$ & $\begin{array}{c}\text { Frecuencia } \\
100 \%\end{array}$ \\
\hline 2 & Desarrolladores y analistas de software y multimedia & 251 & $94 \%$ \\
\hline 3 & Directores de servicios de tecnología de la información y las comunicaciones & 133 & $78 \%$ \\
\hline 4 & Profesores de universidades y de la enseñanza superior & 231 & $78 \%$ \\
\hline 5 & Especialistas en bases de datos y en redes de computadoras & 252 & $78 \%$ \\
\hline 6 & Ingenieros (excluyendo electrotecnólogos) & 214 & $67 \%$ \\
\hline 7 & Ingenieros en electrotecnología & 215 & $61 \%$ \\
\hline 8 & Herreros, herramentistas y afines & 722 & $56 \%$ \\
\hline 9 & Arquitectos, urbanistas, agrimensores y diseñadores & 216 & $50 \%$ \\
\hline 10 & Físicos, químicos y afines & 211 & $44 \%$ \\
\hline 11 & Profesores de formación profesional & 232 & $44 \%$ \\
\hline 12 & Técnicos en ciencias físicas y en ingeniería & 311 & $44 \%$ \\
\hline 13 & Pagadores y cobradores de ventanilla y afines & 421 & $44 \%$ \\
\hline 14 & Operadores de instalaciones de procesamiento y recubridoras de metales & 812 & $44 \%$ \\
\hline 15 & Directores de administración y servicios & 121 & $39 \%$ \\
\hline 16 & Directores de industrias manufactureras, de minería, construcción y distribución & 132 & $39 \%$ \\
\hline 17 & Profesionales de las ventas, la comercialización y las relaciones públicas & 243 & $39 \%$ \\
\hline 18 & Instaladores y reparadores de equipos electrónicos y de telecomunicaciones & 742 & $39 \%$ \\
\hline 19 & Técnicos en telecomunicaciones y radiodifusión & 352 & $33 \%$ \\
\hline 20 & Empleados de servicios de información al cliente & 422 & $33 \%$ \\
\hline
\end{tabular}

Fuente: OCDE, con base en datos del PIAAC Database, octubre 2015.

La Figura 4 muestra la intensidad de especialistas en las TIC en el conjunto de la economía en 2011 y 2014. El indicador fue calculado por la ponderación de la intensidad de especialidad en las TIC por ocupación con la proporción de empleo por cada ocupación. Es una aproximación de la demanda total de habilidades especializadas en el uso de las TIC en el trabajo en un país. 
Figura 4. Demanda de habilidades especializadas en TIC por país, 2011 y 2014

Porcentaje de individuos empleados que usan lenguajes de programación diariamente en el trabajo

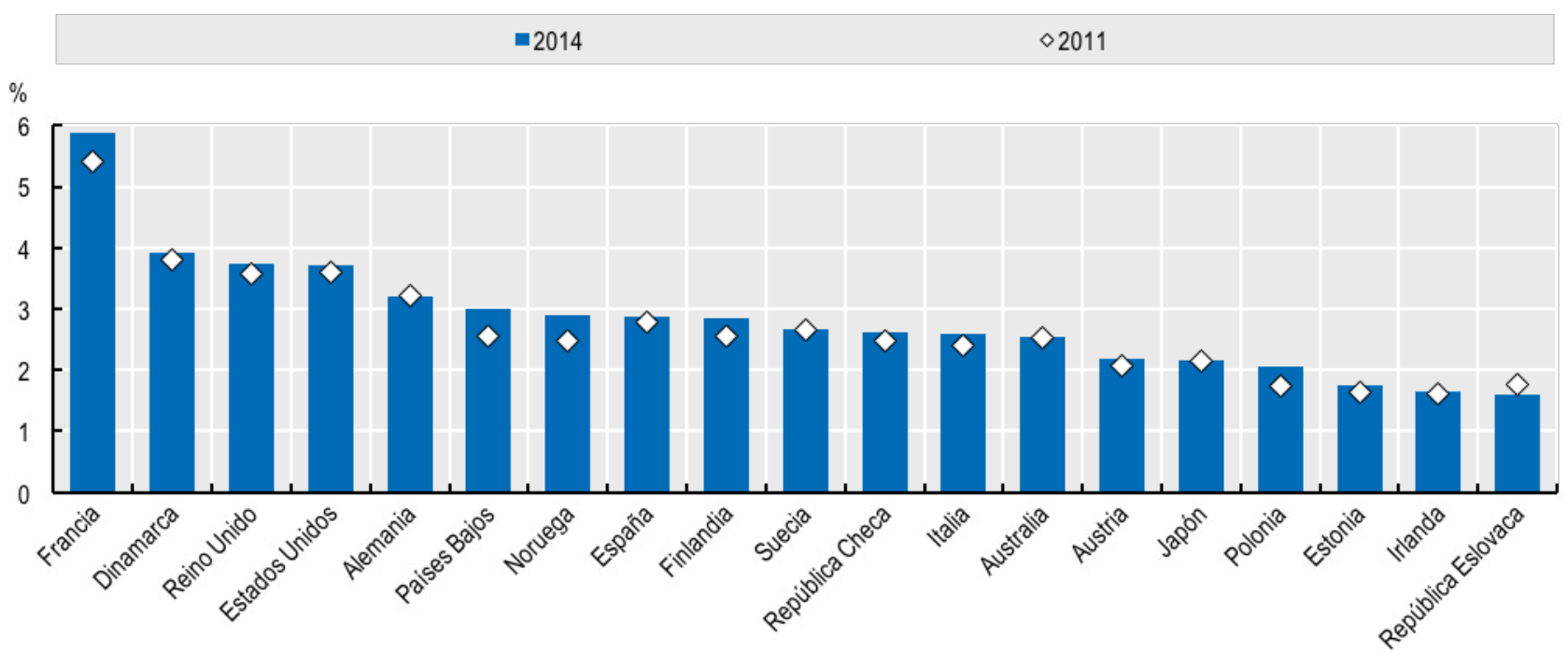

Nota: 2011 se refiere al 2010 para Japón.

Fuente: OCDE, con base en datos del PIAAC Database y de las encuestas nacionales de población activa, enero 2016.

Las diferencias entre los países de la demanda de habilidades en el uso de las TIC son más reducidas en las especializadas que en las genéricas. En 2014 la proporción de especialistas en TIC estuvo entre el 5.9\% en Francia y 1.6\% en Irlanda y la República Eslovaca; la mayoría de los países se posicionó alrededor del 3\%.

Entre 2011 y 2014 la proporción de empleo de las ocupaciones en TIC se incrementó en todos los países, excepto en la República Eslovaca (-0.15 puntos porcentuales). Las proporciones fueron más bien estables con un modesto incremento de 0.18 puntos porcentuales, menor al incremento promedio observado en las habilidades genéricas para el uso de las TIC para el uso de CBI y SPO (respectivamente 0.9 y 0.7 puntos porcentuales). El mayor incremento se dio en Francia, seguido por Países Bajos y Noruega.

\subsection{Vacantes en los servicios de la información y las comunicaciones: tendencias recientes}

Los índices de vacantes de empleo son las medidas utilizadas comúnmente para ver el desequilibrio entre la demanda y la oferta en el mercado laboral. Los índices de vacantes de una determinada ocupación se definen como la relación entre el número de vacantes y el número de puestos cubiertos y no cubiertos, es decir, vacantes más empleos en esa ocupación. Un incremento en el índice de vacantes de empleo indica que la demanda de habilidades requeridas en determinada ocupación está creciendo más rápido que su oferta. $\mathrm{Si}$ las habilidades requeridas están disponibles en la fuerza de trabajo, el desequilibrio mencionado desaparece con el tiempo a medida que hay mayores oportunidades de empleo y salarios más altos para atraer gente de la inactividad o de otras ocupaciones. En cambio, una tendencia ascendente de las tasas de vacantes señala que las habilidades requeridas no están disponibles en el mercado laboral, esto significa escasez de habilidades.

Los argumentos antes mencionados se aplican a todas las ocupaciones de TI, pero las estadísticas oficiales solo recaban información de los índices de vacantes para los servicios de la información y las comunicaciones (actividad J de la Clasificación Internacional Uniforme de Ocupaciones [CIUO], Rev. 4 y 51 del Sistema de Clasificación de la Industria Norteamericana [NAICS] de 2007). Sin embargo, su cobertura es menor que las ocupaciones de TIC por dos razones. En primer lugar, las industrias de las TIC a saber, manufactura y servicios, emplean alrededor de la mitad de todas las ocupaciones de TIC. En segundo lugar, las estadísticas oficiales no incluyen vacantes de las industrias manufactureras de TIC.

Los datos de esta sección fueron recogidos de diferentes fuentes. Los principales datos se utilizaron a partir de las gráficas publicadas en línea por las oficinas nacionales de estadísticas, de las bases de datos de la Organización Internacional del Trabajo y de Eurostat. Los informes, artículos y encuestas sobre vacantes de 
empleo fueron utilizadas como fuentes secundarias para tener una visión más amplia sobre la percepción de la escasez de habilidades en el uso de las TIC entre los Estados miembros. La cobertura de los datos abarca de 2009 a 2014, con algunas excepciones de algunos países cuyos datos disponibles solo abarcaban un periodo limitado de tiempo.

Figura 5. Promedio de índices de vacantes en servicios de TIC, 2009 y 2014

Porcentaje anual de índices trimestrales

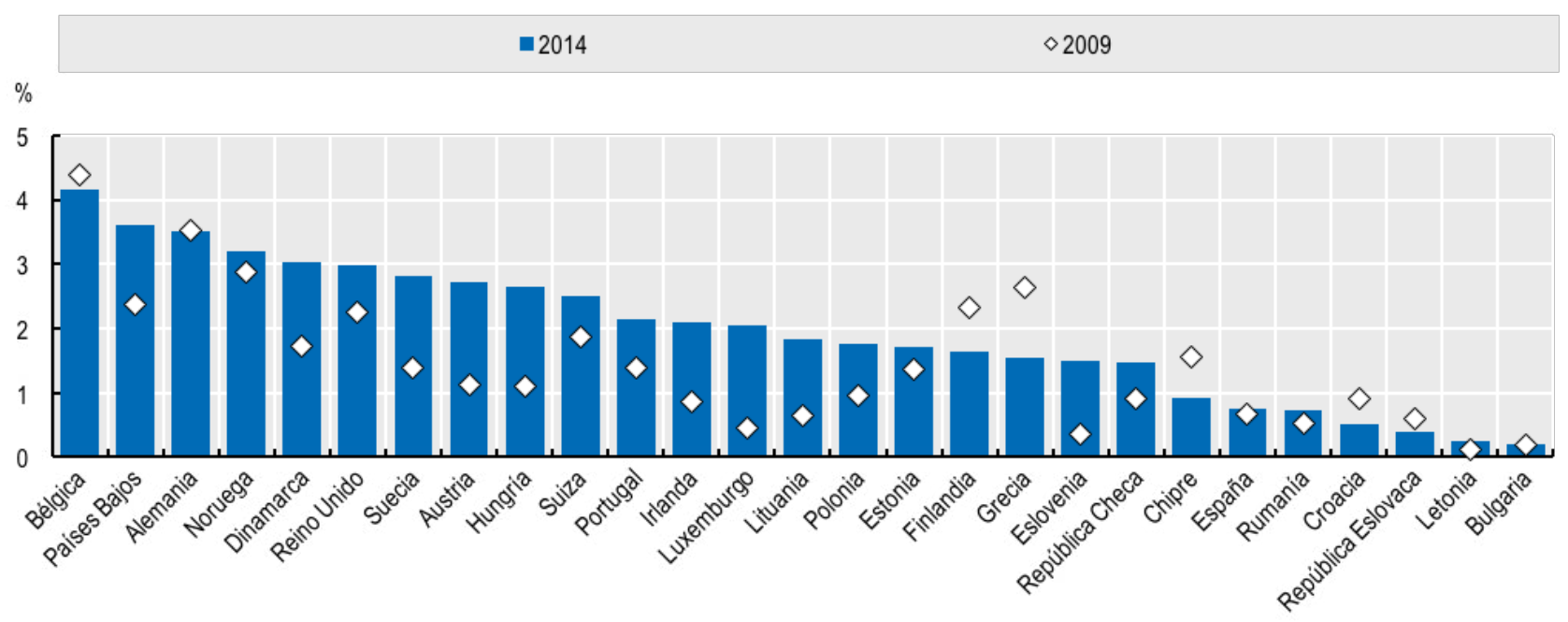

Nota: CIUO Rev. 4, Sector J. El primer año disponible es 2010 para Bélgica, Dinamarca y Noruega; 2011 para Alemania; 2012 para Croacia y 2013 para España. El último año disponible es 2015 para la República Checa, Alemania, Eslovenia y el Reino Unido. Nota sobre Turquía:

La información en este documento referente a "Chipre" se refiere a la parte sur de la Isla. No hay ninguna autoridad que represente tanto al pueblo turco como chipriota en la Isla. Turquía reconoce la República Turca del Norte de Chipre (RTNC). Hasta que no se alcance una solución duradera y equitativa en el contexto de las Naciones Unidas, Turquía preservará su postura respecto a la "cuestión de Chipre". Nota de todos los Estados Miembros de la Unión Europea de la OCDE y de la Unión Europea:

Todos los miembros de las Naciones Unidas con excepción de Turquía reconocen a la República de Chipre. La información contenida en este documento se refiere al área bajo el control efectivo del Gobierno de la República de Chipre.

Fuente: OCDE, basada en Eurostat, Estadísticas de vacantes de empleo, enero 2016.

La Figura 5 reporta los índices anuales de vacantes en servicios de la información y las comunicaciones en 2014 y 2008, o el año anterior disponible, en Europa. La figura muestra grandes diferencias entre los índices de vacantes de los países. En 2014 los índices de vacantes en TIC se establecieron en el 4.15\% en Bélgica y $0.3 \%$ en Letonia y Bulgaria. Los índices de vacantes estuvieron por encima del 3\% en Países Bajos, Alemania, Noruega y Dinamarca; entre el 3 y $2 \%$ en el Reino Unido, Suecia, Austria, Hungría, Suiza, Portugal, Irlanda y Luxemburgo, y por debajo en todos los demás países.

Los cambios a través del tiempo muestran una imagen variada. En Austria, Dinamarca, Hungría, Irlanda, Lituania, Luxemburgo, Países Bajos, Eslovenia y Suecia, los índices de vacantes de empleo crecieron significativamente entre 2009 y 2014. En cambio, bajaron significativamente en Finlandia y Grecia.

Las diferencias que se observan entre los países respecto a las vacantes y a través del tiempo pueden estar relacionadas con el ciclo económico. Para efectos del control del ciclo económico, la Figura 6 traza la relación de los índices de vacantes entre los servicios de las TIC y el total del sector económico (CIUO Rev. 4, actividades B a S) en 2009, o el año anterior disponible, y 2014. Los índices de vacantes en los servicios de las TIC tienden a ser más altos que el total de los sectores económicos. En 2014, la relación entre los dos indicadores excedió 3.5 en Portugal y Polonia, no fue menor a 2.5 en Irlanda y los Países Bajos y estuvo por encima de 2 en Luxemburgo y Suiza. No obstante, los índices de vacantes en los servicios de las TIC fueron más o menos los mismos del total del sector económico en Estonia, Eslovenia y el Reino Unido, incluso fueron más bajos en países como Letonia, Croacia, la República Eslovaca y Bulgaria. Por lo tanto, la posible escasez de habilidades en los servicios de las TIC parece estar limitado a ciertos países. 
La relación de los índices de vacantes crecieron en la mayoría de los países en donde hay disponibilidad de datos a excepción de Austria, Alemania, Finlandia, Estonia, el Reino Unido, la República Checa y la República Eslovaca. Por lo tanto, en países con desaceleración económica los índices de vacantes disminuyeron en los servicios de las TIC menos que en el resto de la economía, mientras que ocurrió lo contrario en la recuperación. El incremento de los índices de vacantes en las TIC fue particularmente importante en Polonia, Países Bajos y Chipre ${ }^{\mathrm{iii}}$.

Figura 6. Promedio de índices de vacantes en servicios de las TIC en relación con el sector económico, 2009 y 2014

Porcentaje anual de índices trimestrales

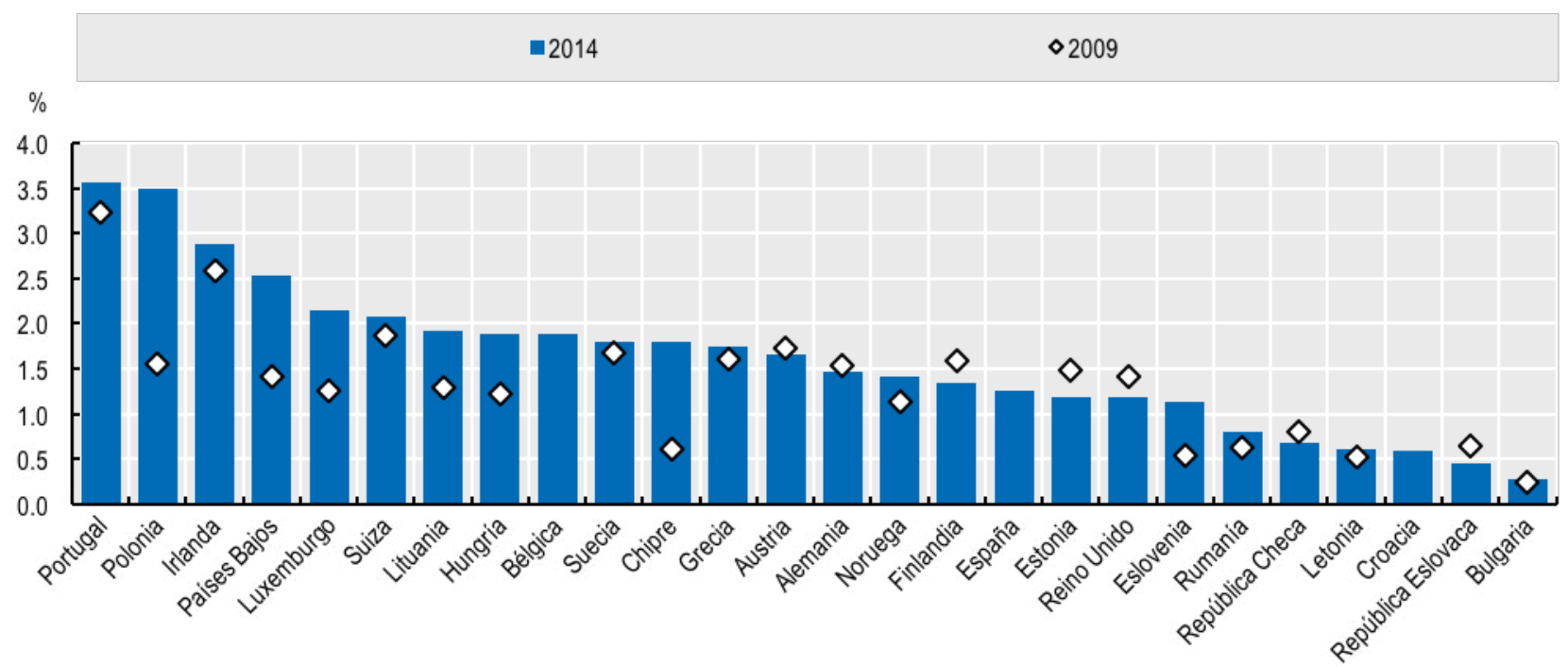

Nota: CIUO Rev. 4, Sector J. El primer año disponible en Austria y Noruega fue 2010. Respecto a Chipre, véase nota de Figura 4. Fuente: OCDE, basada en Eurostat, Estadísticas de vacantes de empleo, enero 2016.

\subsection{Salarios para servicios de las TIC: tendencias recientes}

La escasez laboral de ciertas habilidades debe resultar en un incremento de los sueldos reales de las ocupaciones que hacen uso intensivo de estas habilidades. Si las habilidades en el uso de las TIC escasean en el mercado laboral, las empresas deberán pagar sueldos reales más altos para atraer trabajadores con esas habilidades.

Los cambios en los sueldos reales no necesariamente son la solución contra la escasez de habilidades. Por un lado, la escasez de habilidades no siempre se traduce inmediatamente en sueldos más altos debido a tiempos de ajuste, como por ejemplo, en la negociación colectiva. Por otro lado, los sueldos pueden elevarse como resultado de una combinación de la productividad en sectores específicos de la industria y el conjunto de la economía. Por lo tanto, un incremento en los sueldos reales puede ser visto como una señal de escasez de habilidades solamente si $i$ ) persiste a través del tiempo; ii) excede el aumento de la productividad laboral ${ }^{\text {iv }}$; iii) es más extensa que en otros sectores de la economía.

La Figura 7 compara los índices del aumento promedio de sueldos -relativo al promedio de la productividad laboral- en los servicios de las TIC y el total del sector económico de 2000 a 2015 . En más de la mitad de los 28 países que tienen datos disponibles, los sueldos aumentaron menos en los servicios de las TIC que en la totalidad del sector económico. En los países restantes, las diferencias en los aumentos de sueldo fueron más bien bastante limitados, a saber, menos del 1\% al año. Estas tendencias confirman que la demanda de especialistas en las TIC está creciendo rápidamente pero sugieren que la posible escasez de habilidades en TIC se limite a un pequeño grupo de países, al menos en Europa. 


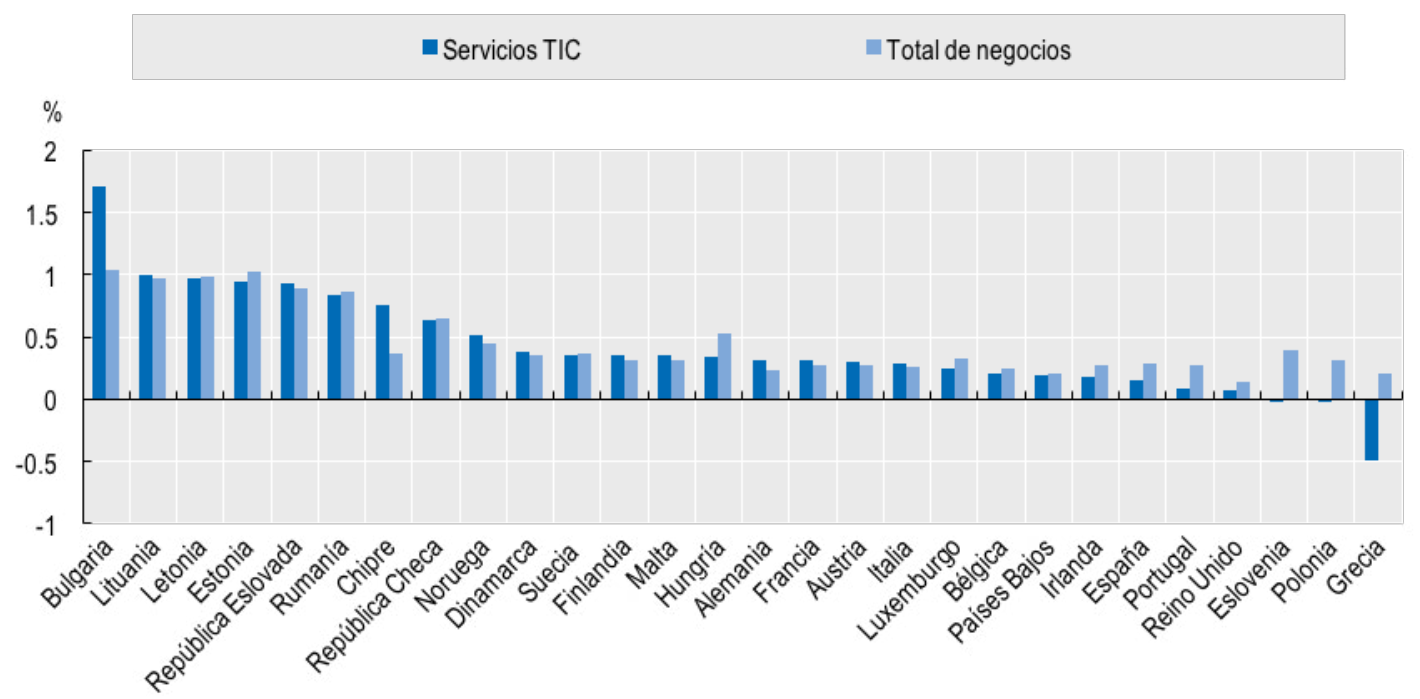

Nota: Para Chipre, la República Checa, Finlandia, Francia, Irlanda, Luxemburgo, los Países Bajos, Polonia, la República Eslovaca y España, los datos hacen referencia al periodo entre 2011-2014. Respecto a Chipre, véase nota de Figura 5.

Fuente: OCDE, basada en Eurostat, Cuentas Estadísticas Nacionales Anuales, enero 2016.

\subsection{Tendencias en las ocupaciones de las TIC: evidencia proveniente de vacantes en línea}

Aunque existen estadísticas oficiales sobre vacantes de empleo en la industria, las vacantes en línea ofrecen información por ocupación. Recientemente un número de empresas privadas y algunas oficinas de estadísticas nacionales empezaron a recolectar y a analizar empleos publicados en línea para compilar estadísticas de vacantes. Esta sección se basará principalmente en los datos de Burning Glass and Jobfeed, dos compañías líderes especializadas en vacantes en línea. ${ }^{\mathrm{V}}$

Las vacantes de empleo en línea tienen un gran potencial como fuente de información de las características de las ofertas de trabajo, de los solicitantes de empleo y de la duración de la publicación. Pueden rastrear las fluctuaciones del mercado laboral en tiempo real por lo que pueden ofrecer datos de alta frecuencia. Además, permiten el análisis de cambios en los perfiles de empleo basados en un amplio índice de requerimientos de habilidades, educación y experiencia.

Sin embargo, para los fines de este documento, las vacantes en línea tienen algunas deficiencias que los futuros desarrollos en la recopilación de datos y el tratamiento podrían superar. En primer lugar, el número total de vacantes en línea tiende a ser significativamente menor (alrededor del 50\%) al número de vacantes de fuentes oficiales. ${ }^{\text {vi }}$ En segundo lugar, solo una pequeña parte de las vacantes en línea puede ser clasificada por la industria, lo que impide una comparación más cercana con los datos oficiales. En tercer lugar, la clasificación de las ocupaciones de TIC, que es una operación compleja en sí misma, no es consistente en todos los países. Finalmente, la cobertura se limita a algunos países.

La clasificación de las vacantes en línea no siempre coincide con las clasificaciones nacionales e internacionales de ocupaciones, por ejemplo, CIUO, US SOC, etcétera, por lo que es difícil calcular los índices de vacantes. A continuación, los índices de vacantes se calcularon utilizando el número de especialistas en TIC como está definido en DST/ICCP/IIS(2013)6. Como el numerador y el denominador no están definidos del mismo modo, se debe considerar esta estadística como una aproximación a los índices de vacantes reales.

La Figura 8 muestra las vacantes de empleo para ocupaciones de las TIC como proporción de todas las vacantes entre 2012 y 2015. En 2014 las ofertas de empleo para las TIC representaron entre el 13\% (Reino Unido) y el 7\% (Francia) de todas las ofertas de trabajo. Esta proporción ha disminuido en Australia ( -4 puntos porcentuales), Nueva Zelanda (-12), el Reino Unido (-2) y los Estados Unidos (-3) de 2012 a 2014. Ha aumentado en Francia (1) y Alemania (2) en comparación con 2012, mientras que se ha mantenido estable en 
los Países Bajos. Los primeros 5 meses de 2015 muestran un aumento más rápido en las ofertas de empleo en las TIC, aunque esto puede reflejar en cierta medida una relación con ciertas temporadas.

Figura 8. Ofertas en línea de empleo para TIC. 2012-2015a

Como porcentaje de todas las publicaciones en línea

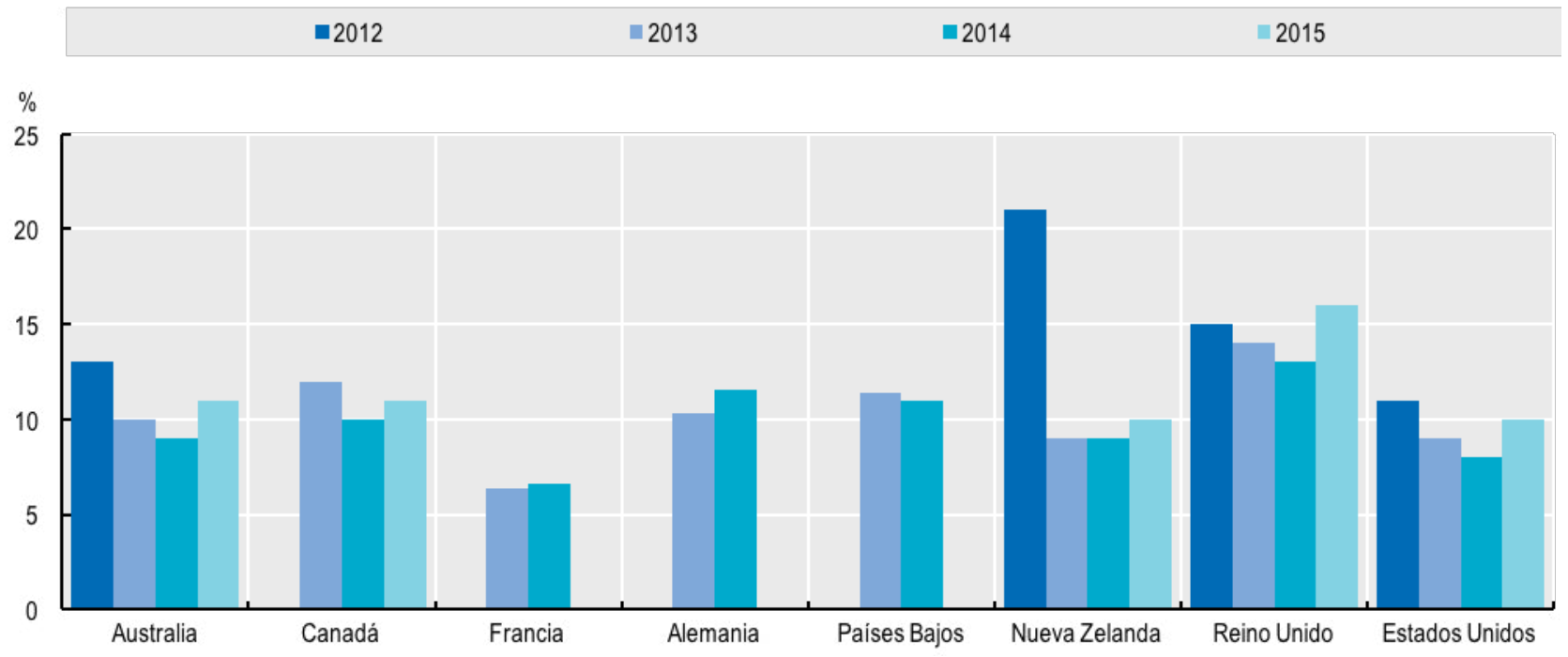

a 2015 se refiere al periodo de 01-01-2015 al 26-05-2015.

Fuente: OCDE, basada en Burning Glass and Jobfeed, mayo 2015.

La Figura 9 muestra los índices de vacantes en línea de las TIC en 2013. Los índices más altos aparecen en el Reino Unido (20.1\%) mientras que oscilan entre el 10.2\% en Nueva Zelanda y el $4.7 \%$ en Australia.

Figura 9. Índices de vacantes en línea para ocupaciones de TIC, 2013

Índices trimestrales medios anuales

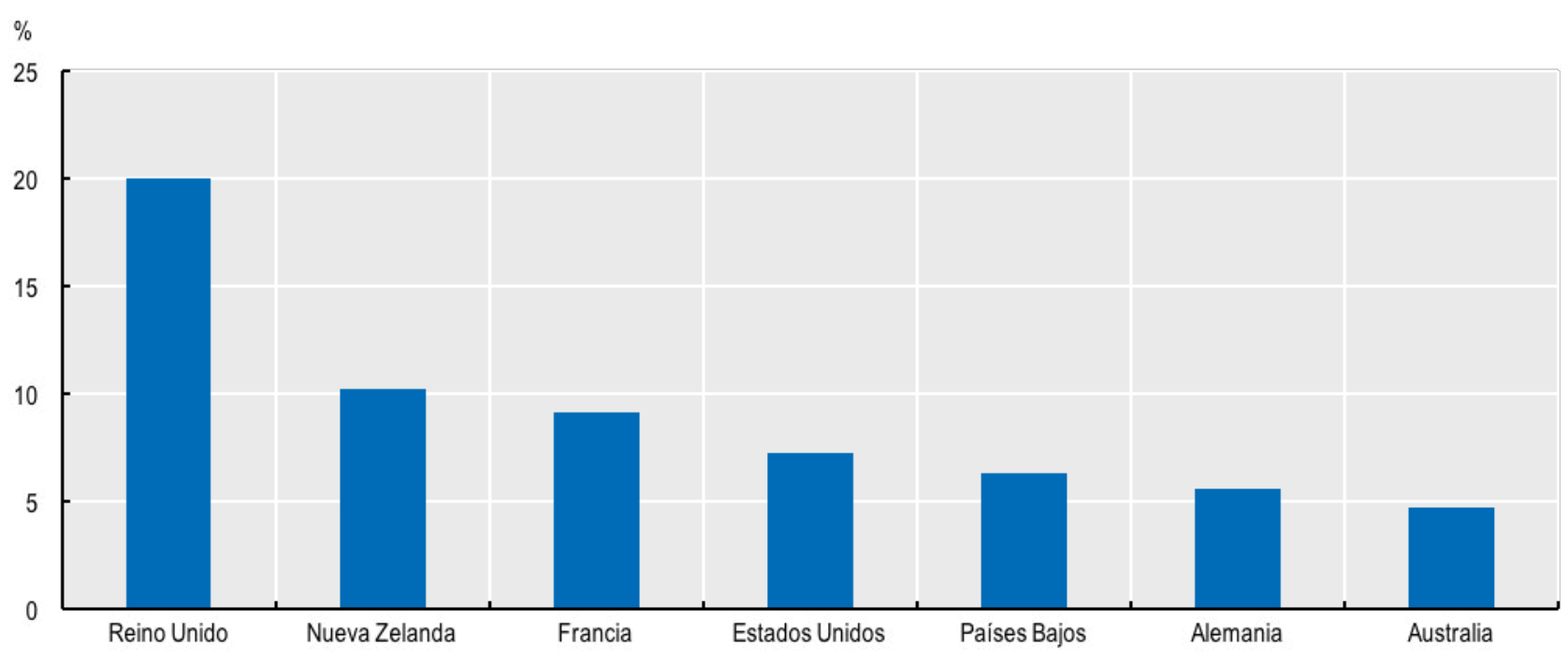

Fuente: OCDE, basada en Burning Glass and Jobfeed, mayo 2015. 
En los Estados Unidos, los índices de vacantes de las TIC pueden ser calculados por un periodo más largo (2010-2014) y muestran una tendencia al alza que va del 5.5\% en 2010 al 7.3\% en 2014.

En lo que se refiere a Australia, el Índice Australiano de Vacantes en Internet calculado por el Departamento del Empleo muestra una fuerte tendencia a la baja en las vacantes en línea para los profesionales de las TIC. El índice cayó después de la crisis y, a pesar de una recuperación parcial a mediados de 2009, siguió disminuyendo a partir de 2010 (Figura 10).

Figura 10. Vacantes en línea para profesionales de las TIC en Australia, 2007-14 Índice Australiano de Vacantes en Internet, enero $2006=100$

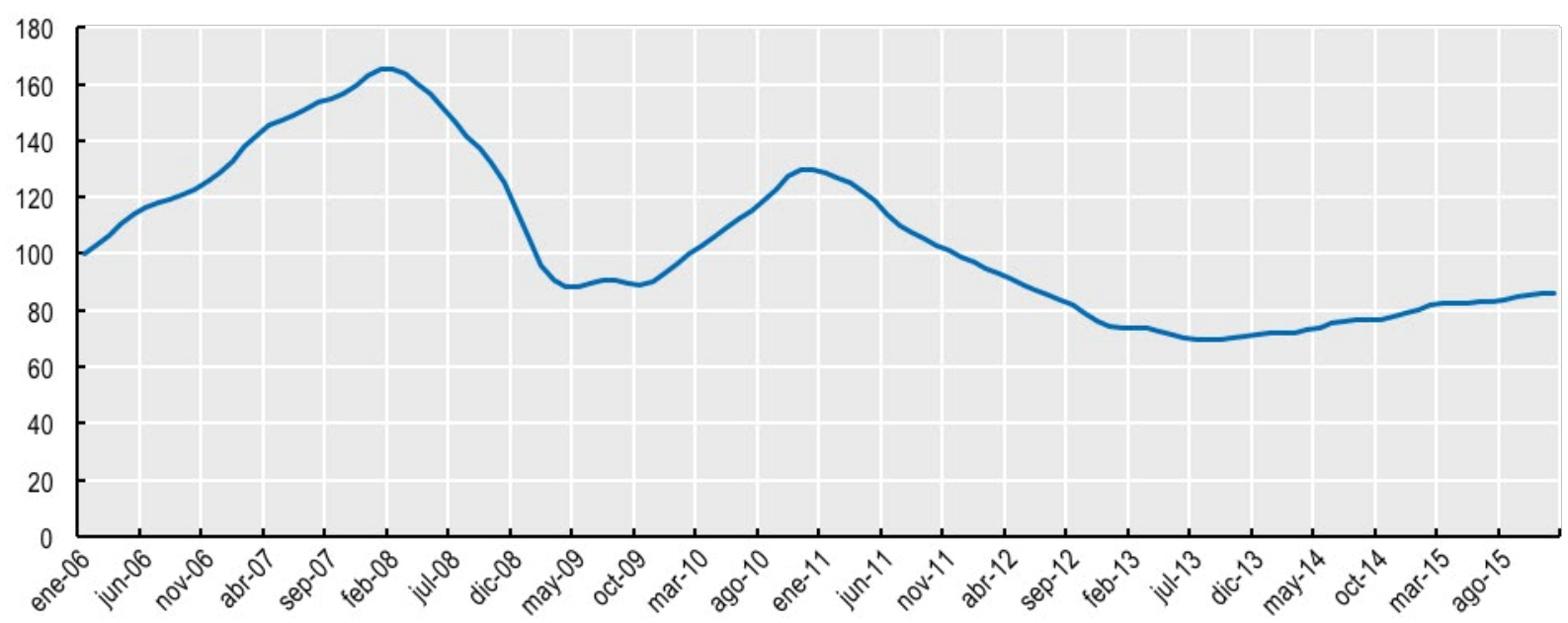

Fuente: Data.gov.au, mayo 2015.

La duración de la vacante, es decir el tiempo que toma cubrirla, proporciona un indicador adicional de los desequilibrios del mercado laboral. Si las habilidades en el uso de las TIC escasearan más que otras habilidades, se esperaría que la duración de la vacante sea mayor para las ocupaciones de las TIC.

Las vacantes en línea permiten medir el tiempo que una vacante determinada permanece publicada en Internet. Sin embargo, las razones para retirar una vacante son desconocidas, es decir, la vacante puede haberse cubierto o la empresa no ha podido encontrar al candidato adecuado para esa posición. Aunque son de naturaleza diferente, en ambos casos la duración más larga se asocia con una mayor dificultad para cubrir una posición.

La Figura 11 muestra la duración media de las vacantes en línea de las TIC en Francia, Alemania y los Países Bajos durante el periodo 2011-2014. En los Países Bajos la duración media se redujo de 54.5 días en 2011 a 33.3 días en 2014. Entre 2013 y 2014 la duración media aumentó de 29.8 a 34 días en Alemania, mientras que se mantuvo casi sin cambios en Francia. 


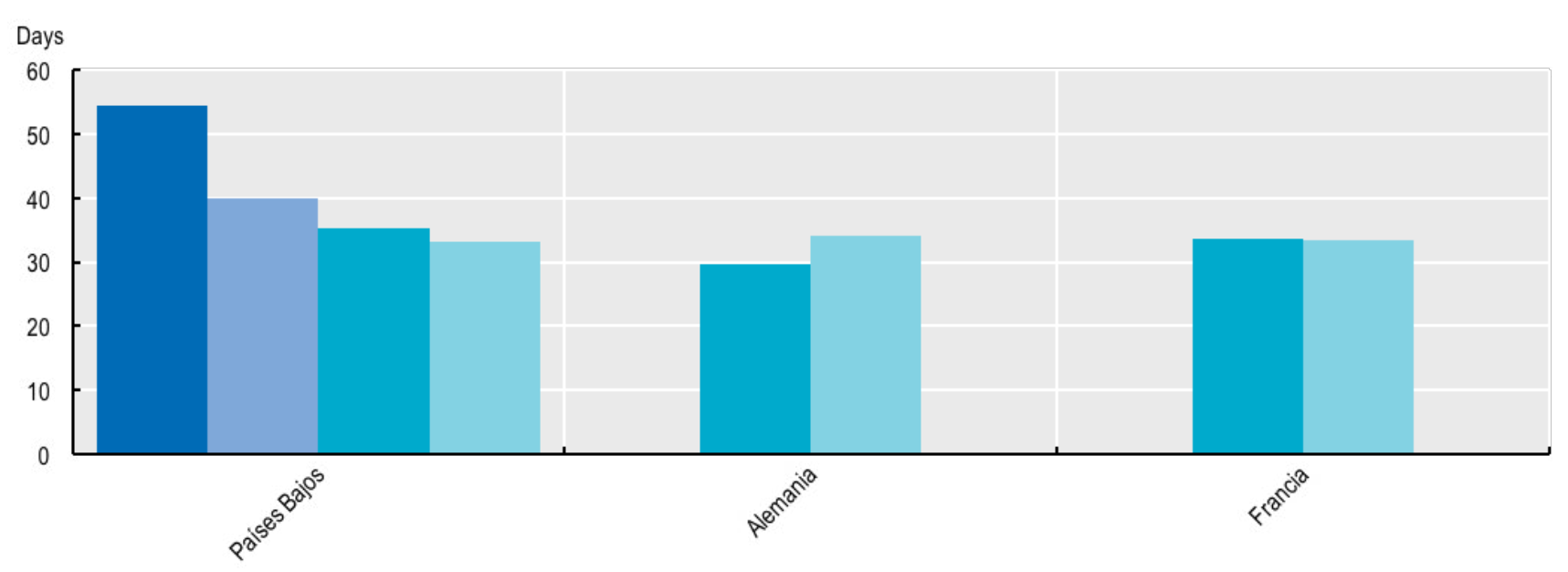

Fuente: OCDE, basada en Jobfeed, mayo 2015.

\subsection{Evidencia a partir de encuestas a los empleadores}

Las encuestas a los empleadores proporcionan información complementaria sobre la posible escasez de habilidades. En la Unión Europea el 38\% de las empresas que buscan un especialista de las TIC informaron tener dificultades para cubrir las vacantes (Figura 12). Sin embargo, el porcentaje de empresas que reportan vacantes difíciles de cubrir para especialistas en las TIC es mucho más pequeño -alrededor del 3\%- y no ha cambiado de 2012 a 2014. Esta proporción disminuyó o se mantuvo estable en la mayoría de los países de la UE. El aumento más significativo (más de 1 punto porcentual) se observó en Dinamarca, Hungría y Eslovenia. Por lo tanto, en la mayoría de los países la potencial escasez de habilidades en el uso de las TIC es poca porque solo una pequeña proporción de empresas está buscando a especialistas en TIC.

Figura 12. Empresas que reportaron vacantes difíciles de cubrir para especialistas en TIC, 2012 y 2014

Como porcentaje de todas las empresas de aquellos que buscan un especialista en TIC

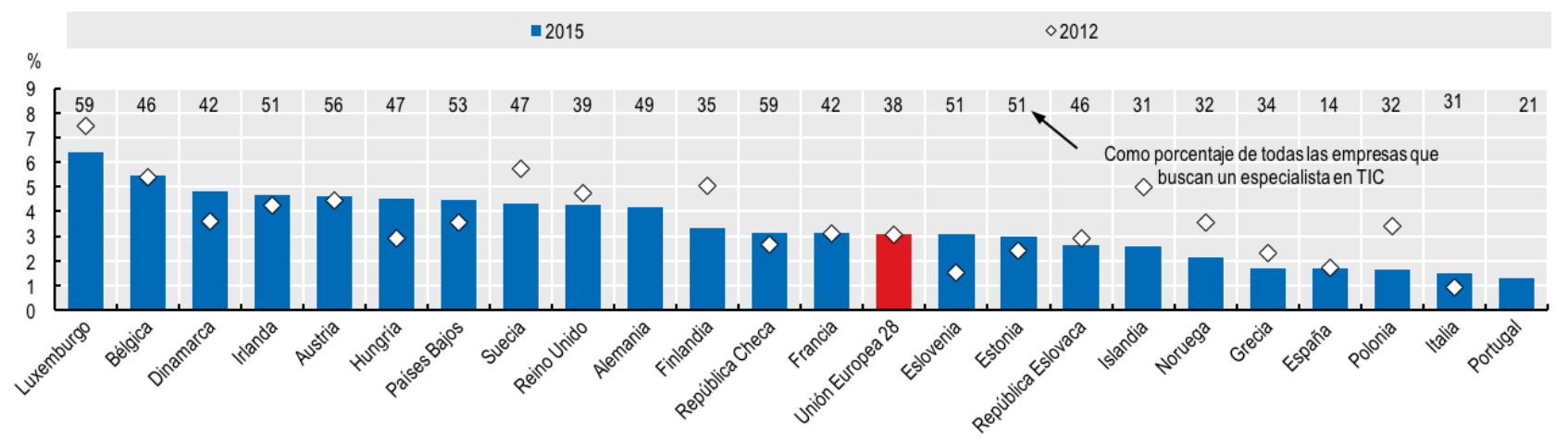

Fuente: OCDE, basada en Eurostat Estadísticas de la Sociedad de la Información, octubre 2015.

El gobierno australiano realizó un estudio similar en 2014. En promedio, fue fácil para los empleadores reclutar profesionales de las TIC con una mayor competencia entre los candidatos cualificados en comparación con años anteriores. Los empleadores agregaron que "había pocos solicitantes con habilidades fuertes no técnicas, como la perspicacia para los negocios, gestión de proyectos y resolución de problemas" y notaron "una mayor demanda de puestos con tecnologías emergentes (como aplicaciones basadas en web)". 
Algunas empresas sugirieron que "en el futuro podría haber una brecha potencial de habilidades para los trabajadores con desarrollo web, aplicaciones móviles y experiencia en computación en la nube".

En cuanto a Nueva Zelanda, la Encuesta de Operaciones Comerciales (Estadísticas de Nueva Zelanda, 2014) reportó que el 39\% de los encuestados no tuvo ninguna dificultad en obtener habilidades informáticas de los solicitantes de empleo, mientras que solo el $6 \%$ dijo haberlas tenido ${ }^{\text {vii }}$.

La Tabla 4 muestra que el "personal de TI" se encuentra entre los 10 primeros puestos de trabajo más difíciles de cubrir para los empleadores según la Encuesta de Escasez de Talentos realizada en más de 40 países de todo el mundo (ManpowerGroup, 2015). Sin embargo, el "personal de TI" ocupa el puesto 9 de 10, justo por encima de "producción/operadores de máquinas" y muy por detrás de "trabajadores especializados en comercio", "ingenieros", "representantes de ventas", "técnicos" y "personal de contabilidad y finanzas". Por lo tanto, las habilidades de TI pueden ser relativamente difíciles de encontrar pero no parecen ser la principal fuente de escasez de habilidades para las empresas.

Tabla 4. Los 10 puestos de trabajo más difíciles de cubrir para los empleadores

\begin{tabular}{|l|l|}
\hline Lugar & Empleo \\
\hline 1 & Trabajadores especializados en comercio \\
\hline 2 & Representantes de ventas \\
\hline 3 & Ingenieros \\
\hline 4 & Técnicos \\
\hline 5 & Choferes \\
\hline 6 & Gerentes/Ejecutivos \\
\hline 7 & Personal de contabilidad y finanzas \\
\hline 8 & Secretarias, asistentes personales, asistentes administrativos, y personal de apoyo de oficina \\
\hline 9 & Personal de TI \\
\hline 10 & Producción/Operadores de máquinas \\
\hline
\end{tabular}

Fuente: Encuesta de Escasez de Talento (ManpowerGroup, 2015).

\section{La demanda de habilidades complementarias para el uso de las TIC}

La expansión de las TIC en el lugar de trabajo no solo ha aumentado la demanda de habilidades especializadas y genéricas para el uso de las TIC, sino que también está cambiando la forma en que se hace el trabajo y ha aumentado la demanda de habilidades complementarias para el uso de las TIC. Estas habilidades no están relacionadas con la capacidad para usar la tecnología de manera efectiva, sino para llevar a cabo el trabajo dentro del nuevo entorno configurado por las TIC, es decir, el "entorno rico en tecnología". Por ejemplo, una mayor frecuencia de información disponible gracias a las TIC exige una mayor capacidad para planificar con anticipación y hacer ajustes rápidamente. Las organizaciones que han aparecido gracias a las TIC tienen un modelo de trabajo horizontal, es decir, hay más trabajo en equipo y menos gestión de arriba hacia abajo, exigen más cooperación y un liderazgo más fuerte. Una mejor difusión de la información entre un mayor número de trabajadores aumenta la importancia de la gestión y la coordinación. Las habilidades de ventas requeridas para una transacción comercial cara a cara no son las mismas que las habilidades implicadas en una venta anónima por medio del comercio electrónico.

Una consecuencia de las tendencias anteriores es que el conjunto de habilidades requeridas para realizar las tareas involucradas en una determinada ocupación -el perfil de habilidades- está cambiando debido a la expansión de las TIC en el trabajo. Si bien hay una conciencia general de que los currículos educativos deben evolucionar para adaptarse a estos cambios, poco se sabe sobre qué tipo de habilidades deberían ser más importantes. El objetivo de esta sección es comenzar a identificar las habilidades que probablemente serán las más importantes en un entorno laboral y empresarial cada vez más permeado por las TIC.

El análisis está organizado de la siguiente manera. La sección 4.1 describe brevemente la literatura económica reciente sobre las TIC y sus habilidades. La sección 4.2 examina las tareas que se asocian con mayor frecuencia a las ocupaciones que requieren el uso de las TIC de manera más intensiva, según la base de datos del PIAAC. Los hallazgos de esta sección, que cubre varios países en un tiempo determinado serán 
complementados en la sección 4.3 con el examen de los cambios en las tareas y el uso intensivo de las TIC a lo largo del tiempo según la encuesta $\mathrm{O}$ *NET realizada en los Estados Unidos.

\subsection{Habilidades complementarias para el uso de las TIC: breve reseña de la literatura}

Un hallazgo clave de la extensa literatura sobre innovación, productividad y crecimiento es que el uso efectivo de las TIC requiere cambios en la organización de la empresa. Debido a la existencia de complementariedades entre las prácticas organizacionales, es posible que deban modificarse al mismo tiempo varios modelos organizativos para mejorar la eficiencia a través del avance tecnológico (Garicano, 2010).

El cambio organizacional en la empresa tiene consecuencias en las tareas que realizan los trabajadores y en las habilidades necesarias para la realización de dichas tareas. Bresnahan, Brynjolfsson y Hitt (2002) aportan pruebas firmes de que la organización permite que la TI aumente la demanda de trabajadores altamente cualificados, confirmando así los hallazgos de estudios anteriores (Goldin y Katz 1999; Autor, Katz y Krueger 1998). Caroli y Van Reenen (2001) afirman que el cambio organizacional tiene un impacto más fuerte en la productividad de las empresas con trabajadores altamente cualificados y que la complementariedad entre las TIC y la innovación organizacional desaparece cuando se toman en cuenta esas habilidades. Arvanitis (2005) y Bartel et al. (2007) mencionan que las empresas aumentan su demanda de trabajadores altamente cualificados cuando invierten en las TIC. Pabilona y Zoghi (2013) proporcionan evidencia de las complementariedades entre las TIC y las habilidades al observar el aumento de la productividad y las primas salariales. Finalmente, Hagsten y Sabadash (2014) presentan evidencia de varios países europeos que respaldan la opinión de que la educación superior complementa el uso de las TIC en el proceso de producción.

Una línea de investigación más reciente ha examinado la complementariedad entre las TIC y las tareas a realizar (véase Autor, 2013 y 2014 para una visión de conjunto). Levy y Murnane (1996) muestran que el uso de computadoras entre los años 1980 y 1990 redujo el tiempo que los empleados del banco dedicaban a las tareas de rutina como la transferencia y entrada de datos y cálculos, mientras que aumentaba el tiempo dedicado a tareas más difíciles como la reelaboración, valoración, comunicación y análisis de datos. Autor, Levy y Murnane (2003) analizaron los datos del Diccionario de Títulos Ocupacionales de Estados Unidos (DOT, por sus siglas en inglés), el antecesor del O*NET, para examinar cómo las tareas asociadas con diferentes ocupaciones han cambiado con el tiempo. Argumentan que las computadoras sustituyen a los trabajadores en la realización de actividades cognitivas y manuales simples que siguen reglas explícitas (tareas "rutinarias") mientras que las computadoras complementan a los trabajadores en la realización de actividades de resolución de problemas y comunicación complejas (tareas "no rutinarias"). Las tareas no rutinarias pueden asociarse ya sea con trabajos conceptuales, como puestos gerenciales y profesionales en el extremo superior de la distribución salarial, o con trabajos manuales, como servicios manuales en el extremo inferior de la distribución salarial.

Varios estudios recientes encuentran evidencia de una disminución en la demanda de tareas rutinarias en los Estados Unidos y en Europa (Autor et al., 2006 y 2008; Goos et al., 2011; Van Reenen, 2011; Autor y Dorn, 2012; Hynninen et al., 2013; Michael et al., 2013). Firpo, Fortin y Lemieux (2011) mencionan que el cambio tecnológico y la desindicalización han desempeñado un papel central en la polarización del trabajo durante los años 80 y 90 , pero no en los años siguientes.

A partir de la Encuesta Alemana de Cualificación y Carrera realizada en cuatro fases, Spitz-Oener (2006) muestra que la mayoría de los cambios en los requisitos de habilidades a lo largo del tiempo se debieron más a cambios en las tareas dentro de las ocupaciones que a la estructura ocupacional del empleo. Sus hallazgos también subrayan que el aumento de la prevalencia del uso de la computadora dentro de las ocupaciones se asocia con un aumento en los requisitos de tareas analíticas e interactivas.

Usando las encuestas británicas de habilidades de 1997, 2001 y 2006 que brindan información sobre los requisitos de trabajo autopublicados, Green et al. (2007) muestran que las habilidades informáticas se han vuelto recientemente más complementarias a un índice de "habilidades de influencia" derivadas de los elementos de la encuesta sobre la importancia de persuadir o influenciar a otros, instruir, capacitar o enseñar, hacer discursos o presentaciones, escribir informes largos, analizar problemas complejos en profundidad y planificar las actividades de otros. 
La solidez del enfoque en la tarea es todavía una cuestión de debate. Green (2012) cuestiona los supuestos de Autor, Levy y Murnane (2003) y de Spitz-Oener (2006) sobre la clasificación de tareas en rutinarias y no rutinarias y argumenta que esto puede afectar los resultados. El propio Autor (2013) analiza las deficiencias en las definiciones actuales de tareas, por ejemplo, la superposición de atributos, los esquemas de clasificación amplios que yuxtaponen distinciones y atributos, etcétera, y plantea "la preocupación de que la literatura sobre tareas emergentes esté significativamente dentro de la frontera de lo que es factible en términos de terminología precisa y medición consistente; por lo tanto, abordar estas deficiencias debería ser una alta prioridad en la agenda de investigación". Un estudio reciente de Marcolin et al. (2016) desarrolla una nueva medida específica de la intensidad de tareas rutinarias por país basada en información a nivel individual proveniente del PIAAC.

\section{2 ¿Qué habilidades son complementarias al uso de las TIC? Evidencia proveniente del PIAAC.}

La encuesta del PIAAC recopila información sobre la frecuencia con la que los encuestados:

1. Realizan un conjunto de tareas en el trabajo;

2. Realizan actividades que implican el uso de habilidades cognitivas.

Las tareas realizadas en el trabajo se organizan en los siguientes grupos:

- Cooperación

- Cooperar o colaborar con compañeros de trabajo (pregunta f_q01b)

- Interacción horizontal:

- Compartir información relacionada del trabajo con colegas (f_q02a)

- Instruir, capacitar o enseñar, individualmente o en grupos (f_q02b)

- Hacer discursos o dar presentaciones frente a cinco o más personas (f_q02c)

- Interacción con el cliente:

- Vender un producto o servicio (f_q02d)

- Asesorar personas (f_q02e)

- Autodirección:

- Planificar actividades propias (f_q03a)

- Organizar el propio tiempo (f_q03c)

- Tareas de gestión:

- Planificar las actividades de otros (f_q03b)

- Influencia:

- Persuadir o influir en las personas (f_q04a)

- Negociar con personas dentro o fuera de la organización (f_q04b)

- Resolución de problemas:

- Resolver problemas en menos de 5 minutos (f_q05a)

- Pensar en una solución para un problema durante al menos 30 minutos (f_q05b)

- Tareas físicas:

- Trabajar físicamente (f_q06b)

- Tareas manuales calificadas:

- Usar habilidad o precisión con los dedos (f_q06c)

A las personas actualmente empleadas o desempleadas menos de 12 meses se les pregunta con qué frecuencia realizan las tareas anteriores. Por ejemplo, la pregunta "¿Con qué frecuencia su trabajo actual/último implica generalmente compartir información del trabajo con sus colegas?" puede responder: "Nunca"; "Menos de una vez al mes"; "Menos de una vez a la semana pero al menos una vez al mes"; "Al menos una vez por semana pero no todos los días"; y "Diariamente".

Si bien las respuestas a las preguntas anteriores no miden las habilidades requeridas en una ocupación, la frecuencia con la que el encuestado realiza ciertas tareas puede ser una aproximación a las habilidades que se espera que él o ella tengan para hacer su trabajo. Estas respuestas, sin embargo, no miden el nivel de 
habilidades que posee el encuestado. Por lo tanto, la encuesta proporciona información sobre la demanda de ciertas habilidades en el trabajo basada en la autoevaluación de los trabajadores.

Dos supuestos sustentan el uso de este enfoque (OCDE, 2011). En primer lugar, se supone que el individuo es una persona bien informada capaz de reportar las actividades relacionadas con su trabajo. Todos los trabajos son diferentes incluso dentro de las ocupaciones categorizadas de forma muy estrecha y se esperaría que el titular del trabajo domine su área. Sin embargo, esto no siempre sucede y cuando el titular del puesto solamente ha estado en él por un periodo breve de tiempo, esta hipótesis puede ser cuestionada. En el caso de los encuestados desempleados, el estudio de campo probó la confiabilidad de su habilidad para recordar las actividades de su trabajo más reciente de los meses anteriores. No se encontraron indicios de que hubiera graves sesgos de memoria.

En segundo lugar, se supone que el individuo reporta estas actividades de manera imparcial. Esta suposición también podría ser cuestionada: las personas podrían hablar de su trabajo para aumentar su autoestima. Sin embargo, se considera que es menos probable que lo hagan cuando informan sobre sus actividades que cuando informan de lo bien que se desempeñan. Para minimizar el sesgo, el principio general es pedir a los encuestados que reporten sobre el comportamiento real, como la frecuencia de uso y la proporción de tiempo empleado en el uso de diferentes habilidades, en lugar de las alternativas frecuentes como la importancia de esas habilidades para el trabajo.

Las actividades que requieren el uso de habilidades cognitivas se agrupan en tres conjuntos: ${ }^{\text {vii }}$

- Conocimientos numéricos:

- Calcular precios, costos o presupuestos; utilizar o calcular fracciones, decimales o porcentajes; usar una calculadora ya sea de mano o de computadora; preparar cuadros, gráficas o tablas; usar álgebra simple o fórmulas; usar matemáticas avanzadas o estadísticas, por ejemplo, cálculos, álgebra compleja, trigonometría o técnicas de regresión.

- Lectura:

- Indicaciones o instrucciones; cartas, memorándums o correos electrónicos; artículos de periódicos, revistas o boletines informativos; artículos en revistas profesionales o publicaciones académicas; libros, manuales o materiales de referencia; cuentas, facturas, estados de cuenta u otros estados financieros; diagramas, mapas o esquemas.

- Escritura:

- Cartas, memorándums o correos electrónicos; artículos de periódicos, revistas o boletines informativos; reportes y formularios.

Se pide que los encuestados informen la frecuencia con la que llevan a cabo cada una de las tareas anteriores en el trabajo. Las respuestas posibles son: 1) Nunca; 2) Menos de una vez al mes; 3) Menos de una vez por semana pero al menos una vez al mes; 4) Al menos una vez por semana pero no todos los días; y 5) Diariamente.

Para cada uno de estos tres grupos de actividades (conocimientos numéricos, lectura y escritura) las respuestas omitidas se han combinado en un indicador sintético. Los índices resultantes son variables continuas que deben interpretarse como una medida de la intensidad de estas actividades en el trabajo. Por ejemplo, las personas con un nivel más alto de conocimientos numéricos realizan con más frecuencia actividades que requieren el uso de habilidades aritméticas.

Para identificar las habilidades complementarias se calcularon los coeficientes de correlación entre las aproximaciones de intensidad de uso de las TIC basados en la comunicación y la búsqueda de información (CBI) y el software de productividad para oficina (SPO) analizados en la sección 2.1 además de: i) la frecuencia con la que se realizan las tareas anteriores en el trabajo y ii) el valor de los índices de intensidad para conocimientos numéricos, lectura y escritura en el trabajo. Una correlación positiva (negativa) entre la intensidad de uso de las TIC y una tarea o actividad dada, significa que un individuo que usa más las TIC realiza esa tarea o actividad más (menos) frecuentemente que un individuo que no las usa. El signo de la correlación, por lo tanto, puede ser interpretado como una medida del grado de complementariedad entre las TIC y otras tareas o actividades en el trabajo. Además, cuanto mayor sea el valor de los coeficientes de correlación mayor será la complementariedad entre las TIC y esas tareas o actividades. 
La Figura 13 muestra los coeficientes de correlación promedio entre las habilidades genéricas de las TIC (CBI y SPO) y otras tareas o actividades en todas las ocupaciones y países. En promedio, el uso intensivo de las TIC en el trabajo se asocia con tareas que requieren un mayor uso de influencia (negociación con personas), resolución de problemas (pensar en una solución durante al menos 30 minutos) e interacciones horizontales (hacer presentaciones), así como menos trabajo físico (trabajar físicamente). Una más alta frecuencia de actividades que requieren habilidades de conocimientos aritméticos, lectura y escritura también se correlaciona con las TIC; la correlación más alta es con la lectura. En general, los coeficientes promedios son ligeramente más altos para las habilidades de CBI que para las habilidades de SPO.

Figura 13. Correlación por pares entre la intensidad de las TIC y la frecuencia de otras tareas o actividades, 2012

Promedio a través de la ocupación y los países

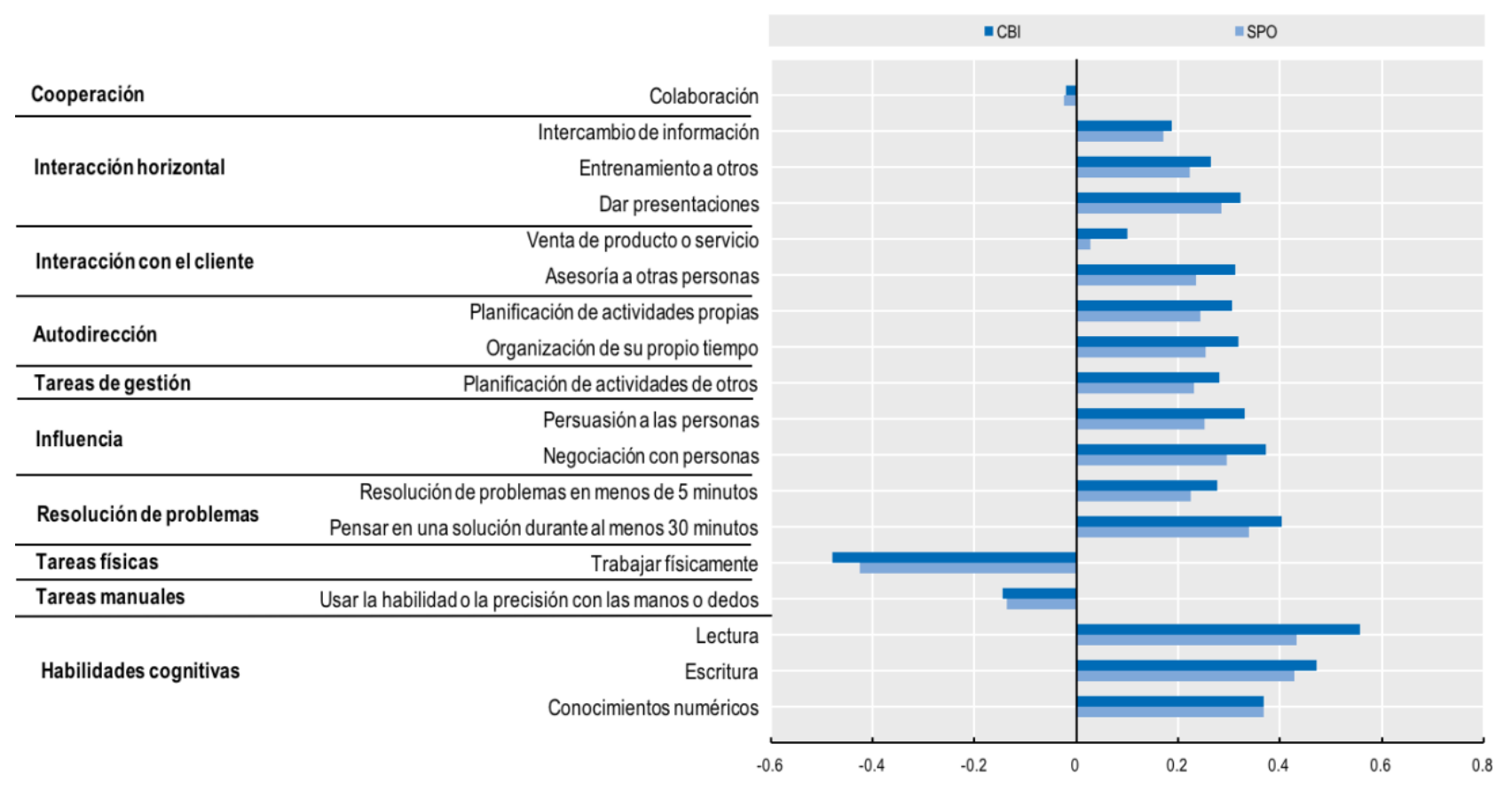

Fuente: OCDE, a partir de la base de datos del PIAAC Database, octubre 2015.

En las Figuras 14a y 14b los coeficientes de correlación entre las TIC y otras tareas o actividades son desglosadas en tres niveles de habilidad: alto, medio y bajo. Los niveles se basan en la correspondencia proporcionada por la OIT (2012) y reflejan las habilidades típicas de las personas empleadas en las ocupaciones que pertenecen a cada nivel. 
Figura 14a. Correlaciones por pares entre la intensidad de las TIC (CBI) y la frecuencia de otras tareas o actividades - por nivel de habilidad, 2012

Promedio entre países

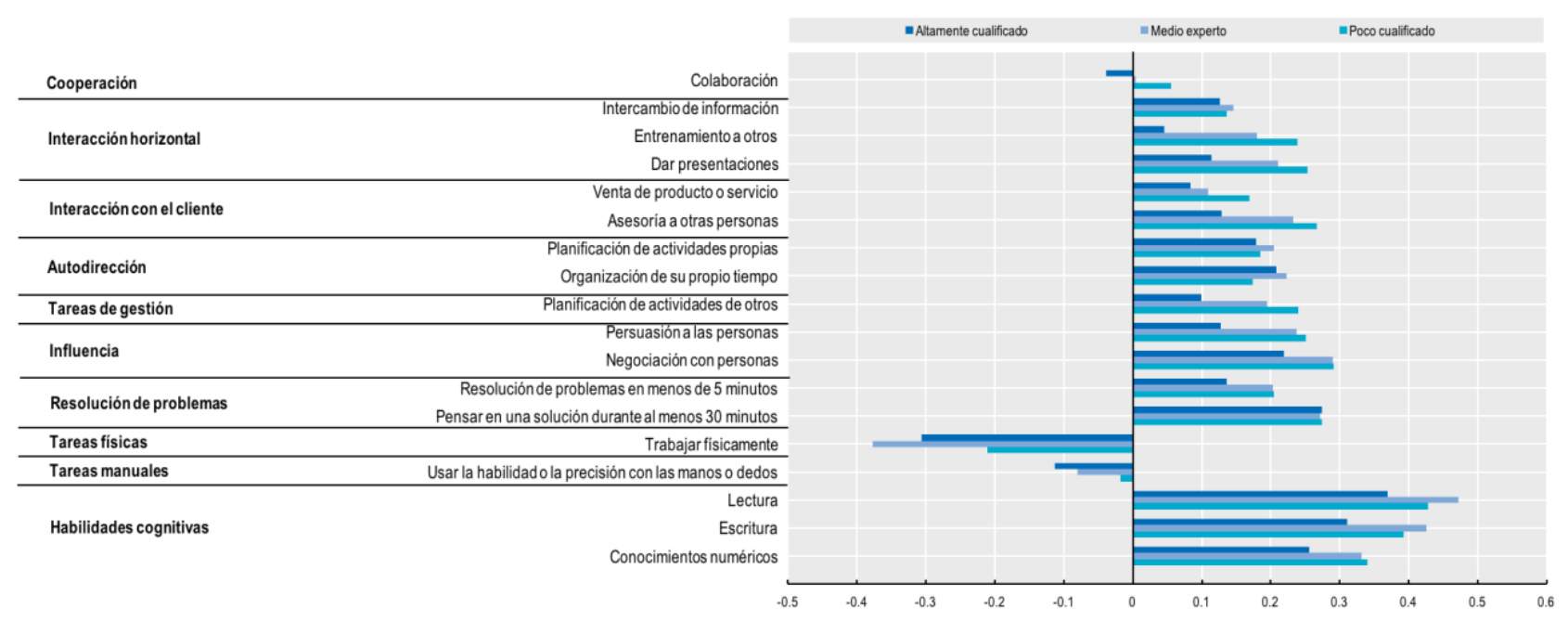

Fuente: OCDE, con base en datos del PIAAC Database, octubre 2015.

Figura 14b. Correlaciones por pares entre la intensidad de las TIC (SPO) y la frecuencia de otras tareas o actividades -por nivel de habilidad, 2012

Promedio entre países

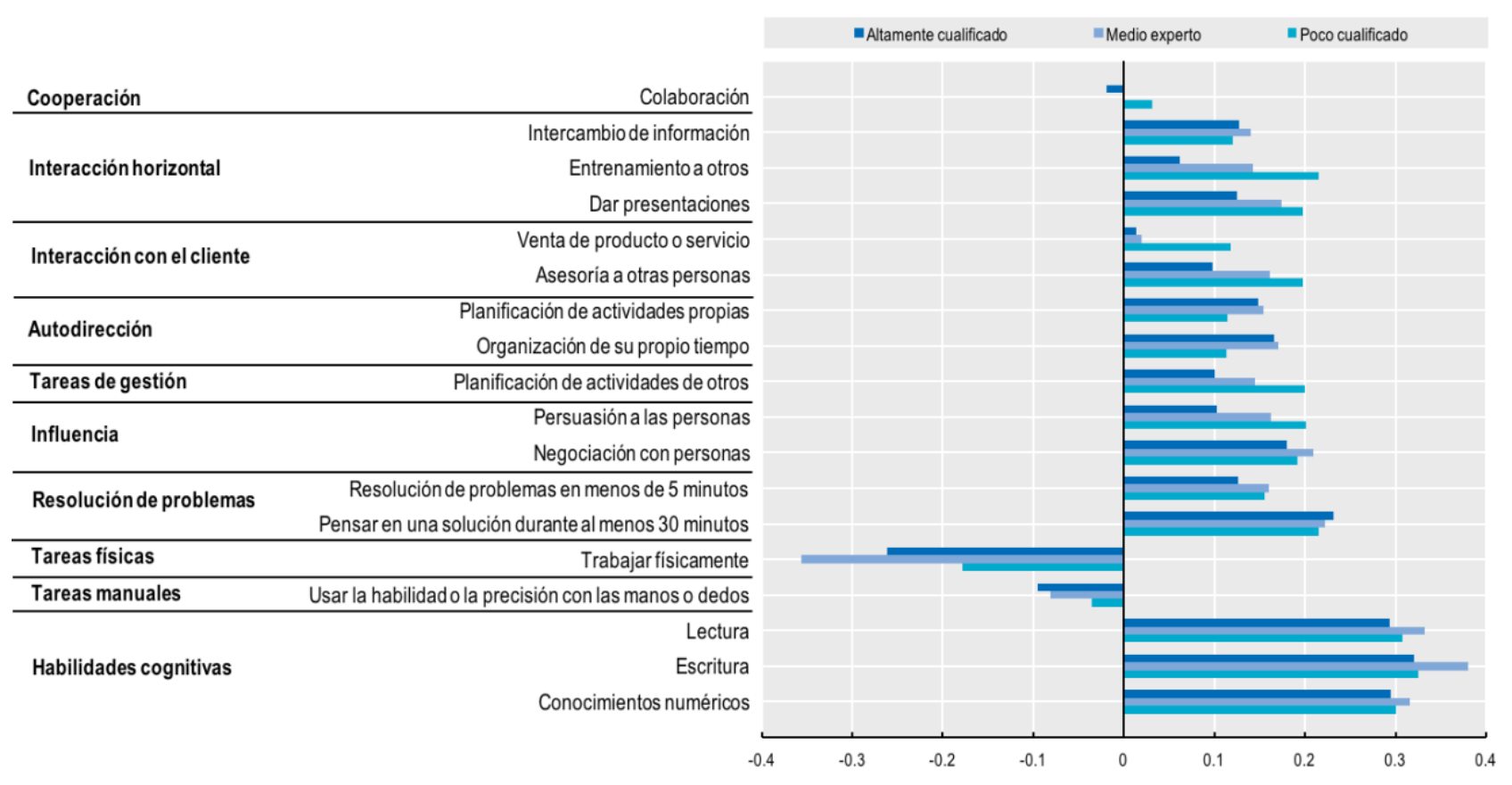

Fuente: OCDE, con base en datos del PIAAC Database, octubre 2015.

En muchas tareas las correlaciones de las TIC tienden a aumentar con el nivel de habilidad típico de la ocupación. Esto implica que las diferencias en el conjunto de tareas asociadas con el uso de las TIC serían mayores para las ocupaciones de baja cualificación que para las de nivel medio y alto. Dicho de otro modo, es 
probable que el perfil de habilidades de un trabajador de una ocupación altamente cualificada cambie poco con el uso de las TIC. Por el contrario, el perfil de habilidades de un trabajador de una ocupación poco cualificada cambiaría más a medida que aumenta el uso de las TIC en el trabajo.

En las ocupaciones con bajas habilidades, las diferencias son particularmente grandes para las interacciones horizontales (dar presentaciones y capacitar a otros), la interacción con el cliente (vender un producto o servicio y asesorar a otros) y las habilidades gerenciales (planificar actividades de otros).

En las ocupaciones con habilidades medias, las diferencias en los requisitos de habilidades son más estrechas que en las de bajas habilidades y más grandes que en las de habilidades altas de la mayoría de las tareas consideradas. Las excepciones incluyen el intercambio de información, la autodirección, las habilidades de lectura y escritura que tienen correlaciones más altas que las ocupaciones con bajas habilidades y la resolución de problemas (pensar en una solución durante al menos 30 minutos) que tienen correlaciones más bajas que en las ocupaciones de educación superior. Para el trabajo físico, las correlaciones son negativas y más altas tanto para las ocupaciones de bajas y altas habilidades.

La principal diferencia para las ocupaciones con educación superior solo está en la resolución de problemas (pensar en una solución durante al menos 30 minutos), donde la correlación con las TIC es más alta que en los otros dos niveles educativos. Los resultados muestran un patrón similar para las tareas de CBI y SPO, sin embargo, los coeficientes generales siguen siendo ligeramente más altos para CBI.

Las Tablas $5 \mathrm{a}$ y $5 \mathrm{~b}$ reportan los coeficientes de correlación promedio entre las TIC (CBI y SPO) y otras tareas o actividades por ocupación principal (1 dígito del CIUO-08) en todos los países. Para mayor simplicidad, se resaltan los tres coeficientes de correlación más altos para cada tarea o actividad.

En las tareas de CBI, las ocupaciones en las que es probable que el uso de las TIC tenga mayores efectos en los perfiles de tareas son los empleos de servicios y ventas, las ocupaciones primarias, los de oficios y trabajadores afines. En el uso de SPO, las ocupaciones en las que es probable que el uso de las TIC tenga mayores efectos en los perfiles de tareas son: empleos de ventas y servicios, empleos especializados en agricultura, silvicultura y pesca y asistentes administrativos.

En los empleos de servicios y ventas el uso de CBI y SPO se correlaciona con una mayor colaboración, influencia (negociación con personas), resolución de problemas (todo tipo de tareas), lectura, escritura y poco trabajo físico.

En las ocupaciones primarias el uso de CBI y SPO se correlaciona con una mayor interacción horizontal (capacitar a otros), interacción con el cliente (todo tipo de tareas), habilidades directivas, influencia (persuadir a las personas) y habilidades numéricas. El uso mayor de CBI y de SPO por parte de los asistentes administrativos se asocia con una mayor frecuencia de intercambio de información, autodirección (todo tipo de tareas) y habilidades de lectura.

Para los trabajadores cualificados de la agricultura, la silvicultura y la pesca, la correlación con el uso de CBI y de SPO es la más alta en influencia (todo tipo de tareas), la interacción con el cliente (todo tipo de tareas) y las habilidades numéricas, y negativa para las habilidades físicas. El uso de SPO también está altamente correlacionado con la interacción horizontal (capacitar a otros y dar presentaciones).

En los profesionales las correlaciones con las tareas complementarias de CBI no son altas en comparación con otras ocupaciones, mientras que las tareas complementarias de SPO son significativas para la interacción horizontal (intercambio de información) y la autodirección.

Las Figuras 15a y 15b muestran los coeficientes de correlación entre la intensidad de las TIC -CBI y SPOde un lado, y del otro, la intensidad de la capacidad numérica, de lectura y escritura por grupos ocupacionales y por país. Mientras que en las ocupaciones de alta y media cualificación la correlación de las habilidades de CBI con la lectura es más alta en la mayoría de los países (panel a), la imagen es menos clara en las ocupaciones de baja cualificación (panel c) para las que no hay un patrón evidente. De manera interesante, en países como Austria, Estonia o Francia las ocupaciones poco cualificadas están más relacionadas con las habilidades numéricas que con leer y escribir. En lo que respecta al uso de SPO, las ocupaciones de alta y media cualificación están fuertemente correlacionadas con las habilidades de escritura en la mayoría de los países, mientras que las ocupaciones de baja cualificación parecen estar más relacionadas con las habilidades numéricas. Estas cifras sugieren que el contenido de las tareas de los grupos de ocupación comunes varía 
según los países y las habilidades complementarias en el uso de las TIC pueden ser en cierta medida específicas para cada país.

Las correlaciones entre la intensidad del uso de las TIC (CBI y SPO) y todas las tareas por país y por ocupación (1 dígito de CIUO-08) se reportan en los Anexos C1 y C2. 
Tabla 5a. Correlaciones por pares entre la intensidad de las TIC (CBI) y la frecuencia de tareas o actividades -por ocupación, 2012

ClUO-08 de 1 Dígito - Promedio por países

\begin{tabular}{|c|c|c|c|c|c|c|c|c|c|c|c|c|c|c|c|c|c|c|}
\hline \multirow[t]{2}{*}{$\mathrm{CBI}$} & \multirow{2}{*}{$\begin{array}{l}\text { Cooperación } \\
\begin{array}{c}\text { Colaboración } \\
\text { F_Q01b }\end{array}\end{array}$} & \multicolumn{3}{|c|}{ Interacción horizontal } & \multicolumn{2}{|c|}{$\begin{array}{l}\text { Interacción con el } \\
\text { cliente }\end{array}$} & \multicolumn{2}{|c|}{ Auto-dirección } & \multirow{2}{*}{$\begin{array}{c}\begin{array}{c}\text { Habilidades } \\
\text { gerenciales }\end{array} \\
\begin{array}{c}\text { Planificar } \\
\text { las }\end{array} \\
\text { actividades } \\
\text { de otros } \\
\text { F_Q03b }\end{array}$} & \multicolumn{2}{|c|}{ Influencia } & \multicolumn{2}{|c|}{$\begin{array}{l}\text { Resolución de } \\
\text { problemas }\end{array}$} & \multirow{2}{*}{$\begin{array}{c}\begin{array}{c}\text { Habilidades } \\
\text { físicas } \\
\text { (resistencia) }\end{array} \\
\\
\text { Trabajo } \\
\text { fisico } \\
\text { F_Q06b }\end{array}$} & \multirow{2}{*}{\begin{tabular}{|c|}
$\begin{array}{c}\text { Habilidades } \\
\text { manuales }\end{array}$ \\
Habilidad o \\
precisión \\
con las \\
manos o los \\
dedos \\
F_Q06c \\
\end{tabular}} & \multicolumn{3}{|c|}{ Variables derivadas } \\
\hline & & $\begin{array}{c}\text { Compartir } \\
\text { información } \\
\text { F_Q02a }\end{array}$ & $\begin{array}{c}\text { Capacitar } \\
\text { a los } \\
\text { demás } \\
\text { F_Q02b }\end{array}$ & $\begin{array}{c}\text { Dar } \\
\text { presentaciones } \\
\text { F_Q02c }\end{array}$ & \begin{tabular}{|c} 
Vender \\
un \\
producto \\
o \\
servicio \\
F_Q02d \\
\end{tabular} & $\begin{array}{c}\text { Asesorar } \\
\text { a otros } \\
\text { F_Q02e }\end{array}$ & $\begin{array}{l}\text { Planificación } \\
\text { de las } \\
\text { propias } \\
\text { actividades } \\
\text { F_Q03a }\end{array}$ & $\begin{array}{c}\text { Organización } \\
\text { del propio } \\
\text { tiempo } \\
\text { F_Q03C }\end{array}$ & & $\begin{array}{l}\text { Persuadir } \\
\text { a las } \\
\text { personas } \\
\text { F_Q04a }\end{array}$ & $\begin{array}{c}\text { Negociar } \\
\text { con las } \\
\text { personas } \\
\text { F_Q04b }\end{array}$ & \begin{tabular}{|c|} 
Resolución \\
de \\
problemas \\
en menos \\
de 5 \\
minutos \\
F_Q05a \\
\end{tabular} & $\begin{array}{c}\text { Pensar en } \\
\text { una } \\
\text { solución } \\
\text { durante al } \\
\text { menos } 30 \\
\text { minutos } \\
\text { F_Q05b }\end{array}$ & & & Lectura & Escritura & $\begin{array}{l}\text { Habilidad } \\
\text { numérica }\end{array}$ \\
\hline Gerentes & -0.015 & 0.158 & 0.135 & 0.218 & -0.065 & 0.163 & 0.116 & 0.112 & 0.101 & 0.184 & 0.178 & 0.106 & 0.219 & -0.299 & -0.091 & 0.342 & 0.350 & 0.225 \\
\hline Profesionales & -0.022 & 0.127 & -0.020 & 0.046 & 0.100 & 0.080 & 0.146 & 0.185 & 0.067 & 0.074 & 0.179 & 0.102 & 0.256 & -0.237 & -0.094 & 0.323 & 0.277 & 0.242 \\
\hline $\begin{array}{l}\text { Técnicos y } \\
\text { profesionales } \\
\text { asociados }\end{array}$ & -0.068 & 0.108 & 0.055 & 0.106 & 0.100 & 0.144 & 0.193 & 0.226 & 0.077 & 0.134 & 0.240 & 0.169 & 0.290 & -0.356 & -0.110 & 0.406 & 0.321 & 0.265 \\
\hline $\begin{array}{l}\text { Trabajadores } \\
\text { de apoyo } \\
\text { clerical }\end{array}$ & 0.053 & 0.189 & 0.149 & 0.136 & 0.056 & 0.201 & 0.238 & 0.246 & 0.135 & 0.186 & 0.228 & 0.245 & 0.294 & -0.347 & -0.011 & 0.443 & 0.378 & 0.253 \\
\hline $\begin{array}{l}\text { Trabajadores } \\
\text { de servicio y } \\
\text { ventas }\end{array}$ & 0.060 & 0.137 & 0.221 & 0.230 & 0.090 & 0.212 & 0.192 & 0.187 & 0.220 & 0.234 & 0.296 & 0.207 & 0.290 & -0.183 & 0.003 & 0.457 & 0.402 & 0.272 \\
\hline $\begin{array}{l}\text { Trabajadores } \\
\text { agrícolas, } \\
\text { forestales y } \\
\text { pesqueros } \\
\text { calificados }\end{array}$ & 0.048 & 0.110 & 0.177 & 0.226 & 0.217 & 0.227 & 0.171 & 0.150 & 0.266 & 0.268 & 0.298 & 0.187 & 0.232 & -0.147 & -0.033 & 0.398 & 0.383 & 0.358 \\
\hline $\begin{array}{l}\text { Trabajadores } \\
\text { artesanales y } \\
\text { afines }\end{array}$ & -0.027 & 0.056 & 0.173 & 0.238 & 0.234 & 0.247 & 0.181 & 0.205 & 0.193 & 0.272 & 0.282 & 0.155 & 0.247 & -0.270 & -0.084 & 0.465 & 0.420 & 0.303 \\
\hline $\begin{array}{l}\text { Operadores y } \\
\text { montadores } \\
\text { de plantas y } \\
\text { máquinas }\end{array}$ & 0.065 & 0.102 & 0.206 & 0.203 & 0.118 & 0.193 & 0.171 & 0.165 & 0.238 & 0.219 & 0.204 & 0.172 & 0.218 & -0.084 & 0.024 & 0.363 & 0.304 & 0.272 \\
\hline $\begin{array}{l}\text { Ocupaciones } \\
\text { elementales }\end{array}$ & 0.056 & 0.137 & 0.239 & 0.254 & 0.168 & 0.267 & 0.185 & 0.174 & 0.240 & 0.250 & 0.292 & 0.205 & 0.274 & -0.211 & -0.018 & 0.428 & 0.393 & 0.339 \\
\hline Promedio & 0.017 & 0.125 & 0.148 & 0.184 & 0.113 & 0.193 & 0.177 & 0.183 & 0.171 & 0.202 & 0.244 & 0.172 & 0.258 & -0.237 & -0.046 & 0.403 & 0.359 & 0.281 \\
\hline $\begin{array}{l}\text { Diferencia * } \\
100\end{array}$ & 0.245 & 0.140 & 0.695 & 0.506 & 0.806 & 0.324 & 0.113 & 0.160 & 0.589 & 0.431 & 0.246 & 0.220 & 0.094 & 0.825 & 0.242 & 0.260 & 0.238 & 0.194 \\
\hline
\end{tabular}

Nota: se resaltan los tres coeficientes de correlación más altos para cada tarea o actividad.

Fuente: OCDE, con base en datos del PIAAC Database, octubre 2015. 
Tabla 5b. Correlaciones por pares entre la intensidad de las TIC (SPO) y la frecuencia de tareas o actividades por ocupación, 2012 ClUO-08 de 1 Dígito - Promedio por países

\begin{tabular}{|c|c|c|c|c|c|c|c|c|c|c|c|c|c|c|c|c|c|c|}
\hline \multirow[t]{2}{*}{ SPO } & \multirow{2}{*}{$\begin{array}{l}\text { Cooperación } \\
\\
\text { Colaboración } \\
\text { F_Q01b }\end{array}$} & \multicolumn{3}{|c|}{ Interacción horizontal } & \multicolumn{2}{|c|}{$\begin{array}{l}\text { Interacción con el } \\
\text { cliente }\end{array}$} & \multicolumn{2}{|c|}{ Auto-dirección } & \multirow{2}{*}{ 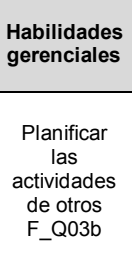 } & \multicolumn{2}{|c|}{ Influencia } & \multicolumn{2}{|c|}{$\begin{array}{l}\text { Resolución de } \\
\text { problemas }\end{array}$} & \multirow{2}{*}{$\begin{array}{c}\begin{array}{c}\text { Habilidades } \\
\text { fisicas } \\
\text { (resistencia) }\end{array} \\
\\
\text { Trabajo } \\
\text { fisico } \\
\text { F_Q06b }\end{array}$} & \multirow{2}{*}{\begin{tabular}{|c|}
$\begin{array}{c}\text { Habilidades } \\
\text { manuales }\end{array}$ \\
Habilidad o \\
precisión \\
con las \\
manos o los \\
dedos \\
F_Q06c \\
\end{tabular}} & \multicolumn{3}{|c|}{ Variables derivadas } \\
\hline & & $\begin{array}{c}\text { Compartir } \\
\text { información } \\
\text { F_Q02a }\end{array}$ & $\begin{array}{c}\text { Capacitar } \\
\text { a los } \\
\text { demás } \\
\text { F_Q02b }\end{array}$ & $\begin{array}{c}\text { Dar } \\
\text { presentaciones } \\
\text { F_Q02c }\end{array}$ & $\begin{array}{c}\text { Vender } \\
\text { un } \\
\text { producto } \\
\text { o } \\
\text { servicio } \\
\text { F_Q02d }\end{array}$ & $\begin{array}{l}\text { Asesorar } \\
\text { a otros } \\
\text { F_Q02e }\end{array}$ & $\begin{array}{l}\text { Planificación } \\
\text { de las } \\
\text { propias } \\
\text { actividades } \\
\text { F_Q03a }\end{array}$ & $\begin{array}{l}\text { Organización } \\
\text { del propio } \\
\text { tiempo } \\
\text { F_Q03c }\end{array}$ & & $\begin{array}{c}\text { Persuadir } \\
\text { a las } \\
\text { personas } \\
\text { F_Q04a }\end{array}$ & $\begin{array}{l}\text { Negociar } \\
\text { con las } \\
\text { personas } \\
\text { F_Q04b }\end{array}$ & $\begin{array}{c}\text { Resolución } \\
\text { de } \\
\text { problemas } \\
\text { en menos } \\
\text { de } 5 \\
\text { minutos } \\
\text { F_Q05a }\end{array}$ & $\begin{array}{c}\text { Pensar en } \\
\text { una } \\
\text { solución } \\
\text { durante al } \\
\text { menos } 30 \\
\text { minutos } \\
\text { F_Q05b }\end{array}$ & & & Lectura & Escritura & $\begin{array}{l}\text { Habilidad } \\
\text { numérica }\end{array}$ \\
\hline Gerentes & 0.015 & 0.149 & 0.146 & 0.205 & -0.120 & 0.146 & 0.107 & 0.108 & 0.086 & 0.126 & 0.153 & 0.120 & 0.218 & -0.272 & -0.060 & 0.313 & 0.369 & 0.307 \\
\hline Profesionales & -0.002 & 0.132 & 0.021 & 0.078 & 0.043 & 0.079 & 0.136 & 0.152 & 0.086 & 0.082 & 0.171 & 0.110 & 0.221 & -0.207 & -0.094 & 0.280 & 0.301 & 0.280 \\
\hline $\begin{array}{l}\text { Técnicos y } \\
\text { profesionales } \\
\text { asociados }\end{array}$ & -0.054 & 0.112 & 0.057 & 0.112 & 0.023 & 0.086 & 0.154 & 0.185 & 0.089 & 0.099 & 0.183 & 0.138 & 0.231 & -0.297 & -0.081 & 0.284 & 0.312 & 0.299 \\
\hline $\begin{array}{l}\text { Trabajadores } \\
\text { de apoyo } \\
\text { clerical }\end{array}$ & 0.030 & 0.136 & 0.130 & 0.126 & -0.028 & 0.112 & 0.213 & 0.225 & 0.127 & 0.119 & 0.164 & 0.183 & 0.239 & -0.245 & 0.003 & 0.314 & 0.347 & 0.294 \\
\hline $\begin{array}{l}\text { Trabajadores } \\
\text { de servicio y } \\
\text { ventas }\end{array}$ & 0.040 & 0.131 & 0.183 & 0.192 & 0.023 & 0.157 & 0.129 & 0.131 & 0.165 & 0.175 & 0.220 & 0.170 & 0.252 & -0.177 & -0.021 & 0.315 & 0.382 & 0.245 \\
\hline $\begin{array}{l}\text { Trabajadores } \\
\text { agrícolas, } \\
\text { forestales y } \\
\text { pesqueros } \\
\text { calificados }\end{array}$ & 0.078 & 0.103 & 0.173 & 0.266 & 0.123 & 0.198 & 0.078 & 0.062 & 0.164 & 0.222 & 0.229 & 0.130 & 0.174 & -0.160 & -0.024 & 0.236 & 0.320 & 0.309 \\
\hline $\begin{array}{l}\text { Trabajadores } \\
\text { artesanales y } \\
\text { afines }\end{array}$ & 0.000 & 0.076 & 0.138 & 0.204 & 0.111 & 0.176 & 0.123 & 0.124 & 0.143 & 0.197 & 0.196 & 0.116 & 0.174 & -0.234 & -0.079 & 0.286 & 0.331 & 0.282 \\
\hline $\begin{array}{l}\text { Operadores y } \\
\text { montadores } \\
\text { de plantas y } \\
\text { máquinas }\end{array}$ & 0.099 & 0.098 & 0.172 & 0.180 & 0.051 & 0.158 & 0.111 & 0.086 & 0.192 & 0.161 & 0.117 & 0.120 & 0.143 & -0.049 & 0.048 & 0.220 & 0.221 & 0.229 \\
\hline $\begin{array}{l}\text { Ocupaciones } \\
\text { elementales }\end{array}$ & 0.031 & 0.120 & 0.215 & 0.197 & 0.118 & 0.197 & 0.115 & 0.113 & 0.200 & 0.201 & 0.192 & 0.156 & 0.214 & -0.178 & -0.035 & 0.308 & 0.326 & 0.301 \\
\hline Promedio & 0.026 & 0.117 & 0.117 & 0.173 & 0.038 & 0.146 & 0.130 & 0.132 & 0.139 & 0.154 & 0.180 & 0.138 & 0.207 & -0.202 & -0.038 & 0.284 & 0.323 & 0.283 \\
\hline $\begin{array}{l}\text { Diferencia * } \\
100\end{array}$ & 0.204 & 0.050 & 0.050 & 0.330 & 0.609 & 0.197 & 0.141 & 0.248 & 0.201 & 0.244 & 0.118 & 0.067 & 0.128 & 0.541 & 0.207 & 0.121 & 0.216 & 0.078 \\
\hline
\end{tabular}

Nota: se resaltan los tres coeficientes de correlación más altos para cada tarea o actividad.

Fuente: OCDE, con base en datos del PIAAC Database, octubre 2015. 
Figura 15a. Correlaciones por pares entre las TIC (CBI) habilidad numérica, lectura y escritura 2012

a) Ocupaciones con altas habilidades

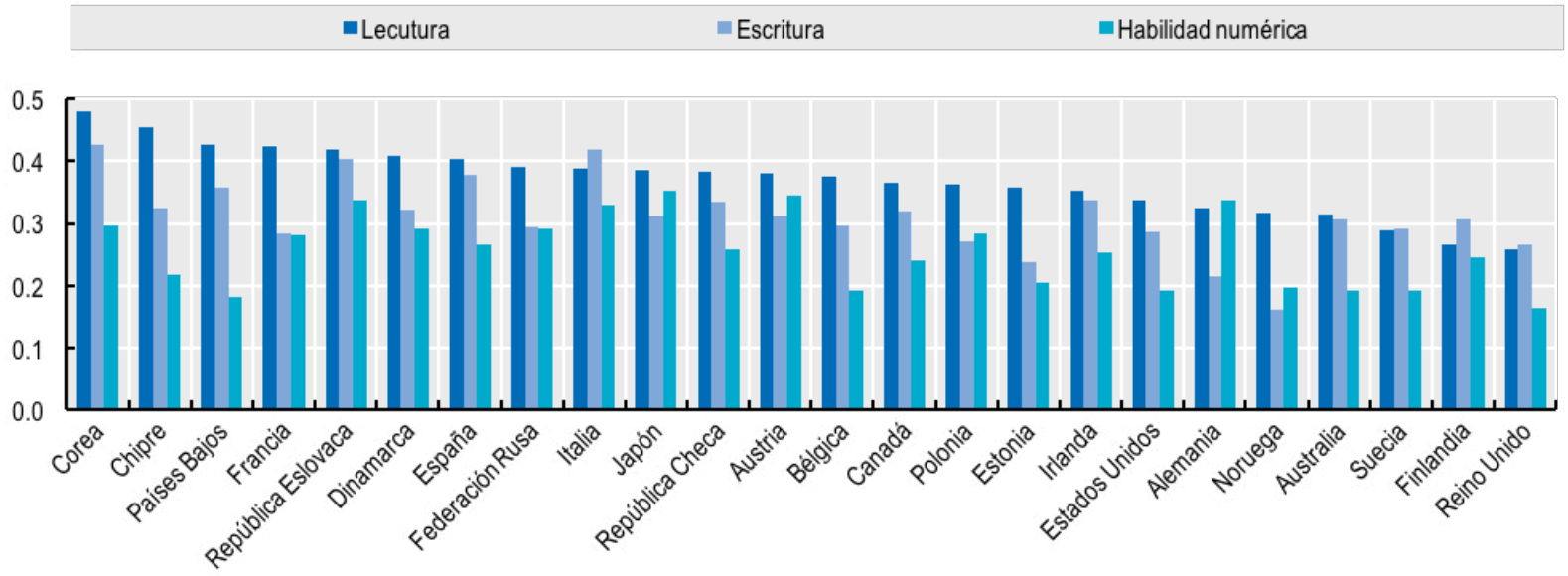

b) Ocupaciones con habilidades medias

-Lecutura $\quad$ Escritura $\quad$ Habilidad numérica

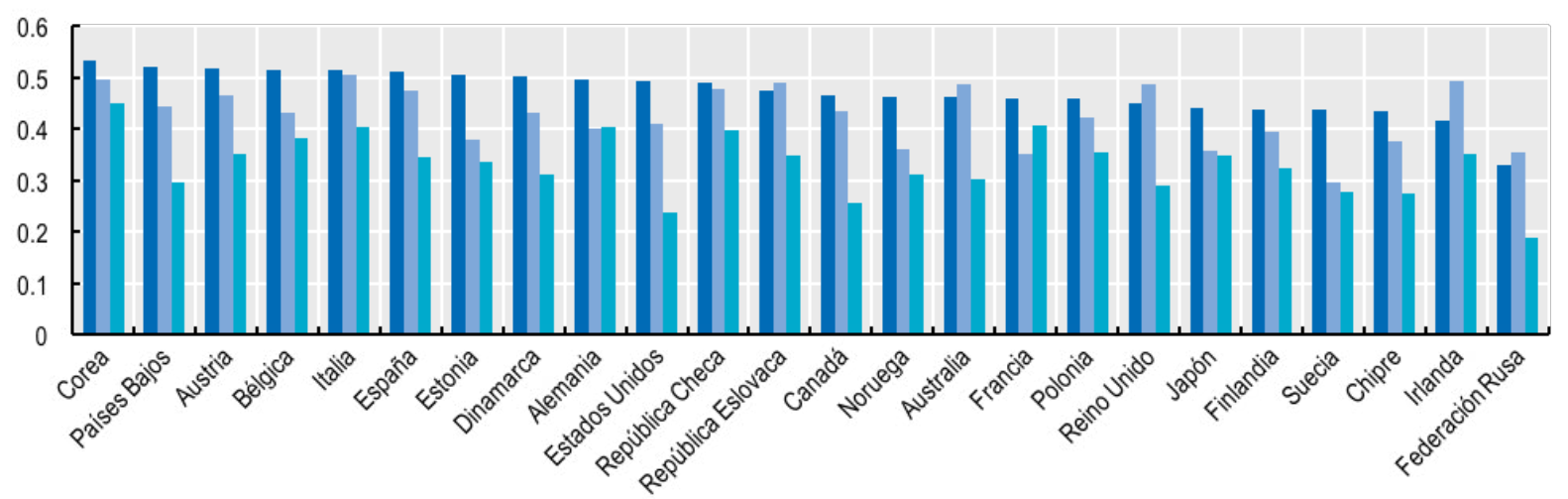

c) Ocupaciones con bajas habilidades

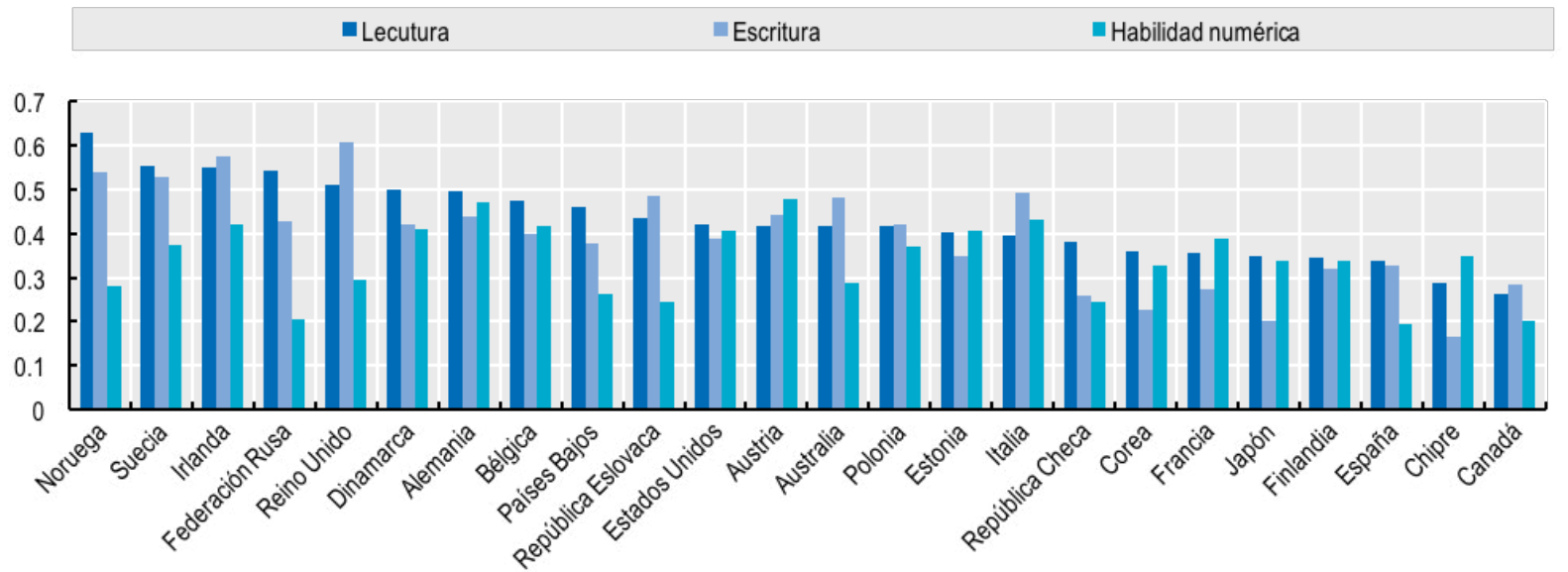

Fuente: OCDE, con base en datos del PIAAC Database, octubre 2015.

Nota: Para Chipre, véase nota de la Figura 5. 
Figura 15b. Correlaciones por pares entre las TIC (SPO) habilidad numérica, lectura y escritura 2012

a) Ocupaciones con altas habilidades

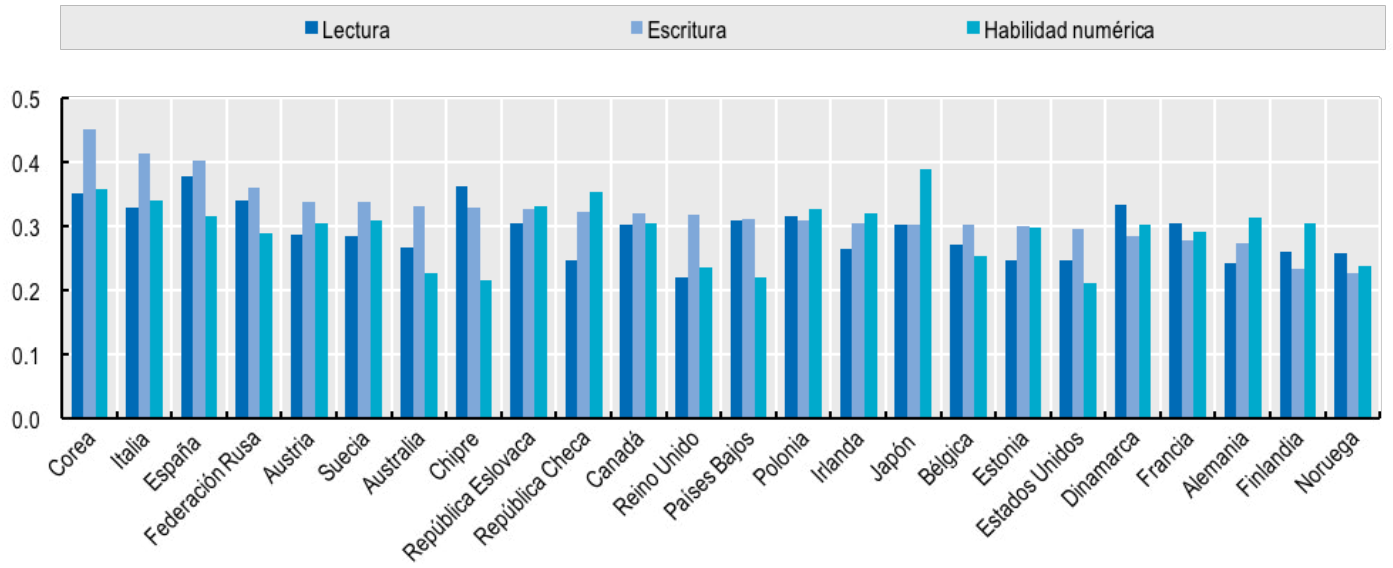

b) Ocupaciones con habilidades medias

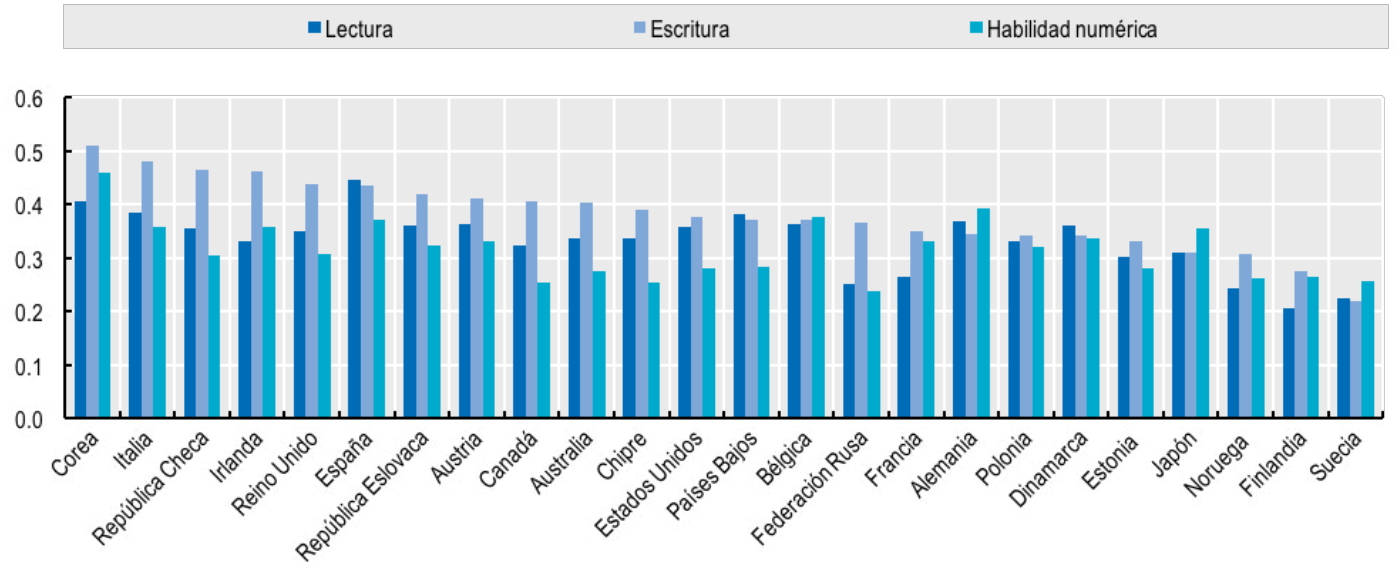

c) Ocupaciones con bajas habilidades

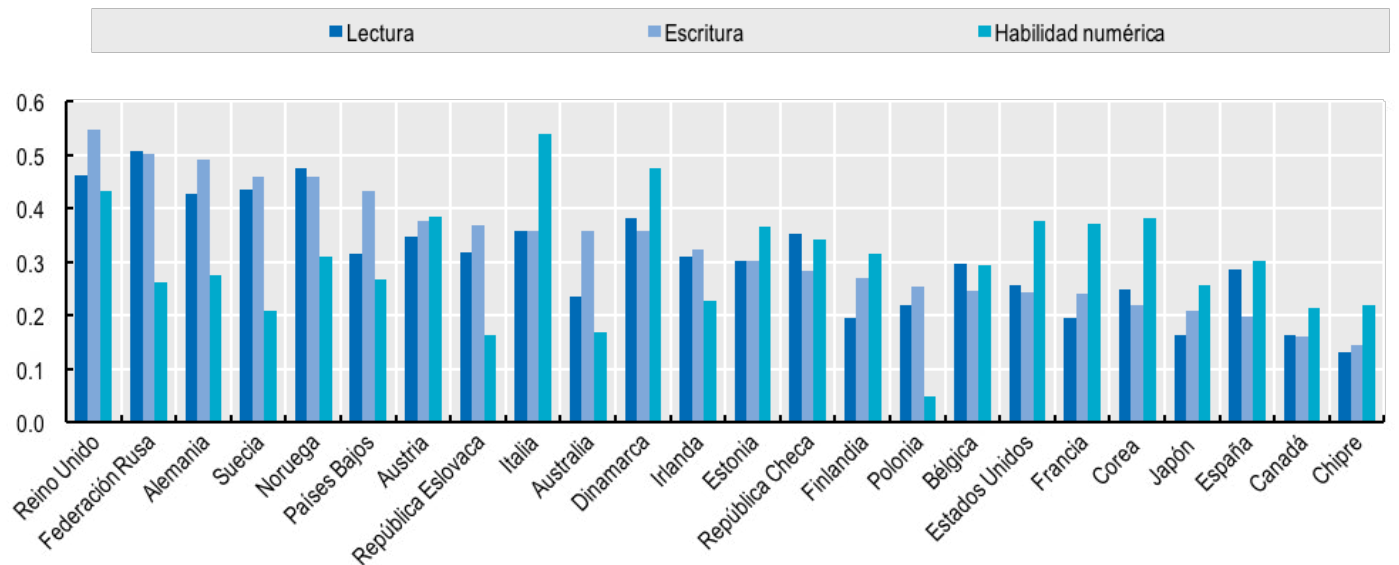

Fuente: OCDE, con base en datos del PIAAC Database, octubre 2015

Nota: Para Chipre, véase nota de la Figura 5. 


\section{3 ¿Qué habilidades son complementarias al uso de las TIC? Evidencia a partir de $O{ }^{*} N E T$}

La Red de Información Ocupacional de los Estados Unidos ( $\mathrm{O}$ NET, por sus siglas en inglés) es un proyecto realizado por el Departamento del Trabajo de los Estados Unidos desde 1998. La última revisión de la base de datos O*NET (julio 2014) abarca alrededor de 1,100 ocupaciones definidas sobre la base del Sistema de Clasificación Ocupacional Estándar de los Estados Unidos (SOC, por sus siglas en inglés). Cada ocupación requiere una combinación diferente de conocimientos, habilidades y competencias y se realiza mediante una variedad de actividades y tareas. Estas características distintivas de una ocupación se describen en el modelo contenido en $\mathrm{O}^{*} \mathrm{NET}$, que define las características clave de una ocupación como un conjunto medible y estandarizado de variables denominadas "descriptores". Estos descriptores están organizados en seis campos principales:

- Características del trabajador

- Requisitos del trabajador

- Experiencia requerida

- Información específica de la ocupación

- Características de la fuerza laboral

- Requisitos ocupacionales

Cada descriptor de O*NET está asociado con una escala, como por ejemplo, de importancia y alcance de la actividad.

Esta sección se centra en el descriptor "Actividades de trabajo generalizadas" y en la escala "importancia". Las "actividades de trabajo generalizadas" consisten en 41 actividades de trabajo que son comunes a un gran número de ocupaciones. Se realizan en casi todas las familias e industrias laborales. La escala "importancia" indica el grado de importancia que un descriptor particular tiene para la ocupación. La escala se ha estandarizado y oscila entre 0 (no importante) y 100 (extremadamente importante).

La base de datos de O*NET se llenó inicialmente con datos recopilados por analistas ocupacionales; esta información se actualiza mediante encuestas actuales de la población de trabajadores en cada ocupación y expertos en el tema. Estos datos se incorporan a las nuevas versiones de la base de datos una vez al año para proporcionar información actualizada sobre las ocupaciones a medida que evolucionan con el tiempo. Hasta la fecha, 940 ocupaciones se han actualizado de manera integral desde el inicio de la encuesta en 1998. De estas ocupaciones, 509 tienen más de una actualización.

Al vincular estas actualizaciones a lo largo del tiempo se puede examinar cómo ha cambiado el conjunto de actividades laborales involucradas en cada ocupación. En particular, los cambios en la importancia del uso de las TIC en el trabajo se pueden correlacionar con los cambios en la importancia de las otras 40 actividades laborales. El uso de las TIC se mide por la importancia de la actividad laboral "interactuar con computadoras". ix Una correlación positiva (negativa) significa que en las ocupaciones donde las TIC se han vuelto más (menos) importantes, ciertas actividades también se han vuelto más (menos) importantes. El signo de una correlación, por lo tanto, puede interpretarse como una medida del grado de complementariedad entre las TIC y otras actividades laborales. Además, cuanto mayor sea el valor de los coeficientes de correlación, mayor será la complementariedad entre las TIC y esas actividades.

La Figura 16 muestra los resultados del análisis de correlación. Para facilitar la interpretación, las actividades se han agrupado en cinco tipos según la clasificación de O*NET:

- Entrada de información: ¿Dónde y cómo se obtiene la información y los datos necesarios para realizar el trabajo?

- Procesos mentales: ¿Qué actividades de procesamiento, planificación, resolución de problemas, toma de decisiones e innovación se realizan con la información relevante para el trabajo?

- Interacción con otros: ¿Qué interacciones con otras personas o actividades de supervisión ocurren al realizar este trabajo? 
- Resultados del trabajo (complejo, técnico): ¿Qué actividades cualificadas que utilizan movimientos coordinados se realizan durante el trabajo?

- Resultados del trabajo (físico, manual): ¿Qué actividades se realizan con el cuerpo y las manos durante el trabajo?

Figura 16. Correlaciones entre cambios en la importancia de las TIC y cambios en la importancia de todas las actividades de trabajo

Interactuar con otros Estableciendo y manteniendo relaciones interpersonales
Actuando para o trabajando directamente con el público Comunicarse con supervisores, compañeroso subordinados Vender o influenciar a otros Entrenando y enseñando a otros Comunicación con personas fuera de la organización Proporcionar consulta y asesoramiento a otros Resolviendo conflictos y negociando con otro Monitoreo y control de recursos Ayudar y cuidar a otros Interpretando el significado de la información para otros Realización de actividades administrativas Coordinar el trabajo y las actividades de los demás Coaching y desarrollo de otros Guiar, dirigir y motivar a los subordinado Desarrollando y construyendo equipos Unidades organizativas de persona Programación de trabajos y actividades Organizar, planificar y priorizar el trabajo Actualización y uso de conocimientos relevantes Desarrollando objetos y estrategias Procesos Mentales Procesando creativamente Procesando información Tomar decisiones y resolver problemas Analizando datos o información Evaluación de la información para determinar el cumplimiento de las normas Juzgando las cualidades de las cosas, servicios o personas

Reparación y mantenimiento de equipos mecánicos Salida de trabajo ( Complejo, técnico) Redacción, diseño y especificación de dispositivos técnicos, piezas y equipo Documentación/grabación de información

Reparación y mantenimiento de equipos electrónicos.

Estimación de las características cuantificables de productos, eventos o información Identificar objetos, acciones y eventos Entrada de información Consiguiendo información Monitoreo de procesos, materiales 0 entorno Inspeccionar equipos, estructuras o materiales Operando vehiculos, dispositivos mecanizados o equipos Realización de actividades fisicas generales Salida de trabajo (Físico, manual) Máquinas y procesos de control Manipulación y movimiento de objetos.

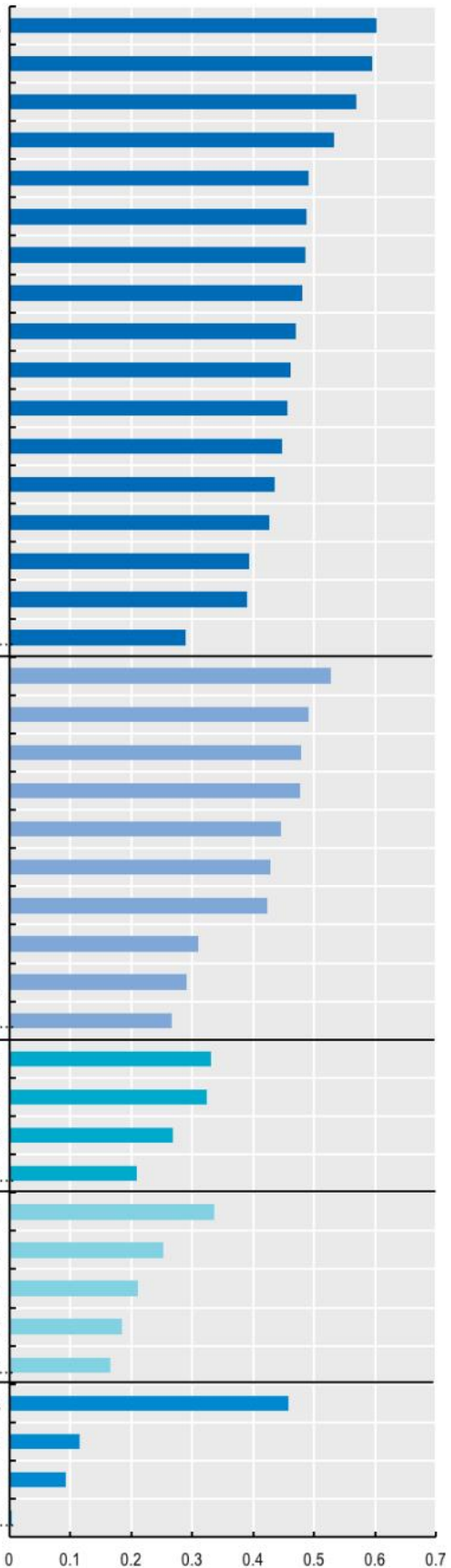

Fuente: OCDE, a partir de la base de datos de O*NET, junio 2015. 
La Tabla 6 muestra un posible mapeo entre los grupos de tareas definidos en la base de datos del PIAAC y los grupos de actividades clasificadas bajo O*NET.

Tabla 6. Mapeo entre tareas y grupos de actividade en PIAAC y O*NET

\begin{tabular}{|c|c|c|c|}
\hline \multicolumn{2}{|r|}{ PIAAC } & \multicolumn{2}{|r|}{ O*NET } \\
\hline & & \multirow{5}{*}{ Salida de información } & Obtención de información \\
\hline & & & Monitoreo de procesos, materiales o entornos \\
\hline & & & Identificación de objetos, acciones y eventos \\
\hline & & & Inspección de equipos, estructuras o materiales \\
\hline & & & $\begin{array}{l}\text { Estimación de las características cuantificables de productos, eventos o } \\
\text { información }\end{array}$ \\
\hline & & \multirow{7}{*}{ Procesos mentales } & $\begin{array}{l}\text { Procesamiento de la información } \\
\text { Evaluación de la información para determinar el cumplimiento de las } \\
\text { normas }\end{array}$ \\
\hline & Resolución de problemas en menos de 5 minutos & & Análisis de datos o información \\
\hline $\begin{array}{r}\text { Resolucion de } \\
\text { problemas }\end{array}$ & Pensar en una solución durante al menos 30 & & Toma de decisiones y resolución de problemas \\
\hline & & & $\begin{array}{l}\text { Juzgar las cualidades de las cosas, servicios o } \\
\text { personas }\end{array}$ \\
\hline & & & Pensamiento creativo \\
\hline & & & Actualización y uso de conocimientos relevantes \\
\hline Auto-dirección & $\begin{array}{l}\text { Organización del propio tiempo } \\
\text { Planificación de las propias actividades }\end{array}$ & & $\begin{array}{l}\text { Calendarización de trabajo y actividades } \\
\text { Organizar, planificar y priorizar el trabajo }\end{array}$ \\
\hline \multirow{6}{*}{$\begin{array}{l}\text { Habilidades físicas } \\
\text { (resistencia) } \\
\text { Habilidades manuales }\end{array}$} & \multirow{5}{*}{$\begin{array}{l}\text { Trabajo físico } \\
\text { Habilidad o precisión con las manos o los } \\
\text { dedos }\end{array}$} & \multirow{4}{*}{$\begin{array}{l}\text { Rendimiento del trabajo } \\
\text { (físico, manual) }\end{array}$} & $\begin{array}{l}\text { Desempeño de actividades físicas en } \\
\text { general }\end{array}$ \\
\hline & & & Maninulación \\
\hline & & & $\begin{array}{l}\text { Control de máquinas y procesos } \\
\text { Operación de vehículos, dispositivos o equipos mecanizados }\end{array}$ \\
\hline & & & \\
\hline & & \multirow{2}{*}{$\begin{array}{l}\text { Rendimiento del trabajo } \\
\text { (complejo, técnico) }\end{array}$} & Reparación y mantenimiento de equipo mecánico \\
\hline & & & $\begin{array}{l}\text { Redacción, diseño y especificación de } \\
\text { dispositivos técnicos, piezas y equipos } \\
\text { Documentar y grabar información }\end{array}$ \\
\hline Cooperación & Colaboración & \multirow{9}{*}{ Interacción con los demás } & $\begin{array}{l}\text { Establecimiento y mantenimiento de relaciones interpersonales } \\
\text { Ayudar y cuidar a los demás } \\
\text { Interpretar el sentido de la información de los otros }\end{array}$ \\
\hline & $\begin{array}{l}\text { Compartir } \\
\text { información }\end{array}$ & & $\begin{array}{l}\text { Comunicación con supervisores, pares o subordinados } \\
\text { Capacitar y enseñar a otros }\end{array}$ \\
\hline Interacción horizontal & $\begin{array}{l}\text { Capacitar a los demás } \\
\text { Dar presentaciones }\end{array}$ & & \\
\hline \multirow{2}{*}{$\begin{array}{r}\text { Interacción con el } \\
\text { cliente }\end{array}$} & Vender un producto o servicio & & Vender o influenciar a otros \\
\hline & Asesorar a otros & & $\begin{array}{l}\text { Brindar asesoría y consejo a otros } \\
\text { Comunicar con personas ajenas a la organización } \\
\text { Trabajar para o directamente con el público }\end{array}$ \\
\hline \multirow[b]{2}{*}{$\begin{array}{l}\text { Habilidades } \\
\text { gerenciales }\end{array}$} & \multirow[b]{2}{*}{ Planificar las actividades de otros } & & Coordinar el trabajo y las actividades de los demás \\
\hline & & & $\begin{array}{l}\text { Desarrollar y formar equipos } \\
\text { Guiar, dirigir y motivar a los demás } \\
\text { Orientar y desarrollar a los demás }\end{array}$ \\
\hline \multirow[t]{2}{*}{ Influencia } & $\begin{array}{l}\text { Negociar con las personas } \\
\text { Persuadir a las personas }\end{array}$ & & Resolver conflictos y negociar con los demás \\
\hline & & & $\begin{array}{l}\text { Desempeñar actividades administrativas } \\
\text { Dotar de personal a las dependencias organizacionales } \\
\text { Control y supervisión de los recursos }\end{array}$ \\
\hline
\end{tabular}

Fuente: OCDE, con base en datos del PIAAC Database y de O*NET, octubre 2015.

Las estimaciones de O*NET muestran las correlaciones más sólidas entre las TIC y en particular las actividades relacionadas con "interactuar con otros", "establecer y mantener relaciones interpersonales" (coeficiente de correlación igual a 0.6), "realizar o trabajar directamente con el público" (0.59), "comunicar con supervisores, pares o subordinados" (0.67) y "vender o influenciar a otros" $(0.53)$.

Los "procesos mentales" son el segundo grupo de actividades de mayor correlación con las TIC: "programación del trabajo y de actividades" $(0.53)$, "organización, planificación y priorización del trabajo" $(0.49)$, así como "actualización y uso del conocimiento relevante" y "desarrollo de objetivos y estrategias" (0.48). 
Es interesante que la correlación entre las TIC y la actividad "operación de vehículos, dispositivos mecanizados o equipos" (0.46) es positiva y más alta que para cualquier otra actividad del grupo "entrada de información". Sin embargo, las otras actividades del grupo "resultados del trabajo (físico, material)", muestran las correlaciones más bajas con las TIC.

La "estimación de las características cuantificables de los productos, eventos o información" muestra la correlación más alta (0.34) dentro del grupo "entrada de información", mientras "reparación y mantenimiento de equipos mecánicos" (0.33) y "redacción, diseño y especificación de dispositivos técnicos, piezas y equipo" muestran la mayor correlación dentro del grupo "resultados de trabajo (complejo, técnico)".

La Figura 17 desglosa las correlaciones anteriores por "zonas de trabajo" definidas por O*NET. Las "zonas de trabajo" de O*NET clasifican las ocupaciones en cinco categorías según el nivel típico de habilidades requeridas por la ocupación, incluida la experiencia laboral, la educación y/o la formación profesional. La zona 1 denota el nivel más bajo de preparación y la zona 5 el nivel más alto.

Figura 17. Correlaciones entre cambios en la importancia de las TIC y cambios en la importancia de los grupos de actividades

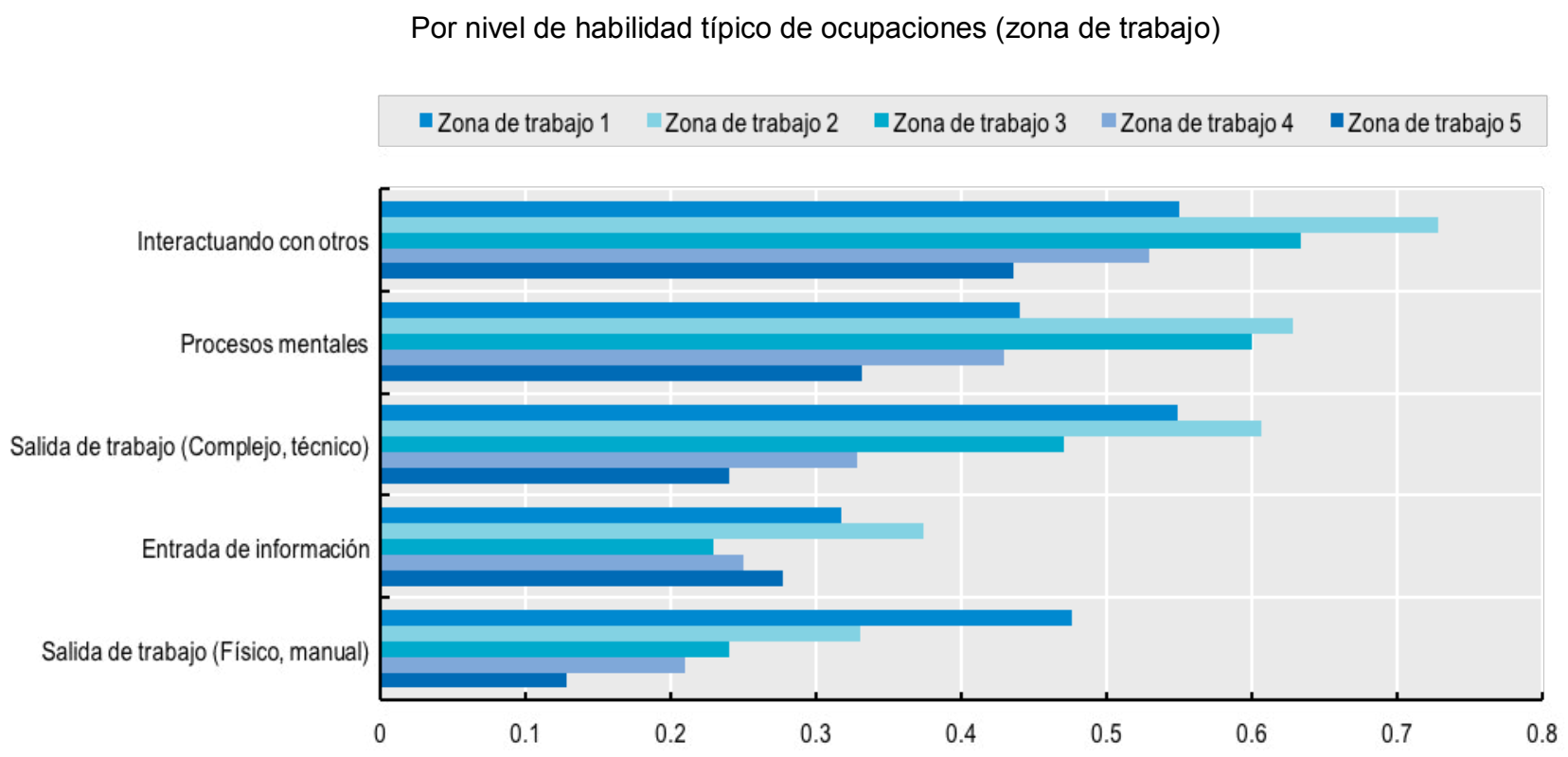

Fuente: OCDE, con base en datos de O*NET Database, junio 2015.

De acuerdo con los hallazgos de la Figura 17, las correlaciones más altas se encuentran entre las TIC y el grupo de actividad "interactuar con otros", y las correlaciones más bajas entre las TIC y "resultados del trabajo (físico, material)", así como con "entrada de información". Además, las correlaciones muestran una clasificación similar en diferentes zonas de trabajo, es decir, niveles de habilidad. La única excepción es la zona de trabajo 1, es decir, el nivel de habilidad más bajo, donde "resultados del trabajo (complejo, técnico)" e "interactuar con otros" están más correlacionados con las TIC. Esto sugiere que, para ocupaciones con baja cualificación, el uso creciente de las TIC está asociado con una actualización en el contenido de la habilidad del trabajo manual.

La fuerza de las correlaciones tiende a disminuir con los niveles de habilidad. Esta observación confirma el hallazgo de la sección anterior basada en datos del PIAAC de que los cambios en el conjunto de tareas asociadas 
con el aumento del uso de las TIC tienden a ser más grandes para las personas en ocupaciones poco cualificadas que para las personas con cualificaciones medias y altas.

Los resultados generales presentados en esta sección sobre la base de los datos del PIAAC y de O*NET también son consistentes con los hallazgos de un estudio reciente de Hammermann y Stettes (2016) que utilizan los datos de IW- Personalpanel de 2014 en Alemania. Los autores muestran que los empleados de empresas altamente digitalizadas parecen tener más habilidades de comunicación y cooperación y más capacidad para planificar, organizar y actuar de forma autónoma en comparación con las empresas menos digitalizadas. El estudio también pronostica un aumento en los requisitos de "habilidades sociales" con el aumento de la digitalización en las empresas, especialmente entre aquellas que participan activamente en la Cuarta Revolución Industrial.

\section{Midiendo la oferta de habilidades genéricas en el uso de las TIC a través del desempeño del PSTRE}

Una vez que se ha medido la demanda de habilidades genéricas de las TIC (sección 2), el siguiente paso es evaluar en qué medida la demanda corresponde con la oferta de dichas habilidades. La información disponible en la evaluación de desempeño del PIAAC, en particular en la sección "solución de problemas en un entorno rico en tecnología" (PSTRE, por sus siglas en inglés), permite realizar esta evaluación.

El marco del PIAAC evalúa las habilidades clave del procesamiento de la información que son:

- Las necesarias para integrarse y participar plenamente en el mercado laboral, la educación y la capacitación, la vida social y cívica.

- Altamente transferibles, ya que son relevantes para muchos contextos sociales y situaciones laborales.

- Que se puedan aprender y, por lo tanto, estén sujetas a las políticas.

En el nivel más fundamental, la alfabetización y las habilidades numéricas constituyen una base para el desarrollo de habilidades cognitivas de orden superior como el razonamiento analítico y son esenciales para tener acceso y comprender dominios específicos del conocimiento. Además, la capacidad para gestionar información y resolver problemas en entornos ricos en tecnología (PSTRE), es decir, para acceder, evaluar, analizar y comunicar información, es cada vez más importante como entender e interpretar información basada en texto y poder manejar datos matemáticos. La capacidad de PSTRE tiene mayor relevancia con la aplicación de las TIC que se están convirtiendo en una de las características más importantes en la mayoría de los lugares de trabajo, en la educación y en la vida cotidiana.

En el PIAAC, la resolución de problemas en entornos ricos en tecnología (PSTRE) se define como "el uso de tecnología digital, herramientas de comunicación y redes para adquirir y evaluar información, comunicarse con otros y realizar tareas prácticas". El primer ciclo de la encuesta se centra en "las habilidades para resolver problemas con fines personales, laborales y cívicos mediante el establecimiento de objetivos y planes apropiados, y el acceso y uso de la información a través de computadoras y redes" (OCDE, 2012).

La resolución de problemas en entornos ricos en tecnología (PSTRE) cubre los tipos específicos de problemas que las personas enfrentan al usar las TIC. Estos problemas comparten las siguientes características:

- El problema es principalmente una consecuencia de la disponibilidad de nuevas tecnologías.

- La solución al problema requiere el uso de instrumentos informáticos (aplicaciones, formatos representativos, procedimientos computacionales).

- Los problemas están relacionados con los entornos ricos en tecnología (por ejemplo, cómo operar una computadora, cómo solucionar un problema de configuración, cómo usar un navegador de Internet).

La resolución de problemas en entornos ricos en tecnología es un dominio de competencia que representa la intersección de lo que a veces se describe como habilidades de "alfabetización informática" (es decir, la capacidad de usar herramientas y aplicaciones de TIC) y las habilidades cognitivas necesarias para resolver problemas. Algunos conocimientos básicos sobre el uso de dispositivos de entrada TIC por ejemplo, el uso de un teclado, un 
ratón y pantallas, herramientas de administración de archivos, aplicaciones como procesadores de textos, correo electrónico e interfaces gráficas son esenciales para realizar tareas de evaluación. Sin embargo, el objetivo no es probar el uso de herramientas y aplicaciones de TIC de forma aislada, sino evaluar la capacidad de los adultos para usar esas herramientas con el fin de acceder, procesar, evaluar y analizar la información de manera efectiva.

La Tabla 7 presenta los diferentes niveles de resolución de problemas de la evaluación de entornos ricos en tecnología y el tipo de tareas completadas exitosamente en cada nivel de competencia.

\section{Tabla 7. Niveles de competencia en la resolución de problemas en la evaluación de entornos ricos en tecnología} (PSTRE)

\begin{tabular}{|c|c|c|}
\hline Nivel & Puntuación & Tipo de tareas completadas exitosamente en cada nivel de competencia \\
\hline $\begin{array}{l}\text { Por } \\
\text { debajo } \\
\text { del } \\
\text { Nivel } 1\end{array}$ & $\begin{array}{l}\text { Debajo de } \\
241 \\
\text { puntos }\end{array}$ & $\begin{array}{l}\text { Las tareas se basan en problemas bien definidos que involucran el uso de una sola } \\
\text { función dentro de una interfaz genérica para cumplir con un criterio explícito sin ningún } \\
\text { razonamiento categórico, inferencial o de transformación de la información. Se } \\
\text { requieren pocos pasos y no se debe generar ningún objetivo secundario. }\end{array}$ \\
\hline 1 & $\begin{array}{l}\text { De } 241 \text { a } \\
\text { menos de } \\
291 \text { puntos }\end{array}$ & $\begin{array}{l}\text { En este nivel, las tareas generalmente requieren el uso de aplicaciones de tecnología } \\
\text { ampliamente disponibles y conocidas, como el software de correo electrónico o un } \\
\text { navegador web. Se requiere poca o ninguna navegación para acceder a la } \\
\text { información o comandos para resolver problemas. Estos se pueden resolver } \\
\text { independientemente del conocimiento y del uso de herramientas y funciones } \\
\text { específicas del encuestado (por ejemplo, una función de clasificación). Las tareas } \\
\text { implican pocos pasos y un número mínimo de operaciones. En el nivel cognitivo, el } \\
\text { encuestado puede inferir fácilmente el objetivo de la tarea; la resolución de problemas } \\
\text { requiere que el encuestado aplique criterios explícitos y hay pocas demandas de } \\
\text { monitoreo (por ejemplo, el encuestado no tiene que verificar si él o ella ha utilizado el } \\
\text { procedimiento apropiado o ha avanzado hacia la solución). La identificación de } \\
\text { contenidos y operaciones se puede hacer a través de un simple cotejo. Solo se } \\
\text { requieren formas simples de razonamiento, como la asignación de elementos a } \\
\text { categorías y no hay necesidad de contrastar o integrar información. }\end{array}$ \\
\hline 2 & $\begin{array}{l}\text { De } 291 \text { a } \\
\text { menos de } \\
341 \text { puntos }\end{array}$ & $\begin{array}{l}\text { En este nivel, las tareas generalmente requieren el uso de aplicaciones de } \\
\text { tecnología tanto genéricas como más específicas. Por ejemplo, el encuestado } \\
\text { puede tener que usar un nuevo formulario en línea. Se requiere cierta navegación a } \\
\text { través de las páginas y aplicaciones para resolver el problema. El uso de herramientas } \\
\text { (por ejemplo, una función de clasificación) puede facilitar la resolución del } \\
\text { problema. La tarea puede involucrar múltiples pasos y operaciones. El encuestado } \\
\text { puede tener que definir el objetivo del problema, aunque los criterios que se deben } \\
\text { cumplir son explícitos. Hay mayores exigencias de seguimiento. Pueden aparecer } \\
\text { algunos resultados inesperados o puntos muertos. La tarea puede requerir evaluar la } \\
\text { relevancia de un conjunto de elementos para descartar distractores. Puede ser } \\
\text { necesaria alguna integración y razonamiento inferencial. }\end{array}$ \\
\hline 3 & $\begin{array}{l}\text { Igual o } \\
\text { mayor a } \\
341 \text { puntos }\end{array}$ & $\begin{array}{l}\text { En este nivel, las tareas generalmente requieren el uso de aplicaciones de tecnología } \\
\text { tanto genéricas como más específicas. Se requiere cierta navegación a través de las } \\
\text { páginas y aplicaciones para resolver el problema. Se requiere el uso de herramientas } \\
\text { (por ejemplo, una función de clasificación) para avanzar hacia la solución. La tarea } \\
\text { puede involucrar múltiples pasos y operaciones. El encuestado puede tener que } \\
\text { definir el objetivo del problema, y los criterios que deben cumplirse pueden o no ser } \\
\text { explícitos. Normalmente hay altas demandas de monitoreo. Es probable que ocurran } \\
\text { resultados inesperados o puntos muertos. La tarea puede requerir evaluar la } \\
\text { relevancia y confiabilidad de la información para descartar distractores. La integración } \\
\text { y el razonamiento inferencial pueden ser necesarios en gran medida. }\end{array}$ \\
\hline
\end{tabular}

Fuente: OCDE (2013).

Según la descripción del PSTRE, parece que el nivel de competencia requerido para el uso eficaz de las TIC se puede establecer de la siguiente manera: 
Tabla 8. Asignación de tareas del PIAAC y O*NET y los grupos de actividades

\begin{tabular}{|l|l|}
\hline Uso de TIC & Niveles de desempeño \\
\hline $\mathrm{CBI}$ & Nivel 1 y superior \\
\hline SPO & Nivel 2 y superior \\
\hline
\end{tabular}

Fuente: OCDE, con base en datos del PIAAC Database, octubre 2015.

Las habilidades para el uso de las TIC relacionadas con las tareas de "Comunicación e intercambio de información (CBI)" se asignan al nivel 1, ya que las personas en este nivel de dominio PSTRE pueden usar un software de correo electrónico o un navegador web. Las habilidades relacionadas con el "Software de programación para oficina (SPO)" se asignan al nivel 2 porque se espera que las personas en este nivel utilicen herramientas o aplicaciones tecnológicas más específicas (por ejemplo, una función de clasificación). No fue posible hacer una asignación de las tareas relacionadas con las habilidades especializadas en el uso de las TIC, ya que la prueba de rendimiento PSTRE no permite distinguir las habilidades de programación específicas entre los individuos en el nivel 3.

Las Figuras 18a y 18b muestran el desglose de los niveles de competencia de PSTRE dentro de la población que usa diariamente CBI y SPO. Los resultados muestran que entre el 7 y el $15 \%$ de la población que reporta el uso de CBI diariamente en realidad no cuenta con las habilidades necesarias para llevar a cabo dichas tareas (por debajo del nivel 1 de PSTRE); el promedio de los países es del 9,5\%. La brecha es aún más significativa para las tareas de SPO ya que el $42 \%$ de los individuos no tienen las habilidades necesarias para llevarlas a cabo (PSTRE nivel 1 e inferior), aunque reportan que lo hacen diariamente. Por lo tanto, un número significativo de trabajadores que usan las TIC todos los días no parece tener las habilidades suficientes para utilizar estas tecnologías de manera efectiva.

Figura 18a. Desglose de las personas que utilizan CBI todos los días por niveles de PRSTE, 2012

\section{Como porcentaje de la población total}

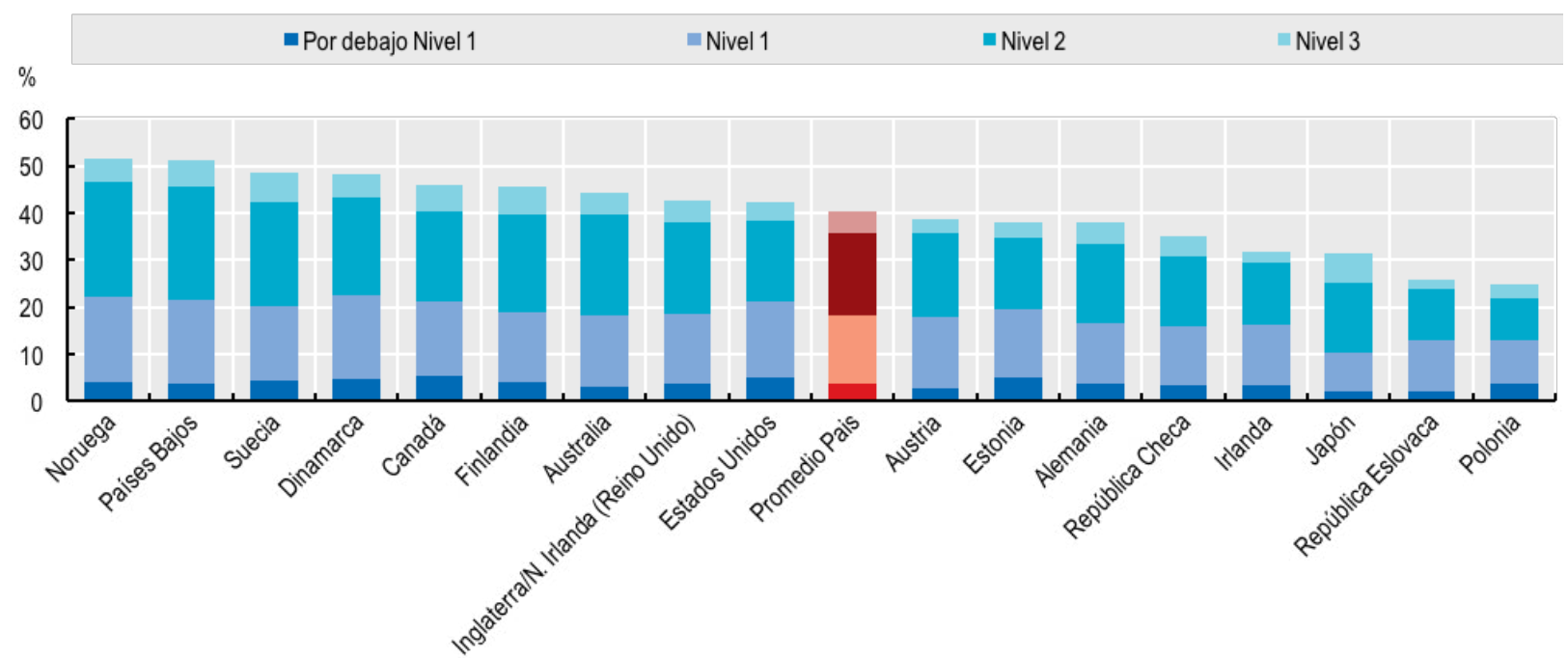

Nota: los datos de evaluación de PSTRE para Francia, Italia y España no están disponibles y no están incluidos en el total de la OCDE. Los individuos en las siguientes categorías de la evaluación PSTRE están excluidos del análisis: "Sin experiencia en computación", "Excluido de la evaluación basada en computadora", "Falla en el núcleo de las TIC/Falta".

Fuente: OCDE, con base en datos del PIAAC Database, enero 2016. 
Figura 18b. Desglose de las personas que utilizan SPO diariamente por niveles de PRSTE, 2012

\section{Como porcentaje de la población total}

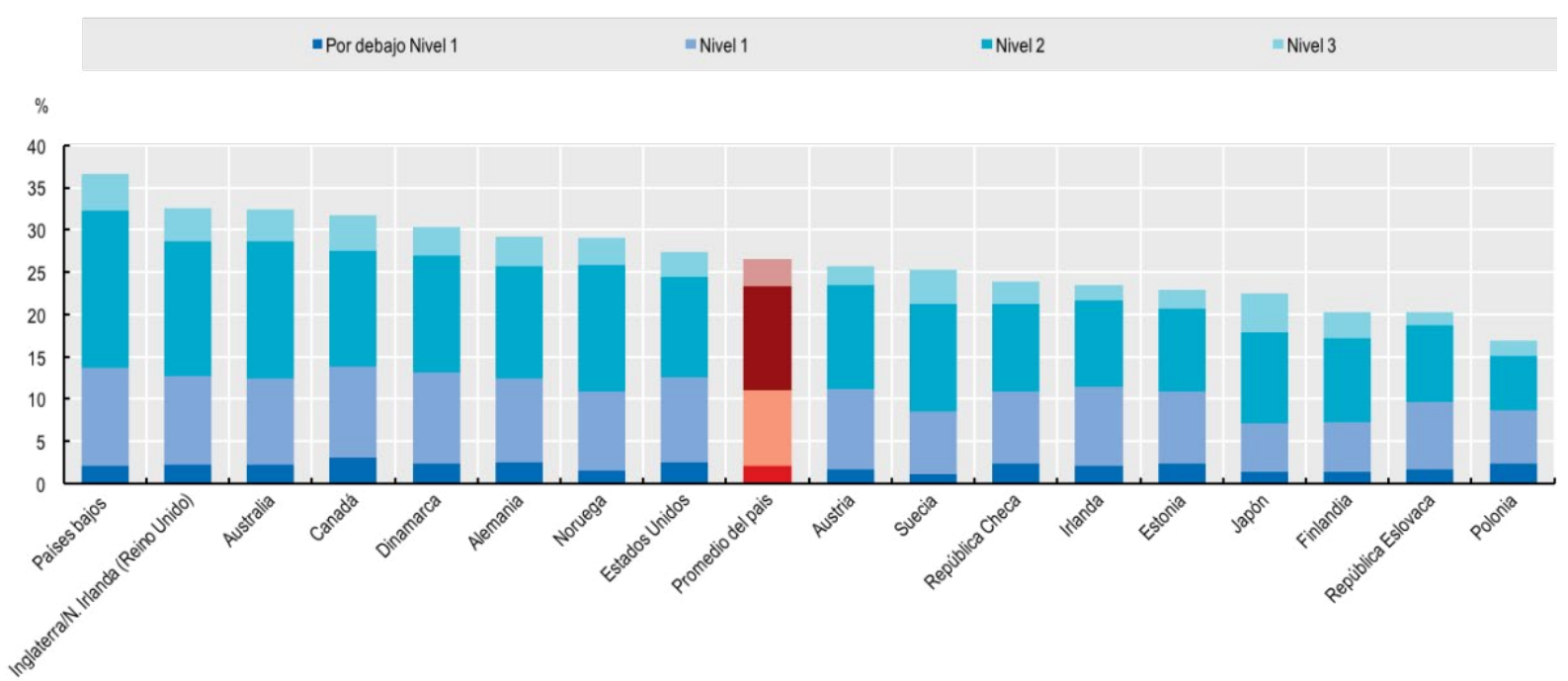

Nota: los datos de evaluación de PSTRE para Francia, Italia y España no están disponibles y no están incluidos en el total de la OCDE. Los individuos en las siguientes categorías de la evaluación PSTRE están excluidos del análisis: "Sin experiencia en computación", "Excluido de la evaluación basada en computadora", "Falla en el núcleo de las TIC/Falta".

Fuente: OCDE, conbase en datos del PIAAC Database, enero 2016.

\section{Conclusiones y orientaciones para futuras investigaciones}

Este documento presenta nueva evidencia sobre cómo el uso de las TIC en el trabajo está cambiando la demanda de tres conjuntos de habilidades relacionadas con las TIC: habilidades genéricas, habilidades especializadas y habilidades complementarias. La demanda de habilidades genéricas en el uso de las TIC también se ha comparado con la oferta de dichas habilidades.

La demanda de habilidades genéricas en el uso de las TIC medida por el uso de CBI y SPO en el trabajo, ha experimentado un modesto aumento en la gran mayoría de los países entre 2011 y 2014. En promedio, la intensidad de la CBI ha aumentado en 0.9 puntos porcentuales; el mayor incremento se ha dado en Noruega $(3,7$ puntos porcentuales) seguido por Francia (2,9 puntos porcentuales). La intensidad del uso de SPO ha aumentado 0,6 puntos porcentuales con los mismos países que muestran los mayores aumentos. Sin embargo, las intensidades de CBI y SPO continúan siendo significativamente diferentes entre los países de la muestra del PIAAC, que oscilan entre el $64 \%$ en Noruega y el $34 \%$ de la población activa en la República Eslovaca y entre el $43 \%$ en el Reino Unido y el 26\% en Polonia.

La demanda de especialistas en las TIC ha crecido rápidamente en los últimos años, pero la evidencia disponible sobre las primas salariales, las tasas de vacantes y la duración de las mismas sugiere que la escasez potencial de habilidades para el uso de las TIC no es muy grande y se limita a un pequeño número de países. Sin embargo, las estadísticas disponibles no permiten abordar estas preguntas en su totalidad y el desarrollo de mejores medidas, basadas tanto en las estadísticas oficiales como en las vacantes en línea, es un paso importante para futuros trabajos.

La expansión de las TIC también está cambiando la forma en que se hace el trabajo, aumentando la demanda de habilidades complementarias para el uso de las TIC. Estas son habilidades que no están relacionadas con la capacidad para usar la tecnología de manera efectiva, sino para llevar a cabo el trabajo en el "entorno rico en tecnología" (PSTRE) configurado por las TIC. 
El documento ha mostrado un enfoque simple y refutable para identificar tareas de trabajo complementarias a las TIC y medir la demanda de habilidades necesarias para realizar dichas tareas. Un hallazgo importante del análisis es que los cambios en el conjunto de tareas asociadas con el aumento del uso de las TIC tienden a ser más grandes para las personas con ocupaciones poco cualificadas que para las personas mediana y altamente cualificadas. En promedio, el uso intensivo de las TIC en el trabajo se asocia con tareas que requieren una mayor interacción con los compañeros de trabajo y los clientes, más resolución de problemas y menos trabajo físico.

Sobre la base de la evaluación de desempeño del PIAAC, especialmente en relación con PSTRE, el documento proporcionó una evaluación de la correspondencia entre la demanda y la oferta de habilidades genéricas en el uso de las TIC. Un significativo número de trabajadores que usan las TIC diariamente no parece tener suficientes habilidades para utilizar estas tecnologías de manera efectiva. La proporción de trabajadores con habilidades genéricas insuficientes es, en promedio, $9 \%$ para CBI y más del $40 \%$ para SPO.

Si bien los resultados anteriores ofrecen algunas ideas nuevas e interesantes, hay varias líneas para un análisis más detallado. Primero, el análisis se basa en combinaciones únicas o predefinidas de habilidades o tareas de acuerdo con las configuraciones de las encuestas originales. Vale la pena explorar si hay evidencia en los datos de que las combinaciones particulares de habilidades a menudo se usan juntas, por ejemplo, por medio de un análisis de componentes principales. Es posible que dichas combinaciones también puedan ser diferentes en otros grupos de habilidades. El interés final sería entonces ver cómo estos perfiles de habilidades por grupos de habilidades laborales se relacionan con las habilidades en el uso de las TIC.

Para futuras investigaciones vale la pena complementar el análisis de la oferta y la demanda de habilidades en el uso de las TIC con otros conjuntos de datos nacionales que pueden recopilar un conjunto más rico de información a lo largo del tiempo. El conjunto de datos alemán IAB/BIBB y la Encuesta Británica de Habilidades, por ejemplo, recopilan información sobre secciones transversales de trabajadores durante una o dos décadas (Spitz-Oener, 2006; Felstead et al. 2007). Además, la Encuesta de Habilidades de los Países Bajos (Ter Weel y Kok, 2013) contiene información sobre el emparejamiento entre la demanda y la oferta de habilidades, según la autoevaluación de los trabajadores, así como si se han adquirido las habilidades necesarias en la educación formal o 'en el trabajo'.

\section{ANEXO A1. LAS 20 OCUPACIONES CON MAYOR INTENSIDAD DE USO DE CBI POR PAÍS, 2012}

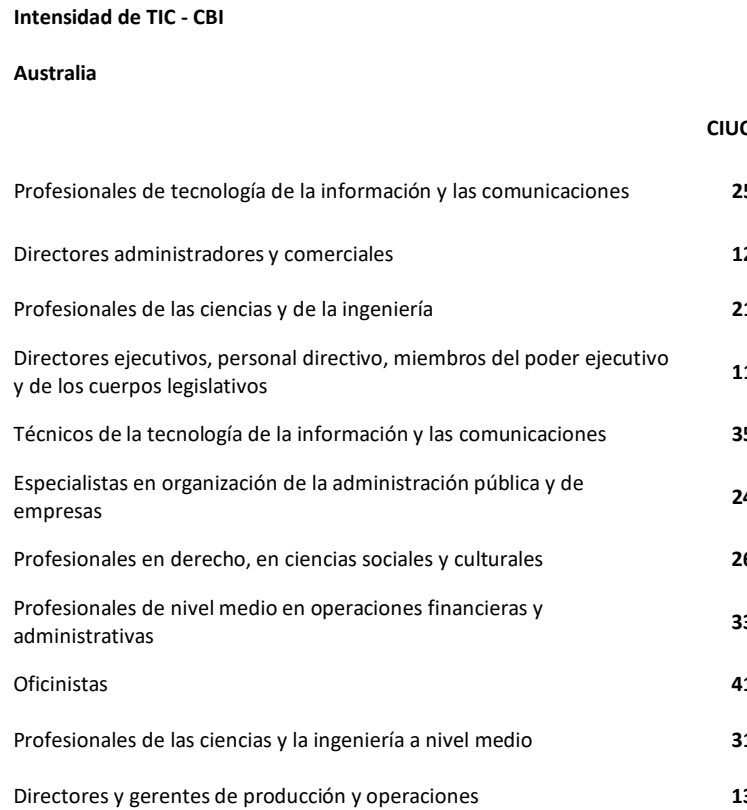

\begin{tabular}{ll}
\hline CIUO & \\
\hline 133 & 100.0 \\
\hline 142 & 100.0 \\
\hline 211 & 100.0 \\
\hline 212 & 100.0 \\
\hline 215 & 100.0 \\
\hline 225 & 100.0 \\
\hline 252 & 100.0 \\
\hline 315 & 100.0 \\
\hline 241 & 97.9 \\
\hline 122 & 97.6 \\
\hline 216 & 97.3 \\
\hline
\end{tabular}


Profesionales de la enseñanza

Empleados contables y encargados del registro de materiales

Gerentes de hoteles, restaurantes, comercios y otros servicios

Empleados en trato directo con el público

Personal de los servicios de protección

Profesionales de la salud

Profesionales de nivel medio de la salud

Trabajadores especializados en electricidad y tecnología

Profesionales de nivel medio de servicios jurídicos, sociales, culturales $y$ afines
2385.3 Autores, periodistas y lingüistas

$264 \quad 97.2$

$43 \quad 85.2$ Profesionales en derecho

1479.0 Desarrolladores y analistas de software y multimedia

$42 \quad 78.6$ Directores de administración y servicios

5478.1 Ingenieros (excluyendo electrotecnólogos)

2270.1 Profesionales de nivel medio en finanzas y matemáticas

$32 \quad 57.3$ Agentes de la administración pública para la aplicación de la ley y afines

7456.0 Profesionales de las ventas, la comercialización y las relaciones públicas

$34 \quad 55.7$ Especialistas en organización de administración
26196.5

25196.5

12196.3

21496.3

$331 \quad 95.7$

33595.5

$243 \quad 95.3$

24295.1
Canadá

Directores de servicios de tecnología de la información y las comunicaciones

Matemáticos, actuarios y estadísticos

Profesionales de medicina tradicional y alternativa

Profesionales de nivel medio de medicina tradicional y alternativa

Ingenieros (excluyendo electrotecnólogos)

Especialistas en bases de datos y en redes de computadoras

Especialistas en finanzas

Desarrolladores y analistas de software y multimedia

Directores de ventas, comercialización y desarrollo

Directores y gerentes de servicios profesionales

Directores de administración y servicios

Profesionales de las ventas, la comercialización y las relaciones públicas

Arquitectos, urbanistas, agrimensores y diseñadores

Especialistas en organización de administración

Directores generales y gerentes generales

Profesores de enseñanza secundaria

Ingenieros en electrotecnología

Técnicos en operaciones de tecnología de la información y las comunicaciones y asistencia al usuario

Profesionales en ciencias biológicas

Miembros del poder ejecutivo y de los cuerpos legislativos

Intensidad de TIC - CBI

Dinamarca

Miembros del poder ejecutivo y de los cuerpos legislativos

Directores generales y gerentes generales

\section{República Checa}

CIUO

cluo

$133 \quad 100.0$ Miembros del poder ejecutivo y de los cuerpos legislativos

111100.0

212100.0 Directores de administración y servicios

121100.0

223100.0 Directores de servicios de tecnología de la información y las comunicaciones

133100.0

323100.0 Directores $y$ gerentes de servicios profesionales

$134 \quad 100.0$

21499.8 Físicos, químicos $y$ afines

211100.0

25299.0 Matemáticos, actuarios y estadísticos

212100.0

24199.0 Arquitectos, urbanistas, agrimensores y diseñadores

216100.0

$25198.1 \quad$ Practicantes paramédicos

$224 \quad 100.0$

12297.9 Veterinarios

$134 \quad 97.8 \quad$ Especialistas en organización de administración

225100.0

242100.0

12197.3 Profesionales de las ventas, la comercialización y las relaciones públicas

243100.0

$243 \quad 97.2$ Especialistas en bases de datos y en redes de computadoras

252100.0

21696.9 Archivistas, bibliotecarios, curadores $y$ afines

262100.0

24296.5 Especialistas en ciencias sociales y teología

$263 \quad 100.0$

11295.0 Profesionales de nivel medio de medicina tradicional y alternativa

$323 \quad 100.0$

23394.8 Técnicos $y$ asistentes veterinarios

$324 \quad 100.0$

21594.7 Secretarios (general)

$412 \quad 99.9$

$351 \quad 94.5 \quad$ Especialistas en finanzas

24199.6

21394.5 Profesionales en derecho

26199.4

11194.4 Técnicos en telecomunicaciones y radiodifusión
Estonia

CIUO

Cluo

$111 \quad 100.0$ Matemáticos, actuarios y estadísticos

212100.0

112100.0 Miembros del poder ejecutivo y de los cuerpos legislativos 
Directores de ventas, comercialización y desarrollo

Directores de producción agropecuaria, silvicultura y pesca

Directores de servicios de tecnología de la información y las comunicaciones

Gerentes de comercios al por mayor y al por menor

Otros gerentes de servicios

Matemáticos, actuarios y estadísticos

Ingenieros en electrotecnología

Practicantes paramédicos

Profesionales en derecho

Archivistas, bibliotecarios, curadores y afines

Agentes de la administración pública para la aplicación de la ley y afines

Pagadores y cobradores de ventanilla y afines

Vendedores callejeros y puestos de mercado

Trabajadores agrícolas de subsistencia

Directores y gerentes de servicios profesionales

Profesionales de las ventas, la comercialización y las relaciones públicas

Directores y gerentes de servicios profesionales

Especialistas en finanzas

Finlandia miembros del poder ejecutivo y de los cuerpos legislativos

Directores administradores y comerciales

Profesionales de tecnología de la información y las comunicaciones

Técnicos de la tecnología de la información y las comunicaciones

Profesionales de nivel medio en operaciones financieras y administrativas

Directores y gerentes de producción y operaciones

Profesionales de la salud

Especialistas en organización de la administración pública y de empresas

Profesionales de las ciencias y de la ingeniería

Empleados en trato directo con el público

Empleados contables y encargados del registro de materiales

Oficinistas

Gerentes de hoteles, restaurantes, comercios y otros servicios

Profesionales de las ciencias y de la ingeniería de nivel medio

Profesionales en derecho, en ciencias sociales y culturales

Profesionales de la enseñanza
122100.0 Practicantes paramédicos

$224 \quad 100.0$

$131 \quad 100.0$ Profesionales de las ventas, la comercialización y las relaciones públicas

$243 \quad 100.0$

133100.0 Profesores de formación profesional

232100.0

142100.0 Especialistas en bases de datos y en redes de computadoras

252100.0

143100.0 Directores de ventas, comercialización y desarrollo

12298.1

212100.0 Agentes de la administración pública para la aplicación de la ley y afines

33598.0

215100.0 Profesores de universidades y de la enseñanza superior

23197.1

224100.0 Especialistas en organización de administración

24297.1

$261 \quad 100.0$ Directores de servicios de tecnología de la información y las comunicaciones

262100.0 Pagadores y cobradores de ventanilla y afines

13396.8

42196.7

335100.0 Profesionales en derecho

26196.5

$421 \quad 100.0$ Directores $y$ gerentes de servicios profesionales

13496.2

$521 \quad 100.0 \quad$ Especialistas en finanzas

24194.1

$631 \quad 100.0$ Desarrolladores $y$ analistas de software y multimedia

$251 \quad 93.3$

13499.4 Ingenieros en electrotecnología

21593.0

24398.5 Directores de administración y servicios

12192.6

23398.5 Autores, periodistas y lingüistas

24197.8 Gerentes de comercios al por mayor y al por menor

$264 \quad 92.4$

14292.3

$11 \quad 100.0$ Miembros del poder ejecutivo y de los cuerpos legislativos

111100.0

12100.0 Directores de ventas, comercialización y desarrollo

122100.0

2598.9 Directores de producción agropecuaria, silvicultura y pesca

$131 \quad 100.0$

3597.8 Directores de servicios de tecnología de la información y las

$133 \quad 100.0$

3396.7 Ingenieros en electrotecnología

215100.0

1395.8 Veterinarios

225100.0

2295.1 Desarrolladores $y$ analistas de software y multimedia

251100.0

2495.0 Especialistas en bases de datos y en redes de computadoras

252100.0

2194.9 Archivistas, bibliotecarios, curadores y afines

262100.0

4290.8 Profesionales de nivel medio de medicina tradicional y alternativa

323100.0

4390.6 Profesionales de nivel medio en finanzas y matemáticas

$331 \quad 100.0$

4189.9 Directores de industrias manufactureras, de minería, construcción y

13299.0

1489.0 Ingenieros (excluyendo electrotecnólogos)

21498.3

3188.0 Especialistas en organización de administración

$242 \quad 97.9$

2686.2 Profesionales en derecho

26196.0

$23 \quad 85.4$ Directores de administración y servicios 
Profesionales de nivel medio de la salud

Personal de los servicios de protección

Profesionales de nivel medio de servicios jurídicos, sociales, culturales y afines

Vendedores

Alemania

Directores de administración y servicios

Directores de ventas, comercialización y desarrollo

Directores de servicios de tecnología de la información y las comunicaciones

Físicos, químicos y afines

Especialistas en organización de administración

Profesionales de las ventas, la comercialización y las relaciones públicas

Desarrolladores y analistas de software y multimedia

Especialistas en bases de datos y en redes de computadoras

Ingenieros (excluyendo electrotecnólogos)

Directores de industrias manufactureras, de minería, construcción y distribución

Especialistas en finanzas

Profesionales en derecho

Agentes comerciales y corredores

Secretarios administrativos y especializados

Arquitectos, urbanistas, agrimensores y diseñadores

Profesionales de nivel medio en finanzas y matemáticas

Profesores de formación profesional

Agentes de la administración pública para la aplicación de la ley y afines

Auxiliares contables y financieros

Técnicos en operaciones de tecnología de la información y las comunicaciones y asistencia al usuario

Intensidad de TIC - CBI

Italia

Japón

Miembros del poder ejecutivo y de los cuerpos legislativos

Directores generales y gerentes generales

Directores de ventas, comercialización y desarrollo

Directores y gerentes de servicios profesionales

Matemáticos, actuarios y estadísticos

Profesores de universidades y de la enseñanza superior

Desarrolladores y analistas de software y multimedia
3276.5 Directores y gerentes de servicios profesionales

$134 \quad 94.6$

5475.0 Profesores de universidades y de la enseñanza superior

$231 \quad 94.2$

$34 \quad 65.4$ Profesionales de las ventas, la comercialización y las relaciones públicas

$243 \quad 94.1$

$52 \quad 57.8$ Especialistas en finanzas

24193.6
ClUO

111100.0

112100.0

122100.0 Directores generales y gerentes generales

$121 \quad 100.0$

122100.0

$211 \quad 100.0$ Directores de ventas, comercialización y desarrollo

133100.0

242100.0 Directores de servicios de tecnología de la información y las comunicaciones

211100.0

212100.0

$232 \quad 100.0$

261100.0

262100.0

314100.0

$331 \quad 100.0$

333100.0

$413 \quad 100.0$

835100.0

41197.3

35196.2

21694.3

24193.9

$263 \quad 93.8$
CIUO

$111 \quad 100.0$ Directores de servicios de tecnología de la información y las comunicaciones

112100.0 Gerentes de comercios al por mayor y al por menor

$122 \quad 100.0 \quad$ Otros gerentes de servicios

$134 \quad 100.0 \quad$ Físicos, químicos $y$ afines

212100.0 Profesionales en ciencias biológicas

$231 \quad 100.0$ Ingenieros en electrotecnología

251100.0 Profesores de universidades y de la enseñanza superior
Cluo

$133 \quad 100.0$

142100.0

$143 \quad 100.0$

211100.0

213100.0

215100.0

$231 \quad 100.0$ 
Especialistas en bases de datos y en redes de computadoras

Archivistas, bibliotecarios, curadores y afines

Técnicos en control de procesos

Técnicos y controladores en navegación marítima y aeronáutica

Autores, periodistas y lingüistas

Profesionales de las ventas, la comercialización y las relaciones públicas

Especialistas en finanzas

Secretarios (general)

Profesionales de nivel medio en finanzas y matemáticas

Especialistas en organización de administración

Profesionales en derecho

Agentes de servicios comerciales

Técnicos en operaciones de tecnología de la información y las comunicaciones y asistencia al usuario

\section{Países Bajos}

Miembros del poder ejecutivo y de los cuerpos legislativos

Directores de ventas, comercialización y desarrollo

Directores de servicios de tecnología de la información y las comunicaciones

Otros gerentes de servicios

Físicos, químicos y afines

Matemáticos, actuarios y estadísticos

Ingenieros en electrotecnología

Especialistas en bases de datos y en redes de computadoras

Archivistas, bibliotecarios, curadores y afines

Técnicos y profesionales de nivel medio en ciencias biológicas y afines

Técnicos en operaciones de tecnología de la información y las comunicaciones y asistencia al usuario

Secretarios (general)

Marineros de cubierta y afines

Especialistas en organización de administración

Especialistas en finanzas

Ingenieros (excluyendo electrotecnólogos)

Desarrolladores y analistas de software y multimedia

Profesionales de nivel medio en finanzas y matemáticas

Directores de administración y servicios

Profesionales en derecho
252100.0 Profesores de formación profesional

232100.0

262100.0 Especialistas en bases de datos y en redes de computadoras

$252 \quad 100.0$

313100.0 Secretarios (general)

412100.0

315100.0 Directores de ventas, comercialización y desarrollo

12298.0

26498.4 Desarrolladores $y$ analistas de software y multimedia

25197.4

24398.2 Técnicos en ciencias físicas y en ingeniería

31196.7

24198.2 Técnicos en operaciones de tecnología de la información y las

35196.6

41294.1 Especialistas en organización de administración

24296.5

33194.1 Directores generales y gerentes generales

11292.6

24293.5 Ingenieros (excluyendo electrotecnólogos)

21490.4

$26192.4 \quad$ Especialistas en finanzas

$33391.3 \begin{aligned} & \text { Directores de industrias manufactureras, de minería, construcción y } \\ & \text { distribución }\end{aligned}$

24189.5

13288.6

35191.0 Directores de administración y servicios

12187.9

\section{Noruega}

CIUO

CIUO

$111 \quad 100.0$ Miembros del poder ejecutivo y de los cuerpos legislativos

111100.0

122100.0 Directores de administración y servicios

$121 \quad 100.0$

$133 \quad 100.0$ Directores de producción agropecuaria, silvicultura y pesca

$131 \quad 100.0$

$143 \quad 100.0$ Directores de servicios de tecnología de la información y las comunicaciones

211100.0 Físicos, químicos y afines

212100.0 Profesionales en ciencias biológicas

215100.0 Ingenieros en electrotecnología

252100.0 Profesores de universidades y de la enseñanza superior

262100.0 Especialistas en finanzas

314100.0 Profesionales de las ventas, la comercialización y las relaciones públicas

$351 \quad 100.0$ Desarrolladores $y$ analistas de software y multimedia

251100.0

$412 \quad 100.0$ Especialistas en bases de datos y en redes de computadoras

252100.0

835100.0 Archivistas, bibliotecarios, curadores $\mathrm{y}$ afines

262100.0

24299.0 Profesionales de nivel medio en finanzas y matemáticas

$331 \quad 100.0$

24198.5 Técnicos en operaciones de tecnología de la información y las comunicaciones y asistencia al usuario

351100.0

21498.4 Secretarios (general)

412100.0

25197.3 Otros oficiales, operarios y artesanos de artes mecánicas y de otros

$754 \quad 100.0$

33196.7 Directores de ventas, comercialización y desarrollo

12298.6

12195.5 Ingenieros (excluyendo electrotecnólogos)

21498.6

26195.4 Archivistas, bibliotecarios, curadores $y$ afines 


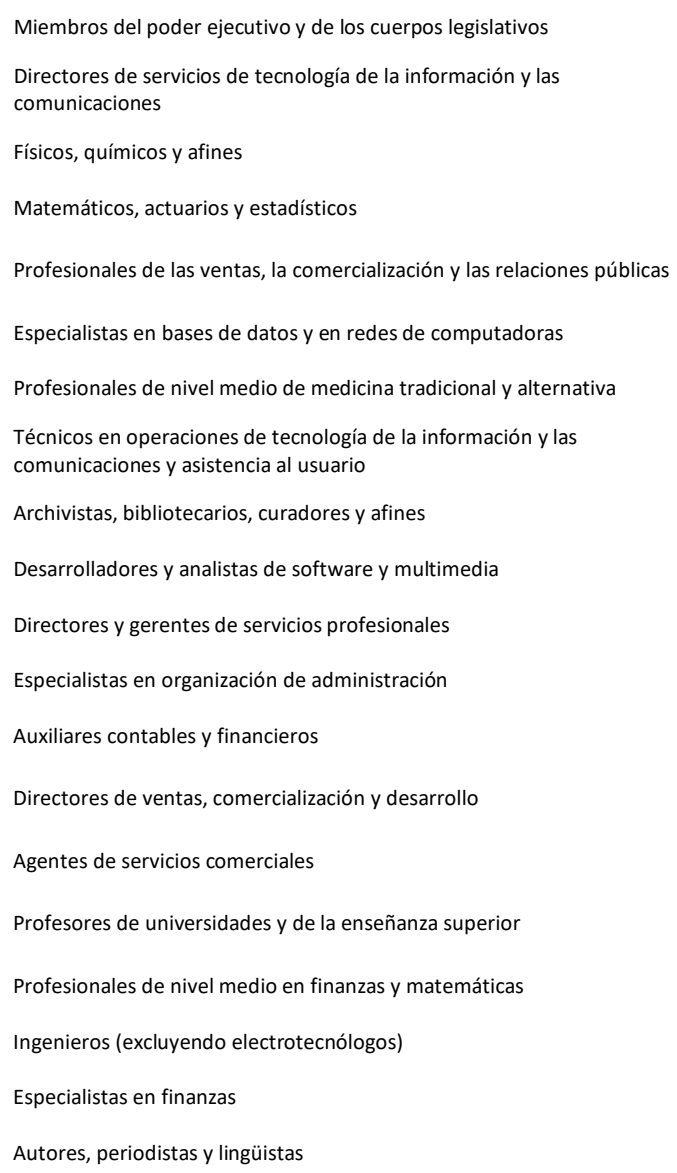

$111 \quad 100.0$ Físicos, químicos y afines

133100.0 Matemáticos, actuarios y estadísticos

211 100.0 Profesionales de enfermería y partería

222100.0

212100.0 Veterinarios

225100.0

243100.0 Profesores de universidades y de la enseñanza superior

$231 \quad 100.0$

252100.0 Especialistas en organización de administración

242100.0

323100.0 Técnicos y controladores en navegación marítima y aeronáutica

315100.0

$351 \quad 98.7 \quad$ Agentes de servicios comerciales

$333 \quad 100.0$

26298.0 Técnicos en telecomunicaciones y radiodifusión

352100.0

25197.8 Especialistas en bases de datos y en redes de computadoras

13495.8 Directores de ventas, comercialización y desarrollo

$242 \quad 95.7 \quad$ Especialistas en finanzas

24195.1

43194.1 Miembros del poder ejecutivo y de los cuerpos legislativos

12294.1 Técnicos en operaciones de tecnología de la información y las

$33391.5 \quad$ Ingenieros en electrotecnología

33190.1 Auxiliares contables $y$ financieros

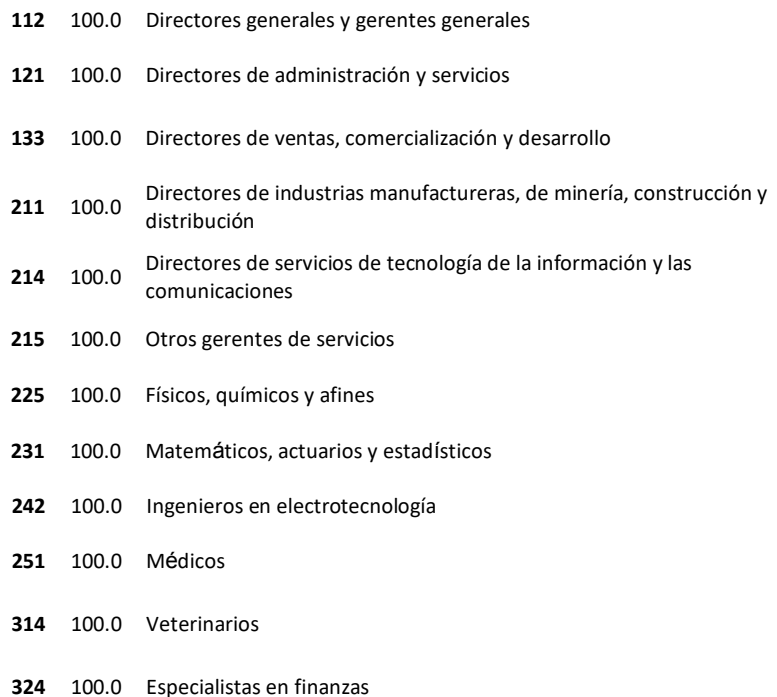


Técnicos en operaciones de tecnología de la información y las comunicaciones y asistencia al usuario

Técnicos en telecomunicaciones y radiodifusión

Operadores de máquinas de oficina

Operadores de instalaciones de procesamiento y recubridoras de metales

Especialistas en finanzas

Especialistas en bases de datos y en redes de computadoras

Auxiliares contables y financieros

Autores, periodistas y lingüistas

\section{Inglaterra/Irlanda del Norte (UK)}

\section{Especialistas en organización de administración}

Profesionales de las ventas, la comercialización y las relaciones públicas

Especialistas en bases de datos y en redes de computadoras

Archivistas, bibliotecarios, curadores y afines

Técnicos en control de procesos

Técnicos y profesionales de nivel medio en ciencias biológicas y afines

Técnicos y controladores en navegación marítima y aeronáutica

Secretarios administrativos y especializados

Directores de ventas, comercialización y desarrollo

Desarrolladores y analistas de software y multimedia

Especialistas en finanzas

Médicos

Directores de servicios de tecnología de la información y las comunicaciones

Técnicos en operaciones de tecnología de la información y las comunicaciones y asistencia al usuario

Directores de producción agropecuaria, silvicultura y pesca

Directores generales y gerentes generales

Directores de administración y servicios

Ingenieros (excluyendo electrotecnólogos)

Profesionales en derecho

Arquitectos, urbanistas, agrimensores y diseñadores
$351 \quad 100.0$ Especialistas en bases de datos y en redes de computadoras

252100.0

352100.0 Archivistas, bibliotecarios, curadores $y$ afines

262100.0

413100.0 Archivistas, bibliotecarios, curadores $y$ afines

$263 \quad 100.0$

813100.0 Técnicos y profesionales de nivel medio en ciencias biológicas y afines

$314 \quad 100.0$

24197.2 Técnicos en telecomunicaciones y radiodifusión

25295.9 Oficinistas generales

$411 \quad 100.0$

43195.6 Auxiliares contables y financieros

$431 \quad 100.0$

26495.4 Otros oficiales, operarios y artesanos de artes mecánicas y de otros

$754 \quad 100.0$

\section{Estados Unidos}

CIUO

CIUO

242100.0 Miembros del poder ejecutivo y de los cuerpos legislativos

111100.0

243100.0 Directores de servicios de tecnología de la información y las comunicaciones

133100.0

252100.0 Profesionales en ciencias biológicas

213100.0

262100.0 Ingenieros (excluyendo electrotecnólogos)

$214 \quad 100.0$

313100.0 Ingenieros en electrotecnología

215100.0

$314 \quad 100.0 \quad$ Veterinarios

225100.0

315100.0 Profesionales de las ventas, la comercialización y las relaciones públicas

$243 \quad 100.0$

334100.0 Autores, periodistas y lingüistas

$264 \quad 100.0$

12299.9 Operadores de máquinas de oficina

$413 \quad 100.0$

25199.9 Marineros de cubierta y afines

835100.0

24199.7 Directores de ventas, comercialización y desarrollo

12299.1

22198.9 Directores y gerentes de servicios profesionales

$233 \quad 98.4$

13398.7 Profesores de universidades y de la enseñanza superior

23198.3

35198.0 Profesionales en derecho

26198.0

13197.9 Desarrolladores $y$ analistas de software y multimedia

25197.8

11296.9 Directores y gerentes de servicios profesionales

13496.5

12196.7 Técnicos en ciencias físicas y en ingeniería

31195.8

21496.2 Especialistas en organización de administración

24295.3

26196.1 Especialistas en bases de datos y en redes de computadoras

$252 \quad 94.7$

21695.6 Secretarios administrativos y especializados

Nota: Australia y Finlandia solamente están disponibles en el nivel de 2 dígitos.

Fuente: OCDE, con base en datos del PIAAC Database, octubre 2015. 


\section{ANEXO A2. LAS 20 OCUPACIONES CON MAYOR INTENSIDAD DE USO DE SPO POR PAÍS, 2012}

Intensidad TIC - SPO

Australia

Profesionales de la salud

Profesionales de la enseñanza

Especialistas en organización de la administración pública y de empresas

Profesionales de tecnología de la información y las comunicaciones

Profesionales en derecho, en ciencias sociales y culturales

Profesionales de las ciencias y la ingeniería a nivel medio

Profesionales de nivel medio de la salud

Profesionales de nivel medio en operaciones financieras y administrativas

Profesionales de nivel medio de servicios jurídicos, sociales, culturales y afines

Técnicos de la tecnología de la información y las comunicaciones

Oficinistas

Empleados en trato directo con el público

Empleados contables y encargados del registro de materiales

Otro personal de apoyo administrativo

Trabajadores de los servicios personales

Vendedores

Trabajadores de los cuidados personales

Personal de los servicios de protección

Agricultores y trabajadores calificados de explotaciones agropecuarias con destino al mercado

Trabajadores forestales calificados, pescadores, cazadores y recolectores de subsistencia

Canadá

Matemáticos, actuarios y estadísticos

Autores, periodistas y lingüistas

Profesionales de las ventas, la comercialización y las relaciones públicas

Directores de ventas, comercialización y desarrollo

Directores de administración y servicios

Especialistas en organización de administración

Especialistas en finanzas

Directores de servicios de tecnología de la información y las comunicaciones

Ingenieros (excluyendo electrotecnólogos)

Auxiliares contables y financieros
Austria

CIUO

\begin{tabular}{|c|c|c|}
\hline 22 & 81.6 & Matemáticos, actuarios y estadísticos \\
\hline 23 & 80.6 & Veterinarios \\
\hline 24 & 78.2 & Técnicos y controladores en navegación marítima y aeronáutica \\
\hline 25 & 75.1 & Directores de administración y servicios \\
\hline 26 & 74.0 & Ingenieros en electrotecnología \\
\hline 31 & 71.9 & $\begin{array}{l}\text { Agentes de la administración pública para la aplicación de la ley y } \\
\text { afines }\end{array}$ \\
\hline 32 & 68.6 & Directores de ventas, comercialización y desarrollo \\
\hline 33 & 68.4 & Autores, periodistas y lingüistas \\
\hline 34 & 68.2 & Especialistas en finanzas \\
\hline 35 & 66.7 & Profesionales de nivel medio en finanzas y matemáticas \\
\hline 41 & 64.2 & Especialistas en bases de datos y en redes de computadoras \\
\hline 42 & 63.2 & Especialistas en ciencias sociales y teología \\
\hline 43 & 62.3 & Secretarios (general) \\
\hline 44 & 56.5 & Profesionales en derecho \\
\hline 51 & 42.8 & $\begin{array}{l}\text { Técnicos en operaciones de tecnología de la información y las } \\
\text { comunicaciones y asistencia al usuario }\end{array}$ \\
\hline 52 & 41.8 & Profesionales en ciencias biológicas \\
\hline 53 & 41.4 & Profesores de universidades y de la enseñanza superior \\
\hline 54 & 38.8 & Especialistas en organización de administración \\
\hline 61 & 35.6 & $\begin{array}{l}\text { Directores de industrias manufactureras, de minería, construcció } \\
\text { distribución }\end{array}$ \\
\hline
\end{tabular}

CIUO

212100.0

225100.0

315100.0

12186.0

$215 \quad 84.9$

33584.0

12280.3

$264 \quad 79.7$

$241 \quad 78.2$

$331 \quad 76.7$

25275.9

$263 \quad 74.9$

$412 \quad 74.0$

$261 \quad 73.4$

$351 \quad 73.3$

$213 \quad 73.0$

23171.6

$242 \quad 70.0$

$132 \quad 69.9$

$334 \quad 69.8$

República Checa

Cluo Cluo

$212100.0 \quad$ Miembros del poder ejecutivo y de los cuerpos legislativos $\quad 111 \quad 100.0$

26490.2 Matemáticos, actuarios y estadísticos $\quad \mathbf{2 1 2} \quad 100.0$

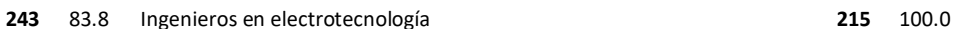

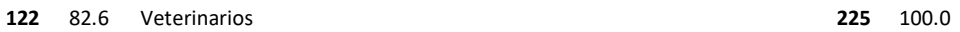

12181.6 Especialistas en bases de datos y en redes de computadoras $\quad 252 \quad 100.0$

24281.2 Especialistas en ciencias sociales y teología $\quad 263 \quad 99.0$

$\begin{array}{lllll}241 & 81.2 & \text { Directores y gerentes de servicios profesionales } & \mathbf{1 3 4} & 94.9\end{array}$

13380.8 Directores de servicios de tecnología de la información y las $\quad 133 \quad 92.3$

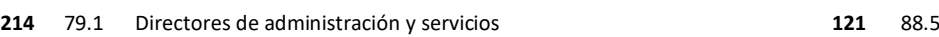

$431 \quad 77.2$ Secretarios administrativos y especializados $\quad 334 \quad 88.2$ 
Secretarios administrativos y especializados

Directores y gerentes de servicios profesionales

Físicos, químicos y afines

Directores generales y gerentes generales

Profesores de universidades y de educación superior

Especialistas en bases de datos y en redes de computadoras

Miembros del poder ejecutivo y de los cuerpos legislativos

Ingenieros en electrotecnología

Profesionales en derecho

Agentes de la administración pública para la aplicación de la ley y afines

Intensidad TIC - SPO

Dinamarca

Directores de producción agropecuaria, silvicultura y pesca

Matemáticos, actuarios y estadísticos

Vendedores callejeros y de puestos de mercado

Profesionales en derecho

Directores de servicios de tecnología de la información y las comunicaciones

Profesores de enseñanza secundaria

Agentes de la administración pública para la aplicación de la ley y afines

Profesores de universidades y de la enseñanza superior

Directores generales y gerentes generales

Especialistas en finanzas

Especialistas en organización de administración

Autores, periodistas y lingüistas

Directores de administración y servicios

Directores y gerentes de servicios profesionales

Secretarios administrativos y especializados

Especialistas en bases de datos y en redes de computadoras

Agentes de servicios comerciales

Profesionales de las ventas, la comercialización y las relaciones públicas

Operadores de máquinas de oficina

Auxiliares contables y financieros

Finlandia

Directores y gerentes de producción y operaciones

Gerentes de hoteles, restaurants, comercios y otros servicios

$\begin{array}{lllll}\mathbf{3 3 4} & \mathbf{7 6 . 6} & \text { Practicantes paramédicos } & \mathbf{2 2 4} & 87.1 \\ \mathbf{1 3 4} & \mathbf{7 6 . 5} & \text { Profesionales en derecho } & \mathbf{2 6 1} & 86.6 \\ \mathbf{2 1 1} & \mathbf{7 6 . 5} & \text { Físicos, químicos y afines } & \mathbf{2 1 1} & 85.0 \\ \mathbf{1 1 2} & \mathbf{7 6 . 2} & \text { Agentes de servicios comerciales } & \mathbf{3 3 3} & 81.3 \\ \mathbf{2 3 1} & \mathbf{7 5 . 5} & \text { Secretarios (general) } & \mathbf{4 1 2} & 80.6 \\ \mathbf{2 5 2} & \mathbf{7 5 . 2} & \text { Técnicos y controladores en navegación marítima y aeronáutica } & \mathbf{3 1 5} & 80.4 \\ \mathbf{1 1 1} & \mathbf{7 4 . 7} & \text { Directores de ventas, comercialización y desarrollo } & \mathbf{1 2 2} & 78.8 \\ \mathbf{2 1 5} & \mathbf{7 4 . 6} & \text { Especialistas en finanzas } & \mathbf{2 4 1} & 78.7 \\ \mathbf{2 6 1} & \mathbf{7 3 . 0} & \text { Especialistas en organización de administración } & \mathbf{2 4 2} & 75.7 \\ \mathbf{3 3 5} & \mathbf{7 2 . 5} & \text { Oficinistas generales } & \mathbf{4 1 1} & 75.7\end{array}$

Estonia

CIUO

CIUO

131 100.0 Matemáticos, actuarios y estadísticos $\quad \mathbf{2 1 2} \quad 100.0$

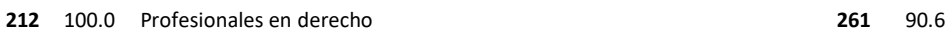

$\begin{array}{lllll}521 & 100.0 & \text { Directores } y \text { gerentes de servicios profesionales } & \mathbf{1 3 4} & 82.4\end{array}$

$\begin{array}{lllll}261 & 96.4 & \text { Autores, periodistas y lingüistas } & \mathbf{2 6 4} & 80.9\end{array}$

13391.9 Miembros del poder ejecutivo y de los cuerpos legislativos $\quad 111 \quad 80.6$

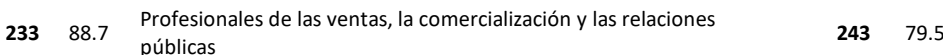

$\begin{array}{lllll}335 & 87.8 & \text { Especialistas en organización de administración } & \mathbf{2 4 2} & \mathbf{7 8 . 5}\end{array}$

$\begin{array}{lllll}231 & 87.7 & \text { Directores de ventas, comercialización y desarrollo } & \mathbf{1 2 2} & 77.3\end{array}$

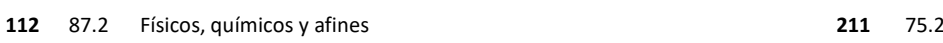

$\begin{array}{lllll}241 & 85.8 & \text { Directores de administración y servicios } & 121 & 71.1\end{array}$

$242 \quad 85$ Técnicos en ciencias físicas y en ingeniería $\quad 311 \quad 69.2$

$\begin{array}{lllll}264 & 84.7 & \text { Operadores de máquinas de oficina } & 413 & 68.3\end{array}$

$\begin{array}{lllll}121 & 84.1 & \text { Especialistas en finanzas } & \mathbf{2 4 1} & 66.8\end{array}$

$\begin{array}{lllll}134 & 81.6 & \text { Secretarios administrativos y especializados } & \mathbf{3 3 4} & 65.7\end{array}$

$\begin{array}{lllll}334 & 80.9 & \text { Especialistas en ciencias sociales y teología } & \mathbf{2 6 3} & 61.5\end{array}$

25280.7 Auxiliares contables y financieros $\quad 431 \quad 61.2$

$333 \quad 79.6$ Especialistas en bases de datos y en redes de computadoras $\quad 252 \quad 58.6$

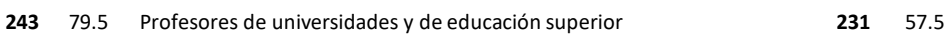

41379.4 Técnicos y profesionales de nivel medio en ciencias biológicas y afines $\quad 314 \quad 57.0$

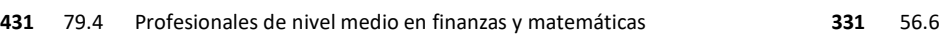

Francia

CIUO ClUO

13 74.4 Directores de producción agropecuaria, silvicultura y pesca $\quad 131 \quad 100.0$

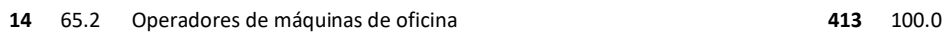


Profesionales de las ciencias y de la ingeniería

Profesionales de la salud

Profesionales de la enseñanza

Especialistas en organización de la administración pública y de empresas

Profesionales de tecnología de la información y las comunicaciones

Profesionales en derecho, en ciencias sociales y culturales

Profesionales de las ciencias y la ingeniería de nivel medio

Profesionales de nivel medio de la salud

Profesionales de nivel medio en operaciones financieras y administrativas

Profesionales de nivel medio de servicios jurídicos, sociales, culturales $y$ afines

Técnicos de la tecnología de la información y las comunicaciones

Oficinistas

Empleados en trato directo con el público

Empleados contables y encargados del registro de materiales

Otro personal de apoyo administrativo

Trabajadores de los servicios personales

Vendedores

Trabajadores de los cuidados personales

\section{Alemania}

Especialistas en finanzas

Directores de ventas, comercialización y desarrollo

Profesionales en derecho

Secretarios administrativos y especializados

Secretarios (general)

Directores de administración y servicios

Ingenieros (excluyendo electrotecnólogos)

Agentes de la administración pública para la aplicación de la ley y afines

Directores y gerentes de servicios profesionales

Profesionales de nivel medio en finanzas y matemáticas

Directores de industrias manufactureras, de minería, construcción y distribución

Técnicos en control de procesos

Auxiliares contables y financieros

Autores, periodistas y lingüista

Técnicos en operaciones de tecnología de la información y las comunicaciones y asistencia al usuario

Especialistas en ciencias sociales y teología

Oficinistas generales

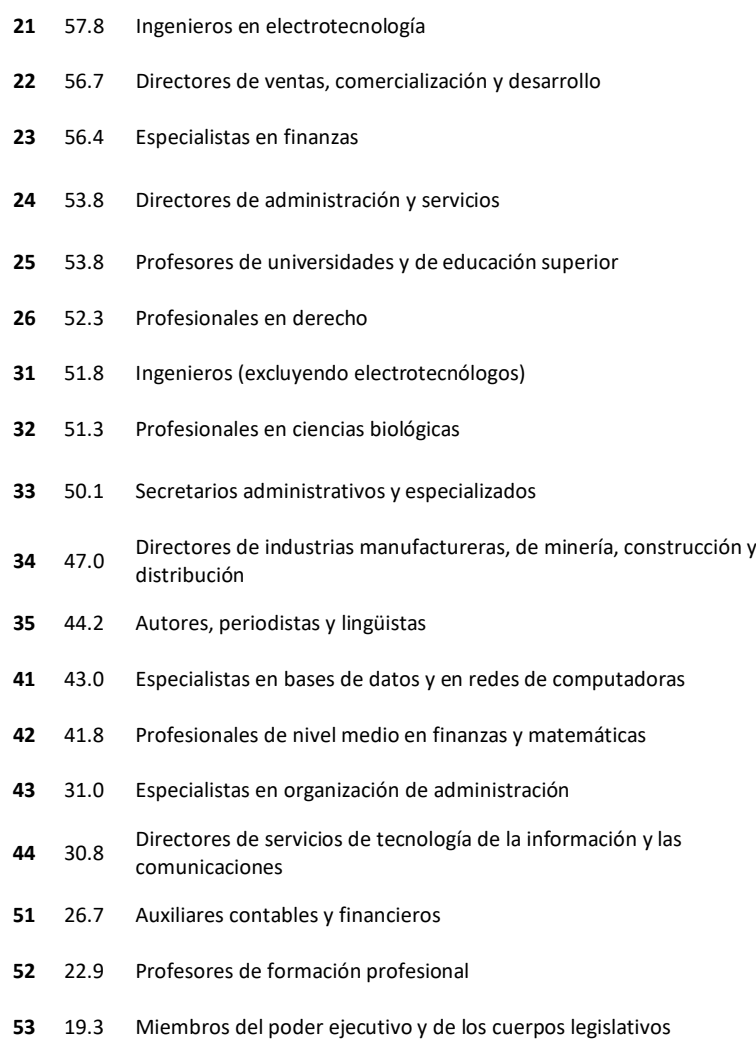

Irlanda

cluo

$24192.3 \quad$ Físicos, químicos $y$ afines

211100.0

212100.0

$333 \quad 100.0$

41197.3

12295.7

33195.2

$121 \quad 93.1$

$232 \quad 92.9$

$241 \quad 90.7$

$133 \quad 87.8$

$231 \quad 86.4$

$242 \quad 85.5$

11281.9

41280.6

$431 \quad 79.6$

$341 \quad 79.6$

$334 \quad 78.0$ 
Agentes de servicios comerciales

Médicos

Profesionales de las ventas, la comercialización y las relaciones públicas

Intensidad TIC - SPO

Italia

Directores de ventas, comercialización y desarrollo

Matemáticos, actuarios y estadísticos

Archivistas, bibliotecarios, curadores y afines

Técnicos y controladores en navegación marítima y aeronáutica

Especialistas en finanzas

Autores, periodistas y lingüistas

Profesionales en derecho

Profesores de universidades y de educación superior

Profesionales de nivel medio en finanzas y matemáticas

Agentes de servicios comerciales

Ingenieros (excluyendo electrotecnólogos)

Desarrolladores y analistas de software y multimedia

Físicos, químicos y afines

Profesionales de las ventas, la comercialización y las relaciones públicas

Profesionales de nivel medio, de servicios jurídicos, sociales y religiosos

Secretarios administrativos y especializados

Especialistas en organización de administración

Agentes comerciales y corredores

Veterinarios

Técnicos en telecomunicaciones y radiodifusión

Países Bajos

Noruega

CIUO

Físicos, químicos y afines

Matemáticos, actuarios y estadísticos

Veterinarios

Marineros de cubierta y afines

Profesionales en derecho

Especialistas en finanzas

Directores de ventas, comercialización y desarrollo

Especialistas en organización de administración

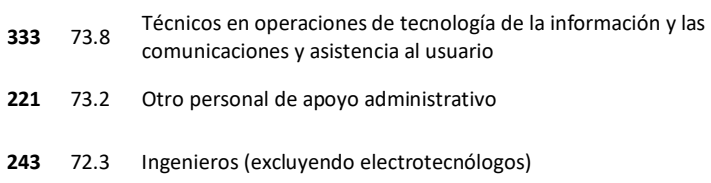

122100.0 Gerentes de comercios al por mayor y al por menor

212100.0 Físicos, químicos $y$ afines

$211 \quad 100.0$

262100.0 Profesionales en ciencias biológicas

$213 \quad 100.0$

315100.0 Ingenieros en electrotecnología

$215 \quad 100.0$

24193.3 Profesionales en derecho

$261 \quad 86.9$

$133 \quad 85.8$

$231 \quad 85.5$

26189.4 Profesores de universidades y de educación superior

$132 \quad 81.9$

$324 \quad 77.7$

$251 \quad 74.0$

$121 \quad 70.3$

$143 \quad 69.4$

$242 \quad 68.1$

$241 \quad 67.4$

$134 \quad 67.2$

$351 \quad 66.6$

$214 \quad 65.0$

$264 \quad 64.7$

$314 \quad 63.7$

$122 \quad 62.6$

212100.0 Especialistas en bases de datos y en redes de computadoras

$252 \quad 100.0$

225100.0 Archivistas, bibliotecarios, curadores $y$ afines

835100.0 Oficiales y operarios de procesamiento de alimentos $y$ afines

26195.4 Profesores de universidades y de educación superior

24192.2 Directores de administración y servicios

$121 \quad 83.9$

12290.0 Especialistas en ciencias sociales y teología

$263 \quad 83.6$

$242 \quad 88.8$ Profesionales en derecho 
Profesionales de nivel medio en finanzas y matemáticas

Secretarios administrativos y especializados

Secretarios (general)

Miembros del poder ejecutivo y de los cuerpos legislativos

Directores de servicios de tecnología de la información y las comunicaciones

Directores de administración y servicios

Especialistas en bases de datos y en redes de computadoras

Profesores de universidades y de educación superior

Especialistas en ciencias sociales y teología

Técnicos en ciencias físicas y en ingeniería

Auxiliares contables y financieros

Agentes de la administración pública para la aplicación de la ley y afines

\section{Polonia}

Miembros del poder ejecutivo y de los cuerpos legislativos

Físicos, químicos y afines

Matemáticos, actuarios y estadísticos

Profesionales en derecho

Especialistas en organización de administración

Directores y gerentes de servicios profesionales

Operadores de máquinas de oficina

Especialistas en ciencias sociales y teología

Profesores de universidades y de educación superior

Ingenieros (excluyendo electrotecnólogos)

Profesionales de las ventas, la comercialización y las relaciones públicas

Agentes de la administración pública para la aplicación de la ley y afines

Técnicos en operaciones de tecnología de la información y las comunicaciones y asistencia al usuario

Profesionales de nivel medio en finanzas y matemáticas

Profesionales de nivel medio, de servicios jurídicos, sociales y religiosos

Directores de administración y servicios

Directores de ventas, comercialización y desarrollo

Autores, periodistas y lingüistas

Agentes de servicios comerciales

Especialistas en finanzas

$\begin{array}{lllll}\mathbf{3 3 1} & 86.9 & \text { Directores de ventas, comercialización y desarrollo } & \mathbf{1 2 2} & 82.1 \\ \mathbf{3 3 4} & \mathbf{8 6 . 3} & \text { Especialistas en finanzas } & \mathbf{2 4 1} & 81.0 \\ \mathbf{4 1 2} & 85.5 & \text { Autores, periodistas y lingüistas } & \mathbf{2 6 4} & 79.7 \\ \mathbf{1 1 1} & 84.6 & \text { Directores y gerentes de servicios profesionales } & \mathbf{1 3 4} & 76.9 \\ \mathbf{1 3 3} & 81.8 & \text { Profesores de formación profesional } & \mathbf{2 3 2} & 76.2 \\ \mathbf{1 2 1} & \mathbf{8 1 . 5} & \text { Secretarios administrativos y especializados } & \mathbf{3 3 4} & 74.8 \\ \mathbf{2 5 2} & 80.9 & \begin{array}{l}\text { Directores de servicios de tecnología de la información y las } \\ \text { comunicaciones }\end{array} & \mathbf{1 3 3} & 72.7 \\ \mathbf{2 3 1} & \mathbf{8 0 . 8} & \text { Especialistas en organización de administración } & \mathbf{2 4 2} & 71.1 \\ \mathbf{2 6 3} & 80.8 & \text { Agentes comerciales y corredores } & \mathbf{3 3 2} & 70.6 \\ \mathbf{3 1 1} & \mathbf{7 9 . 8} & \text { Ingenieros (excluyendo electrotecnólogos) } & \mathbf{2 1 4} & 69.5 \\ \mathbf{4 3 1} & \mathbf{7 9 . 4} & \text { Agentes de servicios comerciales } & \mathbf{3 3 3} & 68.3 \\ \mathbf{3 3 5} & \mathbf{7 8 . 3} & \text { Médicos } & \mathbf{2 2 1} & 65.3\end{array}$

\section{República Eslovaca}

CIUO

$111 \quad 100.0$ Matemáticos, actuarios y estadísticos

212100.0

211100.0 Veterinarios

212100.0 Profesores de universidades y de educación superior

$225 \quad 100.0$

$231 \quad 100.0$

$242 \quad 100.0$

$341 \quad 100.0$

$413 \quad 94.0$

$412 \quad 85.9$

$211 \quad 85.9$

$333 \quad 84.4$

$261 \quad 84.2$

$351 \quad 81.8$

$262 \quad 81.3$

$252 \quad 79.5$

$241 \quad 79.3$

$431 \quad 77.7$

$334 \quad 74.4$

$411 \quad 72.0$

$335 \quad 71.3$

$215 \quad 68.2$

$332 \quad 68.1$ 
Directores de administración y servicios

Directores de servicios de tecnología de la información y las comunicaciones

Físicos, químicos y afines

Matemáticos, actuarios y estadísticos

Veterinarios

Técnicos y profesionales de nivel medio en ciencias biológicas y afines

Técnicos en telecomunicaciones y radiodifusión

Secretarios (general)

Especialistas en finanzas

Miembros del poder ejecutivo y de los cuerpos legislativos

Autores, periodistas y lingüistas

Profesionales en ciencias biológicas

Especialistas en organización de administración

Profesionales en derecho

Técnicos en operaciones de tecnología de la información y las comunicaciones y asistencia al usuario

Auxiliares contables y financieros

Agentes de la administración pública para la aplicación de la ley y afines

Ingenieros (excluyendo electrotecnólogos)

Profesionales de nivel medio, de servicios jurídicos, sociales y religiosos

Directores generales y gerentes generales

\section{Inglaterra/Irlanda del Norte (UK)}

CIUO

Técnicos en control de procesos

Técnicos y controladores en navegación marítima y aeronáutica

Secretarios administrativos y especializados

Profesionales en derecho

Autores, periodistas y lingüistas

Especialistas en finanzas

Agentes de servicios comerciales

Archivistas, bibliotecarios, curadores y afines

Agentes de la administración pública para la aplicación de la ley y afines

Físicos, químicos y afines

Directores de ventas, comercialización y desarrollo

Operadores de máquinas de oficina

Directores de servicios de tecnología de la información y las comunicaciones

121100.0

Directores de servicios de tecnología de la información y las comunicaciones

$133 \quad 100.0$

133100.0 Matemáticos, actuarios y estadísticos

212100.0

211100.0 Profesionales en derecho

26194.8

212100.0 Especialistas en finanzas

$241 \quad 88.3$

225100.0 Especialistas en organización de administración

$242 \quad 81.6$

314100.0 Directores de ventas, comercialización y desarrollo

$122 \quad 79.9$

352100.0 Directores de administración y servicios

$121 \quad 79.1$

41291.3 Secretarios (general)

24191.3 Archivistas, bibliotecarios, curadores $y$ afines

$412 \quad 78.8$

$262 \quad 76.1$

11190.8 Especialistas en ciencias sociales y teología

$263 \quad 75.5$

26490.7 Especialistas en bases de datos y en redes de computadoras

$252 \quad 74.6$

$215 \quad 73.3$

$21390.3 \quad$ Ingenieros en electrotecnología

$334 \quad 71.8$

$231 \quad 69.7$

26184.9 Profesores de universidades y de educación superior

$112 \quad 69.3$

$311 \quad 69.1$

43184.3 Técnicos en ciencias físicas y en ingeniería

$132 \quad 68.9$

33582.6 Directores de industrias manufactureras, de minería, construcción y distribución

21482.5 Profesores de formación profesional

34180.8 Ingenieros (excluyendo electrotecnólogos)

11280.2 Físicos, químicos y afines

Estados Unidos

\begin{tabular}{lll}
$\mathbf{3 1 3}$ & 100.0 & Marineros de cubierta y afines \\
$\mathbf{3 1 5}$ & 100.0 & Técnicos y asistentes veterinarios \\
$\mathbf{3 3 4}$ & $\mathbf{1 0 0 . 0}$ & $\begin{array}{l}\text { Directores de servicios de tecnología de la información y las } \\
\text { comunicaciones }\end{array}$ \\
$\mathbf{2 6 1}$ & 95.9 & Especialistas en organización de administración \\
$\mathbf{2 6 4}$ & 95.5 & Profesores de universidades y de educación superior \\
$\mathbf{2 4 1}$ & 94.0 & Miembros del poder ejecutivo y de los cuerpos legislativos \\
$\mathbf{3 3 3}$ & 91.2 & $\begin{array}{l}\text { Profesionales de las ventas, la comercialización y las relaciones } \\
\text { públicas }\end{array}$ \\
$\mathbf{2 6 2}$ & 90.1 & Especialistas en finanzas \\
$\mathbf{3 3 5}$ & 89.0 & Autores, periodistas y lingüistas \\
$\mathbf{2 1 1}$ & 88.8 & Directores de ventas, comercialización y desarrollo \\
$\mathbf{1 2 2}$ & 86.9 & Especialistas en ciencias sociales y teología \\
$\mathbf{4 1 3}$ & 86.9 & Profesionales en derecho \\
\hline $\mathbf{1 3 3}$ & 85.7 & Directores de administración y servicios
\end{tabular}

cluo

$835 \quad 100.0$

$324 \quad 89.2$

$133 \quad 82.9$

$242 \quad 82.2$

$231 \quad 81.6$

$111 \quad 80.9$

$243 \quad 78.9$

$241 \quad 78.7$

$264 \quad 78.7$

$122 \quad 75.6$

$263 \quad 75.5$

$261 \quad 74.1$

$121 \quad 73.8$ 


\section{Secretarios (general)}

Técnicos en operaciones de tecnología de la información y las comunicaciones y asistencia al usuario

Desarrolladores y analistas de software y multimedia

Auxiliares contables y financieros

Especialistas en organización de administración

Directores de administración y servicios

Profesionales de nivel medio en finanzas y matemáticas

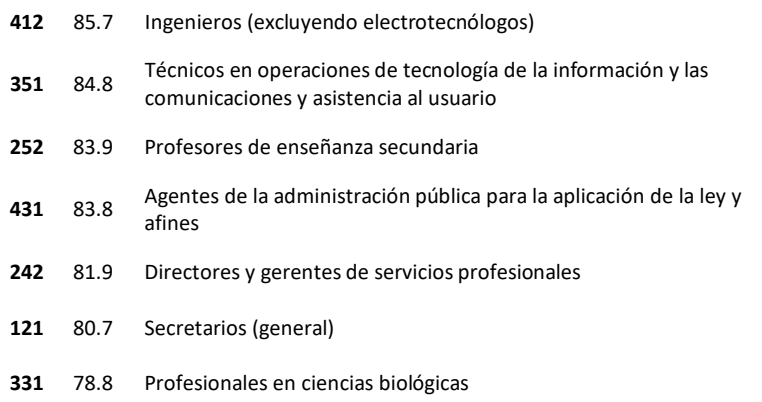

Nota: Australia y Finlandia solamente están disponibles en el nivel de 2 dígitos.

Fuente: OCDE, con base en datos del PIAAC Database, octubre 2015.

\section{ANEXO B. LAS 20 OCUPACIONES ESPECIALISTAS EN TIC CON MAYOR INTENSIDAD DE USO POR PAIÍS, 2012}

Intensidad de especialistas en TIC

Australia

Profesionales de tecnología de la información y las comunicaciones
Técnicos de la tecnología de la información y las comunicaciones
Profesionales de las ciencias y de la ingeniería
Oficinistas

Profesionales de nivel medio de servicios jurídicos, sociales, culturales y afines

Profesionales de nivel medio en operaciones financieras y administrativas

Oficiales y operarios de la metalurgia, la construcción mecánica y afines

Trabajadores especializados en electricidad y la electrotecnología

Directores administradores y comerciales

Directores ejecutivos, personal directivo de la administración pública y miembros del poder ejecutivo y de los cuerpos legislativos

Empleados en trato directo con el público

Directores y gerentes de producción y operaciones

Especialistas en organización de la administración pública y de empresas

Profesionales en derecho, en ciencias sociales y culturales

Gerentes de hoteles, restaurantes, comercios y otros servicios

Trabajadores de los cuidados personales

Vendedores

Conductores de vehículos y operadores de equipos pesados móviles

Profesionales de la enseñanza

Empleados contables y encargados del registro de materiales
Austria

\begin{tabular}{|c|c|c|}
\hline 25 & 48.1 & Desarrolladores y analistas de software y multimedia \\
\hline 35 & 32.8 & Especialistas en bases de datos y en redes de computadoras \\
\hline 21 & 6.6 & Profesores de Universidad y de educación superior \\
\hline 41 & 5.2 & Artesanos \\
\hline 34 & 5.2 & $\begin{array}{l}\text { Técnicos en operaciones de tecnología de la información y las } \\
\text { comunicaciones y asistencia al usuario }\end{array}$ \\
\hline 33 & 3.4 & Físicos, químicos y afines \\
\hline 72 & 3.3 & Herreros, herramentistas y afines \\
\hline 74 & 2.9 & Ingenieros en electrotecnología \\
\hline 12 & 2.4 & Técnicos en telecomunicaciones y radiodifusión \\
\hline 11 & 2.1 & Técnicos en ciencias físicas y en ingeniería \\
\hline 42 & 1.9 & Profesionales de las ventas, la comercialización y las relaciones públicas \\
\hline 13 & 1.8 & Cajeros y expendedores de billetes \\
\hline 24 & 1.7 & Directores y gerentes de servicios profesionales \\
\hline 26 & 1.5 & Moldeadores, soldadores, chapistas, montadores de estructuras \\
\hline 14 & 1.3 & Médicos \\
\hline 53 & 1.2 & $\begin{array}{l}\text { Directores de industrias manufactureras, de minería, construcción y } \\
\text { distribución }\end{array}$ \\
\hline 52 & 1.0 & Instaladores y reparadores de equipos eléctricos \\
\hline 83 & 0.9 & Artistas creativos e interpretativos \\
\hline 23 & 0.9 & Gerentes de hotel y restaurantes \\
\hline 43 & 0.9 & Personal de los servicios de protección \\
\hline
\end{tabular}




\author{
Desarrolladores y analistas de software y multimedia \\ Matemáticos, actuarios y estadísticos \\ Desarrolladores y analistas de software y multimedia \\ Ingenieros en electrotecnología \\ Arquitectos, urbanistas, agrimensores y diseñadores \\ Directores de servicios de tecnología de la información y las \\ comunicaciones \\ Herreros, herramentistas y afines \\ Profesores de Universidad y de educación superior \\ Operadores de instalaciones y máquinas de productos químicos y \\ fotográficos \\ Directores generales y gerentes generales \\ Autores, periodistas y lingüistas \\ Técnicos en operaciones de tecnología de la información y las \\ comunicaciones y asistencia al usuario \\ Archivistas, bibliotecarios, curadores y afines \\ Físicos, químicos y afines \\ Técnicos en ciencias físicas y en ingeniería \\ Oficinistas generales \\ Empleados de servicios de información al cliente \\ Especialistas en finanzas \\ Profesores de formación profesional
}

Profesionales de las ventas, la comercialización y las relaciones públicas
25157.7 Desarrolladores y analistas de software y multimedia 251

21237.8 Otros profesionales de nivel medio de medicina tradicional

25230.2 Instaladores y reparadores de equipos electrónicos y de telecomunicaciones

$742 \quad 29.5$

21526.0 Miembros del poder ejecutivo y de los cuerpos legislativos

$111 \quad 24.5$

216 Técnicos en operaciones de tecnología de la información y las

$133 \quad 14.3$ Herreros, herramentistas $y$ afines

72214.3 Ingenieros (excluyendo electrotecnólogos)

$214 \quad 11.7$

$231 \quad 12.3$ Secretarios administrativos y especializados

81310.3 Gerentes de comercios al por mayor y al por menor

$142 \quad 9.9$

1127.9 Directores de servicios de tecnología de la información y las

2647.3 Operadores de instalaciones de procesamiento y recubridoras de

1339.0

$812 \quad 7.1$

3517.2 Directores de administarción y servicios

$121 \quad 5.8$

2626.7 Directores de ventas, comercialización y desarrollo

$122 \quad 5.7$

2116.4 Personal al servicio directo de los pasajeros

3116.2 Autores, periodistas y lingüistas

$511 \quad 5.3$

$264 \quad 5.1$

4115.8 Arquitectos, urbanistas, agrimensores y diseñadores

$216 \quad 4.0$

4225.6 Mecánicos y reparadores de máquinas

$723 \quad 3.8$

2415.6 Directores y gerentes de servicios profesionales

$134 \quad 3.5$

2324.6 Profesores de Universidad y de educación superior

$231 \quad 3.1$

Intensidad de especialistas en TIC

Dinamarca

\section{Estonia}

Matemáticos, actuarios y estadísticos

21259.5 Desarrolladores y analistas de software y multimedia

25147.0 Especialistas en bases de datos y en redes de computadoras

Desarrolladores y analistas de software y multimedia

Técnicos en operaciones de tecnología de la información y las comunicaciones y asistencia al usuario

35127.1 Físicos, químicos $y$ afines

81226.3 Matemáticos, actuarios y estadísticos

Técnicos en telecomunicaciones y radiodifusión

35222.0 Directores de servicios de tecnología de la información y las

31.7 Operadores de instalaciones de procesamiento y recubridoras de

Artesanos

Especialistas en bases de datos y en redes de computadoras

Moldeadores, soldadores, chapistas, montadores de estructuras

Ensambladores

Ingenieros (except electrotecnólogos)

Ingenieros en electrotecnología

$133 \quad 14.5$

$812 \quad 14.2$

$351 \quad 11.2$

$215 \quad 10.5$

$131 \quad 7.5$

$231 \quad 7.1$

$722 \quad 4.1$ 
Conductores de automóviles, camionetas y motocicletas

Pagadores y cobradores de ventanilla y afines

Profesores de Universidades y de la enseñanza superior

Otros gerentes de servicios

Técnicos en control de procesos

Profesores de formación profesional

Profesionales de las ventas, la comercialización y las relaciones públicas

Empleados encargados del registro de materiales y de transportes

Mecánicos y reparadores de máquinas

Finlandia

Profesionales de tecnología de la información y las comunicaciones

Técnicos de la tecnología de la información y las comunicaciones

Profesionales de las ciencias y de la ingeniería

Oficiales y operarios de la construcción excluyendo electricistas

Trabajadores especializados en electricidad y la electrotecnología

Directores ejecutivos, personal directive de la administración pública y miembros del poder ejecutivo y de los cuerpos legislativos

Otro personal de apoyo administrativo

Profesionales de las ciencias y la ingeniería de nivel medio

Empleados contables y encargados del registro de materiales

Directores y gerentes de producción y operaciones

Operarios y oficiales de procesamiento de alimentos, de la confección, ebanistas, otros artesanos $y$ afines

Empleados en trato directo con el público

Operadores de instalaciones fijas y máquinas

Profesionales de la enseñanza

Oficinistas

Profesionales de nivel medio de la salud

Especialistas en organización de la administración pública y de empresas

Trabajadores de los cuidados personales

Profesionales de nivel medio en operaciones financieras y administrativas

Vendedores

Alemania

Desarrolladores y analistas de software y multimedia

Físicos, químicos y afines
Irlanda

CIUO

25171.3 Oficiales y operarios de las artes gráficas

CIUO

$\begin{array}{lllll}\mathbf{8 3 2} & 11.0 & \text { Artistas creativos e interpretativos } & \mathbf{1 4 1} & 4.0 \\ \mathbf{4 2 1} & 10.8 & \text { Técnicos en telecomunicaciones y radiodifusión } & \mathbf{3 5 2} & 3.7 \\ \mathbf{2 3 1} & 10.7 & \text { Gerentes de comercios al por mayor y al por menor } & \mathbf{1 4 2} & 3.6 \\ \mathbf{1 4 3} & 9.5 & \text { Secretarios administrativos y especializados } & \mathbf{3 3 4} & 3.4 \\ \mathbf{3 1 3} & \mathbf{9} & \text { Artistas creativos e interpretativos } & \mathbf{2 6 5} & 3.0 \\ \mathbf{2 3 2} & \mathbf{8} & \text { Directores de administración y servicios } & \mathbf{1 2 1} & 2.8 \\ \mathbf{2 4 3} & 7.8 & \text { Otros profesionales de la salud } & \mathbf{2 2 6} & 2.8 \\ \mathbf{4 3 2} & 6.8 & \text { Especialistas en finanzas } & \mathbf{2 4 1} & 2.0 \\ \mathbf{7 2 3} & 6.7 & \text { Empleados de servicios de información al cliente } & \mathbf{4 2 2} & 1.8\end{array}$

Francia

CIUO

21156.9 Técnicos en operaciones de tecnología de la información y las comunicaciones y asistencia al usuario
$732 \quad 24.3$

$351 \quad 23.2$ 
Técnicos en operaciones de tecnología de la información y las comunicaciones y asistencia al usuario

Herreros, herramentistas $y$ afines

Profesionales de formación profesional

Ingenieros en electrotecnología

Técnicos en telecomunicaciones y radiodifusión

Profesores de Universidad y de educación superior

Operadores de instalaciones de procesamiento y recubridoras de metales

Operadores de máquinas de oficina

Oficiales y operarios de las artes gráficas

Directores de servicios de tecnología de la información y las comunicaciones

Técnicos en ciencias físicas y en ingeniería

Arquitectos, urbanistas, agrimensores y diseñadores

Supervisores en ingeniería de minas, de industrias manufactureras y de la construcción

Desarrolladores y analistas de software y multimedia

Operadores de máquinas para fabricar productos de caucho, de papel y de material plástico

Instaladores y reparadores de equipos electrónicos y de telecomunicaciones

Otros oficiales, operarios y artesanos de artes mecánicas y de otros oficios

Empleados de servicios de información al cliente

Intensidad de especialistas en TIC

Italia

Profesionales de las ventas, la comercialización y las relaciones públicas

Físicos, químicos y afines

Profesionales de la formación profesiona

Autores, periodistas y lingüistas

Especialistas en organización de administración

Arquitectos, urbanistas, agrimensores y diseñadores

Directores de industrias manufactureras, de minería, construcción y distribución

Ingenieros (excluyendo electrotecnólogos)
Japón

CIUO

25180.9 Desarrolladores $y$ analistas de software y multimedia

31327.5 Especialistas en bases de datos y en redes de computadoras

$732 \quad 23.7$ Miembros del poder ejecutivo y de los cuerpos legislativos

35122.2 Profesionales de nivel medio en finanzas y matemáticas $21520.9 \begin{aligned} & \text { Directores de servicios de tecnología de la información y las } \\ & \text { comunicaciones }\end{aligned}$

25213.9 Profesores de Universidades y de educación superior

$243 \quad 12.9$ Técnicos y profesionales de nivel medio en ciencias biológicas y afines

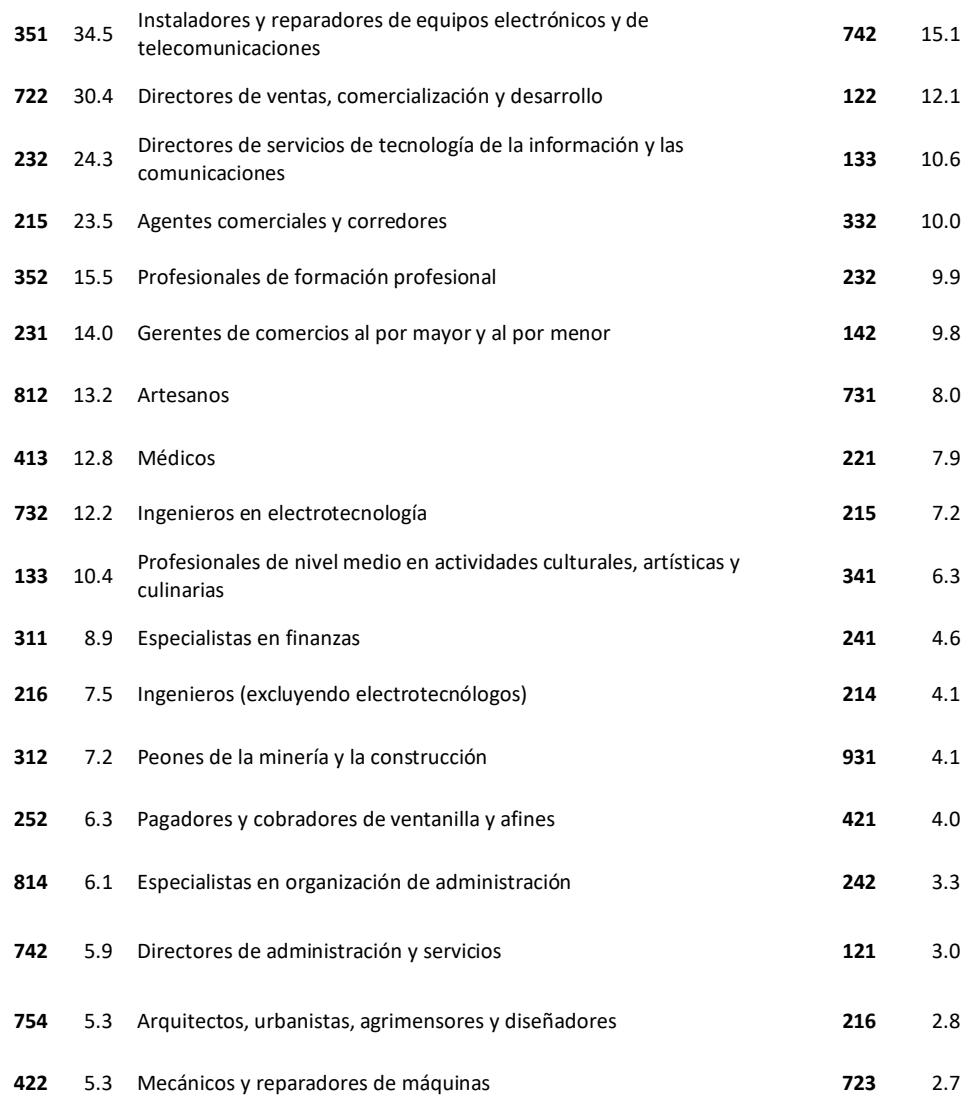

$211 \quad 11.5$ Ingenieros (excluyendo electrotecnólogos)

23210.2 Profesionales de las ventas, la comercialización y las relaciones públicas

$243 \quad 12.2$

$732 \quad 12.1$

26410.0 Oficiales y operarios de las artes gráficas

$216 \quad 11.7$

$351 \quad 10.4$

$731 \quad 7.8$

$132 \quad 7.5$ Artesanos

$311 \quad 7.4$ 
Pagadores y cobradores de ventanilla y afines

Agentes comerciales y corredores

Profesionales en derecho

Profesionales de nivel medio en operaciones financieras y administrativas

Profesores de enseñanza secundaria

Oficinistas generales

\section{Países Bajos}

Desarrolladores y analistas de software y multimedia

Ingenieros en electrotecnología

Especialistas en bases de datos y en redes de computadoras

Ingenieros (excluyendo electrotecnólogos)

Directores de servicios de tecnología de la información y las comunicaciones

Instaladores y reparadores de equipos electrónicos y de telecomunicaciones

Arquitectos, urbanistas, agrimensores y diseñadores

Técnicos y controladores en navegación marítima y aeronáutica

Profesionales de nivel medio en actividades culturales, artísticas y culinarias

Herreros, herramentistas $y$ afines

Técnicos en operaciones de tecnología de la información y las comunicaciones y asistencia al usuario

Oficiales y operarios del tratamiento de la madera, ebanistas y afines

Profesionales en ciencias biológicas

Técnicos en control de procesos

Técnicos medicos y farmacéuticos

Directores de administración y servicios

Otros gerentes de servicios

Gerentes de comercios al por mayor y al por meno

Directores generals y gerentes generales

Especialistas en organización de administración

Polonia

Matemáticos, actuarios y estadísticos

Desarrolladores y analistas de software y multimedia

Directores de servicios de tecnología de la información y las comunicaciones

Técnicos en operaciones de tecnología de la información y las comunicaciones y asistencia al usuario
4216.5 Agentes de la administración pública para la aplicación de la ley y afines

$335 \quad 5.7$

$332 \quad 6.2$ Otros operadores de máquinas y de instalaciones fijas

2615.8 Directores de industrias manufactureras, de minería, construcción y distribución

3315.5 Operadores de instalaciones de procesamiento y recubridoras de

\section{Noruega}

25157.3 Desarrolladores $y$ analistas de software y multimedia

21526.5 Supervisores en ingeniería de minas, de industrias manufactureras y de la construcción

$312 \quad 38.6$

$252 \quad 25.3$ Profesionales en ciencias biológicas

$213 \quad 32.1$

214 18.4 Operadores de instalaciones de procesamiento y recubridoras de

$812 \quad 21.1$

133 Técnicos en operaciones de tecnología de la información y las

comunicaciones y asistencia al usuario

$742 \quad 17.8$ Directores de servicios de tecnología de la información y las comunicaciones

$216 \quad 16.4$ Agentes de servicios comerciales

31514.9 Agentes de la administración pública para la aplicación de la ley y afines

$343 \quad$ 13.6 Empleados de servicios de información al cliente

$722 \quad 12.0$ Operadores de instalaciones y máquinas de productos químicos y

$813 \quad 9.4$

$351 \quad 11.3$ Técnicos en ciencias físicas y la ingeniería de nivel medio

$311 \quad 6.8$

$752 \quad 11.1$ Otras ocupaciones elementales

$962 \quad 5.7$

2139.8 Gerentes de comercios al por mayor y al por menor

$142 \quad 5.6$

3139.0 Operadores de máquinas para elaborar alimentos y productos afines

3217.9 Directores de industrias manufactureras, de minería, construcción y distribución

$132 \quad 4.3$

1216.6 Conductores de automóviles, camionetas y motocicletas

$832 \quad 3.6$

1436.3 Mecánicos y reparadores de máquinas

$723 \quad 3.4$

1425.6 Profesores de Universidad y de educación superior

$231 \quad 3.1$

1125.1 Camareros

$513 \quad 3.0$

2424.3 Ingenieros (excluyendo electrotecnólogos)

\section{República Eslovaca}

CIUO 
Otros oficiales, operarios y artesanos de artes mecánicas y de otros oficios

Agentes de servicios comerciales

Profesores de formación profesional

Profesores de universidades y de la educación superior

Empleados de servicios de información al cliente

Desarrolladores y analistas de software y multimedia

Directores de ventas, comercialización y desarrollo

Operadores de máquinas de oficina

Herreros, herramentistas y afines

Otros vendedores

Ingenieros (excluyendo electrotecnólogos)

Oficinistas generales

Agentes comerciales y corredores

Directores de industrias manufactureras, de minería, construcción y distribución

Operadores de máquinas para fabricar productos de caucho, de papel y de material plástico

Mecánicos y reparadores de máquinas

Intensidad de especialistas en TIC

España

Suecia

CIUO

25186.8 Desarrolladores y analistas de software y multimedia

21253.7 Técnicos en telecomunicaciones y radiodifusión

$214 \quad 48.5$ Ingenieros en electrotecnología

35138.4 Herreros, herramentistas $y$ afines

$731 \quad 22.3 \quad$ Artesanos

81216.8 Físicos, químicos y afines

311 Técnicos en operaciones de tecnología de la información y las comunicaciones y asistencia al usuario

Técnicos en ciencias físicas y en ingeniería

Otros oficiales, operarios y artesanos de artes mecánicas y de otros oficios

Oficiales y operarios de las artes gráficas

Especialistas en finanzas

Directores de servicios de tecnología de la información y las comunicaciones

Desarrolladores y analistas de software y multimedia

Pagadores y cobradores de ventanilla y afines

Técnicos médicos y farmacéuticos

Directores de ventas, comercialización y desarrollo

Profesores de Universidad y de educación superior

Oficinistas generales
$754 \quad 21.1$ Ingenieros (excluyendo electrotecnólogos)
CIUO

$251 \quad 56.4$

$352 \quad 24.6$

$215 \quad 19.5$

$722 \quad 18.6$

$731 \quad 15.1$

$211 \quad 14.6$

$351 \quad 11.1$

$\begin{array}{ll}742 & 9.4\end{array}$

$213 \quad 8.5$

$232 \quad 7.7$

$821 \quad 7.6$

$231 \quad 7.3$

$311 \quad 5.2$

$\begin{array}{ll}712 & 4.7\end{array}$

$216 \quad 4.4$

$134 \quad 4.1$

$241 \quad 3.7$ 
Profesores de enseñanza secundaria

Médicos

Moldeadores, soldadores, chapistas, montadores de estructuras

Inglaterra / Irlanda del Norte (UK)

Desarrolladores y análisis de software y multimedia

Técnicos en operaciones de tecnología de la información y las comunicaciones y asistencia al usuario

Directores de servicios de tecnología de la información y las comunicaciones

Arquitectos, urbanistas, agrimensores y diseñadores

Instaladores y reparadores de equipos electrónicos y telecomunicaciones

Especialistas en bases de datos y en redes de computadoras

Profesionales de las ventas, la comercialización y las relaciones públicas

Herreros, herramentistas y afines

Técnicos médicos y farmacéuticos

Físicos, químicos y afines

Especialistas en organización de administración

Profesionales de nivel medio en actividades culturales, artísticas y culinarias

Empleados de servicios de información al cliente

Directores de administración y servicios

Técnicos en ciencias físicas y en ingeniería

Profesores de Universidad y de educación superior

Directores de industrias manufactureras, de minería, construcción y distribución

Pagadores y cobradores de ventanilla y afines

Profesionales en ciencias biológicas

Profesionales de nivel medio en finanzas y matemáticas
2336.2 Supervisores de mantenimiento y limpieza de edificios

\section{Estados Unidos}

ClUO

25155.7 Desarrolladores $y$ analistas de software y multimedia

35130.2 Directores de servicios de tecnología de la información

$133 \quad 26.7$ Especialistas en bases de datos y en redes de computadoras

21619.0 Técnicos en operaciones de tecnología de la información

$351 \quad 32.2$

74218.5 Profesores de formación profesional

25216.1 Ingenieros en electrotecnología

$243 \quad 16.0$ Herreros, herramentistas $y$ afines

$722 \quad 14.1$

$722 \quad 15.6$ Otros gerentes de servicios

$143 \quad 11.0$

$321 \quad 11.5$ Pagadores y cobradores de ventanilla y afines

$421 \quad 10.0$

2119.1 Otros oficiales, operarios y artesanos de artes mecánicas y de otros oficios

$754 \quad 8.8$

2428.6 Oficinistas generales

4118.5

3438.0 Otros profesionales de nivel medio de medicina tradicional

$325 \quad 7.9$

4226.9 Agricultores y trabajadores calificados de jardines y de cultivos para el mercado

$611 \quad 7.7$

$\begin{array}{lllll}121 & 6.3 & \text { Especialistas en organización de administración } & 242 & 7.5\end{array}$

3115.0 Ingenieros (excluyendo electrotecnólogos)

$214 \quad 7.2$

2314.3 Operadores de máquinas de oficina

$413 \quad 6.9$

1324.0 Moldeadores, soldadores, chapistas, montadores de estructuras

$721 \quad 6.7$

4213.5 Instaladores y reparadores de equipos eléctricos

$741 \quad 5.9$

2133.4 Otro personal de apoyo administrativo

$441 \quad 5.7$

$331 \quad 3.3$ Técnicos en control de procesos

Nota: Australia y Finlandia solamente están disponibles en el nivel de 2 dígitos.

Fuente: OCDE, con base en datos del PIAAC Database, octubre 2015. 
ANEXO C1. Tablas de correlación de pares basadas en el PIAAC en grupos del CIUO de 1 dígito (CBI), 2012.

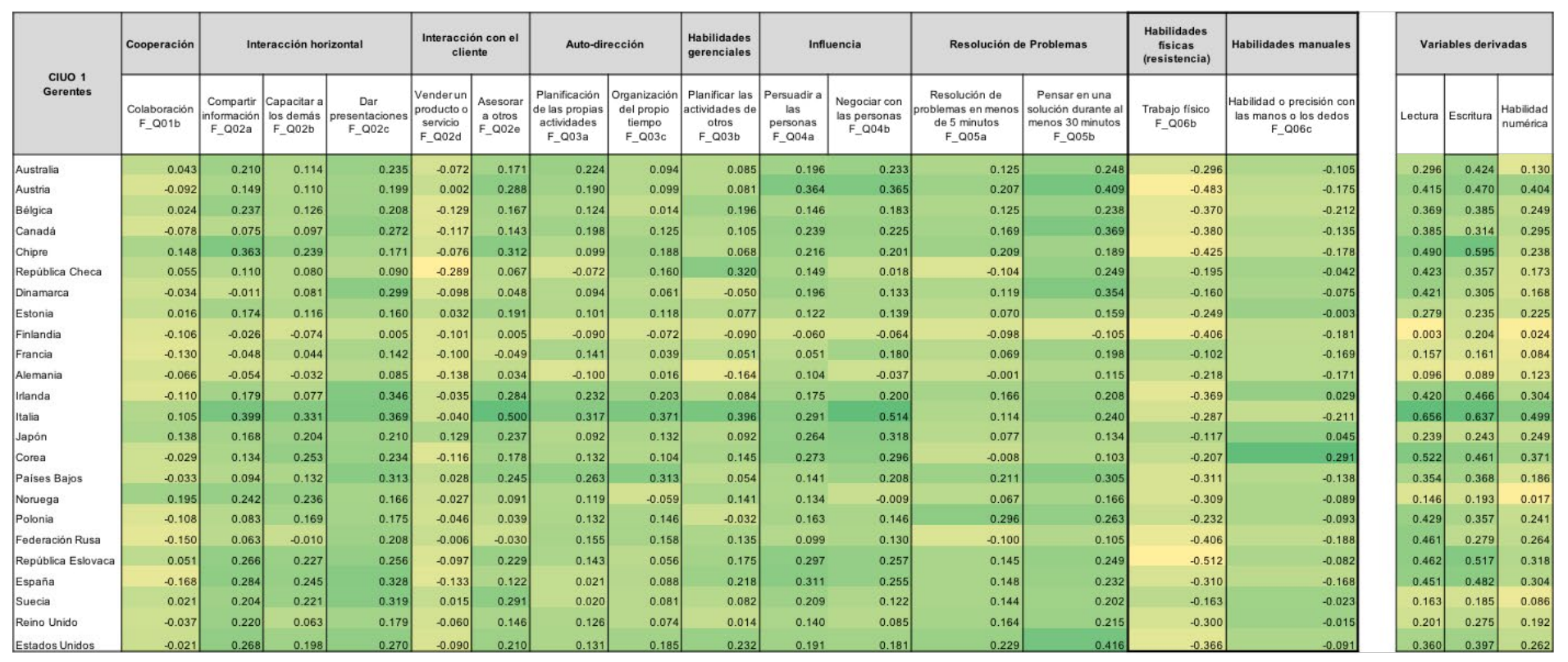

El código de colores refleja el significado de los coeficientes. El amarillo intenso indica coeficientes negativos fuertes y el verde oscuro indica coeficientes positivos fuertes. Nota: Para Chipre, véase la nota de la Figura 5. 


\begin{tabular}{|c|c|c|c|c|c|c|c|c|c|c|c|c|c|c|c|}
\hline \multirow{2}{*}{$\begin{array}{l}\text { Clvo } 2 \\
\text { Profesionales }\end{array}$} & \multirow{2}{*}{$\begin{array}{c}\text { Cooperación } \\
\begin{array}{c}\text { Colaboración } \\
\text { F_001b }\end{array}\end{array}$} & \multicolumn{3}{|c|}{ Interacción horizontal } & \multicolumn{2}{|c|}{$\begin{array}{c}\text { Interacción con el } \\
\text { cliente }\end{array}$} & \multicolumn{2}{|c|}{ Auto-dirección } & \multirow{2}{*}{\begin{tabular}{|c|}
$\begin{array}{c}\text { Habilidades } \\
\text { gerenciales }\end{array}$ \\
$\begin{array}{c}\text { Planificar las } \\
\text { actividades dos de } \\
\text { fotros } \\
F_{-} 003 b\end{array}$
\end{tabular}} & \multicolumn{2}{|c|}{ Influencia } & \multicolumn{2}{|c|}{ Resolución de Problemas } & \multirow{2}{*}{$\begin{array}{c}\begin{array}{c}\text { Habilitades } \\
\text { (risicases } \\
\text { (resistencia) }\end{array} \\
\begin{array}{c}\text { Trabajoj fisico } \\
\text { F_006b }\end{array}\end{array}$} & \multirow{2}{*}{ 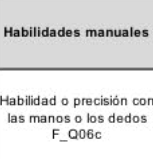 } \\
\hline & & 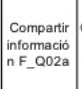 & 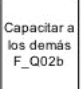 & $\begin{array}{c}\text { Dar } \\
\text { resestatacion } \\
F_{-} \text {- } 022 c\end{array}$ & 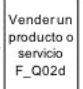 & $\begin{array}{l}\text { Asesorar } \\
\text { a ouros } \\
F_{-} \text {-0.2e }\end{array}$ & $\begin{array}{l}\text { Planificación } \\
\text { de alas propias } \\
\text { actividades } \\
\text { F_aouas }\end{array}$ & \begin{tabular}{|c} 
Organización \\
del propio \\
tiempo \\
$F_{-} 003 c$
\end{tabular} & & 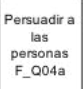 & 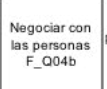 & $\begin{array}{l}\text { Resolución de } \\
\text { obblemasen mentos } \\
\text { de } 5 \text { minutos } \\
\text { F_aiosa }\end{array}$ & \begin{tabular}{|c} 
Pensar en una \\
solucior durante al \\
menos 30 minutos \\
F_a $205 \mathrm{~b}$
\end{tabular} & & \\
\hline Australa & -0.046 & 0.076 & 0.019 & 0.144 & 0.090 & -0.016 & 0.180 & 0.245 & 0.037 & 0.065 & 0.030 & 0.079 & 0.163 & -0.210 & 0.040 \\
\hline Austria & -0.006 & 0.070 & 0.005 & -0.042 & 0.154 & 0.162 & 0.087 & 0.246 & 0.092 & 0.043 & 0.230 & 0.087 & 0.284 & -0.322 & -0.182 \\
\hline Bélgica & -0.081 & 0.109 & -0.033 & 0.117 & 0.089 & 0.113 & 0.157 & 0.126 & 0.142 & 0.101 & 0.119 & 0.046 & 0.233 & -0.341 & -0.215 \\
\hline Canadá & -0.038 & 0.147 & -0.030 & 0.109 & 0.104 & 0.076 & 0.175 & 0.214 & -0.021 & 0.044 & 0.122 & 0.103 & 0.290 & -0.307 & \\
\hline Chipre & 0.016 & 0.100 & 0.042 & 0.066 & 0.095 & 0.035 & 0.029 & 0.072 & 0.140 & 0.124 & 0.182 & 0.129 & 0.243 & -0.226 & \\
\hline Repúbica Checa & -0.090 & 0.115 & -0.079 & -0.011 & 0.142 & -0.132 & 0.012 & 0.025 & 0.031 & -0.033 & 0.169 & -0.007 & 0.317 & -0.322 & -0.162 \\
\hline Dinamarca & -0.109 & 0.104 & 0.062 & 0.142 & 0.137 & 0.162 & 0.219 & 0.268 & 0.092 & 0.106 & 0.165 & 0.090 & 0.236 & -0.350 & -0.123 \\
\hline Estonia & -0.009 & 0.154 & 0.075 & 0.050 & 0.065 & 0.112 & 0.195 & 0.238 & 0.071 & 0.054 & 0.129 & 0.154 & 0.252 & -0.149 & -0.051 \\
\hline Finlandia & -0.067 & 0.090 & 0.012 & 0.134 & 0.109 & 0.130 & 0.089 & 0.166 & 0.060 & 0.083 & 0.128 & 0.049 & 0.121 & -0.285 & -0.183 \\
\hline Francia & 0.030 & 0.193 & -0.086 & -0.048 & 0.078 & -0.003 & 0.115 & 0.142 & 0.012 & 0.098 & 0.1 & 0.072 & 0.168 & -0.256 & \\
\hline Alemania & 0.079 & 0.165 & -0.178 & -0.117 & 0.094 & 0.094 & 0.055 & 0.270 & 0.046 & 0.053 & 0.218 & 0.025 & 0.307 & -0.168 & -0.135 \\
\hline Iranda & -0.014 & 0.100 & 0.011 & 0.163 & 0.104 & 0.073 & 0.256 & 0.247 & 0.036 & 0.043 & 0.138 & 0.174 & 0.285 & -0.302 & -0.137 \\
\hline Italia & 0.042 & 0.115 & -0.172 & -0.173 & 0.256 & 0.123 & 0.190 & 0.225 & 0.121 & 0.163 & 0.458 & 0.206 & 0.383 & -0.241 & -0.050 \\
\hline Japón & -0.174 & 0.075 & 0.118 & 0.175 & 0.176 & 0.032 & 0.077 & 0.160 & 0.130 & 0.063 & 0.300 & 0.125 & 0.245 & -0.268 & -0.089 \\
\hline Corea & 0.042 & 0.262 & 0.026 & 0.123 & 0.015 & 0.156 & 0.158 & 0.209 & 0.151 & 0.212 & 0.298 & 0.187 & 0.382 & -0.063 & 0.174 \\
\hline Paises Bajos & -0.080 & 0.171 & 0.061 & 0.176 & 0.054 & 0.149 & 0.203 & 0.181 & 0.101 & 0.147 & 0.174 & 0.268 & 0.331 & -0.217 & -0.091 \\
\hline Noruga & -0.136 & 0.098 & 0.046 & 0.086 & 0.033 & 0.046 & 0.216 & 0.237 & 0.000 & 0.070 & 0.0 & 0.058 & 0.233 & 274 & \\
\hline Polonia & 0.062 & 0.102 & -0.055 & -0.085 & 0.160 & 0.036 & 0.175 & 0.150 & 0.078 & 0.003 & 0.297 & 0.073 & 0.274 & 228 & -0.031 \\
\hline Federación Rusa & 0.030 & 0.121 & 0.070 & 0.113 & 0.082 & 0.028 & 0.131 & 0.099 & 0.130 & 0.077 & 0.205 & 0.0 & 0.164 & & -0.148 \\
\hline República Eslovaca & 0.140 & 0.082 & -0.145 & -0.126 & 0.106 & 0.127 & 0.137 & 0.195 & 6 & 0.084 & 0.241 & 0.13 & 0.325 & -0.195 & 0.031 \\
\hline Espaaña & 0.005 & 0.135 & -0.121 & 0.011 & 0.128 & 0.153 & 0.096 & 0.101 & 0.055[ & 0.009 & 0.172 & 0.089 & 0.193 & - -0.147 & -0.125 \\
\hline Suecia & - 0.180 & 0.085 & -0.083 & 0.066 & 0.060 & 0.067 & 0.173 & 0.198 & 0.060 & 0.020 & 0.096 & 0.002 & 0.201 & -0.293 & -0.171 \\
\hline Reino Unido & 0.045 & 0.218 & -0.047 & -0.008 & 0.048 & 0.084 & 0.163 & 0.205 & 0.025 & 0.127 & 0.126 & 0.155 & 0.275 & -0.142 & -0.001 \\
\hline tados & 0.002 & 152] & & & & & 0.224 & & & 0.027 & 1 & & & & \\
\hline
\end{tabular}

\begin{tabular}{|c|c|c|}
\hline \multicolumn{3}{|c|}{ Variables derivadas } \\
\hline actura & Escritura & Habisidad \\
\hline 0.264 & & \\
\hline 0.322 & 0.316 & 0.351 \\
\hline 0.353 & 0.237 & 0.164 \\
\hline & 0.226 & 0.228 \\
\hline 0.474 & 0.246 & 0.221 \\
\hline 0.310 & 0.289 & 0.262 \\
\hline 0.418 & 0.308 & 0.308 \\
\hline 0.301 & 0.231 & 0.226 \\
\hline 0.252 & 0.301 & 0.198 \\
\hline 0.238 & 0.226 & 0.205 \\
\hline 0.258 & 0.249 & 0.307 \\
\hline & 0.251 & 0.254 \\
\hline 0.4077 & 0.413 & 0.350 \\
\hline 0.398 & 0.267 & 0.34 \\
\hline 0.413$\}$ & 0.410 & 0.225 \\
\hline 0.3966 & 0.298 & 0.151 \\
\hline 0.303 & 0.216 & 0.178 \\
\hline & 0.200 & 0.300 \\
\hline 0.4 & 0.363 & 0.291 \\
\hline 0.36 & 0.380 & 349 \\
\hline 0.2 & 0.263 & 0.205 \\
\hline 0.2 & 0.286 & 0.16 \\
\hline 0.193 & 0.242 & . \\
\hline
\end{tabular}

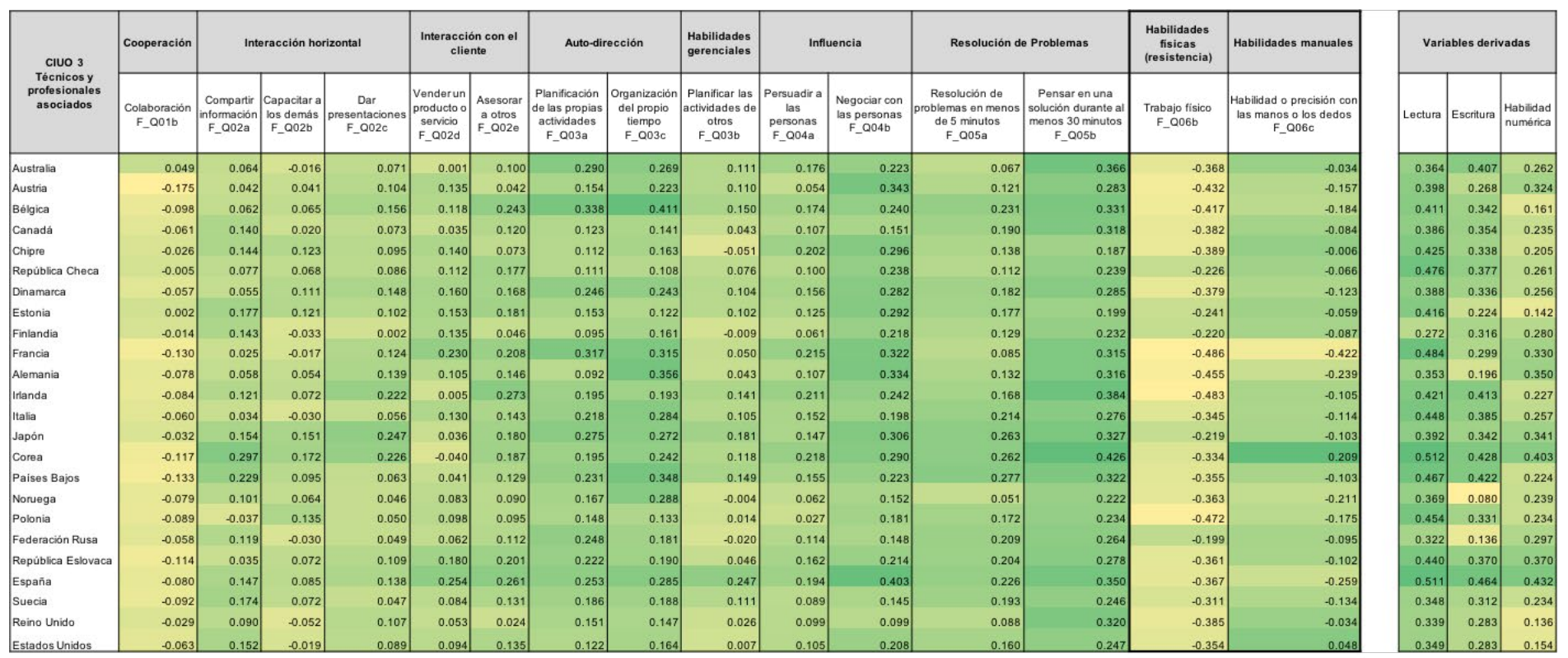

El código de colores refleja el significado de los coeficientes. El amarillo intenso indica coeficientes negativos fuertes y el verde oscuro indica coeficientes positivos fuertes. Nota: Para Chipre, véase la nota de la Figura 5. 


\begin{tabular}{|c|c|c|c|c|c|c|c|c|c|c|c|c|c|c|c|c|c|c|}
\hline \multirow{2}{*}{ 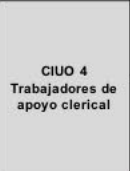 } & \multirow{2}{*}{\begin{tabular}{|c} 
Cooperación \\
$\begin{array}{c}\text { Colaboración } \\
F_{-} 0016\end{array}$
\end{tabular}} & \multicolumn{3}{|c|}{ Interacción horizontal } & \multicolumn{2}{|c|}{$\begin{array}{l}\text { Interacción con el } \\
\text { cliente }\end{array}$} & \multicolumn{2}{|c|}{ Auto-dirección } & \multirow{2}{*}{ 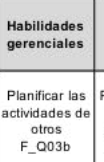 } & \multicolumn{2}{|c|}{ Influencia } & \multicolumn{2}{|c|}{ Resolución de Problemas } & \multirow{2}{*}{ 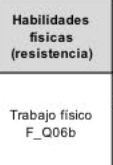 } & \multirow{2}{*}{ 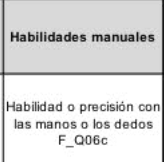 } & \multicolumn{3}{|c|}{ Variables derivadas } \\
\hline & & $\begin{array}{l}\text { compartit } \\
\text { intromacio } \\
\text { n F }-002 a\end{array}$ & 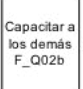 & $\begin{array}{l}\text { Dar } \\
\text { esontaciones } \\
F_{-} 002 c\end{array}$ & 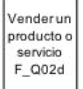 & $\begin{array}{c}\text { Asesororar } \\
\text { a atros } \\
F_{-} 002 \theta \\
\end{array}$ & \begin{tabular}{|c} 
Planificación \\
de alas propias \\
actividades \\
F_a03a
\end{tabular} & \begin{tabular}{|c|} 
Organizacaion \\
del propio \\
tiempo \\
F_a03c
\end{tabular} & & $\begin{array}{c}\text { Persuadira } \\
\text { las } \\
\text { personas } \\
F_{-} 0 \text { Oo4a }\end{array}$ & 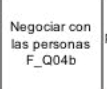 & $\begin{array}{l}\text { Resolución de } \\
\text { robolemas on menos } \\
\text { de } 5 \text { minutos } \\
\text { F_a } 005 \mathrm{a}\end{array}$ & \begin{tabular}{|c|} 
Pensar en una \\
solucion durante al \\
menos 30 minutos \\
F_a Q055b
\end{tabular} & & & Lectura & Scctitur & 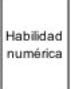 \\
\hline Australa & 0.152 & 0.386 & 0.206 & 0.140 & 0.074 & 0.356 & 0.280 & 0.388 & 0.149 & 0.178 & 0.300 & 0.387 & 0.387 & -0.109 & & 0.420 & 0.433 & \\
\hline Austria & 0.034 & 0.268 & 0.158 & 0.156 & 0.210 & 0.279 & 0.274 & 0.237 & 0.202 & 0.200 & 0.261 & 0.279 & 0.325 & -0.391 & 0.007 & 0.484 & 0.345 & 0.284 \\
\hline Bélgica & -0.058 & 0.112 & 0.052 & 0.180 & 0.174 & 0.280 & 0.318 & 0.283 & 0.173 & 0.277 & 0.285 & 0.238 & 0.310 & -0.565 & -0.199 & 0.540 & 0.435 & 0.309 \\
\hline Canadá & 0.044 & 0.127 & 0.098 & 0.054 & 0.014 & 0.203 & 0.212 & 0.197 & 0.148 & 0.118 & 0.211 & 0.221 & 0.291 & -0.361 & -0.058 & 0.393 & 0.377 & 0.181 \\
\hline Chipre & 0.032 & 0.121 & 0.208 & 0.185 & 0.021 & 0.127 & 0.094 & 0.130 & 0.055 & 0.255 & 0.222 & 0.223 & 0.193 & -0.253 & 0.098 & 0.461 & 0.373 & 0.215 \\
\hline República Checa & -0.002 & 0.041 & 0.198 & 0.096 & -0.109 & -0.023 & 0.148 & 0.261 & 0.153 & -0.060 & 0.063 & -0.036 & 0.173 & -0.308 & -0.121 & 0.430 & 0.418 & 0.280 \\
\hline Dinamarca & 0.254 & 0.268 & 0.244 & 0.217 & 0.152 & 0.313 & 0.329 & 0.209 & 0.203 & 0.362 & 0.295 & 0.401 & 0.412 & -0.326 & & 0.552 & 0.472 & 0.195 \\
\hline Estonia & -0.024 & 0.083 & 0.143 & 0.082 & 0.322 & 0.310 & 0.133 & 0.141 & 0.024 & 0.217 & 0.275 & 0.340 & 0.316 & -0.381 & & 0.580 & 0.359 & 0.350 \\
\hline Finlandia & 0.020 & 0.187 & 0.194 & 0.192 & 0.129 & 0.306 & 0.334 & 0.199 & 0.100 & 0.202 & 0.298 & 0.227 & 0.270 & -0.471 & & 0.457 & 0.404 & 0.279 \\
\hline Francia & 0.126 & 0.289 & 0.123 & 0.155 & -0.047 & 0.060 & 0.393 & 0.376 & 0.168 & 0.145 & 0.167 & 0.244 & 0.299 & -0.226 & -0.107 & 0.388 & 0.282 & 0.271 \\
\hline Alemania & 0.048 & 0.170 & 0.140 & 0.165 & 0.145 & 0.237 & 0.172 & 0.261 & 0.188 & 0.209 & 0.267 & 0.233 & 0.336 & -0.468 & -0.055 & 0.456 & 0.359 & 0.261 \\
\hline Iranda & -0.050 & 0.200 & 0.003 & 0.079 & -0.063 & 0.098 & 0.121 & 0.142 & -0.040 & 0.075 & 0.139 & 0.135 & 0.136 & -0.428 & 0.090 & 0.403 & 0.307 & 0.163 \\
\hline |talia & 0.006 & 0.178 & 0.118 & 0.092 & 0.098 & 0.087 & 0.365 & 0.299 & 0.175 & 0.190 & 0.193 & 0.211 & 0.312 & -0.484 & -0.1 & 0.469 & 0.434 & \\
\hline Japón & 0.002 & 0.137 & 0.136 & 0.239 & -0.010 & 0.217 & 0.255 & 0.250 & 0.186 & 0.173 & 0.2 & 0.238 & 0.250 & -0.116 & & 0.410 & 0.328 & 0.233 \\
\hline Corea & 0.070 & 0.267 & 0.190 & 0.168 & -0.003 & 0.177 & 0.242 & 0.258 & 0.126 & 0.207 & 0.223 & 0.248 & 0.309 & -0.128 & 0.2 & 0.374 & 0.468 & 0.358 \\
\hline Paises Bajos & 0.097 & 0.302 & 0.142 & 0.163 & 0.128 & 0.310 & 0.310 & 0.349 & 0.276 & 0.290 & 0.269 & 0.306 & 0.342 & -0.517 & -0.055 & 0.504 & 0.380 & 0.205 \\
\hline Polonia & 0.024 & 0.130 & 0.113 & 0.179 & -0.031 & 0.159 & 0.188 & 0.296 & 0.059 & 0.099 & 0.200 & 0.208 & 0.226 & -0.422 & -0.143 & 0.467 & 0.416 & \\
\hline Federación Rusa & 0.363 & 0.161 & 0.281 & 0.199 & 0.043 & 0.267 & 0.280 & 0.286 & 0.146 & 0.284 & 0.276 & 0.409 & 0.308 & -0.221 & 0.090 & 0.499 & 0.365 & 0.211 \\
\hline Repúbica Esto & 0.100 & 0.162 & 0.067 & 0.021 & -0.091 & 0.039 & 0.294 & 0.252 & 0.084 & 0.025 & 0.1 & 0.195 & 0.241 & -0.5 & & 0.432 & 0.406 & 0.345 \\
\hline Españáa & -0.039 & 0.131 & 0.133 & 0.126 & 0.158 & 0.313 & 0.350 & 0.363 & 0.209 & 0.230 & & 0.294 & & $-0.48 \mathrm{r}$ & & 0.428 & 0.430 & \\
\hline Suecia & -0.011 & 0.117 & 0.278 & 0.133 & -0.145 & 0.218 & 0.106 & 0.084 & 0.103 & 0.215 & & 0.184 & 0.333 & -0.449 & & 0.396 & 0.270 & 0.377 \\
\hline Reino Unido & 0.048 & 0.239 & 0.173 & 0.175 & -0.078 & 0.192 & 0.252 & 0.337 & 0.174 & 0.192 & 0.197 & 0.253 & 0.390 & -0.213 & 0.101 & 0.267 & 0.423 & 0.203 \\
\hline Estados Unidos & 0.098 & 0.231 & 0.051 & 0.004 & 0.042 & 0.177 & -0.055 & $0.053]$ & 0.052 & 0.164 & 0.117 & 0.249 & 0.269 & -0.124 & 0.218 & 0.363 & 0.237 & 0.17 \\
\hline
\end{tabular}

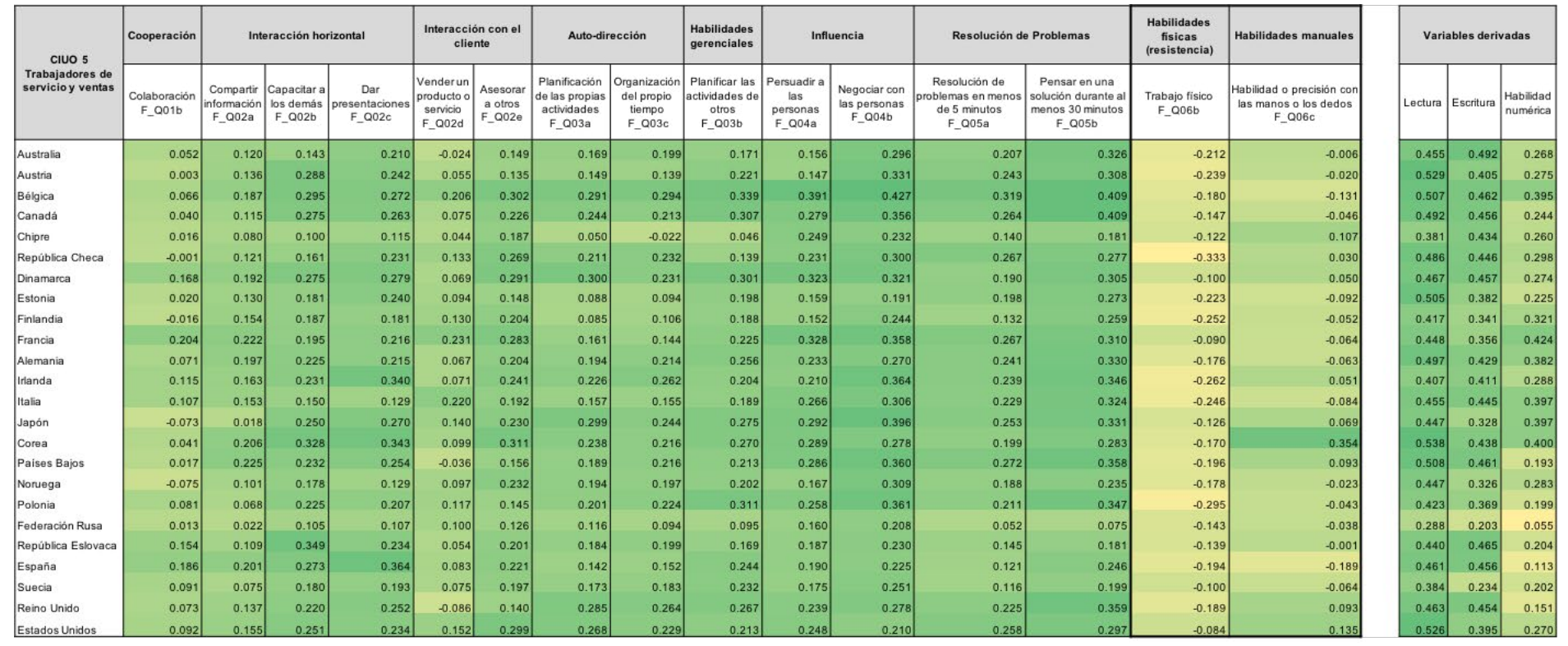

El código de colores refleja el significado de los coeficientes. El amarillo intenso indica coeficientes negativos fuertes y el verde oscuro indica coeficientes positivos fuertes. Nota: Para Chipre, véase la nota de la Figura 5. 


\begin{tabular}{|c|c|c|c|c|c|c|c|c|c|c|c|c|c|c|c|c|c|c|}
\hline \multirow{2}{*}{$\begin{array}{l}\text { CluO } 6 \\
\text { Trabajadores } \\
\text { agricolas, } \\
\text { forestales y } \\
\text { pesqueros } \\
\text { calificados }\end{array}$} & \multirow{2}{*}{\begin{tabular}{|l} 
Cooperación \\
$\begin{array}{c}\text { Colaboración } \\
F_{-} \text {Q0110 }\end{array}$
\end{tabular}} & \multicolumn{3}{|c|}{ Interacción horizontal } & \multicolumn{2}{|c|}{$\begin{array}{c}\text { Interaccion con el } \\
\text { cliente }\end{array}$} & \multicolumn{2}{|c|}{ Auto-dirección } & \multirow{2}{*}{\begin{tabular}{|l}
$\begin{array}{c}\text { Aabilidadades } \\
\text { gerenciales }\end{array}$ \\
$\begin{array}{c}\text { Planificar las } \\
\text { attividades de } \\
\text { otros } \\
F_{-} 003 b\end{array}$ \\
\end{tabular}} & \multicolumn{2}{|c|}{ Influencia } & \multicolumn{2}{|c|}{ Resolución de Problemas } & \multirow{2}{*}{ 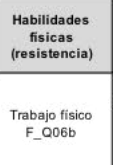 } & \multirow{2}{*}{ 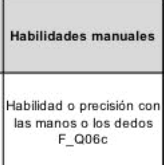 } & \multicolumn{3}{|c|}{ Variables derivadas } \\
\hline & & 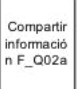 & 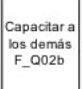 & $\begin{array}{c}\text { Dar } \\
\text { resentaciones } \\
F_{-}-022 c\end{array}$ & 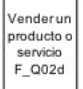 & $\begin{array}{l}\text { Asesorar } \\
\text { a torros } \\
F_{-} 002 e \\
\end{array}$ & \begin{tabular}{|c} 
Planificación \\
de alis propias \\
actividades \\
F_a03a
\end{tabular} & \begin{tabular}{|c|} 
Organizacaion \\
del propio \\
tiempo \\
F_a03c
\end{tabular} & & $\begin{array}{c}\text { Persuadira } \\
\text { las } \\
\text { personas } \\
F_{-} 0 \text { Oo4a }\end{array}$ & $\begin{array}{c}\text { Negociar con } \\
\text { las portsonas } \\
\text { F_-004b }\end{array}$ & $\begin{array}{l}\text { Resolución de } \\
\text { problemas on menos } \\
\text { de } 5 \text { minutos } \\
\text { F_a } 005 \mathrm{a}\end{array}$ & \begin{tabular}{|c|} 
Pensar en una \\
solucion durante al \\
menos 30 minutos \\
F_a Q055
\end{tabular} & & & Lectura & Escritu & 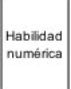 \\
\hline Australa & 0.079 & 0.106 & 0.190 & 0.305 & 0.327 & 0.165 & 0.320 & 0.264 & 0.439 & 0.278 & 0.398 & 0.214 & 0.235 & -0.109 & -0.007 & 0.448 & 0.414 & \\
\hline Austria & -0.021 & 0.047 & 0.128 & 0.458 & 0.307 & 0.253 & 0.132 & 0.125 & 0.288 & 0.244 & 0.190 & 0.070 & 0.122 & -0.059 & 0.049 & 0.417 & 0.344 & 0.359 \\
\hline Bélgica & -0.104 & 0.016 & 0.121 & 0.037 & 0.196 & 0.014 & 0.120 & 0.199 & -0.081 & 0.039 & 0.022 & 0.127 & 0.279 & -0.108 & -0.190 & 0.205 & 0.101 & 0.199 \\
\hline Canadá & 0.112 & 0.028 & 0.046 & 0.115 & 0.205 & 0.111 & 0.210 & 0.158 & 0.173 & 0.212 & 0.186 & 0.212 & 0.178 & 0.017 & -0.002 & 0.395 & 0.325 & 0.366 \\
\hline Chipre & -0.035 & -0.215 & 0.165 & -0.044 & -0.084 & 0.128 & -0.016 & 0.089 & 0.179 & 0.058 & 0.102 & 0.120 & 0.257 & 0.066 & -0.263 & 0.139 & $0.293]$ & 0.056 \\
\hline República Checa & 0.199 & -0.111 & 0.094 & 0.056 & 0.003 & -0.151 & 0.144 & 0.075 & 0.431 & 0.495 & 0.239 & 0.253 & 0.385 & 0.012 & -0.614 & 0.418 & 0.270 & 0.079 \\
\hline Estonia & -0.017 & 0.129 & 0.223 & 0.368 & 0.293 & 0.149 & 0.244 & 0.290 & & 0.343 & 0.435 & 0.398 & 0.278 & -0.175 & & 0.490 & 0.526 & 0.394 \\
\hline Finlandia & -0.156 | & 0.181 & 0.242 & 0.165 & 0.435 & 0.401 & 0.264 & 0.160 & 0.366 & 0.357 & 0.351 & 0.191 & 0.187 & -0.226 & 0.1 & 0.472 & 0.364 & 0.361 \\
\hline Francia & -0.162 & -0.068 & -0.156 & -0.018 & 0.313 & 0.164 & 0.231 & 0.316 & 0.196 & 0.324 & 0.358 & 0.251 & 0.185 & -0.192 & -0.007 & 0.375 & 0.280 & 0.453 \\
\hline Alemania & -0.143 & 0.265 & 0.016 & 0.222 & 0.316 & 0.073 & 0.185 & 0.209 & 0.337 & 0.409 & 0.397 & 0.130 & 0.204 & 0.026 & 0.163 & 0.329 & 0.276 & 0.437 \\
\hline Iranda & 0.057 & 0.139 & 0.180 & 0.151 & 0.015 & 0.196 & -0.033 & -0.012 & 0.184 & 0.300 & 0.162 & 0.011 & 0.120 & -0.212 & -0.0 & 0.272 & 0.288 & 0.242 \\
\hline |talia & 0.336 & 0.255 & 0.277 & 0.262 & 0.099 & 0.178 & 0.173 & 0.172 & 0.256 & 0.359 & 0.321 & 0.287 & 0.112 & 0.009 & & 0.516 & 0.394 & 0.518 \\
\hline Japón & -0.014 & -0.092 & 0.053 & 0.094 & 0.260 & -0.028 & 0.083 & 0.053 & 0.011 & -0.032 & 0.095 & 0.041 & 0.201 & -0.100 & -0.0 & 0.257 & -0.058 & 0.227 \\
\hline Corea & 0.059 & 0.147 & 0.172 & 0.209 & 0.062 & 0.146 & 0.117 & 0.200 & 0.213 & 0.190 & 0.122 & 0.266 & 0.208 & 0.004 & 0.2 & 0.279 & 0.458 & 0.422 \\
\hline Paises Bajos & -0.192 & - 0.054 & 0.229 & 0.162 & 0.240 & 0.420 & 0.348 & 0.377 & 0.252 & 0.238 & 0.556 & 0.516 & 0.414 & -0.456 & & 0.532 & 0.404 & $0.48 B$ \\
\hline Polonia & 0.097 & 0.072 & 0.083 & 0.210 & 0.089 & 0.319 & 0.099 & 0.074 & 0.127 & 0.328 & 0.376 & 0.040 & 0.212 & -0.199 & -0.055 & 0.301 & 0.482 & 0.322 \\
\hline Federación Rusa & 0.187 & 0.315 & 0.346 & 0.483 & 0.253 & 0.352 & 0.121 & -0.418 & 0.312 & 0.355 & 0.365 & -0.189 & -0.090 & -0.266 & & 0.655 & 0.729 & 0.185 \\
\hline España & 0.131 & 0.137 & -.0.004 & 0.018 & 0.071 & 0.150 & 0.136 & 0.123 & -0.052 & 0.052 & 0.2 & 0.101 & -0.00 & -0.041 & & 91 & & \\
\hline Reino Unido & 0.721 & 0.465 & 0.549 & 0.624 & 0.427 & 0.508 & 0.146 & 0.180 & 0.666 & 0.470 & 0.518 & 0.390 & 0.459 & -0.409 & 0.110 & 69 & 0.520 & 0.478 \\
\hline Estados Unidos & $-0.307 \mid$ & 0.148 & 0.088 & 0.459 & 0.482 & 0.454 & 0.168 & 0.223 & 0.275 & 0.471 & 0.554 & 0.357 & 0.380 & 0.028 & 0.051 & 0.347] & 0.6 & 0.48 \\
\hline
\end{tabular}

\begin{tabular}{|c|c|c|c|c|c|c|c|c|c|c|c|c|c|c|c|c|c|c|}
\hline \multirow{2}{*}{ 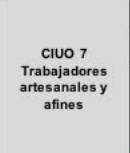 } & \multirow{2}{*}{\begin{tabular}{|c|} 
Cooperación \\
$\begin{array}{c}\text { Colaboración } \\
F_{-} \text {Q01b }\end{array}$
\end{tabular}} & \multicolumn{3}{|c|}{ Interacción horizontal } & \multicolumn{2}{|c|}{$\begin{array}{l}\text { Interacción con el } \\
\text { cliente }\end{array}$} & \multicolumn{2}{|c|}{ Auto-dirección } & \multirow{2}{*}{\begin{tabular}{|c|}
$\begin{array}{c}\text { Habilildades } \\
\text { gerenciales }\end{array}$ \\
$\begin{array}{c}\text { Planificar las } \\
\text { actividades de } \\
\text { otros } \\
F_{0} 003 \mathrm{~b}\end{array}$ \\
\end{tabular}} & \multicolumn{2}{|c|}{ Inffuencia } & \multicolumn{2}{|c|}{ Resolución de Problemas } & \multirow{2}{*}{ 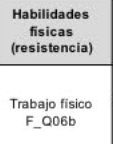 } & \multirow{2}{*}{ 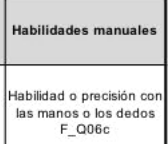 } & \multicolumn{3}{|c|}{ Variables derivadas } \\
\hline & & $\begin{array}{l}\text { compartifi } \\
\text { intromacion } \\
F_{-} \text {-ao2a }\end{array}$ & 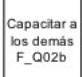 & $\begin{array}{l}\text { Dar } \\
\text { esentacines } \\
F_{-} 0022 c\end{array}$ & 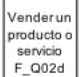 & $\mid \begin{array}{l}\text { Asesorar } \\
\text { a ouros } \\
F_{-} 0020\end{array}$ & 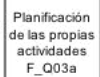 & $\begin{array}{c}\text { Organizacaion } \\
\text { del prepoi } \\
\text { tiempo } \\
F_{-} 0.03 c\end{array}$ & & $\begin{array}{c}\text { Persuadira } \\
\text { las } \\
\text { personas } \\
\text { penoua }_{\text {F }}\end{array}$ & 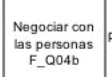 & $\begin{array}{l}\text { Resolución de } \\
\text { robimas an menos } \\
\text { de } 5 \text { minutos } \\
\text { F_aosa }\end{array}$ & 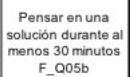 & & & Lectura & Escritura & 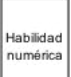 \\
\hline Australa & 0.097 & 0.104 & 0.205 & 0.270 & 0.212 & 0.302 & 0.112 & 0.207 & 0.264 & 0.264 & 0.305 & 0.161 & 0.245 & -0.310 & & 0.491 & 0.483 & \\
\hline Austria & -0.160 & 0.093 & 0.299 & 0.361 & 0.266 & 0.331 & 0.208 & 0.234 & 0.321 & 0.401 & 0.416 & 0.164 & 0.286 & -0.450 & -0.3 & 0.487 & 0.525 & 0.28 \\
\hline Bélgica & -0.128 & -0.005 & 0.136 & 0.230 & 0.272 & 0.300 & 0.354 & 0.297 & 0.288 & 0.347 & 0.402 & 0.237 & 0.285 & -0.253 & -0.0 & 0.536 & 0.400 & 0.359 \\
\hline Canadá & -0.014 & 0.002 & 0.107 & 0.213 & 0.240 & 0.267 & 0.154 & 0.180 & 0.150 & 0.244 & 0.284 & 0.115 & 0.320 & -0.283 & -0.148 & 0.486 & 0.474 & 0.233 \\
\hline Chipre & -0.201 & -0.132 & 0.015 & 0.037 & 0.122 & 0.001 & 0.008 & 0.195 & -0.008 & 0.148 & 0.120 & 0.093 & 0.151 & -0.240 & 0.041 & 0.382 & 0.089 & 0.221 \\
\hline Dinamarca & -0.068 & 0.045 & 0.142 & 0.273 & 0.345[ & 0.263 & 0.226 & 0.139 & 0.289 & 0.282 & 0.367 & 0.072 & 0.215 & -0.337 & & 0.494 & 0.423 & \\
\hline Estonia & -0.049 & 0.052 & 0.191 & 0.213 & 0.333 & 0.261 & 0.153 & 0.137 & 0.187 & 0.256 & 0.2 & 0.180 & 0.180 & -0.166 & & 0.430 & 0.389 & \\
\hline Finlandia & 0.138 & 0.084 & 0.208 & 0.239 & 0.353 & 0.315 & 0.066 & 0.204 & 0.170 & 0.293 & 0.2 & 0.097 & 0.183 & -0.170 & -0.1 & 0.469 & 0.451 & 0.275 \\
\hline Francia & 0.050 & 0.015 & 0.177 & 0.288 & 0.430 & 0.368 & 0.332 & 0.288 & 0.340 & 0.399 & 0.437 & 0.231 & 0.352 & -0.106 & & 0.527 & 0.399 & 0.447 \\
\hline Alemania & -0.106 & 0.034 & 0.140 & 0.321 & 0.213 & 0.271 & 0.115 & 0.226 & 0.229 & 0.243 & 0.309 & 0.193 & 0.322 & -0.339 & -0.100 & 0.470 & 0.306 & 0.309 \\
\hline rianda & -0.018 & 0.194 & 0.253 & 0.357 & 0.017 & 0.265 & 0.062 & 0.135 & 0.219 & 0.230 & 0.187 & 0.130 & 0.303 & -0.358 & -0.226 & 0.468 & 0.534 & 0.341 \\
\hline Italia & 0.035 & -0.003 & 0.167 & 0.190 & 0.244 & 0.192 & 0.124 & 0.104 & 0.226 & 0.392 & 0.414 & 0.195 & 0.183 & -0.118 & & 0.450 & 0.439 & 0.354 \\
\hline Japón & -0.032 & 0.127 & 0.234 & 0.312 & 0.156 & 0.281 & 0.245 & 0.251 & 0.147 & 0.309 & 0.4 & 0.216 & 0.372 & -0.266 & & 0.483 & 0.470 & 0.392 \\
\hline Corea & -0.041 & 0.165 & 0.269 & 0.270 & 0.223 & 0.187 & 0.275 & 0.320 & 0.158 & 0.337 & 0.22 & 0.1 & 0.268 & -0.1 & & 0.525 & 0.478 & 0.323 \\
\hline Paises Bajos & -0.079 & 0.165 & 0.186 & 0.170 & 0.276 & 0.263 & 0.244 & 0.272 & 0.158 & 0.224 & 0.2 & 0.158 & 0.197 & -0.226 & 0.0 & 0.481 & 1 & 0.340 \\
\hline Nonuga & - 0.049 & 0.013 & 0.193 & 0.302 & 0.206 & 0.226 & $0.258]$ & 0.231 & 0.241 & 0.269 & $0.2 \mathrm{Z}$ & 0.162 & 0.24 & -0.406 & & 0.492 & 0.415 [ & 0.318 \\
\hline Federac & 0.063 & 0.146 & 0.086 & 0.025 & 0.022 & 0.090 & 0.0 & 0.018 | & 0.05 & 35 & & 0.0 & 0.00 & -0.402 & & 64 & 0.452 & 0.117 \\
\hline Repúbica : & -0.012 & 0.061 & 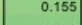 & 0.247 & 0.05 & 0.17 & & 0.1 & 0.142 & 95 & 0.11 & 0.0. & 0.2 & -0.320 & & ${ }^{48}$ & 66 & \\
\hline España & -0.006 & 0.110 & 0.204 & 0.254 & 0.237 & 0.322 & 0.259 & 0.18 & 0.288 & 0.382 & 0.3 & 0.234 & 0.307 & -0.160 & 1 & 0.483 & 0.347 & $0.378 \mathrm{r}$ \\
\hline Suecia & -0.078 & 0.062 & 0.108 & 0.230 & 0.341 & 0.223 & 0.174 & 0.237 & 0.151 & 0.208 & 0.2 & 0.102 & 0.225 & -0.159 & & 0.487 & 0.348 & \\
\hline nido & 0.036 & 0.073 & 0.151 & 0.269 & ( & 0.294 & 0.190 & 0.276 & 0.15 & 0.27 & 0.320 & 0.318 & 0.3 & -0.359 & -0.162 & 0.511 & 554 & \\
\hline & & & 0.200 & & 0.255 & & & $0.277 \mid$ & 0.162 & & 0.188 & 0.126 & & -0.231 & & 0.464 & 0.437 & \\
\hline
\end{tabular}

El código de colores refleja el significado de los coeficientes. El amarillo intenso indica coeficientes negativos fuertes y el verde oscuro indica coeficientes positivos fuertes. Nota: Para Chipre, véase la nota de la Figura 5. 


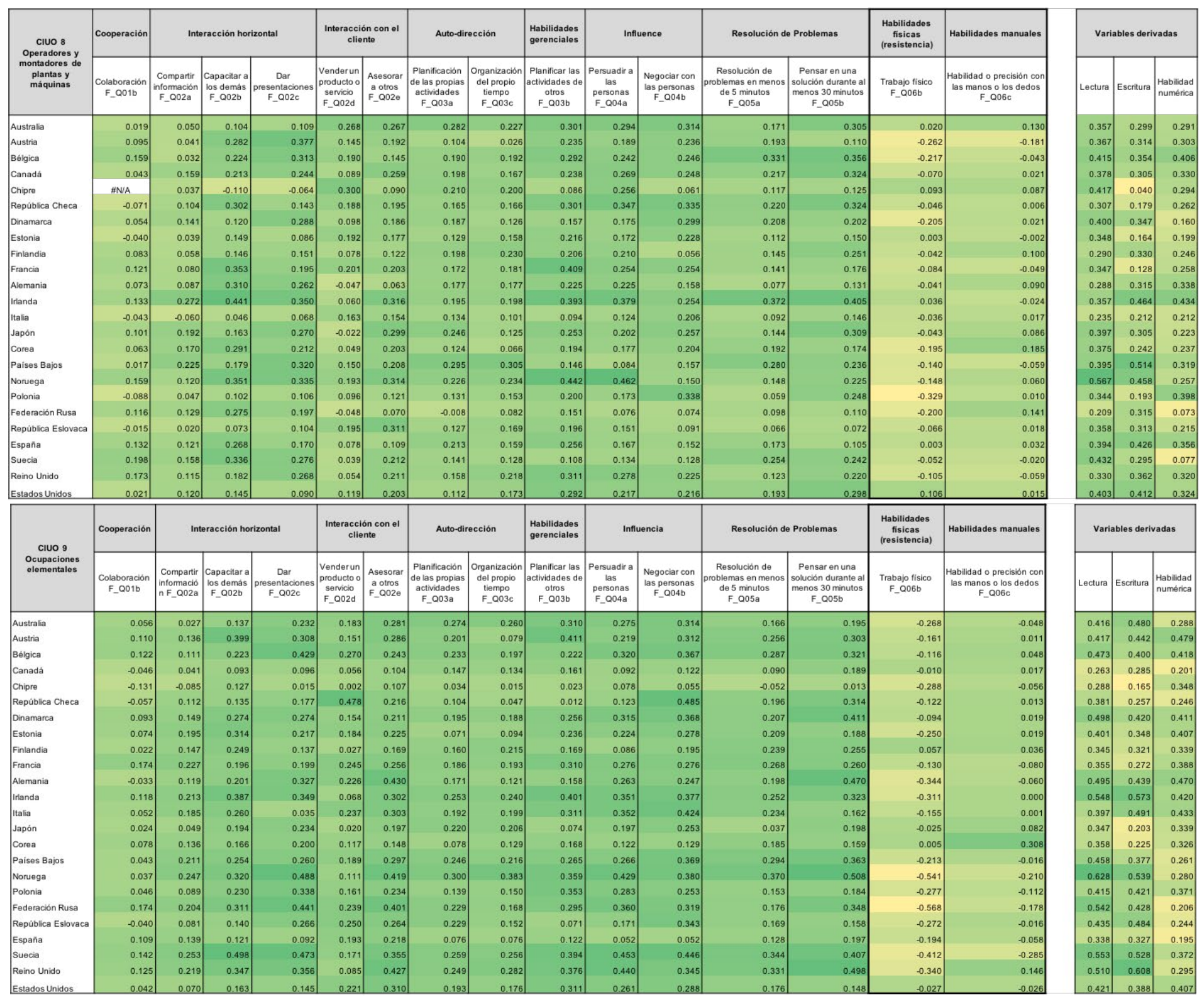

El código de colores refleja el significado de los coeficientes. El amarillo intenso indica coeficientes negativos fuertes y el verde oscuro indica coeficientes positivos fuertes. Nota: Para Chipre, véase la nota de la Figura 5.

Fuente: OCDE, con base en datos del PIAAC Database, octubre 2015. 
ANEXO C2. Tablas de correlación de pares basadas en el PIAAC por grupos del CIUO de 1 dígito (SPO), 2012.

\begin{tabular}{|c|c|c|c|c|c|c|c|c|c|c|c|c|c|c|c|c|c|c|}
\hline \multirow{2}{*}{$\begin{array}{l}\text { cluo } 1 \\
\text { Gerentes }\end{array}$} & \multirow{2}{*}{\begin{tabular}{|c} 
Cooperación \\
$\begin{array}{c}\text { Colaboración } \\
\text { F_a01b }\end{array}$
\end{tabular}} & \multicolumn{3}{|c|}{ Interacción horizontal } & \multicolumn{2}{|c|}{$\begin{array}{l}\text { Interacción con el } \\
\text { cliente }\end{array}$} & \multicolumn{2}{|c|}{ Autodirección } & \multirow{2}{*}{\begin{tabular}{|c|}
$\begin{array}{c}\text { Habilidades } \\
\text { gerenciales }\end{array}$ \\
$\begin{array}{c}\text { Planificar lat } \\
\text { activivades } \\
\text { ottos d } \\
\text { F_aosb }\end{array}$ \\
\end{tabular}} & \multicolumn{2}{|c|}{ Influencia } & \multicolumn{2}{|c|}{ Resolución de Problemas } & \multirow{2}{*}{ 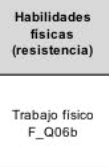 } & \multirow{2}{*}{ 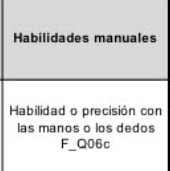 } & \multicolumn{3}{|c|}{ Variables derivadas } \\
\hline & & $\begin{array}{c}\text { Compartit } \\
\text { intomadion } \\
F_{-} \text {- } 002 a\end{array}$ & 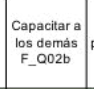 & 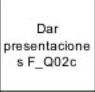 & $\begin{array}{c}\text { Venderun } \\
\text { productio } \\
\text { soncio } \\
\text { F_aozd }\end{array}$ & $\mid$\begin{tabular}{|c|} 
Asesorar \\
a otros \\
$F_{-}$-002e
\end{tabular} & 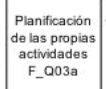 & \begin{tabular}{|l} 
Organización \\
del propio \\
tiempo \\
F_a $_{-} 030$
\end{tabular} & & $\begin{array}{c}\text { Persuadira } \\
\text { las } \\
\text { personas } \\
\text { F- } 004 a\end{array}$ & 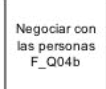 & $\begin{array}{l}\text { Resolución de } \\
\text { problemas en menos } \\
\text { de } 5 \text { minutos } \\
\text { F_c005a }\end{array}$ & $\begin{array}{c}\text { Pensar en una } \\
\text { solución durante } \\
\text { al menos } 30 \\
\text { minutos } \\
\text { F_Cosb }\end{array}$ & & & Lectura & Escritura & $\begin{array}{l}\text { Habilidad } \\
\text { numericica }\end{array}$ \\
\hline Australia & 0.049 & 0.195 & 0.079 & 0.248 & -0.060 & 0.129 & 0.143 & 0.135 & 0.032 & 0.147 & 0.198 & 0.126 & 0.227 & -0.236 & & 0.277 & 0.412 & 0.258 \\
\hline Austria & & 0.166 & 0.090 & 0.135 & -0.093 & 0.073 & 0.132 & 0.047 & 0.082 & 0.192 & 0.268 & 0.221 & 0.313 & -0.264 & -0.148 & 0.308 & 0.352 & 0.344 \\
\hline Bếlgica & 0.070 & 0.253 & 0.207 & 0.240 & -0.172 & 0.104 & 0.159 & 0.074 & 0.199 & 0.077 & 0.112 & 0.100 & 0.295 & -0.326 & -0.162 & 0.272 & 0.313 & 0.259 \\
\hline Canadá & -0.026 & 0.085 & 0.058 & 0.196 & -0.115 & 0.125 & 0.148 & 0.108 & 0.086 & 0.185 & 0.199 & 0.196 & 0.334 & -0.320 & -0.125 & 0.357 & 0.335 & 0.334 \\
\hline Chipre & 0.142 & 0.274 & 0.268 & 0.239 & -0.210 & 0.208 & 0.174 & 0.166 & 0.151 & 0.146 & 0.062 & 0.319 & 0.219 & -0.351 & -0.013 & 0.448 & 0.563 & 0.294 \\
\hline República Checa & 0.078 & 0.050 & 0.178 & 0.254 & -0.256 & 0.125 & -0.077 & 0.086 & 0.187 & 0.147 & 0.194 & 0.069 & 0.244 & -0.240 & 0.080 & 0.368 & 0.486 & 0.390 \\
\hline Dinamarca & 0.073 & 0.099 & 0.091 & 0.153 & -0.052 & 0.162 & 0.182 & 0.164 & 0.070 & 0.171 & 0.148 & 0.211 & 0.268 & -0.139 & -0.0 & 0.276 & 0.332 & 0.297 \\
\hline Estonia & 0.049 & 0.207 & 0.142 & 0.271 & -0.083 & 0.192 & 0.145 & 0.091 & 0.116 & 0.231 & 0.240 & 0.186 & 0.224 & -0.251 & -0.0 & 0.323 & 0.310 & 0.315 \\
\hline Finlandia & -0.050 & 0.095 & 0.030 & 0.037 & -0.112 & 0.021 & 0.053 & -0.028 & 0.068 & 0.001 & 0.110 & 0.151 & 0.131 & -0.324 & -0.152 & 0.175 & 0.239 & 0.229 \\
\hline Francia & 0.019 & -0.013 & 0.061 & 0.186 & -0.056 & 0.012 & 0.167 & 0.139 & 0.107 & 0.043 & 0.069 & 0.024 & 0.208 & -0.057 & -0.110 & 0.172 & 0.197 & 0.182 \\
\hline Alemania & 0.011 & 0.097 & 0.130 & 0.036 & -0.036 & 0.239 & 0.070 & 0.175 & -0.142 & 0.195 & 0.096 & 0.141 & 0.215 & -0.072 & 0.046 & 0.188 & 0.282 & 0.352 \\
\hline Irtanda & -0.095 & 0.179 & 0.182 & 0.391 & -0.092 & 0.271 & 0.207 & 0.241 & 0.162 & 0.214 & 0.166 & 0.164 & 0.225 & -0.463 -0 & -0.027 & 0.338 & 0.471 & 0.404 \\
\hline Halia & 0.150 & 0.248 & 0.292 & 0.190 & 0.031 & 0.382 & 0.194 & 0.133 & 0.174 & 0.240 & 0.324 & -0.086 & 0.157 & -0.280 & -0.215 & 0.520 & 0.541 & 0.475 \\
\hline Japón & 0.031 & 0.147 & 0.055 & 0.110 & 0.002 & 0.121 & -0.019 & -0.006 & -0.031 & -0.034 & 0.076 & 0.014 & 0.009 & -0.103 & 0.046 & 0.200 & 0.253 & 0.341 \\
\hline Corea & 0.174 & 0.119 & 0.165 & 0.211 & -0.167 & 0.105 & 0.168 & 0.089 & 0.111 & 0.180 & 0.185 & -0.042 & 0.107 & -0.186 & 0.391 & 0.424 & 0.482 & 0.431 \\
\hline Paises Bajos & -0.170 & 0.136 & 0.143 & 0.343 & -0.163 & 0.116 & 0.061 & 0.165 & -0.056 & 0.064 & 0.151 & 0.205 & 0.323 & -0.398 & -0.136 & 0.266 & 0.351 & 0.259 \\
\hline Noruega & 0.166 & 0.187 & 0.131 & 0.270 & -0.207 & 0.141 & 0.011 & 0.081 & 0.107 & 0.112 & 0.011 & 0.191 & 0.275 & -0.384 & $-0.240 \mid$ & 0.246 & 0.307 & 0.266 \\
\hline Polonia & 0.141 & 0.131 & 0.227 & 0.153 & -0.131 & 0.090 & 0.039 & 0.044 & 0.039 & 0.130 & 0.211 & 0.235 & 0.298 & -0.354 & -0.0 & 0.314 & 0.340 & 0.321 \\
\hline Federación Rusa & -0.163 & 0.037 & 0.045 & -0.066 & -0.132 & 0.032 & 0.081 & 0.074 & -0.014 & -0.134 & 0.032 & -0.073 & 0.167 & -0.241 & -0.051 & 0.357 & 0.3866 & 0.112 \\
\hline Repúbilica Estovovace & -0.022 & 0.240 & 0.257 & 0.238 & -0.123 & 0.254 & 0.107 & 0.038 & 0.122 & 0.191 & 0.175 & 0.002 & 0.122 & -0.343 & -0.028 & 0.393 & 0.412 & 0.382 \\
\hline España & -0.058 & 0.175 & 0.171 & 0.366 & -0.244 & 0.062 & 0.115 & 0.140 & 0.243 & 0.185 & 0.206 & 0.120 & 0.203 & -0.317 & -0.213 & 0.490 & 0.470 & 0.327 \\
\hline Suecia & -0.108 & 0.123 & 0.289 & 0.241 & 0.148 & 0.253 & 0.035 & 0.145 & 0.048 & $0.169>\mathrm{C}$ & 0.182 & 0.170 & 0.228 & -0.225 & $-0.038 \mathrm{~B}$ & 0.341 & 0.333 & 0.288 \\
\hline Reino Unido & 0.013 & 0.162 & 0.151 & 0.244 & -0.070 & 0.113 & 0.255 & 0.194 & 0.140 & 0.073 & 0.165 & 0.074 & 0.159 & -0.305 & -0.078 & 0.206 & 0.369 & 0.219 \\
\hline & -0.024 & 0.180 & 0.064 & 0.236 & & 0.180 & $0.026]$ & & 0.068 & & 0.094 & & & & 0.084 & $0.248 \mathrm{r}$ & 0.024 & 0.289 \\
\hline
\end{tabular}

El código de colores refleja el significado de los coeficientes. El amarillo intenso indica coeficientes negativos fuertes y el verde oscuro indica coeficientes positivos fuertes. Nota: Para Chipre, véase la nota de la Figura 5. 


\begin{tabular}{|c|c|c|c|c|c|c|c|c|c|c|c|c|c|c|c|}
\hline \multirow{2}{*}{$\begin{array}{c}\text { Cluo } 2 \\
\text { Profesionales }\end{array}$} & \multirow{2}{*}{$\begin{array}{c}\text { Cooperación } \\
\begin{array}{c}\text { Colaboración } \\
\text { F_a01b }\end{array}\end{array}$} & \multicolumn{3}{|c|}{ Interacción horizontal } & \multicolumn{2}{|c|}{$\begin{array}{l}\text { Interaccicín con el } \\
\text { cliente }\end{array}$} & \multicolumn{2}{|c|}{ Auto-direccioion } & \multirow{2}{*}{\begin{tabular}{|c|}
$\begin{array}{c}\text { Habilidades } \\
\text { gerenciales }\end{array}$ \\
$\begin{array}{c}\text { Planificar las } \\
\text { actividades de } \\
\text { otos } \\
\text { F_aosb }\end{array}$ \\
\end{tabular}} & \multicolumn{2}{|c|}{ Influencia } & \multicolumn{2}{|c|}{ Resolución de Proble } & \multirow{2}{*}{ 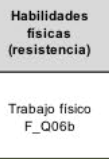 } & \multirow{2}{*}{ 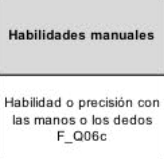 } \\
\hline & & 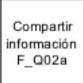 & 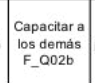 & $\begin{array}{c}\text { Dar } \\
\text { presentacione } \\
\text { sF_a022 }\end{array}$ & 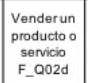 & 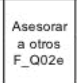 & 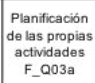 & 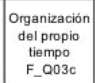 & & $\begin{array}{c}\text { Persuadira } \\
\text { las } \\
\text { personas } \\
\text { F_-004a }\end{array} \mid$ & 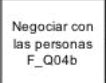 & 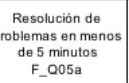 & 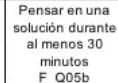 & & \\
\hline Australia & -0.007 & 0.099 & 0.070 & 0.122 & 0.070 & 0.067 & 0.218 & 0.236 & 0.107 & 0.103 & 0.076 & 0.108 & 0.142 & -0.114 & \\
\hline Austria & 0.006 & 0.104 & 0.075 & 0.033 & 0.099 & 0.168 & 0.083 & 0.129 & 0.055 & 0.068 & 0.208 & 0.056 & 0.237 & -0.282 & \\
\hline Bélgica & 0.004 & 0.079 & -0.001 & 0.099 & 0.007 & 0.060 & 0.185 & 0.135 & 0.140 & 0.089 & 0.075 & 0.048 & $0.19 \mathrm{C}$ & -0.241 & \\
\hline Canadà & -0.001 & 0.149 & 0.018 & 0.134 & 0.043 & 0.058 & 0.138 & 0.157 & 0.015 & 0.044 & 0.125 & 0.069 & 0.25 & -0.288 & \\
\hline Chipre & 0.054 & 0.073 & 0.062 & 0.036 & 0.095 & 0.058 & -0.018 & 0.052 & 0.138 & 0.143 & 0.188 & 0.187 & 0.213 & -0.245 & \\
\hline República Checa & 0.066 & 0.166 & 0.029 & 0.029 & 0.016 & 0.013 & 0.115 & 0.150 & 0.209 & 0.101 & 0.235 & 0.174 & 0.226 & -0.158 & \\
\hline Dinamarca & -0.093 & 0.060 & 0.040 & 0.159 & 0.118 & 0.137 & 0.212 & 0.218 & 0.111 & 0.110 & 0.200 & 0.065 & 0.236 & -0.289 & -0.100 \\
\hline Estonia & 0.061 & 0.208 & 0.057 & 0.032 & 0.056 & 0.039 & 0.071 & 0.103 & -0.010 & 0.045 & 0.148 & 0.109 & 0.216 & -0.173 & \\
\hline Finlandia & 0.024 & 0.114 & 0.006 & 0.064 & 0.032 & 0.014 & 0.042 & 0.086 & 0.018 & -0.039 & 0.022 & 0.056 & 0.165 & -0.212 & \\
\hline Francia & -0.043 & 0.182 & 0.046 & 0.051 & 0.010 & 0.003 & 0.076 & 0.109 & 0.041 & 0.069 & 0.073 & 0.146 & 0.128 & -0.163 & \\
\hline Alemania & 0.008 & 0.139 & -0.055 & 0.054 & 0.045 & 0.159 & 0.160 & 0.190 & 0.107 & 0.153 & 0.218 & 0.080 & 0.250 & -0.155 & \\
\hline |rranda & -0.016 & 0.115 & 0.009 & 0.135 & 0.050 & 0.054 & 0.176 & 0.193 & -0.011 & 0.003 & 0.142 & 0.130 & 0.241 & -0.336 & \\
\hline thalia & 0.013 & 0.106 & -0.101 & -0.069 & 0.171 & 0.078 & 0.165 & 0.227 & 0.081 & 0.127 & 0.349 & 0.141 & 0.324 & -0.208 & \\
\hline Japón & -0.116 & 0.134 & 0.111 & 0.207 & 0.033 & 0.112 & 0.125 & 0.168 & 0.123 & 0.101 & 0.225 & 0.162 & 0.316 & -0.146 & -0.140 \\
\hline Corea & -0.001 & 0.243 & 0.037 & 0.157 & -0.038 & 0.129 & 0.111 & 0.111 & 0.137 & 0.138 & 0.192 & 0.221 & 0.305 & -0.032 & 0.200 \\
\hline Paises Bajos & -0.023 & 0.152 & 0.040 & 0.133 & -0.010 & 0.140 & 0.205 & 0.195 & 0.099 & 0.145 & 0.153 & 0.183 & 0.276 & -0.241 & \\
\hline Noruega & -0.040 & 0.118 & 0.066 & 0.131 & -0.022 & 0.079 & 0.164 & 0.209 & 0.115 & 0.099 & 0.103 & 0.041 & 0.17 & & \\
\hline Polonia & 0.024 & 0.108 & 0.017 & -0.003 & 0.061 & 0.039 & 0.172 & 0.151 & 0.134 & 0.107 & 0.294 & 0.074 & $0.23 \mathrm{~s}$ & -0.238 & \\
\hline Federacaión Rusa & -0.025 & 0.130 & 0.059 & 0.117 & 0.002 & 0.048 & 0.101 & 0.027 & 0.137 & 0.029 & 0.242 & 0.036 & 0.155 & -0.206 & \\
\hline República Eslovaca & 0.157 & 0.131 & -0.071 & -0.053 & 0.042 & 0.112 & 0.156 & 0.153 & 0.014 & 0.062 & 0.220 & 0.104 & $0.218 \mathrm{~S}-2$ & -0.168 & -0.056 \\
\hline España & 0.026 & 0.104 & -0.046 & 0.023 & 0.118 & 0.147 & 0.042 & 0.054 & 0.059 & 0.017 & 0.2 & 0.153 & $0.2>2>$ & -0.172 & \\
\hline Suecia & -0.163 & 0.073 & -0.018 & 0.118 & 0.028 & 0.012 & 0.157 & 0.142 & 0.100 & 0.024 & 0.102 & 0.047 & 0.24 & -0.326 & \\
\hline Reino Unido & 0.074 & 0.241 & 0.021 & 0.084 & -0.028 & 0.097 & 0.187 & 0.230 & 0.077 & 0.152 & 0.211 & 0.181 & 0.195 & - -0.196 & \\
\hline Estados Unidos & - -0.028 & 0.138 & 0.025 & 0.089 & $0.029]$ & $0.080]$ & 0.229 & 0.220 & 0.077 & 0.072 & 0.090 & 0.058 & & 0.13 & \\
\hline
\end{tabular}

\begin{tabular}{|c|c|c|}
\hline \multicolumn{3}{|c|}{ Variables derivadas } \\
\hline Lectura & Escritura & $\mid \begin{array}{l}\text { Habilidad } \\
\text { numarica }\end{array}$ \\
\hline 0.266 & 0.222 & \\
\hline 0.299 & 0.367 & 0.293 \\
\hline 0.267 & 0.252 & 0.229 \\
\hline 0.277 & 0.2833 & 0.283 \\
\hline 0.380 & 0.263 & 0.243 \\
\hline 0.270 & 0.315 & 0.274 \\
\hline 0.357 & 0.274 & \\
\hline 0.160 & 0.294 & 0.277 \\
\hline 0.254 & 0.281 & 0.258 \\
\hline 0.224 & 0.243 & 0.238 \\
\hline 0.192 & 0.3577 & \\
\hline 0.241 & 0.221 & 0.32 \\
\hline 0.345 & 0.436 & 0.33 \\
\hline 0.316 & 0.275 & 0.393 \\
\hline 0.31 & 0.411 & 0.344 \\
\hline 0.255 & 0.275 & 0.206 \\
\hline 0.266 & 0.233 & \\
\hline 0.308 & 0.262 & \\
\hline 0.396 & 0.427 & 0.33 \\
\hline 0.312 & 0.316 & \\
\hline 0.312 & 0.331 & 0.31 \\
\hline 0.319 & 0.355 & \\
\hline 0215 & 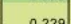 & 0.24 \\
\hline
\end{tabular}

\begin{tabular}{|c|c|c|c|c|c|c|c|c|c|c|c|c|c|c|c|}
\hline \multirow{2}{*}{$\begin{array}{c}\text { Clico } 3 \\
\text { Tecnicosy } \\
\text { protestionales } \\
\text { asociados }\end{array}$} & \multirow{2}{*}{\begin{tabular}{|c|} 
Cooperación \\
$\begin{array}{c}\text { Colaboración } \\
F_{-} 0016\end{array}$ \\
\end{tabular}} & \multicolumn{3}{|c|}{ Interacción horizontal } & \multicolumn{2}{|c|}{\begin{tabular}{|c|c} 
IInteracción con el \\
cliente
\end{tabular}} & \multicolumn{2}{|c|}{ Auto-dirección } & \multirow{2}{*}{$\begin{array}{c}\begin{array}{c}\text { Habilidades } \\
\text { gerenciales }\end{array} \\
\begin{array}{c}\text { Planificar las } \\
\text { actividades de } \\
\text { ottros } \\
\text { F_003b }\end{array}\end{array}$} & \multicolumn{2}{|c|}{ Influencia } & \multicolumn{2}{|c|}{ Resolución de Problemas } & \multirow{2}{*}{$\begin{array}{c}\begin{array}{c}\text { Habilidades } \\
\text { fisicas } \\
\text { (ressistencia) }\end{array} \\
\begin{array}{c}\text { Trabajo fisico } \\
\text { F_006b }\end{array}\end{array}$} & \multirow{2}{*}{ 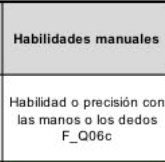 } \\
\hline & & $\begin{array}{c}\text { Compatiti } \\
\text { intomamacion } \\
F_{-}<022 a\end{array}$ & $\begin{array}{c}\text { capactiar a } \\
\text { los demás } \\
\text { F_coo2b }\end{array}$ & $\begin{array}{c}\text { Dar } \\
\text { presentacione } \\
\text { sF_aco2c }\end{array}$ & 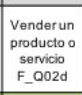 & \begin{tabular}{|l} 
Asesorar \\
a o otros \\
F_a02e \\
-20
\end{tabular} & 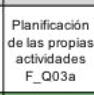 & \begin{tabular}{|l} 
Organizizacion \\
delp propio \\
tiempo \\
F_a03c
\end{tabular} & & $\begin{array}{c}\text { Persuadira } \\
\text { personas } \\
\text { Pe_aota }\end{array}$ & 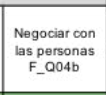 & 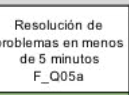 & 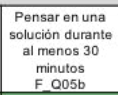 & & \\
\hline Australia & 0.095 & 0.121 & 0.045 & 0.096 & -0.011 & 0.112 & 0.245 & 0.211 & 0.140 & 0.146 & 0.205 & 0.096 & 0.257 & -0.243 & 0.005 \\
\hline Austria & -0.097 & 0.048 & 0.034 & 0.092 & 0.016 & 0.021 & 0.098 & 0.164 & 0.094 & 0.061 & 0.188 & 0.158 & 0.258 & -0.357 & -0.138 \\
\hline Bélgica & -0.050 & 0.076 & 0.084 & 0.149 & 0.042 & 0.145 & 0.275 & 0.260 & 0.161 & 0.162 & 0.156 & 0.114 & 0.186 & -0.322 & -0.177 \\
\hline Canadáa & -0.052 & 0.102 & 0.000 & 0.089 & -0.002 & 0.052 & 0.132 & 0.152 & 0.061 & 0.050 & 0.123 & 0.131 & 0.251 & -0.342 & -0.065 \\
\hline Chipre & -0.009 & 0.127 & 0.001 & 0.040 & 0.019 & 0.035 & 0.077 & 0.117 & -0.008 & 0.163 & 0.242 & 0.134 & 0.144 & -0.345 & $-0.04 c$ \\
\hline Repúbilica Checa & -0.049 & 0.150 & -0.005 & 0.034 & -0.041 & 0.043 & 0.066 & 0.106 & 0.066 & 0.186 & 0.141 & 0.068 & 0.129 & -0.195 & $-0.096 \mathrm{C}>\mathrm{C}$ \\
\hline Dinamarca & 0.010 & 0.145 & 0.154 & 0.147 & 0.003 & 0.114 & 0.232 & 0.229 & 0.120 & 0.162 & 0.224 & 0.152 & 0.212 & -0.309 & -0.10 \\
\hline Estonia & -0.049 & 0.212 & 0.131 & 0.115 & 0.122 & 0.127 & 0.173 & 0.180 & 0.135 & 0.060 & 0.272 & 0.121 & 0.209 & -0.185 & -0.047 \\
\hline Finlandia & -0.054 & 0.073 & 0.020 & 0.110 & 0.090 & -0.031 & 0.095 & 0.136 & 0.039 & -0.003 & 0.124 & 0.079 & 0.213 & -0.171 & -0.07 \\
\hline Francia & -0.052 & 0.067 & 0.032 & 0.154 & 0.107 & 0.122 & 0.249 & 0.230 & 0.112 & 0.154 & 0.232 & 0.131 & 0.266 & -0.365 & -0.375 \\
\hline Alemania & -0.075 & 0.005 & 0.057 & 0.115 & 0.107 & 0.128 & 0.053 & 0.246 & 0.019 & 0.060 & 0.236 & 0.069 & 0.202 & -0.345 & -0.163 \\
\hline |rtanda & $-0.139 \mathrm{~s}>\mathrm{C}$ & $0.137 \mathrm{~T}>\mathrm{C}$ & 0.094 & 0.169 & -0.016 & 0.200 & 0.143 & $0.238 \mathrm{~B}$ & 0.134 & 0.138 & 0.16 & 0.104 & 0.262 & -0.534 & -0.063 \\
\hline tralia & -0.097 & -0.012 & 0.030 & 0.105 & 0.130 & 0.053 & 0.121 & 0.179 & 0.153 & 0.087 & 0.2 & 0.232 & 0.278 & -0.312 & -0.080 \\
\hline Japón & 0.020 & 0.164 & 0.121 & 0.210 & 0.002 & 0.167 & 0.152 & 0.194 & 0.089 & 0.105 & 0.183 & 0.214 & 0.247 & -0.174 & -0.072 \\
\hline Corea & -0.126 & 0.255 & 0.124 & 0.098 & -0.185 & 0.081 & 0.173 & 0.168 & 0.155 & 0.115 & 0.2 & & 0.316 & -0.272 & 0.312 \\
\hline Paises Bajos & $-0.152>>>$ & 0.136 & 0.105 & 0.136 & 0.080 & 0.116 & 0.275 & 0.309 & 0.144 & 0.151 & 0.212 & 0.232 & 0.318 & -0.390 & -0.163 \\
\hline Noruega & -0.021 & 0.100 & 0.114 & 0.103 & 0.073 & 0.097 & 0.203 & 0.209 & 0.082 & 0.106 & 0.170 & 0.101 & 0.212 & -0.233 & -0.160 \\
\hline Polonia & 0.031 & 0.121 & 0.126 & 0.078 & -0.095 & -0.011 & 0.096 & 0.117 & 0.088 & 0.025 & 0.048 & 0.206 & 0.212 & -0.339 & -0.028 \\
\hline Federación Rusa & -0.067 & 0.194 & 0.057 & 0.126 & -0.076 & 0.143 & 0.109 & 0.166 & 0.072 & 0.128 & 0.210 & 0.140 & 0.299 & -0.325 & -0.096 \\
\hline Repübicaca & -0.051 & 0.035 & 0.051 & 0.097 & 0.112 & 0.147 & 0.185 & 0.1 & 0.026 & 0.143 & $0.1>>3$ & 0.154 & 0.200 & & .034. \\
\hline Esрап̆а & -0.046 & 0. & 0.022 & 0.102 & 0.077 & 0.098 & 0.1 & 0.183 & 0.205 & 0.093 & 0.30 & 0.146 & 0.312 & -0.250 & 202 \\
\hline Suecia & -0.065 & 0.110 & 0.083 & 0.150 & -0.064 & 0.060 & 0.115 & 0.134 & 0.059 & 0.046 & 0.089 & 0.146 & 0.191 & -0.200 & $-0.09 c$ \\
\hline Reino Unido & -0.099 & 0.101 & -0.130 & 0.028 & 0.096 & -0.036 & 0.190 & 0.180 & -0.004 & -0.007 & 0.045 & 0.060 & 0.157 & -0.321 & 030 \\
\hline & & 0.115 & & 0.146 & -0.032 & 0.092 & 0.087 & 0.167 & -0.018 & & 0.157 & 0.167 & & & \\
\hline
\end{tabular}

\begin{tabular}{|c|c|c|}
\hline \multicolumn{3}{|c|}{ Variables derivadas } \\
\hline ectura & Escritura & \begin{tabular}{|l} 
Habitidad \\
numerica
\end{tabular} \\
\hline 0.254 & 4.46 & 0.22 \\
\hline 0.257 & 0.310 & \\
\hline 0.287 & 0.365 & 0.264 \\
\hline 0.267 & 0.332 & 0.309 \\
\hline 0.293 & 0.343 & 0.155 \\
\hline 0.205 & 0.248 & 0.355 \\
\hline 0.285 & 0.274 & 0.254 \\
\hline 0.281 & 0.288 & 0.304 \\
\hline 0.208 & 0.188 & 0.347 \\
\hline 0.298 & 0.279 & 0.325 \\
\hline 70 & 0.195 & \\
\hline 0.288 & 0.350 & 0.275 \\
\hline 0.382 & 0.368 & 0.318 \\
\hline 0.285 & 0.312 & 0.369 \\
\hline 0.350 & 0.4822 & 0.380 \\
\hline 83 & 0.335 & 0.222 \\
\hline & 0.18 & \\
\hline 49 & 0.362 & 0.352 \\
\hline 0.24 & 0.166 & 0.3 \\
\hline & & 0.352 \\
\hline 0.398 & 0.4711 & 0.411 \\
\hline 0.264 & 0.295 & 0.249 \\
\hline & & \\
\hline
\end{tabular}

El código de colores refleja el significado de los coeficientes. El amarillo intenso indica coeficientes negativos fuertes y el verde oscuro indica coeficientes positivos fuertes Nota: Para Chipre, véase la nota de la Figura 5. 


\begin{tabular}{|c|c|c|c|c|c|c|c|c|c|c|c|c|c|c|c|}
\hline \multirow{2}{*}{$\begin{array}{c}\text { Civo } 4 \\
\text { Trabajadores de } \\
\text { apoyo clerical }\end{array}$} & \multirow{2}{*}{$\begin{array}{l}\text { Cooperación } \\
\begin{array}{c}\text { Colaboración } \\
\text { F_a01b }\end{array}\end{array}$} & \multicolumn{3}{|c|}{ Interacción horizontal } & \multicolumn{2}{|c|}{$\begin{array}{l}\text { Interacción con el } \\
\text { cliente }\end{array}$} & \multicolumn{2}{|c|}{ Auto-dirección } & \multirow{2}{*}{\begin{tabular}{|c|}
$\begin{array}{c}\text { Habilidades } \\
\text { gerenciales }\end{array}$ \\
$\begin{array}{c}\text { Planificar las } \\
\text { attividados de } \\
\text { otros } \\
\text { F_003b }\end{array}$ \\
\end{tabular}} & \multicolumn{2}{|c|}{ Influencia } & \multicolumn{2}{|c|}{ Resolución de Problemas } & \multirow{2}{*}{$\begin{array}{c}\begin{array}{c}\text { Habilidades } \\
\text { fisicas } \\
\text { (resistencia) }\end{array} \\
\begin{array}{c}\text { Trabajo fisico } \\
\text { F_aobb }\end{array}\end{array}$} & \multirow{2}{*}{ 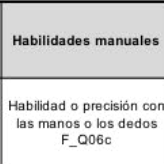 } \\
\hline & & 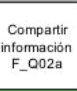 & 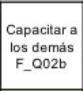 & $\begin{array}{c}\text { Dar } \\
\text { presestatione } \\
\text { sF_-0022 }\end{array}$ & \begin{tabular}{|c|} 
Venderun \\
productoo \\
senvicio \\
F_ao2d \\
\end{tabular} & \begin{tabular}{|c|} 
Asesorar \\
a oortos \\
$F_{-}$-002e
\end{tabular} & \begin{tabular}{|c}
$\begin{array}{c}\text { Planificación } \\
\text { de las propias } \\
\text { actividades } \\
\text { F_aosas }\end{array}$ \\
\end{tabular} & \begin{tabular}{|c} 
Organización \\
del propio \\
tiempo \\
F_a03c
\end{tabular} & & $\begin{array}{c}\text { Persuadira } \\
\text { las } \\
\text { personas } \\
\text { F_o } 04 a\end{array}$ & \begin{tabular}{|l} 
Negociar con \\
las pepsonas \\
F_-
\end{tabular} & \begin{tabular}{c|} 
Resolución de \\
roblemas en menos \\
de 5 minutos \\
F_a05a
\end{tabular} & $\begin{array}{c}\text { Pensar en una } \\
\text { solución durante } \\
\text { al menos } 50 \\
\text { minutos } \\
\text { Fo } 0.05 \mathrm{~b}\end{array}$ & & \\
\hline Australia & 0.048 & 0.287 & 0.130 & & & 0.308 & & 0.266 & 0.143 & & & & & & \\
\hline Austria & 0.070 & 0.226 & 0.138 & 0.118 & -0.016 & 0.126 & 0.213 & 0.162 & 0.164 & 0.095 & 0.195 & 0.192 & 0.248 & -0.209 & 0.01 \\
\hline Bèlgica & -0.022 & 0.135 & 0.094 & 0.061 & 0.097 & 0.200 & 0.347 & 0.411 & 0.099 & 0.243 & 0.230 & 0.205 & 0.199 & -0.312 & -0.10 \\
\hline $\begin{array}{l}\text { Canadá } \\
\text { Cand }\end{array}$ & 0.035 & 0.151 & 0.094 & 0.149 & -0.146 & 0.103 & 0.206 & 0.179 & 0.104 & 0.028 & 0.047 & 0.216 & 0.276 & -0.311 & -0.02 \\
\hline Chipre & 0.039 & 0.106 & 0.141 & 0.070 & -0.161 & 0.012 & 0.076 & 0.047 & 0.016 & 0.016 & 0.021 & 0.126 & 0.188 & -0.278 & 0.08 \\
\hline República Checa & 0.011 & 0.119 & 0.144 & 0.054 & -0.106 & 0.110 & 0.226 & 0.224 & 0.211 & 0.082 & 0.090 & 0.105 & 0.323 & -0.234 & -0.01 \\
\hline Dinamarca & 0.219 & 0.170 & 0.187 & 0.229 & 0.079 & 0.188 & 0.201 & 0.149 & 0.175 & 0.254 & 0.235 & 0.318 & 0.267 & -0.281 & 0.01 \\
\hline Estonia & 0.009 & 0.103 & 0.140 & 0.166 & 0.086 & 0.129 & 0.196 & 0.175 & 0.213 & 0.150 & 0.221 & 0.259 & 0.231 & -0.185 & 0.13 \\
\hline Finlandia & .0.033 & 0.125 & 0.168 & 0.199 & 0.131 & 0.215 & 0.303 & 0.221 & 0.123 & 0.178 & 0.243 & 0.202 & 0.213 & -0.261 & -0.05 \\
\hline Francia & -0.025 & 0.106 & 0.085 & 0.055 & -0.199 & -0.070 & 0.278 & 0.293 & 0.174 & 0.064 & 0.086 & 0.162 & 0.202 & -0.188 & -0.072 \\
\hline Alemania & 0.003 & 0.080 & 0.107 & 0.150 & 0.014 & 0.093 & 0.153 & 0.251 & 0.116 & 0.096 & 0.156 & 0.126 & 0.147 & -0.332 & -0.05 \\
\hline Irranda & -0.036 & 0.176 & 0.107 & 0.174 & -0.155 & 0.063 & 0.117 & 0.129 & 0.046 & 0.053 & 0.126 & 0.122 & 0.257 & -0.231 & 0.11 \\
\hline thalia & -0.028 & 0.036 & 0.162 & 0.115 & 0.023 & 0.031 & 0.159 & 0.210 & 0.130 & 0.097 & 0.201 & 0.103 & 0.296 & -0.317 & 0.02 \\
\hline Japoón & 0.030 & 0.099 & 0.129 & 0.172 & -0.064 & 0.079 & 0.191 & 0.181 & 0.142 & 0.123 & 0.230 & 0.191 & 0.184 & -0.125 & -0.03 \\
\hline Corea & -0.021 & 0.214 & 0.133 & 0.127 & 0.007 & 0.207 & 0.238 & 0.225 & 0.105 & 0.229 & 0.193 & 0.224 & 0.252 & $\begin{array}{l}-0.140 \\
-120\end{array}$ & 0.21 \\
\hline Paises Bajos & 0.031 & 0.292 & 0.107 & 0.125 & 0.014 & 0.187 & 0.372 & 0.419 & 0.246 & 0.205 & 0.178 & 0.187 & 0.231 & -0.345 & 0.002 \\
\hline Noruega & -0.117 & 0.009 & 0.095 & 0.182 & 0.047 & 0.035 & 0.223 & 0.301 & 0.080 & 0.085 & 0.184 & 0.056 & 0.193 & -0.273 & -0.13 \\
\hline Polonia & 0.122 & 0.114 & 0.140 & 0.296 & -0.085 & 0.091 & 0.233 & 0.257 & 0.066 & 0.075 & 0.179 & 0.194 & 0.189 & -0.287 & $-0.04 z$ \\
\hline Federación Rusa & 0.363 & 0.115 & 0.257 & 0.133 & 0.092 & 0.129 & 0.237 & 0.254 & 0.047 & 0.178 & 0.166 & 0.334 & 0.171 & -0.159 & 0.097 \\
\hline República Es & 0.000 & 0.005 & -0.082 & -0.115 & -0.207 & -0.005 & 0.173 & 0.236 & -0.033 & 0.024 & 0.193 & 0.104 & 0.133 & -0.452 & \\
\hline España & -0.065 & 0.056 & 0.168 & 0.158 & 0.097 & 0.190 & 0.321 & 0.309 & 0.250 & 0.139 & 0.187 & & 0.235 & & -0.298 \\
\hline Suecia & -0.021 & 0.145 & 0.200 & 0.194 & -0.086 & 0.058 & 0.074 & 0.135 & 0.160 & 0.180 & 0.181 & 0.179 & 0.389 & $\begin{array}{l}-0.417 \\
-0.217\end{array}$ & -0.20 \\
\hline Reino Unido & 0.086 & 0.209 & 0.132 & 0.097 & -0.197 & 0.079 & 0.283 & 0.230 & 0.164 & 0.053 & 0.083 & 0.135 & 0.321 & -0.249 & 0.00 \\
\hline Estados & 0.11 & & 0402 & & 0.057 & & & & & & & 0.993 & & & \\
\hline
\end{tabular}

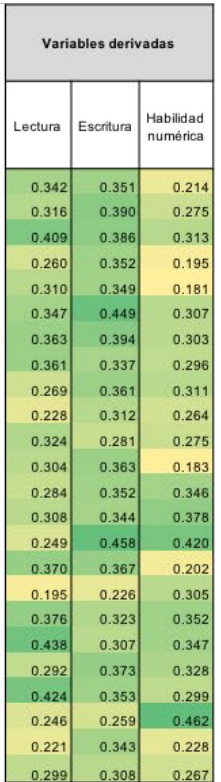

\begin{tabular}{|c|c|c|c|c|c|c|c|c|c|c|c|c|c|c|c|}
\hline \multirow{2}{*}{$\begin{array}{l}\text { Cluo } 5 \\
\begin{array}{l}\text { Crabajadores de } \\
\text { servicioy ventas }\end{array}\end{array}$} & \multirow{2}{*}{\begin{tabular}{|c|} 
Cooperación \\
$\begin{array}{c}\text { Colaboración } \\
F_{-} 001 b\end{array}$ \\
\end{tabular}} & \multicolumn{3}{|c|}{ Interacción horizontal } & \multicolumn{2}{|c|}{$\begin{array}{l}\text { Interacción con el } \\
\text { cliente }\end{array}$} & \multicolumn{2}{|c|}{ Auto-dirección } & \multirow{2}{*}{\begin{tabular}{|c|c|}
$\begin{array}{c}\text { Habilididades } \\
\text { gerenciales }\end{array}$ \\
$\begin{array}{c}\text { Planificar las } \\
\text { actividades de } \\
\text { otros } \\
\text { F- } 003 \mathrm{~b}\end{array}$ \\
\end{tabular}} & \multicolumn{2}{|c|}{ Influencia } & \multicolumn{2}{|c|}{ Resolución de Problemas } & \multirow{2}{*}{$\begin{array}{c}\begin{array}{c}\text { Habilidades } \\
\text { ficicas } \\
\text { (resistencia) }\end{array} \\
\begin{array}{c}\text { Trabajof fisico } \\
\text { F_a06b }\end{array}\end{array}$} & \multirow{2}{*}{ 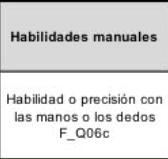 } \\
\hline & & 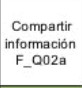 & 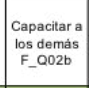 & $\begin{array}{c}\text { Dar } \\
\text { presesentacione } \\
\text { sF_-0o2c }\end{array}$ & 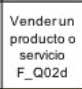 & \begin{tabular}{|c|} 
Asesorar \\
a o otros \\
F_a02e
\end{tabular} & 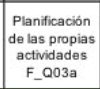 & \begin{tabular}{|c|} 
Organización \\
del propio \\
tiempo \\
F_003c
\end{tabular} & & \begin{tabular}{|c} 
Persuadir a \\
las \\
personas \\
F-O04a
\end{tabular} & 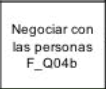 & $\begin{array}{l}\text { Resolución de } \\
\text { problemasas en menos } \\
\text { de } 5 \text { minutos } \\
\text { F_Co5a }\end{array}$ & \begin{tabular}{|c|} 
Pensar en una \\
solución durante \\
al menos 30 \\
minutos \\
Fo 0.55 \\
\end{tabular} & & \\
\hline Australia & 0.037 & 0.111 & 0.087 & 0.137 & -0.053 & 0.105 & 0.174 & 0.188 & 0.152 & 0.123 & 0.196 & 0.150 & 0.276 & -0.150 & 0.031 \\
\hline Austria & -0.041 & 0.065 & 0.190 & 0.172 & -0.006 & 0.065 & 0.084 & 0.087 & 0.170 & 0.070 & 0.2 & 0.171 & 0.224 & -0.225 & -0.010 \\
\hline Beilgica & -0.064 & 0.102 & 0.280 & 0.267 & 0.057 & 0.168 & 0.217 & 0.190 & 0.260 & 0.258 & 0.284 & 0.221 & 0.296 & -0.262 & -0.223 \\
\hline Canadáa & 0.027 & 0.113 & 0.219 & 0.258 & 0.043 & 0.167 & 0.132 & 0.113 & 0.208 & 0.191 & 0.276 & 0.189 & 0.301 & - 0.1111 & -0.023 \\
\hline Chipre & 0.067 & 0.135 & 0.115 & 0.173 & 0.009 & 0.141 & 0.013 & -0.042 & 0.046 & 0.156 & 0.179 & 0.122 & 0.152 & -0.165 & 0.001 \\
\hline República Checa & 0.050 & 0.183 & 0.121 & 0.121 & 0.007 & 0.203 & 0.100 & 0.138 & 0.146 & 0.212 & 0.254 & 0.1 & 0.316 & -0.250 & -0.059 \\
\hline Dinamarca & 0.082 & 0.082 & 0.164 & 0.166 & 0.072 & 0.190 & 0.152 & 0.155 & 0.168 & 0.186 & 0.2 - $>2$ & 0.106 & 0.222 & -0.139 & -0.039 \\
\hline Estonia & 0.021 & 0.114 & 0.191 & 0.124 & 0.024 & 0.131 & 0.114 & 0.120 & 0.201 & 0.146 & 0.217 & 0.226 & 0.260 & -0.124 & -0.022 \\
\hline Finlandia & 0.008 & 0.097 & 0.109 & 0.072 & 0.094 & 0.114 & 0.028 & 0.032 & 0.088 & 0.070 & 0.140 & 0.067 & 0.198 & -0.115 & -0.067 \\
\hline Francia & 0.147 & 0.124 & 0.127 & 0.172 & 0.105 & 0.203 & 0.099 & 0.113 & 0.161 & 0.240 & 0.283 & 0.226 & 0.258 & -0.146 & -0.109 \\
\hline Alemania & 0.058 & 0.197 & 0.208 & 0.175 & 0.006 & 0.146 & 0.147 & $0.138 \mathrm{~S}-\mathrm{s}$ & 0.202 & 0.155 & $0.2>-2>$ & 0.186 & 0.271 & -0.265 & -0.078 \\
\hline Irtanda & 0.104 & 0.142 & 0.171 & 0.315 & -0.016 & 0.154 & 0.165 & $0.202 \mathrm{P}>\mathrm{C}$ & 0.140 & $0.1>>$ & 0.2 & 0.222 & 0.363 & -0.261 & -0.013 \\
\hline |halia & 0.133 & 0.158 & 0.207 & $0.130 \mathrm{C}$ & 0.057 & 0.128 & 0.055 & 0.089 & 0.121 & 0.200 & 0.186 & 0.148 & 0.176 & $-0.2>2-2$ & -0.041 \\
\hline Japón & - 0.101 - & 0.087 & 0.173 & $0.308 \mathrm{C}-\mathrm{s}$ & 0.011 & 0.188 & 0.241 & 0.171 & 0.243 & $0.227 \mathrm{\gamma}>\mathrm{C}$ & 0.250 & 0.198 & 0.262 & -0.071 - & 0.012 \\
\hline Corea & 0.012 & 0.198 & 0.263 & 0.258 & 0.020 & 0.218 & 0.177 & 0.157 & 0.210 & $0.207 \mathrm{Y}>\mathrm{C}$ & 0.225 & 0.216 & 0.260 & - 0.138 & 0.328 \\
\hline Paises Bajc & 0.011 & 0.200 & 0.178 & 0.261 & -0.065 & 0.108 & 0.176 & 0.213 & 0.161 & & 0.261 & 0.269 & 0.358 & & $-0.027 \mathrm{P}-\mathrm{C}$ \\
\hline Noruega & 0.028 & 0.091 & 0.127 & $0.127 \mathrm{Y}>\mathrm{C}$ & 0.013 & 0.169 & 0.118 & $0.14 \mathrm{~S}$ & 0.164 & 0.166 & $0.2-2>3$ & 0.174 & 0.182 & 2. & -0.009 \\
\hline Polonia & 0.006 & 0.087 & 0.221 & 0.175 & 0.068 & 0.151 & 0.122 & $0.142 \mathrm{Y}>\mathrm{C}$ & 0.153 & 0.161 & $0.2>-2>$ & 0.216 & 0.31 & -0.260 & $-0.030 \mathrm{P}-\mathrm{C}$ \\
\hline Federación Rusa & $0.0<>>$ & 0.177 & & 0.199 & 0.093 & 0.164 & $0.1>>>$ & $0.1 \quad-1$ & 0.135 & $0.2>2>3$ & $0.1 \mathrm{Y}-\mathrm{C}$ & & $0.1>>1$ & & \\
\hline Repüblica Estovaca & 0.1 & 0.118 & 0.256 & 0.0 & -0.038 & 0.087 & & 0.168 & 0.064 & & & 0.0 & 0.138 & -0.213 & \\
\hline España & 0.191 & 0.243 & 0.299 & 0.312 & -0.020 & 0.184 & 0.058 & 0.068 & 0.238 & 0.166 & 0.192 & 0.150 & 0.248 & - 0.191 & -0.167 \\
\hline Suecia & -0.020 & 0.041 & 0.116 & 0.151 & 0.057 & 0.166 & 0.085 & 0.091 & 0.138 & 0.161 & 0.101 & 0.101 & 0.195 & -0.112 & -0.032 \\
\hline Reino Unido & 0.082 & 0.1. & 0.274 & 0.274 & 制 & $0.12-3>$ & $0.2 .2-3$ & 0.1 & $0.2-2>3$ & & & 0.2 & 0.3 & -0.164 & \\
\hline & & 0.114 & & & 0.088 & 0.240 & & & & & & & & & \\
\hline
\end{tabular}

\begin{tabular}{|c|c|c|}
\hline \multicolumn{3}{|c|}{ Variables derivadas } \\
\hline Lectura & Escotitura & $\begin{array}{l}\text { Habilidad } \\
\text { numidrica }\end{array}$ \\
\hline 0.297 & 0.367 & \\
\hline 0.363 & 0.415 & 0.22 \\
\hline 0.290 & 0.364 & 0.39 \\
\hline 0.321 & 0.433 & 0.2 \\
\hline 0.331 & 0.445 & \\
\hline 0.292 & 0.500 & 0.151 \\
\hline 0.351 & 0.376 & 0.233 \\
\hline 0.340 & 0.387 & \\
\hline 0.178 & 0.216 & \\
\hline 0.305 & 0.361 & 0.34 \\
\hline 0.377 & 0.393 & 0.352 \\
\hline 0.344 & 0.409 & 0.364 \\
\hline & & 0.25 \\
\hline 0.390 & 0.493 & 0.37 \\
\hline 0.367 & 0.380 & 0.2 \\
\hline 0.242 & 0.328 & 0.19 \\
\hline 0.3. & 0.305 & 0.20 \\
\hline & 0.364 & \\
\hline 0.386 & 0.331 & 0.21 \\
\hline 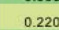 & . & \\
\hline 0.383 & 0.432 & 0.17 \\
\hline
\end{tabular}

El código de colores refleja el significado de los coeficientes. El amarillo intenso indica coeficientes negativos fuertes y el verde oscuro indica coeficientes positivos fuertes. Nota: Para Chipre, véase la nota de la Figura 5. 


\begin{tabular}{|c|c|c|c|c|c|c|c|c|c|c|c|c|c|c|c|}
\hline \multirow{2}{*}{$\begin{array}{l}\text { CIUO } 6 \\
\text { Trabajadores } \\
\text { agricolas, } \\
\text { forestales y } \\
\text { pesqueros } \\
\text { calificados }\end{array}$} & \multirow{2}{*}{\begin{tabular}{|c} 
Cooperación \\
$\begin{array}{c}\text { Colaboración } \\
F_{-} 0016\end{array}$
\end{tabular}} & \multicolumn{3}{|c|}{ Interacción horizontal } & \multicolumn{2}{|c|}{$\begin{array}{l}\text { Interacción con el } \\
\text { cliente }\end{array}$} & \multicolumn{2}{|c|}{ Auto-dirección } & \multirow{2}{*}{\begin{tabular}{|c|}
$\begin{array}{c}\text { Habilididades } \\
\text { gerenciales }\end{array}$ \\
$\begin{array}{c}\text { Planificar las } \\
\text { actividades de } \\
\text { ottos } \\
\text { F_ao3b }\end{array}$ \\
\end{tabular}} & \multicolumn{2}{|c|}{ Infuencia } & \multicolumn{2}{|c|}{ Resolución de Problemas } & \multirow{2}{*}{$\begin{array}{c}\begin{array}{c}\text { Habililidades } \\
\text { fisicas } \\
\text { (resistencia) }\end{array} \\
\begin{array}{c}\text { Trabajo fisico } \\
F_{-} 006 \mathrm{~b}\end{array}\end{array}$} & \multirow{2}{*}{ 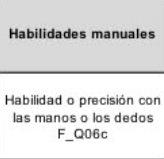 } \\
\hline & & $\begin{array}{c}\text { Compartit } \\
\text { intomación } \\
F_{-} 002 a\end{array}$ & 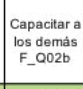 & $\begin{array}{l}\text { Dar } \\
\text { presentacione } \\
\text { sF_C020 }\end{array}$ & 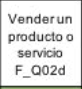 & \begin{tabular}{|c|} 
Asesorar \\
a outros \\
F $_{-} 0022$
\end{tabular} & 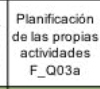 & \begin{tabular}{|c|} 
organización \\
del propio \\
tiempo \\
F_a $_{-} 03 \mathrm{c}$ \\
\end{tabular} & & \begin{tabular}{|c|} 
Persuadir a \\
las \\
personas \\
F_a04a
\end{tabular} & $\begin{array}{c}\text { Negociar con } \\
\text { lats personas } \\
\text { F_0 }\end{array}$ & $\begin{array}{l}\text { Resolución de } \\
\text { problemas en menos } \\
\text { de } 5 \text { minutos } \\
\text { F_c005a }\end{array}$ & \begin{tabular}{|c|} 
Pensar en una \\
solución durante \\
al menos 30 \\
minutos \\
F_ 005b \\
\end{tabular} & & \\
\hline Austraia & -0.045 & $\begin{array}{ll}0.018 \\
\end{array}$ & 0.116 & 0.201 & 0.150 & 0.084 & 0.166 & 0.139 & 0.381 & 0.311 & \begin{tabular}{l|l}
0.213 \\
\end{tabular} & 0.095 & 0.101 & & -0.152 \\
\hline Austria & 0.116 & 0.031 & 0.034 & 0.378 & 0.185 & 0.157 & 0.077 & 0.088 & 0.156 & 0.131 & 0.126 & 0.127 & 0.068 & -0.019 & 0.061 \\
\hline Bélgica & -0.104 & 0.197 & 0.458 & -0.079 & 0.048 & 0.437 & -0.131 & 0.136 & 0.248 & 0.369 & 0.368 & 0.276 & 0.328 & -0.454 & -0.242 \\
\hline Canadá & 0.064 & 0.117 & 0.084 & 0.161 & 0.108 & 0.195 & 0.104 & 0.087 & 0.181 & 0.165 & 0.220 & 0.136 & 0.163 & -0.031 & 0.030 \\
\hline Chipre & NNA & \#NAA & HNA & \#NA & \#NA & $\# N / A$ & \#NA & \#NA & \#NA & \#N/A & HNA & \#NA & \#N/A & \#NA & \#NA \\
\hline República Checa & 0.197 & 0.093 & 0.103 & -0.014 & 0.113 & 0.161 & 0.050 & 0.024 & 0.198 & 0.258 & 0.215 & 0.097 & 0.075 & -0.135 & -0.142 \\
\hline Dinamarca & 0.136 & -0.094 & -0.058 & 0.110 & 0.196 & 0.304 & 0.086 & 0.075 & -0.006 & 0.036 & 0.190 & 0.051 & 0.268 & -0.034 & -0.185 \\
\hline Estonia & -0.072 & -0.041 & 0.085 & 0.329 & 0.072 & 0.152 & 0.029 & 0.066 & 0.155 & 0.167 & 0.158 & 0.056 & 0.120 & -0.018 & -0.004 \\
\hline Finlandia & 0.137 & 0.134 & 0.091 & 0.284 & 0.079 & 0.169 & 0.118 & 0.106 & 0.099 & 0.073 & 0.108 & 0.128 & 0.037 & -0.022 & 0.069 \\
\hline Francia & 0.078 & -0.023 & -0.067 & 0.018 & 0.084 & 0.096 & 0.108 & 0.108 & 0.152 & 0.125 & 0.090 & 0.044 & 0.099 & -0.186 & -0.134 \\
\hline Alemania & 0.032 & 0.226 & -0.005 & 0.196 & 0.135 & 0.213 & 0.094 & 0.127 & 0.098 & 0.201 & 0.194 & 0.008 & 0.071 & -0.071 & 0.120 \\
\hline Irtanda & 0.049 & 0.090 & 0.075 & 0.110 & -0.045 & 0.000 & 0.060 & 0.060 & 0.042 & 0.086 & 0.054 & -0.025 & 0.050 & & 0.062 \\
\hline Italia & 0.284 & 0.185 & 0.244 & 0.342 & 0.115 & 0.113 & 0.139 & 0.143 & 0.305 & 0.214 & 0.194 & 0.239 & 0.070 & -0.021 & 0.091 \\
\hline Japón & -0.202 & -0.111 & -0.006 & 0.251 & -0.080 & -0.019 & 0.114 & 0.073 & -0.054 & 0.019 & 0.094 & 0.164 & 0.003 & -0.034 & 0.048 \\
\hline Corea & 0.080 & 0.146 & 0.058 & 0.177 & -0.100 & 0.049 & -0.008 & 0.007 & 0.106 & 0.145 & 0.044 & 0.187 & 0.235 & -0.241 & 0.278 \\
\hline Paises Bajos & -0.111 & -0.085 / & 0.201 & 0.275 & 0.196 & 0.414 & 0.160 & 0.142 & 0.139 & 0.325 & 0.361 & 0.315 & 0.453 & -0.732 & -0.234 \\
\hline Nonuga & 0.234 & 0.077 & 0.183 & 0.326 & 0.098 & 0.138 & -0.088 & -0.120 & -0.066 & -0.003 & 0.008 & 0.094 & 0.066 & & -0.082 \\
\hline Polonia & 0.088 & 0.104 & 0.318 & 0.575 & 0.121 & 0.219 & 0.004 & 0.019 & 0.140 & 0.2 & 0.1 & 0.112 & 0. & 04 & -0.082 \\
\hline Federación Rusa & 0.225 & 0.348 & 0.365 & 0.515 & 0.273 & 0.346 & 0.115 & -0.450 & 0.308 & 0.337 & 0.399 & -0.192 & .0.101 & -0.285 & 0.118 \\
\hline República Eslovaca & $\# N / A$ & \#NA & N WA & \#NA & \#N/A & \#N/A & VA & VA & NA & N/A & IA & \#NA & \#N/A & \#NA & \#NAA \\
\hline España & -0.053 & 0.202 & 0.072 & -0.045 & 0.172 & 0.186 & 0.125 & 0.113 & - -0.037 & 0.200 & 0.418 & 0.0 & 0.072 & -0.066 & -0.103 \\
\hline Suecia & -0.049 & 0.145 & 0.396 & 0.342 & 0.200 & 0.114 & 0.158 & 0.097 & 0.335 & 0.505 & 0.502 & 0.225 & 0.446 & -0.284 & -0.163 \\
\hline Reino Unido & 0.625 & 0.360 & 0.727 & 0.813 & 0.264 & 0.524 & 0.184 & 0.131 & 0.576 & 0.574 & 0.526 & 0.415 & 0.676 & -0.554 & 0.027 \\
\hline Unidos & 0.014 & 0.143 & 0.339 & 0.578 & & 312 & 0.062 & 0.189 & 0.157 & & 0.368 & 0.212 & & ( & 0.087 \\
\hline
\end{tabular}

\begin{tabular}{|c|c|c|}
\hline \multicolumn{3}{|c|}{ Variables derivadas } \\
\hline Lectura & Escritura & $\mid \begin{array}{l}\text { Habuilidad } \\
\text { numintica }\end{array}$ \\
\hline 0.123 & 0.248 & \\
\hline 0.213 & 0.182 & 0.32 \\
\hline 0.173 & 0.373 & 0.520 \\
\hline 0.358 & 0.410 & \\
\hline$\#$ NAA & ANA & \#NA \\
\hline 0.206 & 0.207 & 0.208 \\
\hline 0.296 & 0.301 & 0.394 \\
\hline 0.047 & 0.008 & 0.138 \\
\hline 0.087 & 0.249 & 0.193 \\
\hline 0.061 & 0.168 & 0.198 \\
\hline 0.157 & 0.264 & \\
\hline 0.097 & 0.140 & \\
\hline 0.449 & 0.416 & 0.40 \\
\hline 0.206 & 0.0755 & 0.02 \\
\hline 0.213 & 0.334 & 0.466 \\
\hline 0.335 & 0.506 & 0.22 \\
\hline 0.131 & 0.277 & 0.05 \\
\hline 0.102 & 0.272 & 0.08 \\
\hline 0.642 & 0.748 & 0.14 \\
\hline \#N/A & ANA & \#NA \\
\hline 0.242 & 0.264 & \\
\hline 0.526 & 0.699 & 1792 \\
\hline 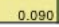 & & \\
\hline
\end{tabular}

\begin{tabular}{|c|c|c|c|c|c|c|c|c|c|c|c|c|c|c|c|}
\hline \multirow{2}{*}{$\begin{array}{c}\text { Cluo } 7 \\
\text { Trabajadores } \\
\text { artesanales y } \\
\text { afines }\end{array}$} & \multirow{2}{*}{\begin{tabular}{c|} 
Cooperación \\
$\begin{array}{c}\text { Colaboración } \\
F_{-} 0016\end{array}$
\end{tabular}} & \multicolumn{3}{|c|}{ Interacción horizontal } & \multicolumn{2}{|c|}{$\begin{array}{l}\text { Interacción con el } \\
\text { cliente }\end{array}$} & \multicolumn{2}{|c|}{ Auto-dirección } & \multirow{2}{*}{\begin{tabular}{|c|}
$\begin{array}{c}\text { Habililidades } \\
\text { gerenciales }\end{array}$ \\
$\begin{array}{c}\text { Planificar las } \\
\text { actividades des de } \\
\text { otros } \\
\text { F_0 } 003 \mathrm{~b}\end{array}$ \\
\end{tabular}} & \multicolumn{2}{|c|}{ Influencia } & \multicolumn{2}{|c|}{ Resolución de Problemas } & \multirow{2}{*}{ 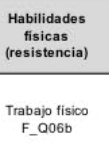 } & \multirow{2}{*}{ 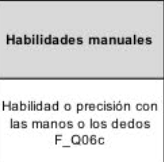 } \\
\hline & & $\begin{array}{c}\text { Compartit } \\
\text { intomamaicin } \\
F_{-} \text {-002a }\end{array}$ & 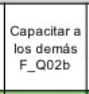 & $\begin{array}{c}\text { Dar } \\
\text { presestatacone } \\
\text { sF_a020 }\end{array}$ & 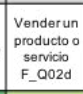 & $\mid \begin{array}{l}\text { Asesorar } \\
\text { a outros } \\
\text { F }_{-} \text {ione2 }\end{array}$ & 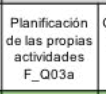 & \begin{tabular}{|c|} 
organizacaion \\
del propio \\
tiempo \\
$F_{-} \alpha 03 c$ \\
\end{tabular} & & 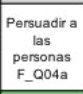 & $\begin{array}{c}\text { Negociar con } \\
\text { las poressonas } \\
F_{-} 0404 \mathrm{~b}\end{array}$ & 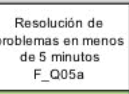 & 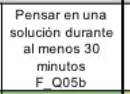 & & \\
\hline Australia & 0.145 & 0.148 & 0.160 & 0.343 & 0.052 & 0.239 & 0.144 & 0.185 & 0.217 & 0.261 & & 0.080 & 0.169 & -0.290 & -0.116 \\
\hline Austria & -0.114 & 0.003 & 0.120 & 0.244 & 0.117 & 0.094 & 0.114 & 0.110 & $0.195]$ & 0.250 & 0.210 & 0.077 & 0.176 & -0.285 & -0.232 \\
\hline Bélgica & -0.038 & 0.071 & 0.123 & 0.262 & 0.137 & 0.217 & 0.187 & 0.099 & 0.218 & 0.171 & 0.246 & 0.148 & 0.190 ] & -0.235 & -0.061 \\
\hline Canadà & -0.003 & 0.005 & 0.114 & 0.297 & 0.095 & 0.208 & 0.133 . & 0.130 & 0.175 [ & 0.234 & 0.264 & 0.073 & 0.249 & -0.325 & -0.188 \\
\hline Chipre & -0.092 & 0.038 & 0.083 & -0.029 & 0.076 & 0.101 & -0.013 & 0.123 & 0.113 & 0.194 & 0.160 & 0.082 & 0.062 & -0.081 & 0.003 \\
\hline República Checa & -0.146 & 0.008 & 0.199 & 0.179 & 0.029 & 0.181 & 0.031 & 0.069 & 0.109 & 0.229 & 0.135 & 0.098 & 0.184 & -0.349 & -0.029 \\
\hline Dinamarca & 0.017 & -0.011 & 0.029 & 0.232 & 0.292 & 0.177 & 0.139 & 0.112 & 0.127 & 0.226 & 0.332 & 0.094 & 0.206 & -0.273 & -0.134 \\
\hline Estonia & -0.026 & 0.085 & 0.107 & 0.077 & 0.101 & 0.174 & 0.107 & 0.090 & 0.102 & 0.145 & 0.078 & 0.102 & 0.002 & -0.228 & -0.038 \\
\hline Finlandia & -0.021 & -0.007 & 0.083 & 0.063 & 0.165 & 0.159 & 0.071 & 0.075 & 0.010 & 0.058 & 0.089 & 0.090 & 0.054 & -0.148 & -0.186 \\
\hline Francia & 0.000 & 0.088 & 0.156 & 0.218 & 0.212 & 0.248 & 0.217 & 0.199 & 0.186 & 0.237 & 0.255 & 0.199 & 0.204 & -0.142 & -0.077 \\
\hline Alemania & -0.052 & 0.006 & 0.139 & 0.307 & 0.167 & 0.209 & 0.105 & 0.167 & 0.181 & 0.182 & 0.204 & 0.138 & 0.286 & -0.200 & -0.003 \\
\hline Irtanda & 0.029 & 0.172 & 0.172 & 0.332 & -0.022 & 0.168 & 0.091 & 0.178 & 0.184 & 0.186 & 0.199 & 0.140 & $0.233]$ & -0.361 & -0.1177 \\
\hline |ltalia & 0.084 & -0.017 & 0.105 & 0.226 & 0.117 & 0.183 & 0.137 & 0.051 & 0.116 & 0.247 & 0.279 & 0.151 & 0.229 & -0.090 & -0.007 \\
\hline Japón & -0.015 & 0.112 & 0.203 & 0.206 & 0.015 & 0.222 & 0.214 & 0.149 & 0.036 & 0.232 & 0.295 & 0.176 & 0.306 & -0.208 & -0.083 \\
\hline Corra & -0.003 & 0.151 & 0.151 & 0.196 & 0.158 & 0.135 & 0.177 ] & 0.216 & 0.104 & 0.221 & 0.128 & 0.149 & 0.276 & -0.182 & 0.144 \\
\hline Paises Bajos & 0.061 & 0.171 & 0.240 & 0.191 & 0.144 & 0.227 & 0.139 & 0.128 & 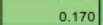 & 0.253 & 0.204 & 0.235 & 0.236 & -0.296 & -0.007 \\
\hline Noruega & -0.064 & 0.057 & 0.044 & 0.218 & 0.174 & 0.120 & 0.080 & 0.149 & 0.218 & 0.177 & 0.136 & 0.081 & 0.130 & -0.430 & -0.281 \\
\hline Polonia & -0.003 & 0.061 & 0.124 & 0.147 & 0.146 & 0.114 & $0.073]$ & 0.102 & 0.063 & 0.121 & 0.120 & 0.127 & 0.129 & -0.310 & 0.007 \\
\hline Federación Rusa & 0.049 & 0.106 & 0.178 & 0.064 & 0.158 & 0.163 & 0.116 & 0.122 & 0.248 & 0.175 & 0.227 & 0.108 & 0.094 & -0.112 & -0.060 \\
\hline Repübica & 0.036 & 0.101 & 0.234 & 0.326 & 0.010 & 0.16 & 0.255 & 0.215 & 0.1 & 0.243 & 0.2 & 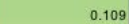 & & & \\
\hline España & 0.042 & 0.080 & 0.222 & 0.210 & $0.1 \quad-1$ & 0.278 & & & 0.271 & 0.258 & 0.237 & & & & 07 \\
\hline Suecia & 0.064 & 0.144 & 0.122 & 0.146 & 0.020 & 0.124 & 0.037 & 0.056 & 0.080 & 0.084 & 0.031 & 26 & 0.079 & 0.040 & -0.025 \\
\hline Reino Unido & 025 & 0.130 & 0.137 & 0.275 & 68 & 0.238 & 101 & 0.045 & 0.079 & 0.184 & $0.2 \mathrm{r}$ & 0.110 & 0.208 & -0.391 & 0.136 \\
\hline & & & & & & & & & & & & & & & \\
\hline
\end{tabular}

\begin{tabular}{|c|c|c|}
\hline \\
\hline Lectura & Escritura & $\begin{array}{l}\text { Habilidad } \\
\text { numerica }\end{array}$ \\
\hline 0.359 & 0.439 & \\
\hline 0.298 & 0.311 & 0.330 \\
\hline 0.369 & 0.360 & 0.327 \\
\hline .349 & 0.399 & 0.315 \\
\hline 174 & 0.203 & 0.22 \\
\hline 0.255 & 0.355 & 0.265 \\
\hline 0.348 & 0.309 & 0.379 \\
\hline 0.242 & 0.247 & 0.223 \\
\hline & 0.254 & \\
\hline 0.283 & 0.333 & 0.347 \\
\hline 0.287 & 0.268 & 0.343 \\
\hline 0.364 & 0.443 & 0.387 \\
\hline 0.351 & 0.469 & 0.244 \\
\hline 0.324 & 0.345 & 0.374 \\
\hline 80 & 0.379 & 0.308 \\
\hline 0.300 & 0.453 & 0.264 \\
\hline 0.267 & 0.282 & 0.279 \\
\hline & 0.278 & \\
\hline 025 & 0.367 & \\
\hline & 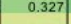 & $0.40 \mathrm{c}$ \\
\hline 0.07 & 0.17 & 14 \\
\hline & & \\
\hline
\end{tabular}

El código de colores refleja el significado de los coeficientes. El amarillo intenso indica coeficientes negativos fuertes y el verde oscuro indica coeficientes positivos fuertes. Nota: Para Chipre, véase la nota de la Figura 5. 


\begin{tabular}{|c|c|c|c|c|c|c|c|c|c|c|c|c|c|c|c|c|c|c|}
\hline \multirow{2}{*}{$\begin{array}{c}\text { Cluo } 8 \\
\text { OPeradores y } \\
\text { montadores de } \\
\text { plantas y } \\
\text { maquinas }\end{array}$} & \multirow{2}{*}{\begin{tabular}{|c} 
Cooperación \\
$\begin{array}{c}\text { Colaboración } \\
\text { F_a01b }\end{array}$
\end{tabular}} & \multicolumn{3}{|c|}{ Interacción horizontal } & \multicolumn{2}{|c|}{\begin{tabular}{|c} 
Interacción con el \\
cliente
\end{tabular}} & \multicolumn{2}{|c|}{ Auto-dirección } & \multirow{2}{*}{ 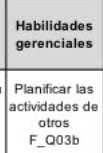 } & \multicolumn{2}{|c|}{ Influencia } & \multicolumn{2}{|c|}{ Resolución de Problemas } & \multirow{2}{*}{ 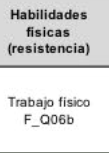 } & \multirow{2}{*}{ 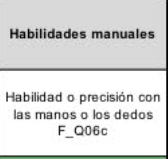 } & \multicolumn{3}{|c|}{ Variables derivadas } \\
\hline & & $\begin{array}{l}\text { Compatir } \\
\text { intomacion } \\
F_{-} \text {-0a2a }\end{array}$ & 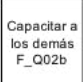 & $\begin{array}{c}\text { Dar } \\
\text { presentacione } \\
\text { sF_-002c }\end{array}$ & \begin{tabular}{|l|l} 
Venderun \\
productoo \\
sencioi \\
F_-002d
\end{tabular} & \begin{tabular}{|l} 
Asesorar \\
a ouros \\
$F_{-}$-0202e
\end{tabular} & 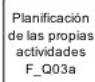 & 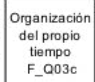 & & $\begin{array}{c}\text { Persuadir a } \\
\text { las } \\
\text { personas } \\
\text { F_-004a }\end{array}$ & \begin{tabular}{|c} 
Nogocolia con \\
las personas \\
$F_{-}-004 \mathrm{~b}$
\end{tabular} & 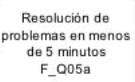 & 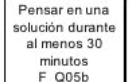 & & & | Lectura & Escrith & \begin{tabular}{|l} 
Habiilidad \\
numeñica
\end{tabular} \mid \\
\hline Australia & 0.133 & 0.100 & 0.140 & 0.163 & 0.225 & 0.230 & 0.202 & 0.152 & 0.308 & 0.235 & 0.265 & 0.082 & 0.170 & 0.025 & 0.124 & 0.276 & 0.243 & 0.254 \\
\hline Austria & 0.192 & 0.148 & 0.239 & 0.441 & 0.213 & 0.262 & 0.136 & -0.056 & 0.351 & 0.300 & 0.190 & 0.175 & 0.236 & -0.207 & -0.077 & 0.234 & 0.178 & 0.188 \\
\hline Bélgica & 0.155 & 0.125 & 0.170 & 0.338 & 0.073 & 0.183 & 0.081 & 0.060 & 0.183 & 0.167 & 0.114 & 0.238 & 0.212 & -0.186 & 0.016 & 0.305 & 0.261 & 0.303 \\
\hline Canadáa & 0.065 & 0.133 & 0.109 & 0.288 & 0.078 & 0.191 & 0.151 & 0.109 & 0.221 & 0.116 & 0.116 & 0.167 & 0.293 & -0.117 & 0.035 & 0.294 & 0.322 & 0.369 \\
\hline Chipre & \#NAA & -0.043 & -0.084 & -0.048 & 0.228 & 0.189 & 0.160 & 0.152 & -0.081 & 0.194 & -0.026 & 0.048 & -0.042 & 0.071 & 0.066 & 0.365 & 0.040 & 0.282 \\
\hline República Checa & 0.081 & 0.133 & 0.370 & 0.189 & -0.008 & 0.085 & 0.081 & 0.011 & 0.245 & 0.131 & 0.181 & 0.112 & 0.134 & 0.066 & 0.143 & 0.235 & 0.113 & 0.053 \\
\hline Dinamarca & 0.069 & 0.039 & 0.128 & 0.059 & -0.035 & 0.157 & 0.070 & 0.073 & 0.093 & 0.156 & 0.173 & 0.123 & 0.173 & -0.069 & -0.036 & 0.289 & 0.277 & 0.195 \\
\hline Estonia & 0.015 & 0.049 & 0.035 & 0.014 & -0.029 & 0.123 & 0.110 & 0.132 & 0.111 & 0.058 & 0.084 & 0.048 & 0.014 & - -0.069 & 0.031 & 0.088 & 0.150 & 0.104 \\
\hline Finlandia & 0.144 & 0.136 & 0.151 & 0.188 & 0.064 & 0.187 & 0.071 & 0.152 & 0.092 & 0.097 & 0.104 & 0.076 & 0.196 & -0.003 & 0.024 & 0.152 & 0.260 & 0.150 \\
\hline Francia & 0.162 & 0.123 & 0.091 & 0.151 & -0.008 & 0.057 & 0.082 & 0.123 & 0.336 & 0.150 & 0.146 & 0.122 & 0.106 & -0.049 & -0.038 & 0.134 & 0.178 & 0.212 \\
\hline Alemania & 0.099 & 0.151 & 0.254 & 0.219 & 0.033 & 0.193 & 0.100 & 0.049 & 0.203 & 0.204 & 0.045 & 0.100 & 0.011 & -0.061 & 0.017 & 0.160 & 0.182 & 0.275 \\
\hline Irtanda & 0.010 & 0.128 & 0.155 & 0.189 & 0.109 & 0.146 & 0.054 & 0.091 & 0.106 & 0.218 & 0.045 & 0.251 & 0.269 & -0.041 & -0.011 & 0.166 & 0.273 & 0.289 \\
\hline |talia & 0.046 & 0.007 & 0.166 & 0.066 & 0.108 & 0.160 & 0.121 & 0.021 & 0.161 & 0.144 & 0.169 & 0.084 & 0.065 & -0.032 & 0.040 & 0.177 & 0.220 & 0.299 \\
\hline Japón & 0.206 & 0.098 & 0.180 & 0.236 & -0.058 & 0.195 & 0.222 & 0.067 & 0.304 & 0.193 & 0.146 & 0.100 & 0.305 & 0.088 & 0.105 & 0.237 & 0.245 & 0.269 \\
\hline Corea & 0.137 & 0.154 & 0.248 & 0.217 & -0.029 & 0.178 & 0.128 & 0.117 & 0.156 & 0.152 & 0.109 & 0.175 & 0.126 & -0.158 & 0.170 & 0.276 & 0.369 & 0.319 \\
\hline Paises Bajos & 0.084 & 0.144 & 0.206 & 0.372 & -0.070 & 0.124 & 0.140 & 0.166 & 0.095 & 0.052 & 0.050 & 0.106 & 0.078 & -0.058 & 0.070 & 0.180 & 0.353 & 0.203 \\
\hline Noruega & 0.106 & 0.019 & 0.255 & 0.261 & 0.115 & 5. 0.144 & 0.115 & 0.095 & 0.241 & 0.204 & 0.091 & 0.214 & 0.179 & -0.104 & 0.042 & 0.322 & 0.408 & 0.295 \\
\hline Polonia & 0.023 & 0.106 & 0.090 & 0.014 & -0.010 & 0.047 & 0.073 & 0.085 & 0.093 & 0.179 & 0.233 & 0.052 & 0.172 & -0.057 & 0.056 & 0.202 & 0.105 & 0.217 \\
\hline Federación Rusas & -0.017 & 0.100 & 0.315 & 0.264 & 0.000 & 0.203 & 0.058 & 0.037 & 0.139 & 0.134 & 0.108 & 0.045 & -0.024 & -0.078 & 0.123 & 0.096 & 0.108 & 0.051 \\
\hline República Eslovaca & 0.088 & 0.026 & 0.149 & 0.025 & 0.127 & 0.133 & 0.008 & 0.063 & 0.199 & 0.104 & 0.071 & 0.008 & 0.151 & -0.116 & 0.068 ] & 0.253 & 0.246 & 0.137 \\
\hline España & 0.153 & 0.085 & 0.311 & 0.210 & 0.095 & 0.215 & 0.119 & 0.058 & 0.270 & 0.072 & 0.031 & 0.108 & 0.102 & -0.029 & 0.087 & 0.214 & 0.029 & 0.378 \\
\hline Suecia & 0.112 & 0.112 & 0.172 & 0.131 & -0.097 & 0.069 & 0.104 & -0.056 & 0.159 & 0.166 & 0.044 & 0.188 & 0.136 & -0.005 & 0.054 & 0.125 & 0.190 & 0.052 \\
\hline Reino Unido & 0.193 & 0.243 & 0.237 & 0.278 & -0.060 & 0.184 & 0.177 & 0.172 & 0.346 & 0.247 & 0.171 & 0.104 & 0.191 & -0.029 & 0.018 & 0.270 & 0.379 & 0.351 \\
\hline Estados Unidos & 0.028 & 0.048 & 0.030 & 0.047 & 0.150 & 0.139 & 0.102 & 0.200 & 0.283 & 0.183 & 0.147 & 0.159 & 0.182 & 0.041 & 0.015 & 0.224 & a.tinu & 0.255 \\
\hline \multirow{2}{*}{$\begin{array}{l}\text { Cluo } 9 \\
\text { Ocupaciones } \\
\text { elementales }\end{array}$} & Cooperación & \multicolumn{3}{|c|}{ Interacción horizontal } & \begin{tabular}{|l}
$\begin{array}{c}\text { Interaccio } \\
\text { clier }\end{array}$ \\
s.
\end{tabular} & $\begin{array}{l}\text { ón con el } \\
\text { nnte }\end{array}$ & Auto-dit & rección & \begin{tabular}{|l} 
Habilidades \\
gerenciales
\end{tabular} & & uencia & Resolución de & - Problemas & $\begin{array}{l}\text { Mabilidades } \\
\text { fisicas } \\
\text { (resistancia) }\end{array}$ & Habilidades manuales & & ables deriv & vadas \\
\hline & \begin{tabular}{|c|} 
Colaboración \\
$F_{-} 001 b$ \\
\end{tabular} & $\begin{array}{l}\text { Compentir } \\
\text { intomamacion } \\
F_{-} \text {-0o2a }\end{array}$ & 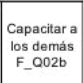 & $\begin{array}{c}\text { Dar } \\
\text { presestataione } \\
\text { sF_a02c }\end{array}$ & 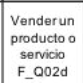 & $\begin{array}{c}\text { Asesorar } \\
\text { a outros } \\
F_{-} \text {-ao2e }\end{array}$ & 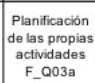 & 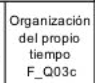 & 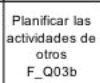 & \begin{tabular}{|c|} 
Persuadira \\
las \\
personas \\
$F_{-}$- $004 a$
\end{tabular} \mid & 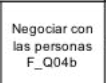 & 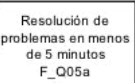 & 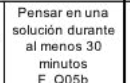 & $\begin{array}{c}\text { Trabajoj fisico } \\
\text { F_a06b }\end{array}$ & 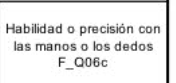 & Lectura & Escrit & $\left|\begin{array}{c}\text { Habilidac } \\
\text { numinicas }\end{array}\right|$ \\
\hline Australia & 0.055 & 0.068 & 0.152 & 0.231 & 0.081 & 0.242 & 0.183 & 0.159 & 0.202 & 0.168 & 0.209 & 0.107 & 0.109 & -0.349 & -0.126 & 0.235 & 0.358 & 0.169 \\
\hline Austria & 0.057 & 0.179 & 0.252 & 0.081 & 0.197 & 0.276 & 0.212 & 0.096 & 0.290 & 0.285 & 0.259 & 0.182 & 0.258 & -0.132 & 0.099 & 0.348 & 0.377 & 0.386 \\
\hline Bélgica & 0.093 & 0.135 & 0.146 & 0.230 & 0.197 & 0.192 & 0.049 & 0.048 & 0.053 & 0.181 & 0.156 & 0.172 & 0.178 & - 0.117 & 0.064 & 0.296 & 0.246 & 0.295[ \\
\hline Canadáa & 0.002 & 0.029 & 0.087 & 0.037 & 0.013 & 0.046 & 0.013 & 0.053 & 0.083 & 0.056 & 0.073 & 0.003 & 0.057 & 0.005 & 0.030 _ & 0.163 & 0.161 & 0.216 \\
\hline Chipre & -0.181 & -0.169 & -0.058 & -0.046 & 0.135 & -0.067 & -0.141 & -0.178 & -0.074 & 0.141 & 0.065 & -0.133 & $-0.0 .0>0$ & - 0.172 & -0.040 ] & 0.131 & 0.145 & 0.220 \\
\hline Repúbica Checa & 0.049 & 0.008 & 0.156 & 0.167 & 0.154 & 0.096 & 0.062 & 0.096 & 0.041 & 0.180 & 0.234 & 0.102 & 0.2 & -0.146 & -0.119] & 0.352 & 0.284 & 0.343 \\
\hline Dinamarca & 0.046 & 0.079 & 0.169 & 0.213 & 0.082 & 0.132 & 0.076 & 0.049 & 0.164 & 0.187 & 0.200 & 0.171 & 0.280 & -0.129 & -0.025 & 0.381 & 0.358 & 0.476 \\
\hline Estonia & 0.028 & 0.136 & 0.198 & 0.218 & 0.114 & 0.172 & 0.101 & 0.081 & 0.257 & 0.132 & 0.167 & 0.156 & 0.149 & -0.259 & 0.006 & 0.303 & 0.303 & 0.366 \\
\hline Finlandia & 0.042 & 0.085 & 0.176 & 0.179 & -0.104 & 0.085 & 0.127 & 0.098 & 0.204 & 0.129 & 0.123 & 0.197 & 0.250 & -0.028 & -0.079 & 0.195 & 0.271 & 0.317 \\
\hline Francia & 0.152 & 0.186 & 0.154 & 0.215 & 0.073 & 0.185 & 0.092 & 0.109 & 0.314 & 0.218 & 0.179 & 0.187 & 0.171 & -0.188 & -0.110 & 0.195 & 0.240 & 0.372 \\
\hline Alemania & 0.029 & 0.170 & 0.303 & 0.269 & 0.209 & 0.353 & 0.117 & 0.107 & 0.210 & 0.262 & 0.270 & 0.260 & 0.462 & -0.278 & -0.03 & 0.427 & 0.4911 & 0.275 \\
\hline Irtanda & 0.044 & 0.077 & 0.267 & 0.298 & 0.083 & 0.237 & 0.172 & 0.173 & 0.181 & 0.274 & 0.291 & 0.163 & 0.237 & -0.218 & $0 . c$ & 0.309 & 0.323 & 0.229 \\
\hline Italia & 0.020 & 0.206 & 0.388 & -0.013 & 0.147 & 0.192 & 0.113 & 0.166 & 0.256 & 0.314 & 0.2 & 0.144 & 0. & -0.094 & -0.6 & 0.358 & 0.358 & 0.539 \\
\hline Japón & 0.047 & 0.118 & 0.174 & 0.105 & 0.035 & 0.014 & 0.027 & 0.149 & 0.010 & 0.021 & 0.150 & 0.161 & 0.266 & 0.105 & -0.081 & 0.164 & 0.209 & 0.257 \\
\hline Correa & 0.057 & 0.171 & 0.181 & 0.131 & 0.051 & 0.100 & 0.064 & 0.085 & 0.198 & 0.132 & 0.054 & 0.163 & 0.092 & -0.003 & 0.221 & 0.249 & 0.219 & 0.381 \\
\hline Paises Bajos & 0.070 & 0.220 & 0.460 & 0.283 & 0.188 & 0.253 & 0.247 & 0.199 & 0.530 & 0.284 & 0.270 & 0.280 & 0.2 & -0.160 & -0.082 & 0.316 & 0.434 & 0.269 \\
\hline |Noruega & -0.036 & 0.208 & 0.296 & 0.428 & 0.012 & 0.339 & 0.200 & 0.269 & 0.292 & 0.316 & 0.25 & 0.270 & 0.434 & -0.469 & $-0.2>-2$ & 0.475 & 0.459 & 0.310[ \\
\hline Polonia & 0.062 & 0.156 & 0.254 & 0.462 & 0.194 & 0.288 & 0.169 & 0.127 & 0.325 & 0.256 & 0.160 & 0.132 & $0.143]$ & -0.043 & $-0.0<>>0$ & 0.219 & 0.255 & 0.049 [ \\
\hline Federación Rusa & -0.020 & 0.244 & 0.301 & 0.225 & 0.326 & 0.387 & 0.231 & 0.182 & 0.213 & 0.334 & 0.266 & 0.189 & 0.253 & . 0.409 & $-0.65>>>2$ & 0.507 & 0.503 & 0.263 \\
\hline púbica Estovaca & -0 & 17 & 0.118 & 0.113 & 0.183 & 0.168 & 0.151 & 0.101 & 0.040 & 0.009 & 0.2 & 0.075 & $0.0 \quad>>2$ & -0.185 & & 0.318 & 0.370 & 0.163 \\
\hline España & 0.097 & 0.083 & 0.067 & 0.063 & 0.210 & 0.235 & 0.056 & 0.048 & 0.119 & 0.135 & 0.011 & 0.077 & 0. & -0.128 & 0.019 & 0.286 & 0.199 & 0.303 \\
\hline Suecia & 0.101 & 0.222 & 0.400 & 0.374 & 0.018 & 0.322 & 0.200 & 0.209 & 0.327 & 0.354 & 0.368 & 0.309 & 0.386 & 0.567 & -0.250 | & 0.435 & 0.461 & 0.209 \\
\hline Reino Unido & 0.115 & 0.186 & 0.327 & 0.401 & 0.085 & 0.305 & 0.175 & 0.193 & 0.361 & 0.329 & 0.230 & 0.252 & $0.371]$ & -0.229 & 0.050 . & 0.462 & 0.547 & 0.434 \\
\hline Estac & -0.082 & 0.062 & 0.186 & 0.073 & 0.137 & 0.186 & 0.062 & 107 & 0.192 & 0 & & 2 & & . & 0.051 & 258 & 0.244 & 0.316 \\
\hline
\end{tabular}

El código de colores refleja el significado de los coeficientes. El amarillo intenso indica coeficientes negativos fuertes y el verde oscuro indica coeficientes positivos fuertes Nota: Para Chipre, véase la nota de la Figura 5.

Fuente: OCDE, con base en datos del PIAAC Database, octubre 2015. 


\section{NOTAS}

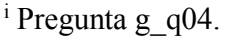

ii Pregunta g_q05g.

iii Véase nota de la Figura 5.

${ }^{\text {iv }}$ La medida de productividad relevante es la productividad laboral marginal, que no es observable, mientras que este documento analiza la productividad laboral promedio, que sí es observable. Estas dos medidas de productividad están perfectamente correlacionadas solo bajo funciones de producción específicas, por ejemplo, un Cobb-Douglas.

${ }^{v}$ Queremos agradecer a Burning Glass y Jobfeed por el uso de sus bases de datos. En particular, agradecemos a Matt Sigelman, Davor Miskulin, Will Markow y Hal Bonella (Burning Glass); Jakub Zavrel y Bauke Visser (Jobfeed).

${ }^{v i}$ Brown y Souto-Otero (2016) han comparado los datos de tasas de vacantes en el Reino Unido basándose en Burning Glass y la encuesta de la fuerza laboral. Las proporciones de Burning Glass son significativamente más altas para ocupaciones profesionales (11.5 puntos porcentuales) y para profesionales asociados y técnicos (8.3), mientras que son más bajas para ocupaciones elementarias $(-7.1)$ y servicios de cuidado, recreación y otros (-5.3).

vii Sin embargo, solo el 0,8\% de las empresas encuestadas estaban en el sector de la información. El resto no tenía vacantes abiertas o no requería habilidades informáticas.

viii Un cuarto grupo es el uso de las TIC, que ya se discutió en la sección 2.1.

ix Variable 4.A.3.b.1 del Diccionario de datos $\mathrm{O} *$ NET.

\section{REFERENCIAS}

Arvanitis, S. (2005), "Computerization, workplace organization, skilled labour and firm productivity: Evidence for the Swiss business sector", Economics of Innovation and New Technology, Vol. 14, No. 4, pp. 225-249.

Australian Government, Department for employment (2014), Labour market research on ICT professions https://docs.employment.gov.au/system/files/doc/other/ictclusterreportaus.pdf.

Australian Workforce and Productivity Agency (2013), Industry snapshot 2013: Information media and telecommunications.

Autor, D. (2014), Polanyi's Paradox and the Shape of Employment Growth, Federal Reserve Bank of Kansas City's economic policy symposium, del 21 al 23 de agosto de 2014, en Jackson Hole, Wyoming.

Autor, D. (2013), “The Task Approach to Labor Markets: An Overview”, NBER Working Papers, No.

18711, http://www.nber.org/papers/w18711.

Autor, D. and D. Dorn (2013), "The Growth of Low-Skill Service Jobs and the Polarization of the U.S. Labor Market", American Economic Review, Vol. 103, No. 5, pp. 1553-1597. 
Autor, D., L. Katz and M. Kearney (2008) “Trends in U.S. Wage Inequality: Revising the Revisionists", The Review of Economics and Statistics, Vol. 90, No. 2, pp. 300-323.

Autor, D., L. Katz and M. Kearney (2006), “The Polarization of the US Labor Market”, American Economic Review Papers and Proceedings, Vol. 96, No. 2, pp. 189-194.

Autor, D., L. Katz and A. Krueger (1998), “Computing Inequality: Have Computers Changed the Labor Market?”, Quarterly Journal of Economics, Vol. 113, No. 4, pp. 1169-1214.

Autor, D.H., F. Levy and R.J. Murnane (2003), “The Skill Content of Recent Technological Change: An Empirical Exploration”, Quarterly Journal of Economics, Vol. 113, No. 4, pp. 1279-1333.

Bartel, A., C. Ichniowski and K. Shaw (2007), "How Does Information Technology Affect Productivity? Plant-Level Comparisons of Product Innovation, Process Improvement and Worker Skills", Quarterly Journal of Economics, Vol. 122, No. 4, pp. 1721-1758.

Bloom, N., R. Sadun and J. Van Reenen (2007), “Americans do I.T. Better: US Multinationals and the Productivity Miracle”, NBER Working Papers, No. 13085.

Bresnahan, T.F., E. Brynjolfsson, and L.M. Hitt (2002), "Information Technology, Workplace Organization, and the Demand for Skilled Labor: Firm-Level Evidence", Quarterly Journal of Economics, Vol. 117, No. 1, pp. 339-376.

Brown, P. and M. Souto-Otero (2016), Changing Conceptions of Merit: The Use of Labour Market Analytics in the Study of Educational Attainment and Social Mobility, Mimeo.

Brynjolfsson, E., L.M. Hitt and S. Yang (2002), "Intangible Assets: How the Interaction of Computers and Organizational Structure Affects Stock Market Valuations", Brookings Papers on Economic Activity, Economic Studies Program, The Brookings Institution, Vol. 33, No. 1, pp 137-198.

BLS (2013), "Careers in growing field of information technology services", Beyond the numbers, Vol. 2, No. 9, abril de 2013.

Burning Glass (2016) http://burning-glass.com/ 
Caroli, E. and J. Van Reenen (2001), "Skill-Biased Organizational Change? Evidence from a Panel of British and French Establishments”, Quarterly Journal of Economics, Vol. 116, No. 4, pp. 14491492.

Data.gov.au (2015), Internet Vacancy Index, https://data.gov.au/dataset/internet-vacancy-index.

Di Pietro, G. (2007), “The Effect of Computer Use on Earnings in Italy”, Empirical Economics, Vol. 33, No. 2, pp. 245-262.

Eckardt, D. and M. Squicciarini (forthcoming), "Mapping SOC-2010 into ISCO-08 Occupations: A New Methodology using Employment Weights", OECD Science, Technology and Industry Working Papers, OECD Publishing.

European Commission (2014a), European Vacancy Monitor, Issue No. 12, febrero de 2014, http://ec.europa.eu/social/BlobServlet?docId=11426\&langId=en.

European Commission (2014b), E-Skills for jobs in Europe: Measuring progress and moving ahead, Final report.

Eurostat (2016), Job vacancy statistics, http://ec.europa.eu/eurostat/web/labour-market/jobvacancies/database.

Eurostat (2016), National Accounts, http://ec.europa.eu/eurostat/web/national-accounts/data.

Firpo, S., N. M. Fortin and T. Lemieux (2011), "Occupational Tasks and Changes in the Wage Structure", IZA Discussion Papers, No. 5542.

Garicano, L. (2010), "Policemen, Managers, Lawyers: New Results on Complementarities between Organization and Information and Communication Technology", International Journal of Industrial Organization, Vol. 28, No. 4, pp. 355-358.

Goldin, C. and L. F. Katz (1998), "The Origins of Technology-Skill Complementarity", Quarterly Journal of Economics, Vol. 113, No. 3, pp. 693-732. 
Green, F. (2012), "Employee Involvement, Technology, and Evolution in Job Skills: A Task-Based Analysis", Industrial and Labor Relations Review, Vol. 65, No. 1, pp. 36-67.

Green, F., A. Felstead, D. Gallie and Y. Zhou (2007), "Computers and Pay", National Institute Economic Review, Vol. 201, No. 1, pp. 63-75.

Goos, M., A. Manning and A. Salomons (2011), "Explaining job polarization: the roles of technology, offshoring and institutions", Center for Economic Studies Discussion Paper Series, No. 11.34, Katholieke Universiteit Leuven, Centrum voor Economische Studiën.

Hagsten, E. and A. Sabadash (2014), "The Impact of Highly-skilled ICT Labour on Firm Performance: Empirical Evidence from Six European Countries”, JRC/ IPTS Technical Reports, Digital Economy Working Paper, 2014/02.

Hammermann A. and O. Stettes (2016), "Qualifikationsbedarf und Qualifizierung: Anforderungen im Zeichen der Digitalisierung”, IW policy papers, 3/2016, Institut der deutschen Wirtschaft Köln, Cologne.

Handel, M. (2012), "Trends in Job Skill Demands in OECD Countries", OECD Social, Employment and Migration Working Papers, No. 143, OECD Publishing, http://dx.doi.org/10.1787/5k8zk8pcq6td-en.

Hynninen, S-M., J. Ojala and J. Pehkonen (2013), "Technological change and wage premiums: Historical evidence from linked employer-employee data”, Labour Economics, Vol. 24, No. 10, pp. 1-11.

ILO (2012), International Standard Classification of Occupations: Structure, group definitions and correspondence tables, Vol. 1, Geneva.Lacey T.A. and B. Wright (2009), Occupational employment projections to 2018, Monthly Labor Review, BLS, Estados Unidos.

Jobfeed (2016) http://www.jobfeed.com/home.php

Lacey, T. Alan and Wright, Benjamin, "Occupational employment projections to 2018," Monthly Labor Review, noviembre de 2009, pp. 82-123.

Levy, F. and R.J. Murnane (1996), "What Skills Are Computers a Complement?”, AEA Papers and Proceedings, No. 86, No. 2, pp. 258-262. 
Marcolin,L., S. Miroudot and M. Squicciarini (2016), "Routine jobs, employment and technological innovation in global value chains", OECD Science, Technology and Industry Working Papers, No. 2016/01, OECD Publishing, Paris, http://dx.doi.org/10.1787/5jm5dcz2d26j-en.

Manpower Group (2015), Talent Shortage Survey, http://www.manpowergroup.com/wps/wcm/connect/manpowergroup-en/home/thoughtleadership/research-insights/talent-shortage-2015.

Michaels, G., A. Natrajz and J. Van Reenen (2014), "Has ICT Polarized Skill Demand? Evidence from Eleven Countries over 25 years", Review of Economics and Statistics, Vol. 96, No. 1, pp. 60-77.

OECD (2016), The Survey of Adult Skills: Reader's Companion, Second Edition, OECD Skills

Studies, OECD Publishing, París, https://doi.org/10.1787/9789264258075-en.

OECD (2014a), Forecasting Future Needs for Advanced ICT Competence in Norway, DSTI/ICCP/IIS(2014)5.

OECD (2014b), Measuring the Digital Economy: A New Perspective, OECD publishing, http://dx.doi.org/10.1787/9789264221796-en.

OECD (2013), The Survey of Adult Skills: Reader's Companion, OECD Publishing, http://dx.doi.org/10.1787/9789264204027-en.

OECD (2012), Literacy, Numeracy and Problem Solving in Technology-Rich Environments: Framework for the OECD Survey of Adult Skills, OECD Publishing, http://dx.doi.org/10.1787/9789264128859- en.

OECD (2011), PIAAC Conceptual Framework of the Background Questionnaire Main Survey, November.

Pabilona, S.W. and C. Zoghi (2013), Which Job Skills Are Complementary To IT Adoption And Use?, Presentado en la reunión de la Sociedad de Economistas Laborales de mayo.

Spitz-Oener, A. (2006), "Technical Change, Job Tasks, and Rising Education Demands: Looking outside the Wage Structure", Journal of Labor Economics, Vol. 24, No. 2, pp. 235-270. 
Statistics New Zealand (2014), Business operations survey, http://www.stats.govt.nz/browse for_stats/businesses/business_growth and innovation/BusinessOp erationsSurvey_HOTP2014.aspx.

Tambe, P., L.M. Hitt and E. Brynjolfsson (2011), “The Extroverted Firm: How External Information Practices Affect Innovation and Productivity”, MIT-Sloan Working Paper Series, No. 291.

Ter Weel, B. and S. Kok (2013), De Nederlandse arbeidsmarkt in taken: Eerste bevindingen uit de Nederlandse Skills Survey, Centraal Planbureau report, The Hague.

Van Reenen, J. (2011), "Wage inequality, technology and trade: 21 st century evidence”, Labour Economics, Vol. 18, No. 6, pp. 730-741.

Van Reenen, J., N. Bloom, M. Draca, T. Kretschmer, R. Sadun, H. Overman and M. Schankerman (2010), The Economic Impact of ICT, Centre for Economic Performance, London School of Economics, Londres.

Yang, S. and E. Brynjolfsson (2001), "Intangible Assets and Growth Accounting: Evidence from Computer Investments", MIT-Sloan Working Paper Series, No. 136. 